\title{
COMPOSIÇÃO FLORÍSTICA, FITOSSOCIOLOGIA, DIVERSIDADE DE ESPÉCIES ARBÓREAS E COMPARAÇÃO DE MÉTODOS DE AMOSTRAGEM NA FLORESTA OMBRÓFILA DENSA DO PARQUE ESTADUAL CARLOS BOTELHO/SP-BRASIL
}

\section{Antonio Cecilio Dias}

Tese apresentada à Escola Superior de Agricultura "Luiz de Queiroz”, Universidade de São Paulo, para obtenção do título de Doutor em Recursos Florestais, com opção em Conservação de Ecossistemas Florestais.

P I R A C I C A B A

Estado de São Paulo - Brasil

Fevereiro - 2005 


\title{
COMPOSIÇÃO FLORÍSTICA, FITOSSOCIOLOGIA, DIVERSIDADE DE ESPÉCIES ARBÓREAS E COMPARAÇÃO DE MÉTODOS DE AMOSTRAGEM NA FLORESTA OMBRÓFILA DENSA DO PARQUE ESTADUAL CARLOS BOTELHO/SP-BRASIL
}

\author{
ANTONIO CECILIO DIAS \\ B I Ó L O GO
}

Orientador: Prof. Dr. HILTON THADEU ZARATE DO COUTO

\begin{abstract}
Tese apresentada à Escola Superior de Agricultura "Luiz de Queiroz”, Universidade de São Paulo, para obtenção do título de Doutor em Recursos Florestais, com opção em Conservação de Ecossistemas Florestais.
\end{abstract}

P I R A C I C A B A

Estado de São Paulo - Brasil

Fevereiro - 2005 
Dados Internacionais de Catalogação na Publicação (CIP) DIVISÃO DE BIBLIOTECA E DOCUMENTAÇÃO - ESALQ/USP

Dias, Antonio Cecilio

Composição florística, fitossociologica, diversidade de espécies arbóreas e compara-ção de métodos de amostragem na floresta ombrófila densa do Parque Estadual Carlos Botelho/SP - Brasil / Antonio Cecilio Dias. - - Piracicaba, 2005. 184 p. : il.

Tese (Doutorado) - - Escola Superior de Agricultura Luiz de Queiroz, 2005. Bibliografia.

1. Amostragem 2. Biodiversidade 3. Comunidade vegetal 4. Ecologia 5. Floresta 6. Parque Estadual 7. População vegetal 8. Proteção ambiental 9. Vegetação I. Título 
Dedico

À minha esposa Beth, pela compressão, amor e incentivo. À minha filha Carolina, pela atenção e dedicação. 


\section{AGRADECIMENTOS}

\section{A DEUS}

O Autor agradece sinceramente a todos que direta ou indiretamente contribuíram para a realização deste trabalho, e em especial.

Ao Instituto Florestal, Instituição de Pesquisa à qual estou vinculado desde o início de minha vida profissional pela contribuição e oportunidades para todo o meu aprimoramento técnico científico.

Ao Prof. Dr. Hilton Thadeu Zarate do Couto, pela paciência e dedicação na orientação deste trabalho, bem como pela amizade que sempre fez parte do nosso relacionamento.

Aos Profs. João Luis Ferreira Batista e Ricardo Ribeiro Rodrigues, por suas sugestões, importantes para a finalização do trabalho.

Ao amigo Alcebíades Custodio Filho, Pesquisador Científico do Instituto Florestal, pela colaboração e ajuda em todas as fases deste trabalho.

Ao PqC João Batista Baitello, Pesquisador Científico do Instituto Florestal, pela colaboração na identificação das espécies da família Lauraceae. 
Ao PqC Osny Tadeu Aguiar. Pela colaboração em todas as fases deste trabalho,desde as atividades de campo à identificação do material botânico, principalmente da família Myrtaceae.

Ao PqC Geraldo Antonio D`arer Correa Franco pela ajuda na identificação do material botânico.

Ao Eng. Agro. Cláudio Henrique Barbosa Monteiro e demais colegas da Estação Experimental de Itapetininga, por entender as minhas prioridades e necessidades para a realização deste trabalho.

À equipe de campo nas pessoas dos Srs. Lauro, Ademir, Ronaldo, Reinaldo, Luiz Carlos, e aos funcionários do Parque Estadual Carlos Botelho, obrigado pela ajuda.

Aos estagiários Bruno, Vânia e Valéria, pela organização do material botânico e ajuda na tabulação dos dados.

Aos colegas de Curso e do Laboratório de Métodos Quantitativos.

Ao Jefferson e Eliza pela atenção e ajuda sempre que necessário.

A Profa. Elizabeth Tadeu Mandarini Dias, pela leitura paciente, correção do texto e sugestões em todas as fases de elaboração do presente trabalho. 


\section{SUMÁRIO}

Página

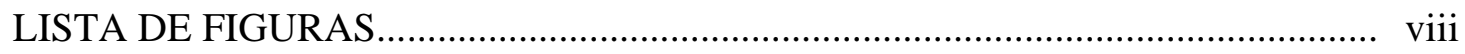

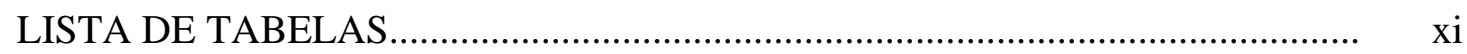

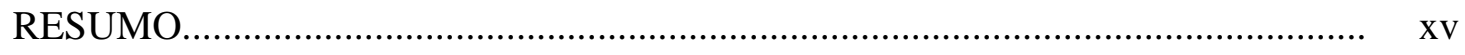

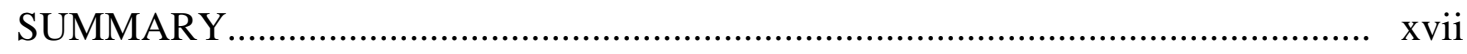

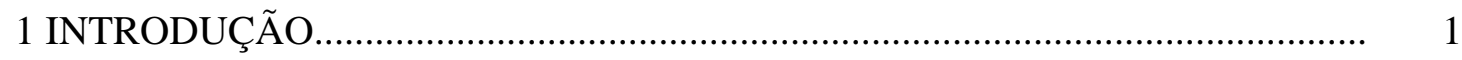

2 REVISÃO BIBLIOGRÁFICA....................................................................... 5

2.1 Da Mata Atlântica...................................................................................................... 5

2.2 Dos Métodos de Amostragem............................................................................ 6

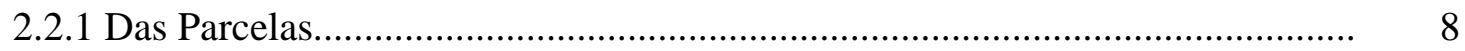

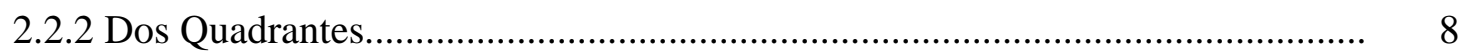

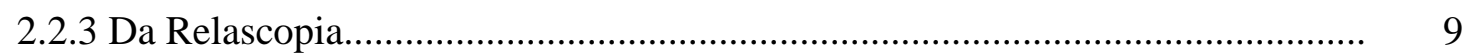

2.3 Da Fitossociologia....................................................................................... 10

2.4 Da diversidade de Espécies.......................................................................... 11

2.5 Comparação de Métodos de Amostragem........................................................ 16

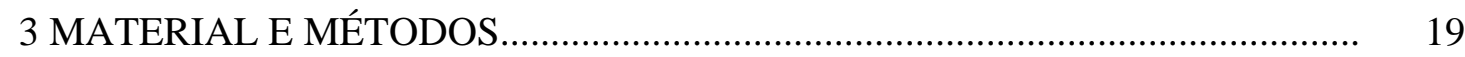

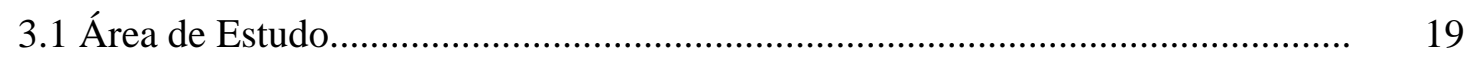

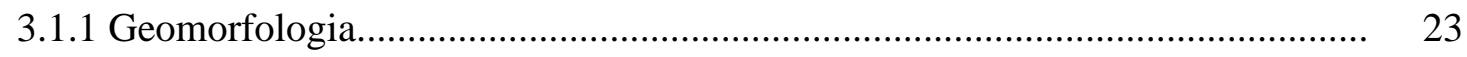

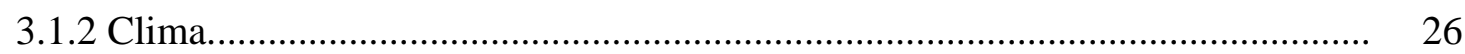

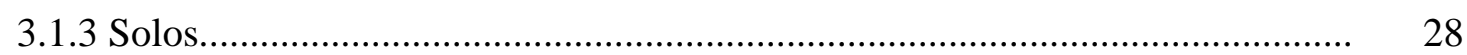

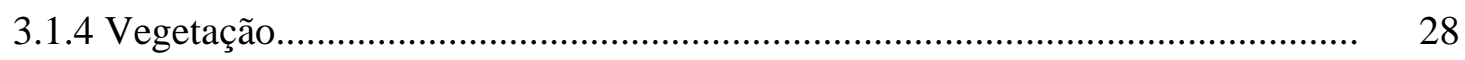

3.2 Área de Amostraagem............................................................................... $\quad 30$

3.3 Métodos de Amostragem Empregados............................................................ 31 
3.4 Procedimento de Campo.............................................................................. $\quad 34$

3.4.1 Instalação de Grades Amostrais..................................................................... 34

3.4.2 Instalação de Parcelas Retangulares............................................................... 35

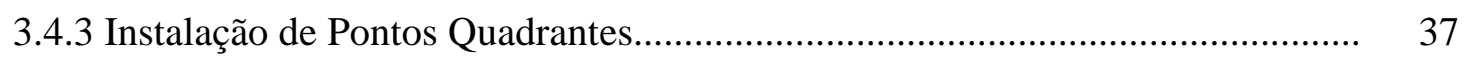

3.4.4 Parcelas de Raios Variáveis (Relascopia)...................................................... 38

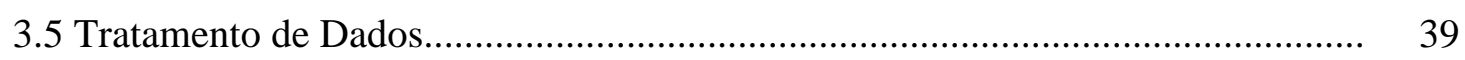

3.5.1 Identificação de Material Botânico................................................................... 39

3.5.2 Parâmetros Fitossociológicos..................................................................... 39

3.5.2.1 Métodos de Parcelas e Quadrantes................................................................ 39

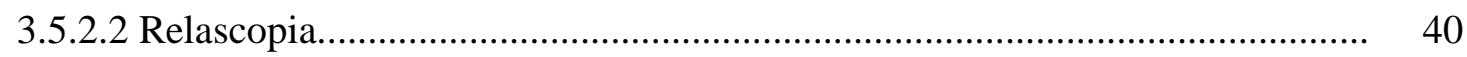

3.5.3 Comparação de Métodos de Amostragem....................................................... 41

4 RESULTADOS E DISCUSSÃO.................................................................... 42

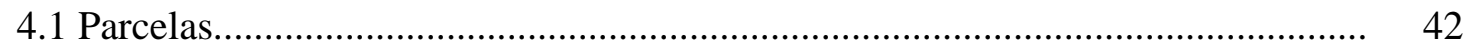

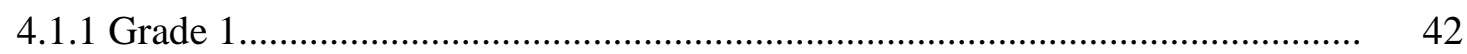

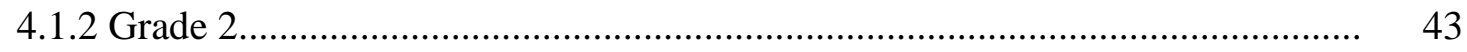

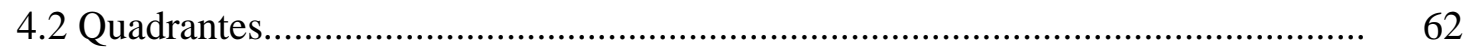

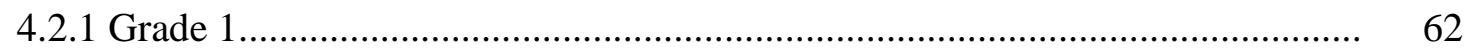

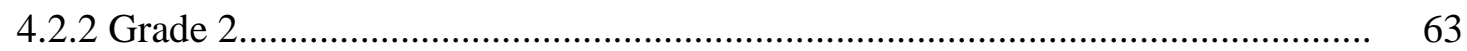

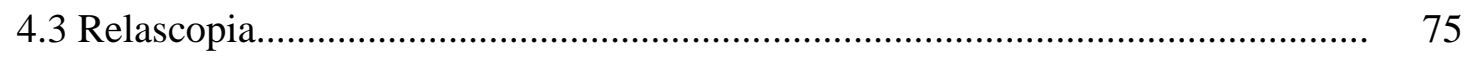

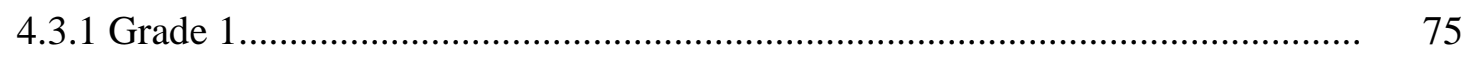

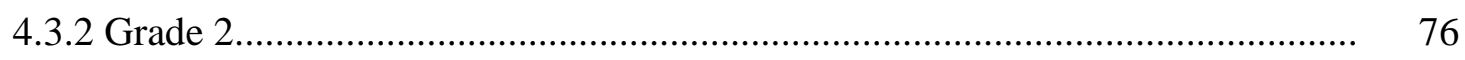

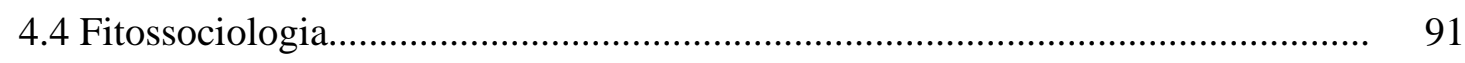

4.5 Diversidade e Equabilidade........................................................................ 135

4.6 Comparação de Métodos de Amostragem........................................................ 137

4.6.1 Composição Florística e Riqueza de Espécies................................................ 137

4.6.2 Distância Euclidiana......................................................................................... 142

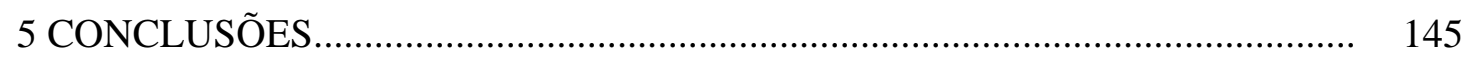

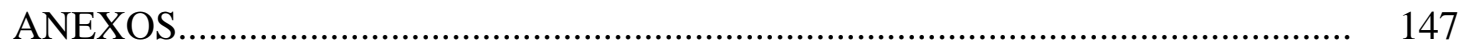

REFERÊNCIAS BIBLIOGRÁFICAS.......................................................... 178 


\section{LISTA DE FIGURAS}

Página

1 Mapa de localização do Parque Estadual Carlos Botelho, com coordenadas geográficas, curvas de nível e localização das áreas de amostragem (Elaborado pela Seção de Manejo e Inventário Florestal - IF)...............

Conjunto de Reservas Florestais que foram unificadas em setembro de 1982, para a criação do Parque Estadual Carlos Botelho

3 Mapa do Parque Estadual Carlos Botelho, onde podem ser visualizados: (I) Planalto Guapiara, (II) Serra de Paranapiacaba e rede de drenagem (Elaborado pela Seção de Manejo e Inventário Florestal - IF)

Representação gráfica do balanço hídrico de Thornthwaite, obtido para o Parque Estadual de Carlos Botelho, Município de São Miguel Arcanjo-SP. (Dias et al., 1995).

5 Localização das duas áreas de amostragem, Grade 1 e Grade 2, no Parque Estadual Carlos Botelho. (Elaborado pela Seção de Manejo e Inventário Florestal - IF). 
Desenho Esquemático da Grade Amostral, com os pontos de Amostragem (Aguiar, 2003)

Desenho Esquemático da Grade Amostral com as parcelas de área fixa. (Aguiar 2003)

Desenho esquemático da parcela, mostrando a localização dos pontos quadrantes a cada 20m (Aguiar, 2003).

Desenho esquemático da parcela, mostrando a localização dos centros das parcelas e Pontos de Relascopia.

Distribuição, em porcentagem das espécies por família, amostrada através do emprego de parcelas no levantamento do componente arbóreo na Floresta Ombrófila Densa (Grade 1 e Grade 2) no Parque Estadual Carlos Botelho. SP. Brasil.

11 Distribuição, em porcentagem das espécies por família, amostrada através do emprego do método de quadrantes no levantamento do componente arbóreo na Floresta Ombrófila Densa (Grade 1 e Grade 2) no Parque Estadual Carlos Botelho. SP. Brasil

12 Distribuição, em porcentagem das espécies por família, amostrada através do emprego do método de relascopia no levantamento do componente arbóreo na Floresta Ombrófila Densa (Grade 1 e Grade 2) no Parque Estadual Carlos Botelho.SP.Brasil 
13 Curva de número de espécies por unidades amostrais, para os métodos de parcelas, quadrantes e relascopia, empregado para o estudo do componente arbóreo da Grade 1, na Floresta Ombrófila Densa, no Parque Estadual Carlos Botelho.SP.Brasil.

14 Curva número de espécies por unidades amostrais, para os métodos de parcelas, quadrantes e relascopia, empregado para o estudo do componente arbóreo da Grade 2, na Floresta Ombrófila Densa, no Parque Estadual Carlos Botelho.SP.Brasil. 


\section{LISTA DE TABELAS}

\section{Página}

1

Relação das famílias e espécies amostradas no componente arbóreo da Floresta Ombrófila Densa, no Parque Estadual Carlos Botelho. SP. Brasil, com o emprego de parcelas.

Relação das famílias e espécies amostradas no componente arbóreo da Floresta Ombrófila Densa, no Parque Estadual Carlos Botelho.SP.Brasil, com o emprego do método de quadrantes. q1 - quadrantes Grade 1 e q2 - Quadrantes Grade 2.

Relação das famílias eespécies amostradas no componente arbóreo na Floresta Ombrófila Densa, no Parque Estadual Carlos Botelho. SP. Brasil, com o emprego do método de relascopia. Gr1 - Grade 1 e Gr2 - Grade 2.

Relação das famílias com maior riqueza de espécies amostrada por três métodos de amostragem (parcelas, quadrantes e relascopia) na Floresta Ombrófila Densa (Grade 1 e Grade 2) - Parque Estadual Carlos Botelho.SP.Brasil. 
Relação de espécies em ordem decrescente de IVI, amostradas pelo método de parcela, na Grade-1, instalada na Floresta Ombrófila Densa, no Parque Estadual Carlos Botelho.SP.Brasil. Ni - Número de Indivíduos; FR - Freqüência Relativa; DR - Densidade Relativa; DOR - Dominância Relativa e IVI - Índice de Valor de Importância

Relação das espécies em ordem decrescente de IVI, amostradas pelo método de quadrantes, na Grade-1, instalada na Floresta Ombrófila Densa, no Parque Estadual Carlos Botelho.SP.Brasil. Ni - Número de Indivíduos; FR - Freqüência Relativa; DR Densidade Relativa; DOR - Dominância Relativa e IVI - Índice de Valor de Importância

7 Relação de espécies em ordem decrescente de IVI, amostradas pelo método de relascopia, na Grade-1, instalada na Floresta Ombrófila Densa, no Parque Estadual Carlos Botelho. SP. Brasil. Ni - Número de Indivíduos; FR - Freqüência Relativa; DR Densidade Relativa; DOR - Dominância Relativa e IVI - Índice de Valor de Importância

Relação de espécies em ordem decrescente de IVI, amostradas pelo método de parcela, na Grade-2, instalada na Floresta Ombrófila Densa, no Parque Estadual Carlos Botelho.SP.Brasil. Ni - Número de Indivíduos; FR - Freqüência Relativa; DR Densidade Relativa; DOR - Dominância Relativa e IVI - Índice de Valor de Importância 
Relação de espécies em ordem decrescente de IVI, amostradas pelo método de quadrantes, na Grade-2, instalada na Floresta Ombrófila Densa, no Parque Estadual Carlos Botelho.SP.Brasil. Ni - Número de Indivíduos; FR - Freqüência Relativa; DR - Densidade Relativa; DOR - Dominância Relativa e IVI - Índice de Valor de Importância.

Relação de espécies em ordem decrescente de IVI, amostradas pelo método de relascopia, na Grade-2, instalada na Floresta Ombrófila Densa, no Parque Estadual Carlos Botelho.SP.Brasil. Ni - Número de Indivíduos; FR - Freqüência Relativa; DR Densidade Relativa; DOR - Dominância Relativa e IVI - Índice de Valor de Importância Relação das espécies com maior valor de IVI, amostradas pelos métodos parcelas, quadrantes e relascopia, para Grade 1 e Grade2, instaladas na Floresta Ombrófila Densa, Parque Estadual Carlos Botelho.SP.Brasil. Par-G1 - parcela Grade 1; Par-G2 parcela Grade 2; Qua-G1 - quadrantes Grade 1; Qua-G2 quadrantes Grade2; Rel-G1 - relascopia Grade 1; Rel-G2 relascopia Grade2.

Valores de diversidade (H’) e equabilidade (J), riqueza de espécies e número de indivíduos, determinados para o componente arbóreo na Grade 1 e Grade 2, instaladas na Floresta Ombrófila Densa, no Parque Estadual Carlos Botelho.SP.Brasil. 
13 Distância Euclidiana calculada entre os valores dos parâmetros fitossociológicos das espécies amostradas pelos métodos de parcelas, quadrantes e relascopia nas duas áreas de amostragem (Grade-1 e Grade-2), instaladas na Floresta Ombrófila Densa, no Parque Estadual Carlos Botelho. SP. Brasil. DE/FR - distância euclidiana para freqüência relativa; DE/DR - distância euclidiana para densidade relativa; DE/DOR - distância euclidiana para dominância relativa; DE/IVI - distância euclidiana para índice de valor de importância 


\section{COMPOSIÇÃO FLORÍSTICA, FITOSSOCIOLOGIA, DIVERSIDADE DE ESPÉCIES \\ E COMPARAÇÃO DE MÉTODOS DE AMOSTRAGEM NA FLORESTA OMBRÓFILA DENSA DO PARQUE ESTADUAL CARLOS BOTELHO/SP-BRASIL}

Autor: ANTONIO CECILIO DIAS

Orientador: Prof. Dr. HILTON THADEU ZARATE DO COUTO

\section{RESUMO}

O presente estudo foi desenvolvido em trecho de Floresta Ombrófila Densa, localizada no Parque Estadual Carlos Botelho. SP., no sul do Estado de São Paulo, nas coordenadas geográficas $24^{\circ} 00^{\prime}-24^{\circ} 15^{\prime}$ de latitude Sul, e $47^{\circ} 55^{\prime}-48^{\circ} 05^{\prime}$ de longitude W, nos município de São Miguel Arcanjo, Sete Barras, Capão Bonito e Tapiraí, com o objetivo de comparar três métodos de amostragem (parcelas, quadrantes e relascopia) na determinação da composição florística, fitossociologia e diversidade de espécies do componente arbóreo. Com o emprego de imagens aéreas foram selecionadas duas áreas de amostragem, sendo a primeira, denominada Grade 1, localizada na parte mais alta do Parque no município de São Miguel Arcanjo - SP, e a segunda, denominada Grade 2, localizada a uma altitude de 650m., no município de Sete Barras - SP. A diferença de altitude entre as duas áreas é de 200m. aproximadamente. Na Grade 1, o método de parcelas amostrou 9543 indivíduos e 250 espécies, quadrantes 1276 indivíduos e 175 espécies e relascopia amostrou 638 indivíduos e 155 espécies. Na Grade 2, foram amostrados pelo método de parcelas 10124 indivíduos e 345 espécies, o método de quadrantes amostrou 1270 indivíduos e 207 espécies e a relascopia amostrou 578 indivíduos e 157 espécies. Foram registradas nas duas áreas de amostragem 65 
famílias botânicas e 427 espécies arbóreas. As famílias Myrtaceae, Lauraceae, Fabaceae e Sapotaceae estavam presentes entre as dez famílias com maior riqueza de espécies, para os três métodos de amostragem empregados. A diversidade de espécies determinada pelo índice de Shannon registrou o maior índice para o método de parcela na Grade 2, $\mathrm{H}^{`}=4,702$, sendo que o menor índice foi obtido pelo método de relascopia, $\mathrm{H}^{`}=4,411$. Estes valores estão entre os maiores determinados até o presente para o componente arbóreo da vegetação do Parque Estadual Carlos Botelho, SP. Euterpe edulis e Ocotea catharinensis foram as espécies que mais se destacaram, por apresentarem os maiores valores de Índice de Valor de Importância (IVI), independente do método de amostragem. A Distância Euclidiana calculada para os parâmetros fitossociológicos Freqüência Relativa, Dominância Relativa, Densidade Relativa e Índice de Valor de Importância, mostra que os métodos de amostragem se comportaram de forma diferente na determinação desses parâmetros nas duas áreas de amostragem. 
Floristic Composition, Phytosociology, Species Diversity and SAMPles

Methods Comparison in the Dense OMbrophilous Forest In the Carlos Botelho

STATE PARK/SP- BRASIL

Author: ANTONIO CECILIO DIAS

Adviser: Prof. Dr. HILTON THADEU ZARATE DO COUTO

\section{SUMMARY}

The following study was developed in tracks of the Dense Ombrophilous Forest, located in the Carlos Botelho State Park, SP., in the southern of the state of São Paulo, geographical coordinates of $24^{\circ} 00^{\prime}-24^{\circ} 15^{\prime}$ South latitude and $47^{\circ} 55^{\prime}-48^{\circ} 05^{\prime}$, West longitude, in the municipalities of São Miguel Arcanjo, Sete Barras, Capão Bonito and Tapiraí, with the objective of comparison of three sampling methods (parcels, point centred quarter and relascope) in determining the species composition, phytosociology and diversity of species in the arboreal component. In this vegetation, the sampling showed of 65 botanical families and 427 arboreas species. With the use of aerial images two areas were selected, the first one, designated Grid 1, being located in the highest part of the Park in the Sao Miguel Arcanjo municipality, and the second, designated Grid 2, located at a height of 650m., in the Sete Barras municipality. The height difference between these two areas is approximately 200m. In the Grid 1, the parcels method showed 9543 individuals and 250 species, the point center quarter method 1276 individuals and 175 species and the relascope method 638 species and 155 species. On Grid 2, we collected by the parcels method 10124 individuals and 345 species, the point 
center quarter method showed 1270 individuals and 207 species and the relascope method 578 individuals and 157 species. The families Myrtaceae, Lauraceae, Fabaceae and Sapotaceae presented the highest species richness in the three samples methods. The diversity of the species determined by the Shannon index recorded the highest index for the parcels method in Grid 2, H'=4.7202 and the smallest index was obtained by the relascope method $\mathrm{H}^{\prime}=4.411$, and these values are among the highest determined up to the present for the arboreal components of the vegetation for the Carlos Botelho State Park, SP. Euterpe edulis and Ocotea catharinensis were the outstanding species, by presenting the highest values in the Significant Value Index, independent of the sampling method. The Euclidian Distance calculated for the phytosociological parameters, Relative Frequency, Relative Dominance, Relative Density and Significant Value Index, shows that the samples methods behaves differently in characterizing the vegetation in Grid 1 and Grid 2. 


\section{INTRODUÇÃO}

Dentre os diversos componentes que formam o ambiente natural, a vegetação pode ser considerada como um bom indicador não só das condições do meio ambiente como também do estado de conservação dos próprios ecossistemas envolvidos.

Tendo em vista que a vegetação responde de forma consideravelmente rápida às variações ambientais, a sua avaliação permite inferir sobre o estado de conservação dos demais componentes do ambiente natural.

No Estado de São Paulo, a cobertura florestal vem sofrendo ao longo de sua história, inúmeros tipos de pressões que culminou com a redução drástica de sua área de ocupação. Dentre estas pressões, Victor (1975) menciona a retirada contínua de madeira, queimadas e instalação da agricultura.

O Inventário Florestal do Estado de São Paulo, elaborado por Kronka et al. (1993), revelou que 7,4\% da cobertura vegetal do Estado correspondem a matas nativas e, juntamente com mais 6\% ocupado com outros tipos de vegetação natural, totalizam 13,4\% em relação á área total do Estado.

A maior extensão de Floresta Natural no Estado de São Paulo localiza-se na Encosta Atlântica e Planície Costeira, sendo um seguimento da Floresta Pluvial Tropical (Negreiros et al. 1995).

Aguiar (2003) salienta que muitos estudos estão sendo desenvolvidos nestas florestas, no entanto, ainda faltam informações quanto a sua composição florística e estrutura fitossociológica.

Considerando a complexidade e a alta diversidade da Floresta Pluvial Tropical, Dias et al. (1989) chamam a atenção para a dificuldade de amostragem desta 
vegetação e propõem adoção de métodos de amostragem menos trabalhosos de serem implantados e que forneçam dados confiáveis.

De acordo com Wilson (1997) a conservação de áreas tropicais é dificultada pela falta de conhecimento e pela escassez de pesquisas. Salienta a necessidade de saber quantas espécies estão presentes, assim como sua amplitude geográfica, propriedades biológicas e possíveis vulnerabilidades às mudanças ambientais.

Conservação da biodiversidade tem se tornado um tema importante, recebendo atenção tanto nacional como internacional.

No entanto, a palavra biodiversidade tem pouco significado para muitas pessoas e pode ter muitas interpretações para aqueles que a estudam. Em função disto existem muitas definições para diversidade biológica.

Um caminho comum para avaliar biodiversidade é através da medida do número e abundância relativa de espécies em uma comunidade ou ecossistema, freqüentemente referido como diversidade de espécies.

Escolher o índice apropriado para avaliar a diversidade em nível de comunidade pode ser difícil tanto pela existência de um grande número de índices como pelas vantagens e desvantagens de cada um.

Magurran (1988) sugere que um critério importante para seleção do índice de diversidade deve incluir sua habilidade de caracterizar diferenciações entre locais, dependência sobre tamanho da amostra, que componente da diversidade será medido e se o índice é amplamente usado e conhecido.

Outro ponto importante a ser considerado diz respeito ao método de amostragem a ser empregado. Isto porque a realização do censo de todos os indivíduos de uma comunidade é raramente praticável, uma vez que demandaria um tempo muito longo e seria de custo elevado. 
Conforme salienta Magurran (1988) os ecologistas tem confiado nas amostragens para fornecer uma representação segura da composição da comunidade e, um grande esforço tem sido despendido para produzir técnicas de amostragem tão eficiente quanto possível.

O método de amostragem mais utilizado é o método de parcelas de áreas fixas, de custos normalmente mais elevados, por exigir maior tempo de levantamento em função da marcação e numeração de um grande número de indivíduos (Farias et al., 2002).

Aplicação de novos métodos de levantamento visando reduzir tempo e custo para execução dos estudos, no entanto, mantendo a precisão, é importante e necessária.

No presente estudo empregou-se o método de parcelas de área fixa, representado por parcelas de $900 \mathrm{~m}^{2}$ (10 x 90m); os métodos de distância ponto a planta, representada pelo método de quadrantes e pelo método de parcelas circulares de área variável (Relascopia). Com o emprego destes métodos, determinou-se: a composição florística da área de estudo; os parâmetros fitossociológicos e a diversidade do componente arbóreo com o emprego do índice de Shannon.

O trabalho foi desenvolvido tendo com premissa a seguinte hipótese:

- Os métodos de parcelas, quadrantes e relascopia, não apresentam diferenças significativas entre si, na amostragem da composição florística, parâmetros fitossociológicos e diversidade de espécies arbóreas.

\section{Objetivos:}

Os principais objetivos do presente trabalho são:

- Comparar os métodos de parcelas de área fixa, pontos quadrantes e pontos de relascopia na estimativa da diversidade de espécies do componente arbóreo em dois trechos de Floresta Ombrófila Densa Montana, no Parque Estadual Carlos Botelho; 
- Determinar a diversidade de espécies arbóreas em duas áreas com gradientes altitudinais variando em torno de 200 metros, em um trecho de Floresta Ombrófila Densa Montana, com o emprego do Índice de Shannon;

- Comparar os resultados obtidos pela aplicação de três métodos de amostragem (parcelas, quadrantes e relascopia) na determinação dos parâmetros fitossociológicos. 


\section{REVISÃO BIBLIOGRÁFICA}

\subsection{Da Mata Atlântica}

Mantovani (1993) chama a atenção para a vegetação que originalmente cobria as serras costeiras desde o Rio Grande do Norte até o Rio Grande do Sul, e salienta que suas variações florísticas e estruturais estão relacionadas com as características do substrato e com as variações climáticas devido às mudanças latitudinais e altitudinais. Salienta que diante destas considerações pode-se afirmar que as florestas na Encosta Atlântica apresentam variações regionais e locais, que as situam entre as florestas mais ricas e diversas no território brasileiro, o que dificulta a exploração racional e o manejo sustentado, que envolvam alterações de suas estruturas.

De acordo com Veloso et al. (1991) a flora da Costa Atlântica faz parte da região florística denominada Dryades, proposta por Martius em 1824 e, em 1826, Gonzaga de Campos a classificou como Floresta Atlântica da Encosta. Salienta ainda que Andrade-Lima, no Primeiro Atlas Geográfico do IBGE, e Veloso no Atlas Florestal do Brasil empregaram o termo formação para dividir os grupos maiores de vegetação e uma terminologia ecológica estrutural nas subdivisões florestais, seguidas de terminologias regionais para subdivisões não florestais. Classificaram as formações florestais, formações não florestais e formações edáficas.

Hueck \& Seibert citado por Ivanauskas (1997) designaram a Mata Atlântica como Floresta Pluviosa Perene da Costa Atlântica, caracterizando-se nas seções setentrionais e meridionais, sendo que a seção setentrional ocorre desde o Estado do Rio Grande do Norte até o Estado do Espírito Santo e a meridional, a partir do Estado do Rio 
de Janeiro até o Nordeste do Estado do Rio Grande de Sul. Estes autores reconheceram ainda uma diferenciação na composição florística e na estrutura desta vegetação, no gradiente altitudinal da Serra do Mar.

Ivanauskas (1997) efetuou estudos sobre os conceitos de Mata Atlântica, com o intuito de demonstrar as divergências existentes sobre quais formações a compõem, e chama a atenção para as diferentes denominações que esta formação vem recebendo ao longo do tempo. Esta autora salienta ainda que estas diferentes denominações variam de acordo com cada sistema de classificação, e que estes sistemas, proposto por diferentes pesquisadores, não devem ser comparados entre si, em função de não terem sido definidos sobre as mesmas bases de estudo.

Ivanauskas et al. (2000) estudaram a similaridade florística entre as áreas de Floresta Atlântica no Estado de São Paulo, e concluíram que existem diferenças significativas entre a cobertura florestal do Planalto Atlântico e a Província Costeira. Chamam a atenção para a necessidade de estudos nestas áreas, principalmente na baixada litorânea onde ocorre vegetação com influência marinha (Floresta de Restinga).

Rizzini (1979) determina dentro da Floresta Atlântica as seguintes formações: Floresta Pluvial Montana, Floresta Pluvial Baixo-Montana, Floresta de Araucária e Floresta Pluvial Ripária ou de Manchas.

\subsection{Dos Métodos de Amostragem}

A vegetação pode ser avaliada qualitativa e quantitativamente através da aplicação de diferentes métodos de amostragem. A aplicação de um ou outro método dependerá do tempo, recursos disponíveis, fitofisionomia da área de estudo, bem como das variações da estrutura da vegetação. Entende-se por métodos de amostragem a forma de obter os valores qualitativos e quantitativos de uma unidade amostral. 
Um grande número de métodos de amostragem tem sido descrito para estudo de comunidades vegetais, e estes podem ser classificados como métodos de área fixa e métodos de distância.

Os Métodos de Área Fixa são os mais antigos métodos de amostragem conhecidos, onde os dados podem ser obtidos pelo emprego de parcelas múltiplas, que consiste em estabelecer várias parcelas em vários locais da comunidade vegetal, ou parcela única com forma e tamanho predefinido. A forma retangular é a mais recomendada para as parcelas, pois em função de serem mais alongadas possui uma grande probabilidade de incluir maior número de espécies que apresentem distribuição agrupada. O tamanho da parcela depende principalmente do porte dos indivíduos que compõe a população, da fase de desenvolvimento da floresta bem como do objetivo do levantamento (http://www.ambientebrasil.com.br).

Os Métodos de Distância ou sem parcelas podem ser divididos em dois grupos de métodos de amostragem: métodos de distância ponto a planta, que considera a distância entre um ponto e o indivíduo mais próximo, e os métodos de distância planta a planta, onde é considerada a distância entre dois indivíduos mais próximos.

\subsubsection{Das Parcelas}

Trata-se de um dos métodos quantitativos mais empregado em estudos fitossociológicos e, segundo Martins (1979), este método consiste no estabelecimento de pequenas parcelas quadradas dentro da área de estudo e, em função desta forma de parcela este método ficou também conhecido como método dos quadrados.

Ainda de acordo com Martins (1979) as primeiras tentativas de quantificar as populações arbóreas de florestas pluviais brasileiras, com a utilização de parcelas, foram realizadas nos Estados do Pará e Amazonas com os trabalhos desenvolvidos por Black et al. (1950), que estimaram a diversidade de espécies e a densidade de populações de 
árvores em três localidades, sendo uma em floresta de igapó e as outras em florestas de terra firme. Para este estudo os autores empregaram o método de parcelas.

No Estado de São Paulo, o trabalho realizado por Heinsdjik \& Campos (1967) está entre os primeiros levantamentos de florestas latifoliadas nativas, na Serra do Mar. Estes autores empregaram parcelas para o conhecimento dos estoques madeireiros e distribuição diamétrica por espécie, nas áreas das Reservas: Carlos Botelho, Capão Bonito, Sete Barras e Travessão.

Diversos pesquisadores empregaram o método de parcelas para o estudo da vegetação da Encosta Atlântica e Planície Costeira, dentre estes citamos: Negreiros (1983), no estudo da regeneração natural do palmito (Euterpe edulis); Negreiros et al. (1990), no estudo da distribuição diamétrica; Ivanauska (1997), na caracterização florística e fisionômica da Floresta Atlântica na região de Pariquera-Açu; Custodio Filho (2002), realizando comparações florísticas nos municípios de São Miguel Arcanjo, Capão Bonito e Sete Barras; Aguiar (2003), na comparação de métodos de amostragem.

\subsubsection{Dos Quadrantes}

Dentre os métodos de distância este é o mais comumente empregado em estudos fitossociológicos no Brasil. De acordo com Martins (1979) trata-se de um método de rápida instalação no campo, pois dispensa a instalação de uma área amostral. Ainda de acordo com Martins (1979) o primeiro a aplicar o método de quadrantes para estudar uma vegetação tropical foi Goodland (1964), na Guiana Inglesa, em estudos fitossociológicos em formação vegetal do tipo savana. Salienta ainda que foi Goodland que introduziu este método no Brasil com o objetivo de estudar a vegetação do cerrado do Triângulo Mineiro. A limitação deste método está no número de árvores amostradas em cada ponto, que torna necessário assumir uma distribuição espacial completamente aleatória, para que se possa ter uma estimativa mais precisa da densidade. 
A partir daí, diversos trabalhos foram desenvolvidos com a aplicação do método de quadrantes para a determinação dos parâmetros fitossociológicos, dentre eles temos: Cavassan et al. (1984), Dias (1993), Baitello et al.(1993) e Mantovani (1990 e 1993).

No Parque Estadual Carlos Botelho, Dias et al. (1995) empregaram o método de quadrantes no levantamento de um trecho de Floresta Pluvial Atlântica, tendo como objetivo determinar a composição florística e a estrutura da comunidade. Ainda nesta mesma área Dias et al. (2000) determinaram a diversidade de espécies arbóreas, através do emprego de seis diferentes índices de diversidade, utilizando método de quadrantes.

\subsubsection{Da Relascopia}

O Método de Parcelas Circulares de Raios Variáveis ou Relascopia é um método de distância ponto a planta, proposto por Bitterlich em 1948, desenvolvido especificamente para o estudo de espécies arbóreas. De acordo com Veiga (1976) este método é de fácil aplicação, uma vez que o número de árvores contadas em um ponto de amostragem, é proporcional à área basal por hectare.

De acordo com Batista (1998) este método aparece na literatura com uma grande variedade de nomes, dentre os quais temos: amostragem com probabilidade proporcional ao tamanho, amostragem por contagem angular, amostragem por parcelas de área variável e amostragem horizontal por pontos. Ainda de acordo com Batista (1998) o Principio de Bitterlich permite a estimativa direta da área basal através da contagem das árvores amostradas em função de um ângulo de visada.

Proposto inicialmente para o estudo de área basal e determinação de volume de povoamentos florestais, este método vem sendo utilizado também para estudos ecológicos. Batista (1998) chama a atenção para a eficiência do método e salienta que o atributo a ser avaliado deve ter uma relação com a área basal da floresta ou com a área 
seccional das árvores individualmente. Alerta ainda para a necessidade de utilização do Fator de Expansão como variável de ponderação para os atributos medidos individualmente nas árvores.

No Parque Estadual Carlos Botelho, Dias et al. (1989), Dias (1993) e Negreiros et al. (1995), empregaram o Método de Relascopia para estudos fitossociológicos na comunidade de Floresta Pluvial Tropical.

\subsection{Da Fitossociologia}

De acordo com Tabarelli et al. (1993) a fitossociologia possibilita a identificação de parâmetros quantitativos de uma comunidade vegetal, definindo abundância, relação de dominância e importância relativa. Permite ainda inferir sobre a distribuição espacial de cada espécie. Estudos fitossociológicos mostram possibilidades de associações intraespecíficas e de estudo em nível específico sobre a agressividade, propagação vegetativa, ciclo de vida e dispersão.

Para Isernhagen (2001) a fitossociologia tem um papel preponderante no embasamento de programas de gestão ambiental. Salienta ainda que os estudos fitossociológicos produzem no mínimo uma listagem florística, a partir da qual pode-se obter uma caracterização da tipologia da vegetação em questão.

De acordo com Mantovani (1987), os estudos fitossociológicos que foram ou que estão sendo desenvolvidos, no Estado de São Paulo, geralmente estão voltados à análise do componente dominante da vegetação, nestes casos, o conhecimento fica restrito apenas à estrutura, e conseqüentemente a diversidade destas comunidades.

Tabarelli et al. (1994) analisaram os processos envolvidos na sucessão secundária na Floresta Ombrófila Densa Montana com base em parâmetros fitossociológicos, em duas áreas com idades diferentes no Parque Estadual da Serra do Mar. 
Mantovani et al. (1990) estudando a vegetação da Serra do Mar, identificaram quatro padrões florestais denominados: Mata de Topo de Morros, Mata de Encosta Voltada para o Oceano Atlântico, Mata de Encosta voltada para o Vale do Paraíba e Mata de Fundo de Vale. Cada um desses padrões foi analisado florística, fisionômica e fitossociologicamente. Estes autores encontraram nas Matas de Encosta voltadas para o Oceano Atlântico, um grande número de espécies raras, o que segundo eles favorece a diversidade da comunidade.

\subsection{Da Diversidade de Espécies}

No estudo da biodiversidade, sempre nos defrontamos com novos desafios. Se por um lado o crescimento extraordinário da população concorre para o aumento da degradação ambiental, por outro lado, novos estudos conduzem para o aproveitamento desta biodiversidade de forma a atender as necessidades humanas e reduzir os efeitos desta degradação. Não se pode perder de vista que esta biodiversidade vem sofrendo perdas irreversíveis, com a destruição dos habitats naturais. Isto vem ocorrendo sem mesmo sabermos ao certo qual o verdadeiro número de espécies que ocorre sobre a terra, conforme alerta Wilson (1997). Este autor salienta ainda que o número de espécies aliado à quantidade de informações genéticas em um organismo constitui apenas em uma parte da diversidade biológica sobre a Terra.

Diversidade de espécies tem sido compreendida como um fenômeno histórico, um reflexo do acúmulo de espécies ao longo do tempo.

Mas, de acordo com Schluter \& Ricklefs (1993), nas últimas décadas, diversidade passou a ser interpretada como expressão resultante de interações ecológicas, em especial a competição. 
Como componente mais relevante da diversidade, tem-se o número de espécies, no entanto, o conceito de diversidade não pode se restringir ao termo Riqueza de Espécies.

Para Magurran (1988) a definição de diversidade é muito difícil, pelo fato de ser formada por dois componentes e não por apenas um, ou seja, ela é representada primeiramente pelo número de espécies e depois pela abundância relativa de espécies.

Assim, diversidade pode ser medida pelo número de espécies, pela descrição de suas abundâncias relativas, ou por uma medida que combine os dois componentes.

Bryant (1999) chama a atenção para a importância do estudo da biodiversidade de espécies arbóreas e estima em 50.000 o número de espécies arbóreas encontradas nos trópicos, enquanto o número de artrópodes na mesma região chega a 30 milhões. Salienta, no entanto, que se $50 \%$ das espécies arbóreas desaparecessem, o número de espécies de artrópodes também seria reduzido à metade.

Para Magurran (1988) existem pelo menos três razões que justificam o interesse dos ecologistas em estudar diversidade ecológica e suas medidas:

- Apesar de diversas preocupações e mudanças comportamentais, diversidade tem se mantido ao longo dos tempos como um tema central em ecologia;

- As variações no padrão espacial e temporal em diversidade, que muito intrigou os primeiros pesquisadores do mundo natural, continuam ainda hoje a estimular a mente dos ecologistas e,

- As medidas de diversidade são tidas freqüentemente como indicadoras de prosperidade de sistemas ecológicos.

Para avaliar o desempenho de uma espécie vegetal ou animal é necessário compreender principalmente três aspectos principais de sua adaptação, que são: a relação entre as suas exigências, suas tolerâncias e suas capacidades. Considerando que 
exigência é a necessidade que um organismo manifesta em relação a um recurso em cada uma de suas fases de vida, e, tolerância é a função do stress sofrida pelo excesso ou pela deficiência de um recurso, sabe-se que um organismo só terá sua sobrevivência garantida em um ou vários ambientes, quando suas exigências mínimas forem satisfeitas e quando suas tolerâncias máximas não são ultrapassadas (Dansereau, 1992).

Em ambientes onde estas condições atendam a um grande número de espécies, podem ser consideradas ricas em espécies.

De acordo com Ricklefs \& Miller (1999) quando estudamos o número de espécies ou riqueza de espécies, os tipos de espécies presentes e suas abundâncias relativas, as características físicas da vegetação e as relações tróficas entre as populações que interagem na comunidade, estamos preocupados com a Estrutura da Comunidade. No entanto, quando estudamos a taxa de fluxo de energia, capacidade de recuperação da comunidade após perturbação e a produtividade, estamos preocupados com a Função da Comunidade. $\mathrm{Na}$ verdade, estrutura e função da comunidade estão relacionadas. No entanto, como menciona Kikkawa (1986) o conceito de comunidade engloba as interações das populações de espécies. Estas constituem geralmente interações do biótopo, interações tróficas e competitivas e mostram padrões espaciais e temporais de distribuição entre os organismos. Os padrões podem ser cíclicos, recorrentes, ordenados ou desordenados. Necessitamos de medidas que reflitam este tipo de interação e sua magnitude, e que permitam comparações de comunidades. Complexidade e diversidade são duas dessas medidas que têm sido desenvolvidas por ecologistas teóricos. Estas medidas têm sido usadas para predizer a estabilidade de comunidades sob várias condições. Sendo a complexidade uma função do número de inter-conecções entre os elementos de um dado local. As interações podem ser classificadas como competitivas, tróficas e simbióticas.

Investigações de diversidade estão freqüentemente restritas às medidas de riqueza de espécies. É importante incorporar mais informações ecológicas nas medidas de diversidade, especialmente quando se tenta usá-las em comunidades a conservar. 
Magurran (1988) chama a atenção para existência de um grande número de índices para determinar a diversidade de uma comunidade. No entanto, todos os índices discutidos até o presente tratam todas as espécies igualmente. Neste caso deveria ser dado um peso maior às espécies raras do que para as espécies comuns.

Hubbel e Foster (1986) sugeriram que a raridade ocorreria mais em função da história de vida do que por razões circunstanciais.

Segundo Guedes-Bruni (1998) riqueza de espécies expressa enormes variações geográficas. De acordo com Schluter \& Ricklefs (1993) muitos são os processos que potencialmente podem interferir no grau de riqueza de espécies, como:

- Fatores Físicos: Clima e suprimento de energia;

- Fatores Históricos: Taxas de especiação e dispersão;

- Interações Bióticas: Predação e competição.

Índice de diversidade procura caracterizar diversidade de uma amostra ou comunidade por um simples número.

As medidas de diversidade de espécies podem ser divididas em três categorias principais:

- Índices de riqueza de espécie - são essencialmente uma medida do número de espécies definida em uma unidade de amostragem;

- Modelos de abundância de espécies - descrevem a distribuição da abundância de espécies. Estes modelos variam desde aqueles que representam uma regularidade, até aqueles que caracterizam casos onde a abundância é muito desigual.

- Índices baseados na abundância proporcional de espécies -são também denominados índices de heterogeneidade uma vez que procuram caracterizar riqueza e regularidade em um mesmo índice. 
As florestas tropicais muito pressionadas pelas ações antrópicas apresentam ecossistemas extremamente ameaçados incapazes muitas vezes de manterem a biodiversidade existente. Nesta situação encontram-se as florestas nativas remanescente do Estado de São Paulo e, a avaliação quanto à capacidade dessas florestas de manter ou aumentar a sua biodiversidade só poderá ser obtida através de levantamentos minuciosos realizados nestas áreas.

De acordo com Barros et al. (2000) o estudo da diversidade de espécies arbóreas em Florestas Tropicais é muito importante, uma vez que oferecem informações qualitativas e quantitativas destas florestas. Estas informações associadas a estudos fitossociológicos possibilitam a tomada de decisão quanto à exploração sustentada dos recursos florestais existentes

Para Melo (2000) o dinamismo natural das Florestas Tropicais aumenta a diversidade da vida por meio da destruição e de regeneração localizada e, salienta a existência de várias teorias para explicar a origem e manutenção da grande diversidade de espécies arbóreas das Florestas Tropicais.

\subsection{Comparação de Métodos de Amostragem}

A definição do método de amostragem que possa ser empregado em diferentes tipos de vegetação e produza resultados precisos e comparáveis entre si, a um menor custo e no menor espaço de tempo possível é esperança de todo aquele que se dedica a esta área de estudo. No entanto o que se observa é que cada pesquisador desenvolve o seu próprio sistema de amostragem produzindo resultados nem sempre comparáveis com outros estudos, mesmo quando são realizados em um mesmo bioma.

Com o objetivo de amenizar esta situação um grande número de trabalhos vem se preocupando com a comparação dos diferentes métodos de amostragens, dentre os quais temos: 
Dias et al. (1989), empregando os métodos de amostragem parcelas de área fixa e os métodos de distância: pontos quadrantes, árvore mais próxima, vizinho mais próximo, pares aleatórios, inglês e relascopia, com os fatores de numeração (Fn) 9, 16 e 25 e, considerando o Índice de Valor de Importância como parâmetro de comparação, não observaram diferenças significativas entre os valores obtidos através do emprego do método de parcelas e método de distância. No entanto, quando considerado o inventário florístico da comunidade, os métodos Árvore Mais Próxima e Relascopia, mostraram-se menos eficientes. Considerando a complexidade e alta diversidade da Mata Atlântica, os autores chamaram a atenção para o grau de dificuldade encontrado em sua amostragem e propõem estudos para a adoção de métodos de amostragem menos trabalhosos de serem implantados e com obtenção de dados confiáveis.

Moscovich et al. (1999) compararam quatro métodos de amostragem de área variável (Strand, Prodan, Quadrantes e Bitterlich) com o método de área fixa, com o objetivo de determinar a eficiência de cada um deles na estimativa de parâmetros quantitativos e qualitativos da população. $\mathrm{O}$ estudo foi desenvolvido em uma área de 1 ha , onde todas as árvores com CAP $\geq 30 \mathrm{~cm}$ foram amostradas. Foram empregados no estudo 10 parcelas de área fixa de $10 \times 100 \mathrm{~m}$, e para os métodos Prodan, Quadrantes e Bitterlich foram empregado 25 pontos amostrais, distribuídos sistematicamente a cada 20m. Para o método de Strand foram empregadas 30 linhas de amostragem de 15,7m. Através da análise de variância, verificou-se que os métodos não apresentaram diferenças significativas na estimativa do volume, área basal e número de árvores por hectare. Porém quando da estimativa do número de espécies amostradas foi observada diferença significativa entre todos os métodos, sendo o método de área fixa o que apresentou melhor resultado.

Gorenstein (2002) comparou diferentes métodos de amostragem no levantamento de comunidades arbóreas em Floresta Estacional Semidecidual. Foram empregados no levantamento parcelas fixas, quadrantes e relascopia. Utilizando-se como critério de inclusão a amostragem de todas as árvores com DAP $\geq 10 \mathrm{~cm}$., e empregando na amostragem 100 parcelas contíguas de $10 \times 10 \mathrm{~m}$., 177 pontos quadrantes e 45 pontos 
de Bitterlich; foram amostrados respectivamente 59, 69 e 57 espécies para cada método empregado. O Método de Bitterlich (Fator-3) foi selecionado por apresentar melhores resultados em relação a tempo gasto e facilidade de aplicação no campo, em comparação aos outros fatores. Considerando o esforço amostral por tempo, o método de quadrantes foi o que apresentou melhor resultado. No entanto este método apresentou desvios, em relação à estimativa de densidade, apresentando uma superestimativa de densidade arbórea para florestas com padrão de distribuição regular e uma sub-estimativa da densidade para florestas com padrão espacial agrupado.

Farias et al. (2002) efetuaram um inventário florestal, em uma floresta estacional semidecidual, localizada na Zona da Mata, no Município de Viçosa - Minas Gerais, onde compararam o método de parcelas fixas com a amostragem por pontos horizontais (Método de Bitterlich). Para este estudo os autores basearam nos parâmetros: número de árvores por hectare, volume por hectare, número de espécies, diâmetro médio, altura média do povoamento, bem como a distribuição diamétrica. Empregaram no levantamento 13 parcelas com $500 \mathrm{~m}^{2}$ (20 x 25m) cada, sendo a maior dimensão de cada parcela direcionada para o sentido de maior declividade. O centro de cada parcela de área fixa foi utilizado como ponto de amostragem, totalizando, portanto 13 pontos. Estes autores concluíram que a relascopia atende os objetivos de diagnósticos rápidos de uma floresta, no entanto salientam que para a amostragem do número de espécies, há necessidade de uma maior intensidade amostral.

Mello et al. (1996) efetuaram estudo visando demonstrar de forma quantitativa a eficiência de vários sistemas de amostragem na descrição da estrutura fitossociológica de uma Floresta Estacional Semidecidual Montana, situada no Município de Lavras - MG. Os autores empregaram no estudo os sistemas de amostragem casual simples, amostragem casual simples com parcelas de tamanhos desiguais, amostragem estratificada, amostragem sistemática, amostragem sistemática com pós-estratificação e amostragem sistemática com o uso de estimador de regressão. Para comparação dos sistemas de amostragem os autores utilizaram as Distâncias Euclidianas como medida de dissimilaridade entre os IVIs obtidos para cada 
procedimento amostral. De acordo com Brower \& Zar citado por Mello et al. (1996) quanto menor a Distância Euclidiana entre duas comunidades, mais próximas elas se apresentam em termos de parâmetros quantitativos por espécies. No presente trabalho o melhor resultado foi observado para amostragem sistemática com parcelas de tamanho desigual, uma vez que apresentou o menor valor para a Distância Euclidiana $(4,19)$. 


\section{MATERIAL E MÉTODOS}

\section{1 Área de Estudo}

O trabalho foi desenvolvido no Parque Estadual Carlos Botelho, que se localiza nas coordenadas geográficas $24^{\circ} 00^{\prime}$ a $24^{\circ} 15^{\prime}$ de latitude $\mathrm{S}$ e $47^{\circ} 55^{\prime}$ a $48^{\circ} 05$ longitude W (Figura 1).

Com uma área de 37.797,43 hectares, suas terras distribuem-se pelos municípios de São Miguel Arcanjo, Capão Bonito, Sete Barras e Tapiraí.

Preservado como unidade de conservação desde 1941, possui a maior parte de sua cobertura vegetal representada por florestas não perturbadas ou com perturbações pouco significativas.

Constituído por quatro reservas florestais, Reserva de Carlos Botelho e Reserva de Capão Bonito, criadas em 1941 e Reserva do Travessão e Reserva de Sete Barras criados em 1957, que foram mantidas visando o estabelecimento de futuros núcleos de colonização e preservação de áreas de refúgios e testemunho da fauna e flora regional (Figura 2).

A unificação destas áreas de reservas e a sua elevação ao "status" de Parque Estadual ocorreram em 1982, sendo mantido o nome de "Carlos Botelho", pela neutralidade do nome e pela importância do homenageado (Carlos Botelho, 1855 1957, médico e Secretário da Agricultura do Estado de São Paulo, em 1904) conforme salienta Custodio Filho (2002). 


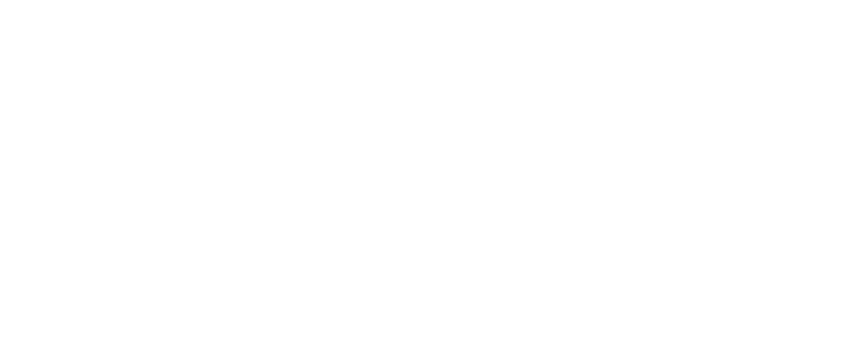

Figura 1 - Mapa de localização do Parque Estadual Carlos Botelho, com coordenadas geográficas, curvas de nível e localização das áreas de amostragem (Elaborado pela seção de Manejo e Inventário Florestal - IF) 


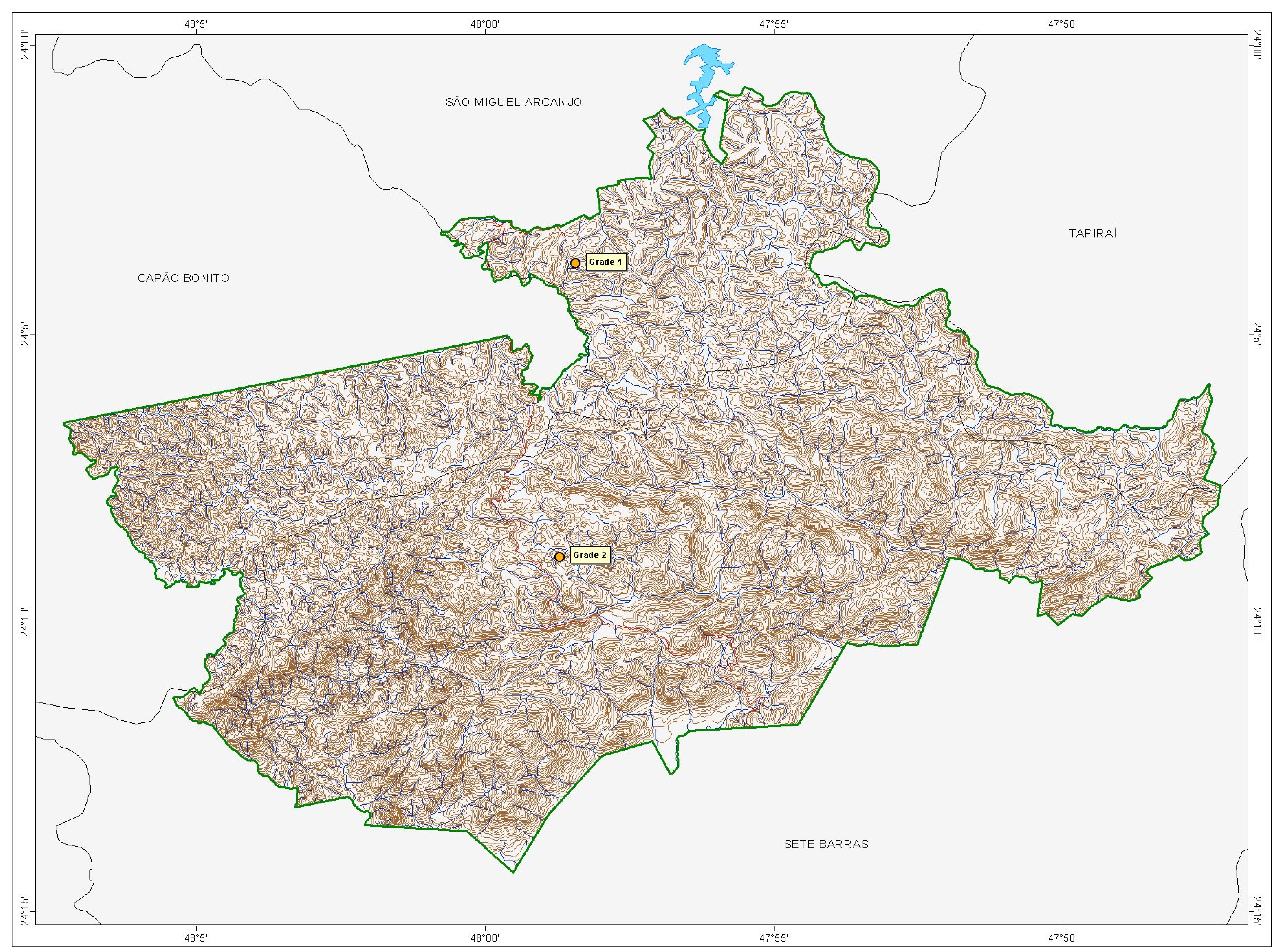

FIGURA 1

Legenda

Curvas de Nível

Curso D'Água

V Vias de Acesso

$\longrightarrow$ Represa

$\longrightarrow$ Limite Municipal

C PE Carlos Botelho

- Grades de Amostragem 1 e 2

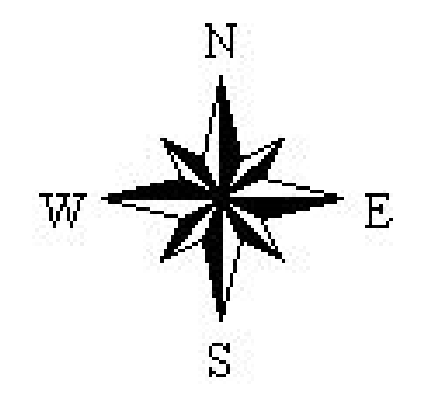

$1: 125000$

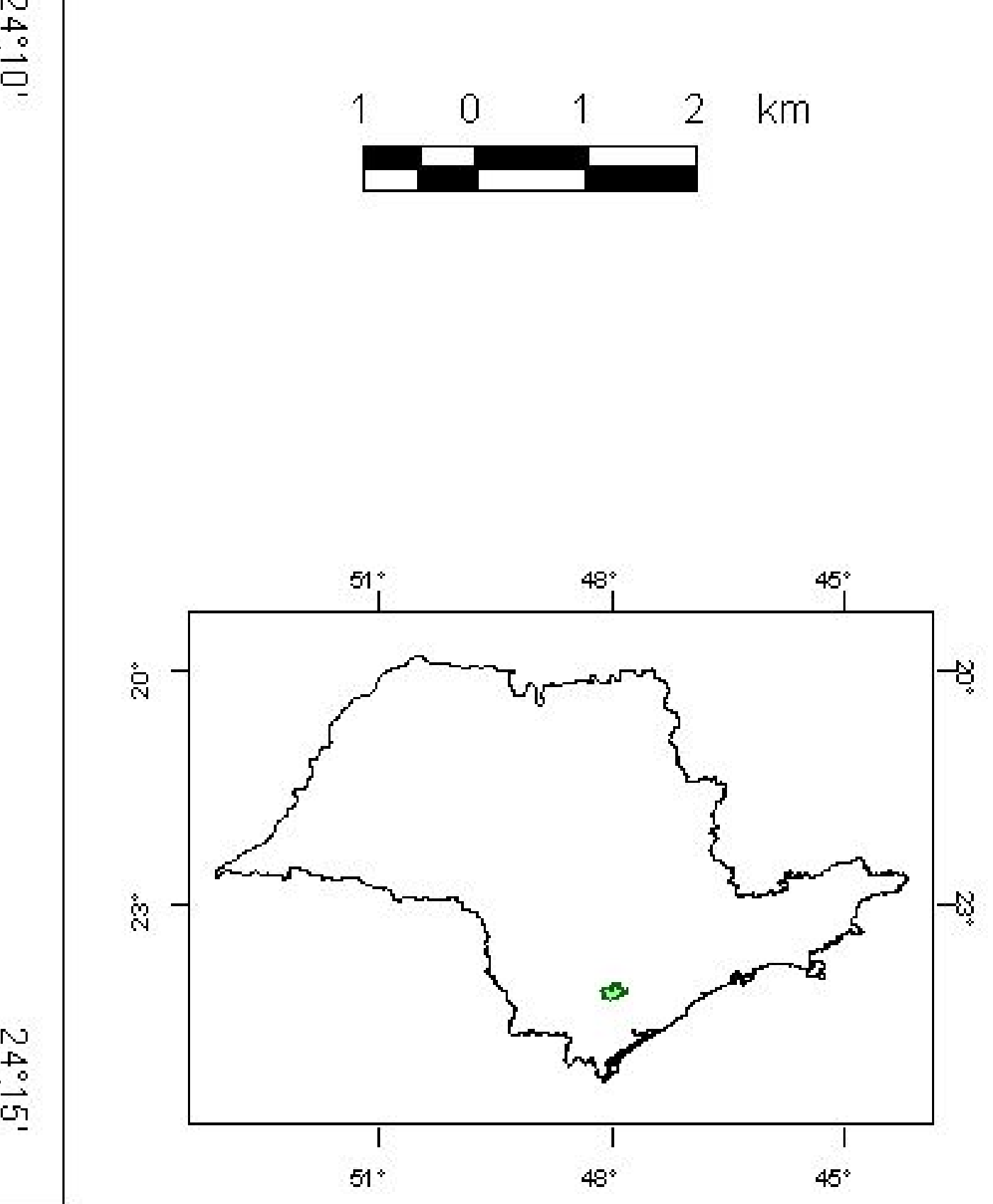




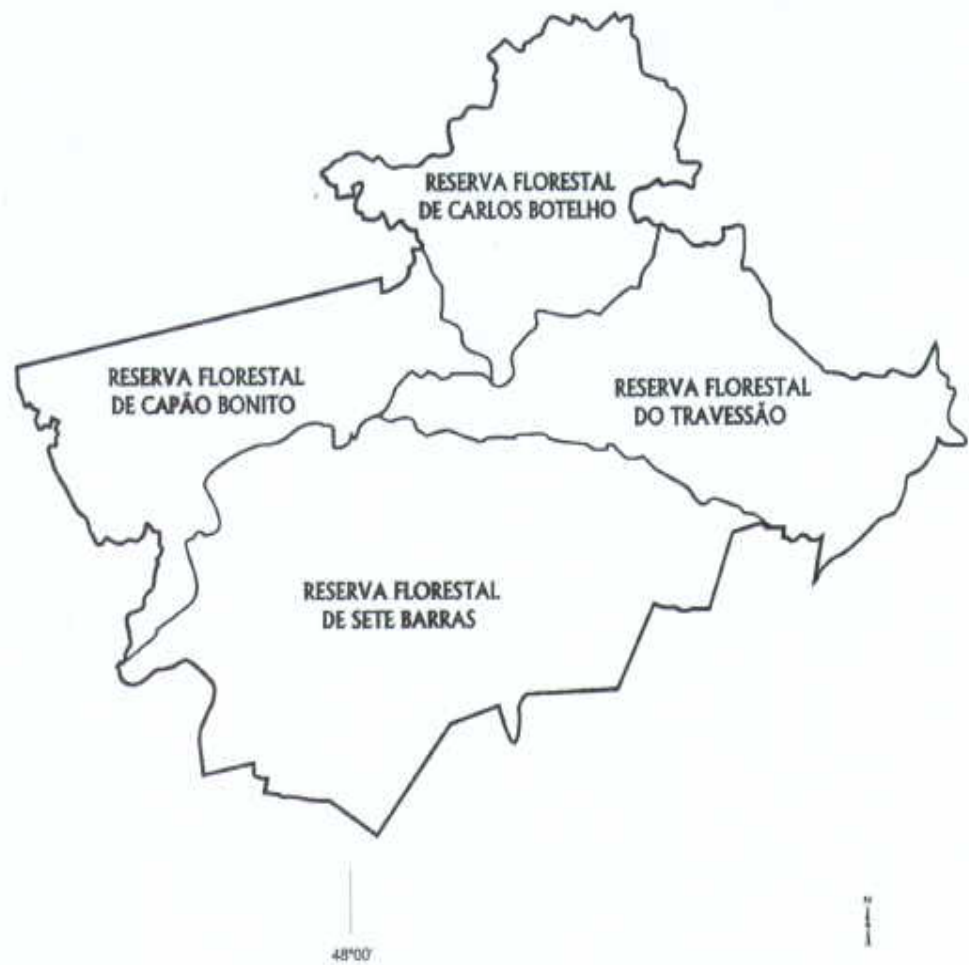

mon onting

Figura 2 - Conjunto de Reservas Florestais que foram unificadas em setembro de 1982, para criação do Parque Estadual Carlos Botelho 


\subsubsection{Geomorfologia}

Domingues \& Silva (1988) detectaram no Parque Estadual Carlos Botelho, um gradiente altitudinal que varia de 30 a $1003 \mathrm{~m}$. Definiram também nesta área duas unidades geomorfológicas: O Planalto de Guapiara, drenado pelos rios que formam a bacia hidrográfica do Rio Paranapanema, e a Serra de Paranapiacaba drenada pelos ribeirões: Travessão, Temível e da Serra e pelos Rios Preto e Quilombo que são formadores da bacia do Rio Ribeira de Iguape (Figura 3).

Para Domingues \& Silva (1988) o Parque Estadual Carlos Botelho constitui parte das vertentes da Serra de Paranapiacaba, onde ocorrem as escarpas litorâneas, com interflúvios em cristas, vales encaixados e entremeados por estreitas planícies alveolares intermontanas, e do Planalto Atlântico, com altitudes em torno de 800 metros, ocorrem metassedimentos do grupo Açungui.

A serra de Paranapiacaba é formada por montanhas com vales profundos, podendo atingir altitudes superiores a 1200 metros. Aí, as escarpas podem estar recuadas até centenas de quilômetros da orla litorânea, abrindo-se um amplo forte erosivo, de aspecto montanhoso, onde os cursos de água se expandem longitudinalmente, nos traçados paralelos à linha da costa (Almeida citado por Mantovani 1993). Este autor, chama ainda a atenção para o fato do Estado de São Paulo ser composto de cinco grandes feições geomorfológicas: Província Costeira, Planalto Atlântico, Depressão Periférica, Cuestas Basálticas e o Planalto Ocidental. A ocorrência da Mata Atlântica “stricto sensu” está restrita apenas ao Planalto Atlântico e à Província Costeira.

De acordo com Câmara citado por Ivanauska (1997) a enorme diversidade biológica da Mata Atlântica, está relacionada à variedade de solos e relevos, apresentando características geomorfológicas e geológicas muito diversificadas. 


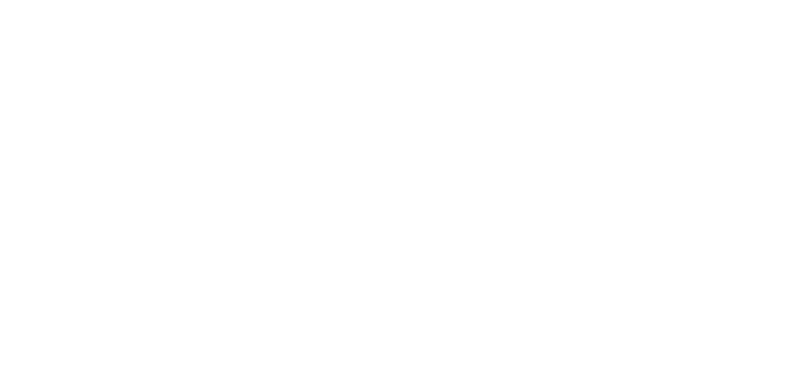

Figura 3 - Mapa do Parque Estadual Carlos Botelho, onde podem ser visualizados: (I) Planalto Guapiara, (II) Serra de Paranapiacaba e rede de drenagem (Elaborado pela seção de Manejo e Inventário Florestal - IF) 


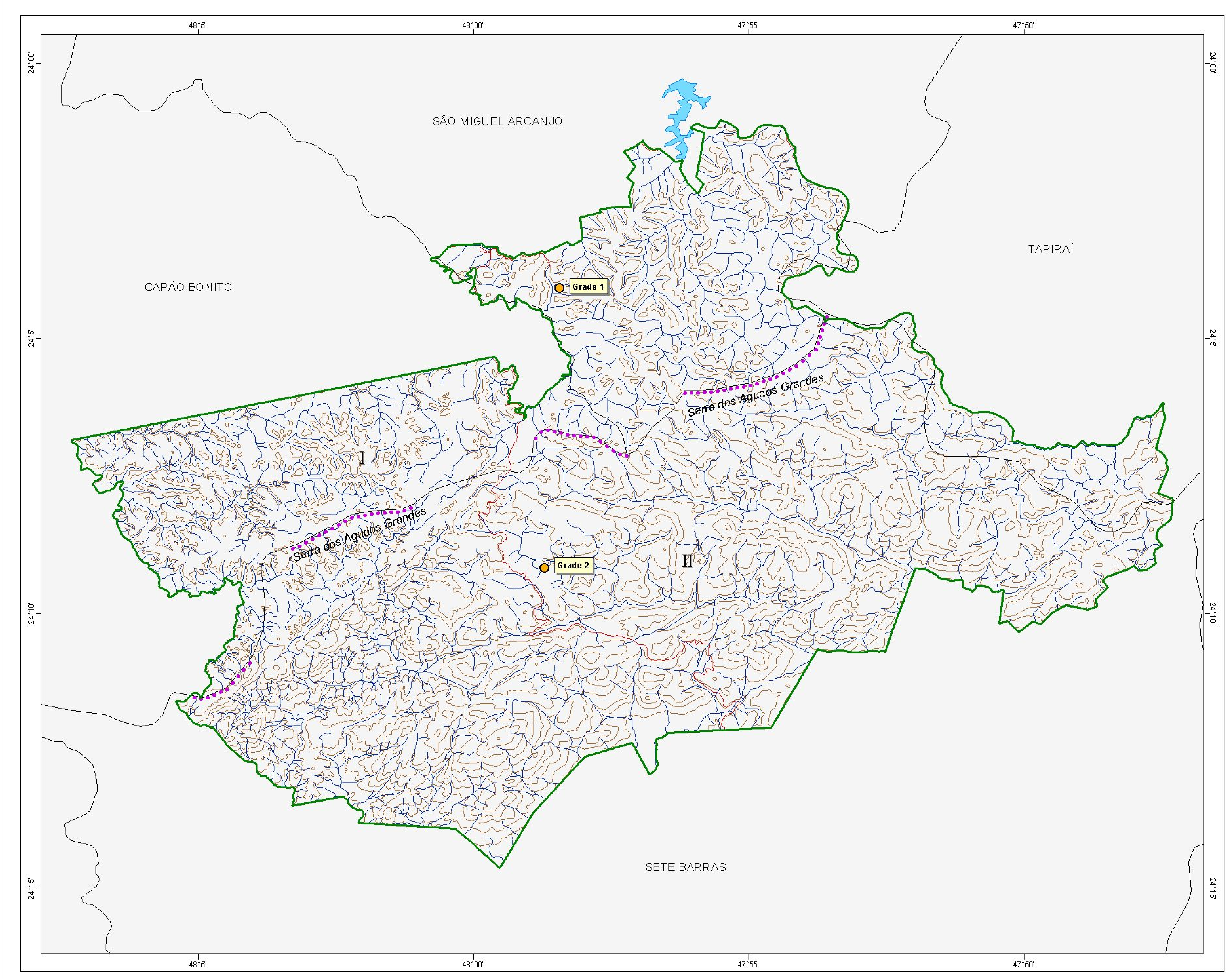

Grades de Amostragem 1 e 2

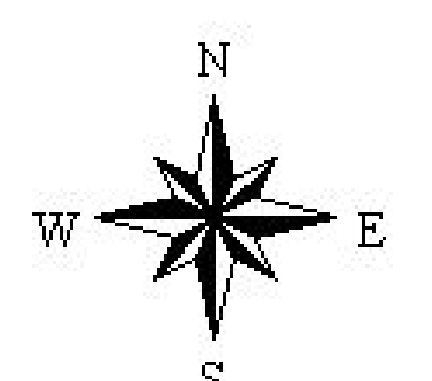

$1: 125000$

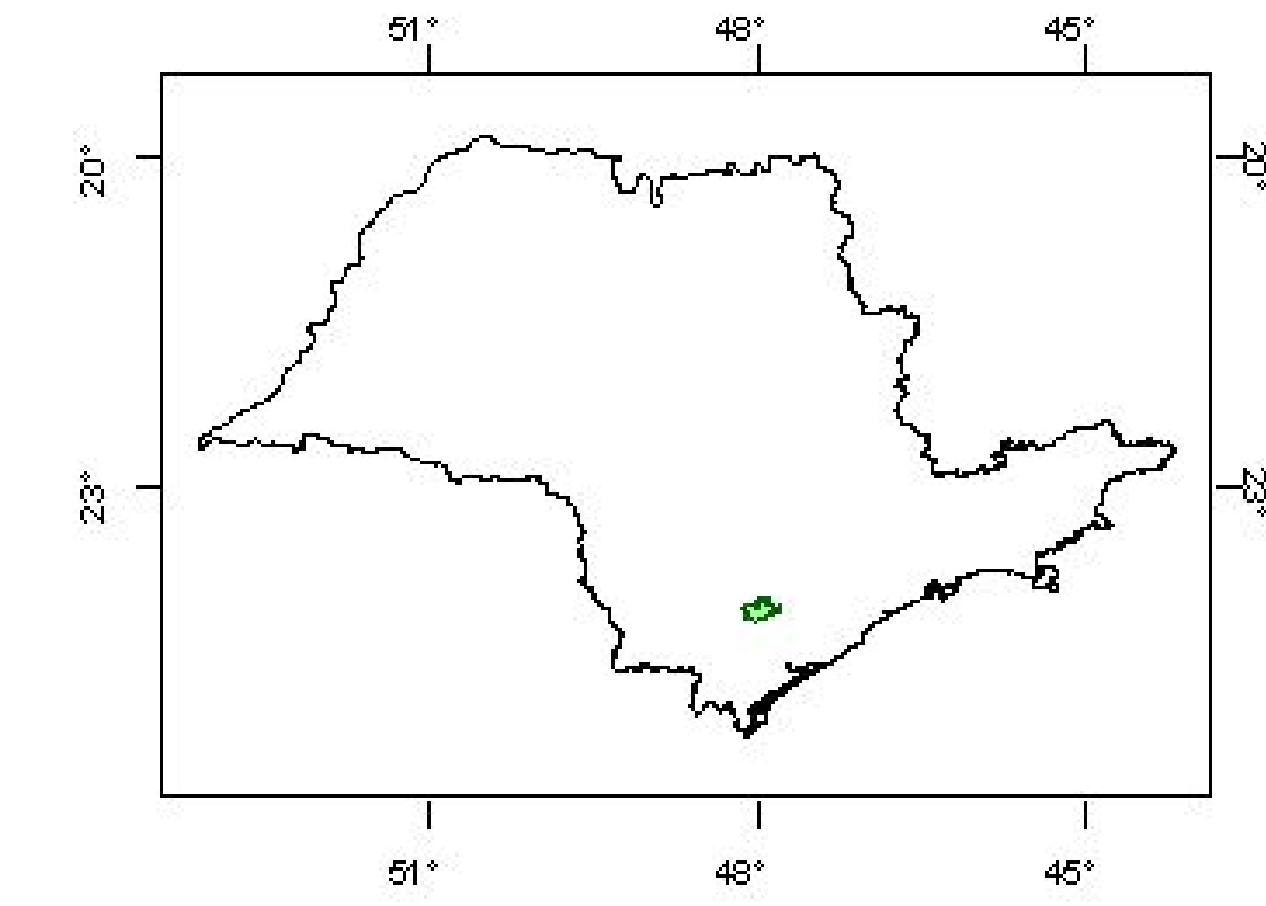




\subsubsection{Clima}

Dados meteorológicos apresentados por Dias et al. (1995), mostram que a temperatura média do mês mais quente é $22^{0} \mathrm{C}$, e a temperatura média do mês mais frio está em torno de $15^{\circ} \mathrm{C}$. De acordo com os dados apresentados por estes autores a precipitação média anual atinge $1.683 \mathrm{~mm}$, e o mês mais seco apresenta um índice pluviométrico médio de $73 \mathrm{~mm}$. (Figura 4).

De acordo com Mantovani (1993) o Litoral Sul do Estado de São Paulo é o local que recebe maior precipitação dos sistemas extra tropicais. Há uma nítida diminuição da chuva orográfica, pois a Serra de Paranapiacaba se afasta a quase $100 \mathrm{~km}$ da linha da costa.

$\mathrm{Na}$ Encosta Atlântica não é a pluviosidade, mas sim a variação na temperatura, principalmente a ocorrência de geada, o mais relevante condicionador climático das mudanças florísticas estruturais.

De acordo com Nimer (1979) a posição marítima da região sudeste, aliada a urbanização, determina uma forte concentração de núcleos de condensação nas camadas inferiores da atmosfera, o que contribui para o aumento de chuvas em seu território, sempre que esta região for atingida por frentes frias e outros fenômenos de ascendência climática. 


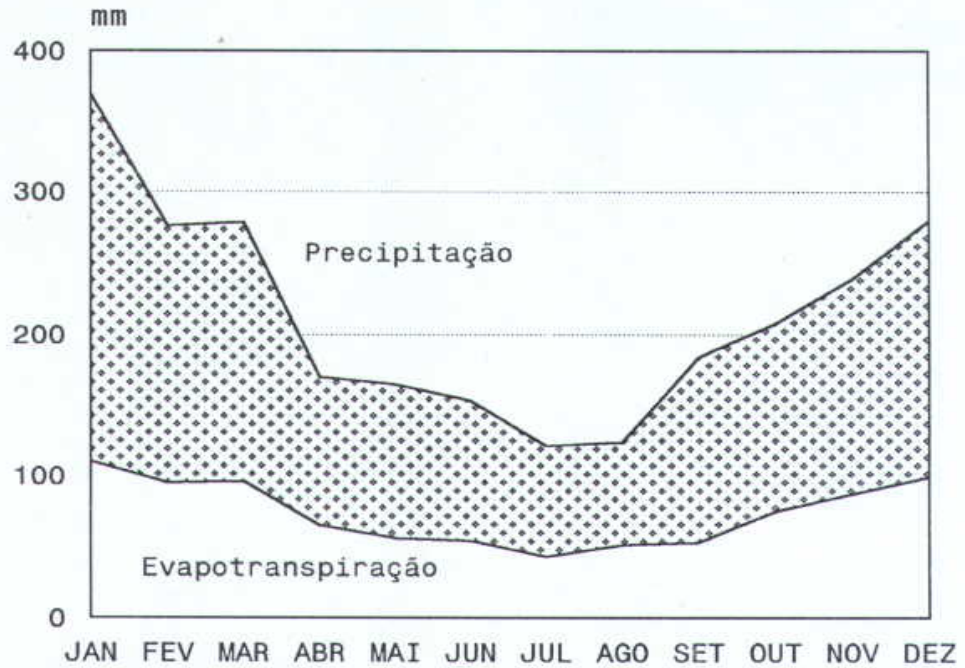

Figura 4 - Representação gráfica do balanço hídrico de Thornthwaite, obtido para o Parque Estadual de Carlos Botelho, Município de São Miguel Arcanjo-SP. (Dias et al., 1995) 


\subsubsection{Solos}

De acordo Pfeifer et al. (1986) os solos do Parque Estadual Carlos Botelho estão inseridos dentre as seguintes classificações: Latossolo Vermelho - Amarelo (LV), Latossolo Vermelho - Amarelo "intergrade" para Podzólico Vemelho - Amarelo (LVP). Podzólico Vermelho-Amarelo "intergrade" para Latossolo Vermelho-Amarelo (PVC), Litossolo fase substrato granito-gnaisse (li-gr) e os solos de Campos do Jordão (LJ).

Para Mantovani (1993) os solos sob as florestas na Encosta Atlântica, têm importância fundamental no armazenamento de água e no suporte das árvores de diferentes tamanhos. Em geral estes solos são pobres em bases trocáveis, lixiviados e ácidos, fazendo com que as raízes tenham um desenvolvimento superficial.

\subsubsection{Vegetação}

O Instituto Brasileiro de Geografia e Estatística - IBGE registra para a região onde se localiza o Parque Estadual Carlos Botelho a Floresta Ombrófila Densa, que é uma denominação da Floresta Pluvial Tropical, de acordo com o novo Sistema Fitofisionômico-ecológico das formações neotropicais adotado pelo Projeto RadanBrasil (Veloso \& Góes Filho, 1982).

A Floresta Ombrófila Densa é constituída de diferentes formas biológicas, com diversas formações e inúmeras associações, de acordo com as condições ambientais e as variações microclimáticas locais.

Na Floresta Ombrófila Densa da Costa Atlântica do Sul do Brasil, segundo o projeto Radan-Brasil, ocorrem cinco formações que obedecem a uma hierarquia fisionômica de acordo com as estruturas florestais e composição florística: 
Floresta Ombrófila Densa Aluvial - formação ombrófila ribeirinha que ocupa planícies recentes, com espécies de rápido crescimento e bem desenvolvidas;

Floresta Ombrófila Densa de Terras Baixas - trata-se de formações florestais com solos em geral mal drenados, que situam desde o nível do mar até aproximadamente 30 metros de altitude.

Floresta Ombrófila Densa Sub-montana - estende-se ao longo das encostas ou escarpas da Serra do Mar e da Serra Geral, em altitudes que variam de 30 a 500 metros. Em função da variabilidade das condições ambientais, sua composição florística apresenta-se bastante heterogênea.

Floresta Ombrófila Densa Montana - ocupa geralmente o alto das escarpas das Serra do Mar e Geral, bem como as diversas ramificações da mesma; abrangendo uma altitude de cerca de 500 a 1000 metros.

A Floresta Ombrófila Densa Montana se caracteriza principalmente, pela maior homogeneidade, menor ocorrência de Euterpe edulis, e uma considerável diminuição em epífitas e lianas.

Floresta Ombrófila Densa Alto-Montana - Ocupa as partes mais altas das escarpas da Serra do Mar e da Serra Geral, em terrenos geralmente muito íngremes. Caracteriza-se pela presença de espécies de altitude, situadas acima de 1000 metros. Normalmente são árvores baixas, as vezes um pouco retorcidas, com grande abundância de Myrtaceae.

Apesar de preservado como unidade de conservação desde 1941, só em 1967 foi realizado o primeiro trabalho sobre a vegetação do Parque. Este trabalho foi desenvolvido por Heinsdijk \& Campos (1967) e teve como objetivo principal o levantamento do potencial madeireiro. Decorridos mais de dez anos, surgiram os trabalhos desenvolvidos por Negreiros (1983); Dias et al. (1986, 1989, 1995, e 2000); Negreiros et al. (1990 e 1995); Custodio Filho et al. (1992); Dias (1993); Custodio Filho 
(2002) e Aguiar (2003), que estavam mais voltados ao conhecimento da composição florística e determinação de parâmetros fitossociológicos da vegetação.

\section{2 Área de Amostragem}

Foram consideradas neste estudo duas áreas de amostragens, ambas dentro dos limites definidos para a Floresta Ombrófila Densa Montana, no entanto, cada área está próxima dos limites desta formação vegetal. A primeira, denominada Grade 1, localizada na parte mais elevada do Parque, apresenta característica que em algum momento lembra a Floresta Ombrófila Densa Alto-Montana, a segunda área, denominada Grade 2, localizada na região de altitude intermediária do Parque, tem em algumas faixas características semelhantes às apresentadas pela Floresta Ombrófila Densa Sub - Montana (Figura 5).

A escolha do local de amostragem foi realizada com o emprego de imagens aéreas, que possibilitaram a caracterização de diferentes fitofisionomias.

Além das diferenças fitofisionômicas, foram consideradas também as diferenças altitudinais para a instalação dos sistemas de amostragem.

\subsection{Métodos de Amostragem Empregados}

Para amostragem foram utilizados três métodos de levantamentos: Parcelas Retangulares de Área Fixa, Parcelas Circulares de Raios Variáveis (Relascopia) e Pontos Quadrantes. Estes métodos de amostragem foram distribuídos ao longo de uma grade amostral composta por um retículo de $8 \times 8$ pontos, sendo a distância entre os pontos de 100 metros. 
Foram instaladas em cada grade amostral 64 parcelas de área fixa com 900m² (10x90m.), 64 parcelas circulares de raios variáveis (Relascopia) e 320 pontos quadrantes. A área total de amostragem em cada grade amostral foi 5,76ha. 


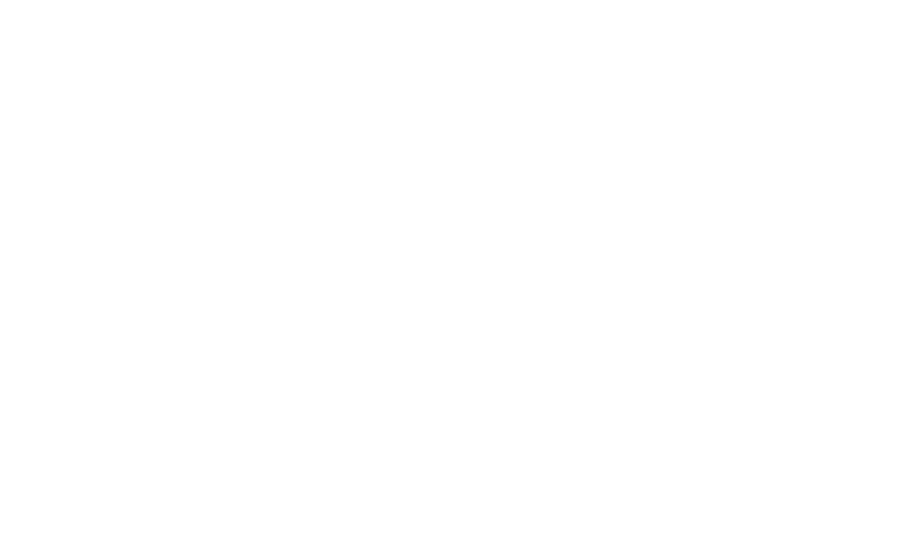

Figura 5 - Localização das duas áreas de amostragem, Grade 1 e Grade 2, no Parque Estadual Carlos Botelho. SP. Brasil (Elaborado pela Seção de Manejo e Inventário Florestal - IF) 


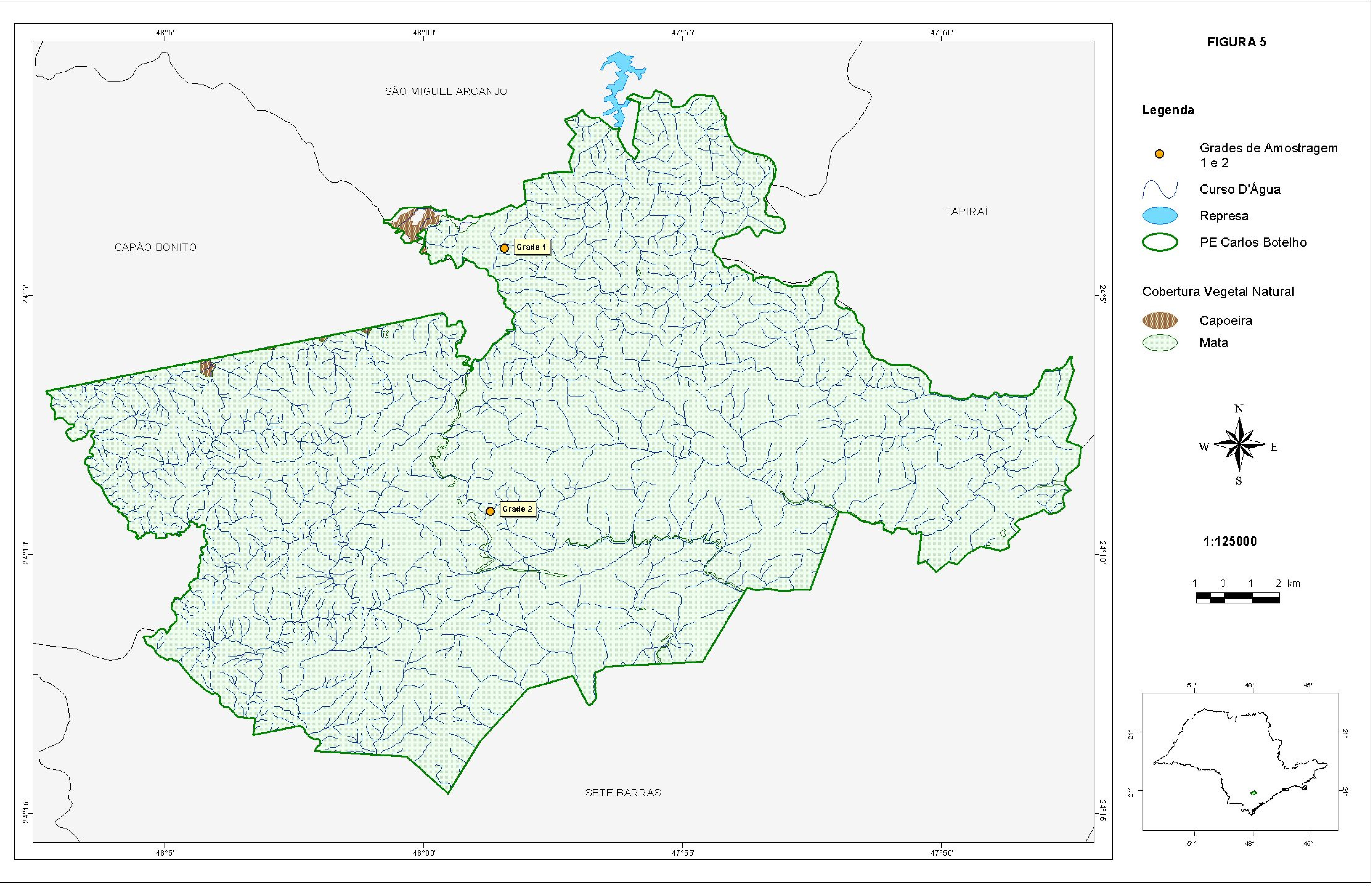




\subsection{Procedimento de Campo}

Após a definição de cada uma das áreas de estudo, os trabalhos de campo obedeceram as seguintes etapas:

\subsubsection{Instalação das Grades Amostrais:}

Para a instalação da grade amostral em cada uma das áreas, foram abertas 8 linhas de picadas paralelas entre si, com distância de 100 metros entre elas. Em cada linha de picada foram locados 8 pontos, com distância de 100 metros entre eles e demarcados com estaca de PVC branco com o objetivo de facilitar a sua visualização no interior da floresta (Figura 6).

\section{PONTO AMOSTRAL}

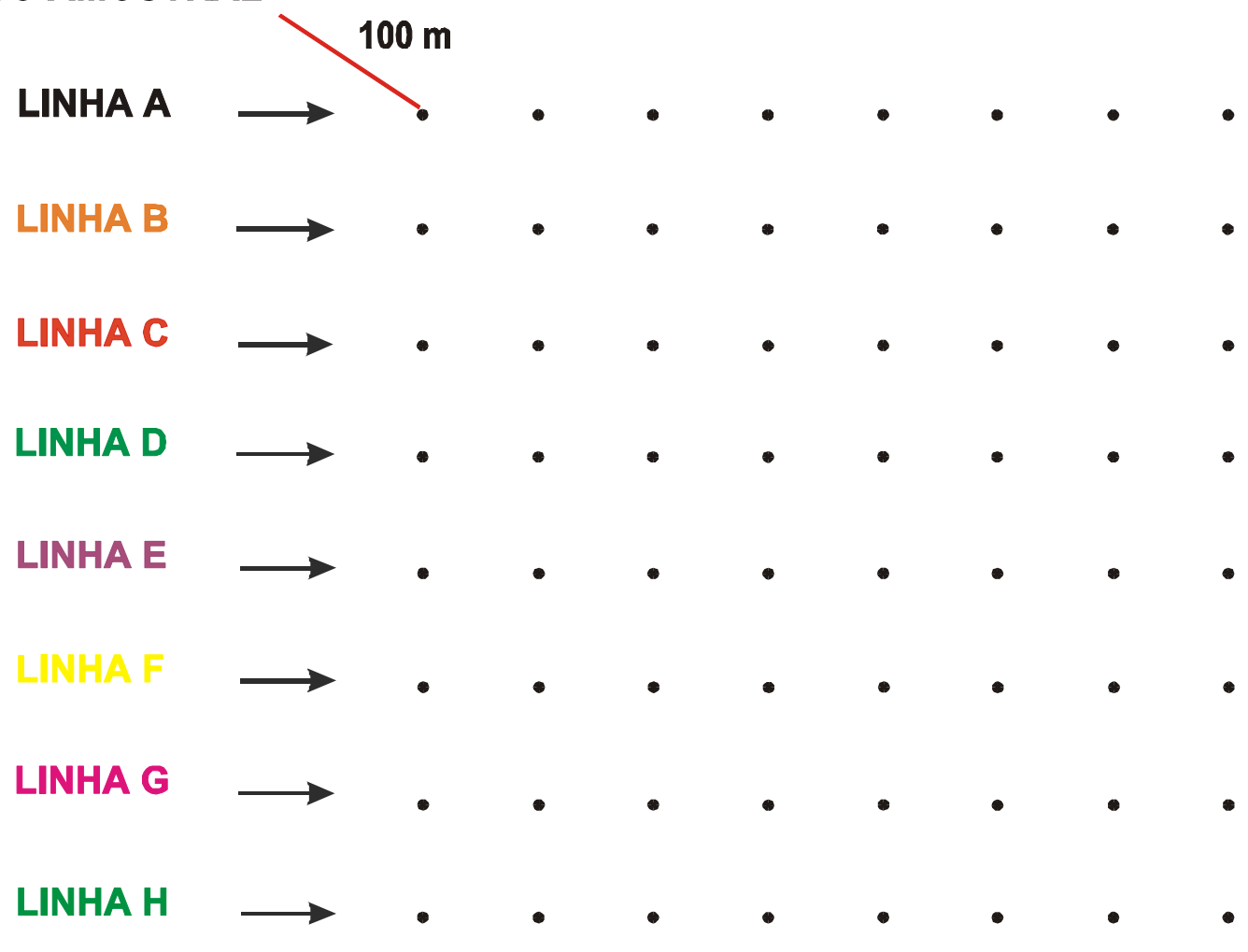

Figura 6 - Desenho Esquemático da Grade Amostral, com os pontos de amostragem (Aguiar, 2003) 


\subsubsection{Instalação das Parcelas Retangulares}

Em cada grade amostral foram instaladas 64 parcelas retangulares com $10 \mathrm{x}$ $90 \mathrm{~m}$, com área de $900 \mathrm{~m}^{2}$, perfazendo um total de 128 parcelas e uma área total de amostragem de 11,52ha (Figura 7).

Para instalação destas parcelas, foi considerada a linha da picada como eixo central da parcela passando pelo ponto de amostragem e cada ponto demarcado com estaca de PVC foi considerado o centro da parcela.

Tendo como centro o ponto demarcado com estaca de PVC, observou-se a distância de 10 metros entre as parcelas que foram instaladas ao longo das linhas de picadas. Nas linhas de picada em cada grade de amostragem os pontos foram definidos como: A1, A2,.....A8, B1, B2, ........B8, até H8. A mesma denominação foi adotada para as parcelas que tem como centro os pontos de amostragem. 


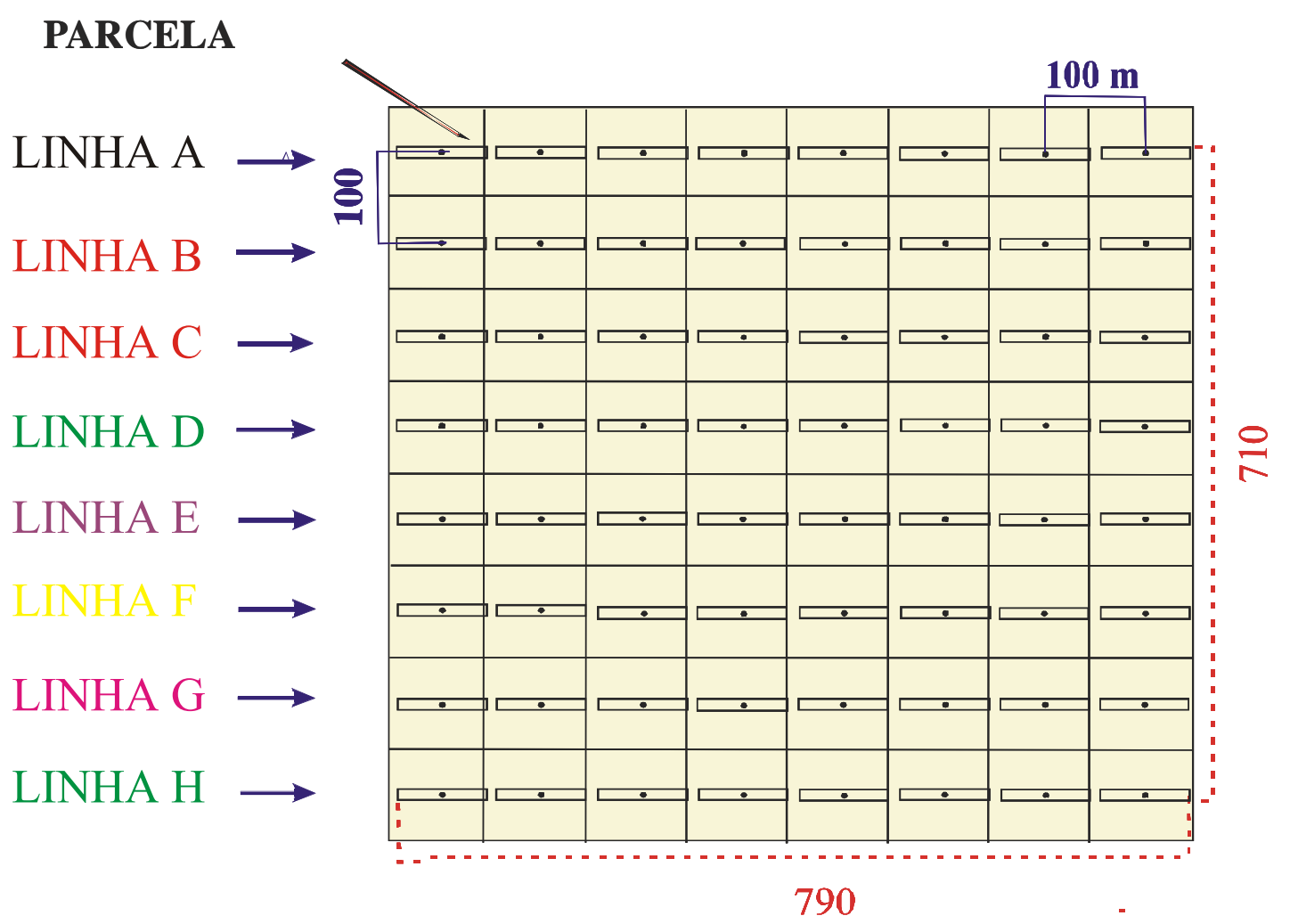

Figura 7 - Desenho Esquemático da Grade Amostral com as parcelas de área fixa. (Aguiar, 2003)

Cada parcela foi subdividida em 09 sub-parcelas de 10 x10 m. Em cada subparcela foram amostrados todos os indivíduos arbóreos com DAP $\geq 5 \mathrm{~cm}$ (Figura 8).

Cada indivíduo foi demarcado com placa de alumínio previamente numerada, medido seu DAP, coletado material para identificação botânica e anotado o estrato vertical (inferior, médio, dossel ou emergente).

Foi registrada ainda a localização de cada indivíduo em relação à linha central da sub-parcela, lado esquerdo e lado direito (E e D). 


\subsubsection{Instalação dos Pontos Quadrantes}

Considerando as linhas de amostragem (picadas) que compõe a grade amostral, já instaladas, os pontos de quadrantes foram locados a cada 20 metros. Em cada linha o primeiro ponto de quadrante foi locado no início da primeira parcela (Figura 8).

Para definição dos quadrantes em cada ponto, foi considerada a linha de amostragem como eixo principal, cortada por uma linha perpendicular passando pelo ponto. Os quadrantes foram numerados no sentido horário, sendo o primeiro quadrante o imediatamente à direita da linha.

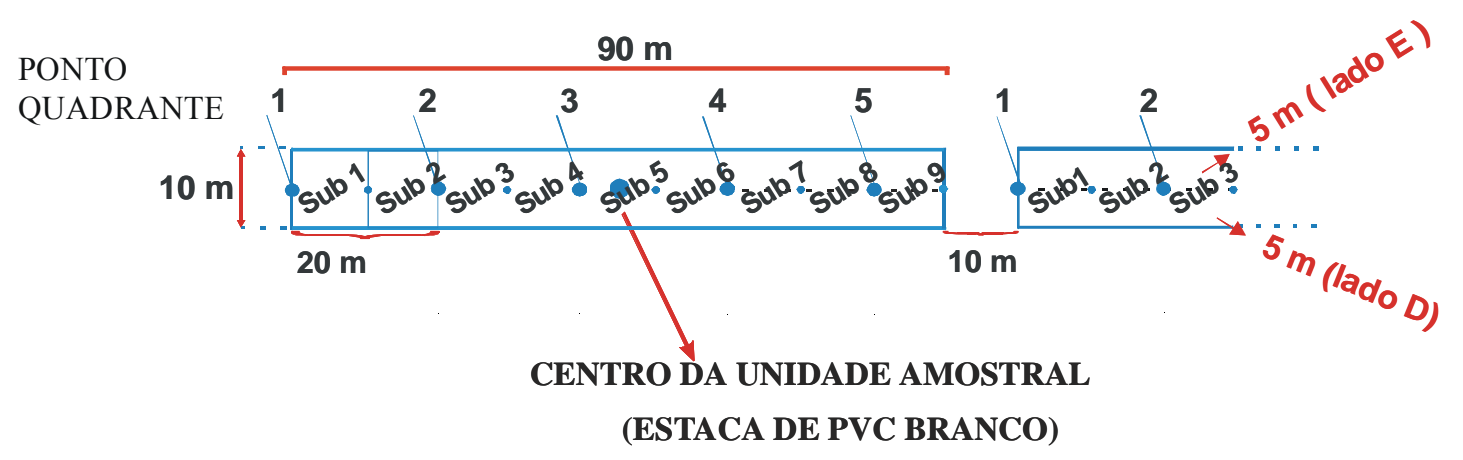

Figura 8 - Desenho esquemático da parcela, mostrando a localização dos pontos quadrantes (1,2,3,4 e 5) a cada 20m (Aguiar, 2003)

Em cada quadrante foi amostrada a árvore mais próxima do ponto.

De cada árvore amostrada foram anotadas as seguintes informações: Distância da árvore ao ponto, DAP, estrato vertical e coleta de material para identificação botânica. Foi anotada ainda a localização da árvore em relação à linha de amostragem, lado direito e lado esquerdo (D e E). 


\subsubsection{Parcelas de Raios Variáveis (Relascopia)}

Foi empregado o fator de área basal $\mathrm{F}=4$, sendo instalado 64 centros de amostragem em cada grade amostral. No campo os centros de amostragem foram demarcados com cano de PVC, ao longo de linhas de picada à distância de 100 metros um do outro (Figura 9).

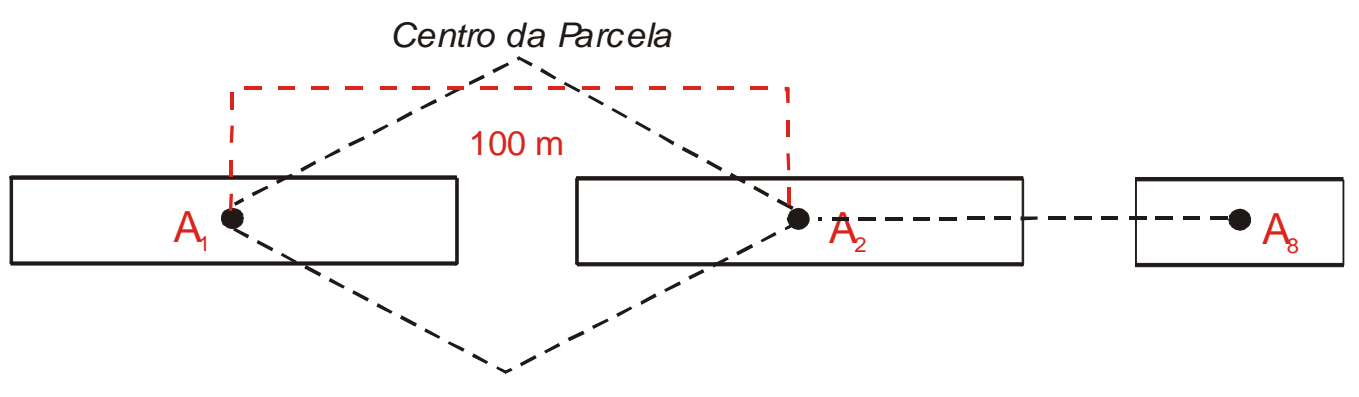

Pontos de relascopia

Figura 9 - Desenho esquemático da parcela, mostrando a localização dos centros das parcelas e Pontos de Relascopia

Utilizando o Relascópio de Bitterlich, e empregando o fator de área basal mencionado anteriormente, em cada centro de amostragem procedeu-se da forma seguinte:

a) Amostrou-se todos os indivíduos arbóreos cujo DAP fosse maior que ângulo de visada;

b) Efetuou-se a mensuração do DAP e a marcação de cada indivíduo com placas de alumínio previamente numeradas; 
c) Anotou-se o estrato vertical a que pertencia cada indivíduo, e efetuou a coleta de material botânico para identificação.

d) Para facilitar localizações futuras, registrou a posição de cada indivíduo em relação à linha de amostragem, lado direito e lado esquerdo (D e E).

\subsection{Tratamento dos Dados}

\subsubsection{Identificação de Material Botânico}

O material botânico coletado permitiu a identificação de quase todos os indivíduos amostrados, possibilitando a definição da composição florística da área de estudo. Este trabalho foi desenvolvido por pesquisadores do Instituto Florestal. Alguns materiais foram enviados à especialistas, como os pertencentes às famílias Rubiaceae, Melastomataceae e alguns exemplares a família Myrtaceae.

\subsubsection{Parâmetros Fitossociológicos}

\subsubsection{Métodos de Parcelas e Quadrantes}

Os dados dendrométricos coletados permitiram a determinação da densidade, dominância, freqüência e índice de valor de importância de cada espécie, em função de cada método de amostragem empregado. Os cálculos destes parâmetros considerados como os mais usuais em levantamentos fitossociológicos foram efetuados através do Programa SAS, tendo como base as equações (5 a 21) constantes no Anexo A, propostas por Mueller-Dombois \& Ellemberg (1974) e Martins (1979). 


\subsubsection{Relascopia}

Para a obtenção dos parâmetros fitossociológicos empregando-se o método de Relascopia, foram utilizadas as equações (22 a 29) constantes no Anexo A, empregadas por Gorenstein (2002). Segundo este autor a definição desses parâmetros ocorre de forma distinta do usualmente empregado por parcelas de área fixa.

\subsubsection{Diversidade de Espécies}

De acordo com Magurran (1988), existe pouco consenso a respeito da melhor medida de diversidade a ser usada, o que dificulta sobremaneira a definição de qual índice deva ser empregado.

No presente trabalho foi utilizado o índice de Shannon $\left(\mathrm{H}^{\prime}\right)$, que faz parte do grupo de medidas baseadas na abundância proporcional de espécies. Este índice, bem como a equabilidade $(\mathrm{J})$ de Pielou, foram definidos através das equações 1 e 3, constantes em Magurran (1988) e Martins (1991).

$$
\begin{aligned}
& H^{\prime}=-\sum \text { piLnpi } \\
& p i=\frac{n i}{N} \\
& J=\frac{H^{\prime}}{L n S}
\end{aligned}
$$

Onde $H^{\prime}$ é o Índice de Diversidade de Shannon, $J$ o Índice de Equabilidade de Pielou, $S$ o número total de espécies, $N$ número total de indivíduos e ni número de indivíduos da espécie $i$. 
Com a aplicação dessas medidas obteve-se informações sobre a diversidade de espécies arbóreas da área de estudo.

\subsubsection{Comparação dos Métodos de Amostragem}

Os três métodos de amostragem empregados no presente estudo (parcelas, quadrantes e relascopia) foram comparados entre si, considerando:

- A composição florística amostrada por cada método;

- Os valores de diversidade e riqueza de espécies;

- Parâmetros fitossociológicos:

Freqüência Relativa

Dominância Relativa

Densidade Relativa

Índice de Valor de Importância

Para comparação empregando os parâmetros fitossociológicos, foi utilizada a Equação (4), proposta por Brower e Zar citado por Mello (1996)

$\mathbf{D E}=\sqrt{\sum_{i=1}^{n}(x i-y i)^{2}}$

Onde:

$\mathrm{DE}=$ Distância Euclidiana

$\mathrm{x}_{\mathrm{i}}=$ Valor do parâmetro para a espécie $i$, amostrada pelo método $x$.

$\mathrm{y}_{\mathrm{i}}=$ Valor do parâmetro para a espécie $i$, amostrada no método $y$.

$\mathrm{n}=$ número de espécies. 


\section{RESULTADO E DISCUSSÃO}

A análise das duas áreas de estudo, amostrada com o emprego dos métodos de parcelas, quadrantes e relascopia, resultou no registro de 65 famílias botânicas e 427 espécies, das quais 7 foram identificadas como morfoespécies, 92 em nível de gênero e 14 em nível de família.(Anexo B).

Mesmo considerando elevado o número de espécies arbóreas, acreditamos ainda estarmos muito aquém do número real de espécies existentes. Cabe ressaltar que um grande número de indivíduos amostrados, foi identificado apenas em nível de gênero, de família, ou considerados como “morfoespécie”. Isto ocorreu principalmente pela dificuldade de identificação encontrada com a utilização de material botânico estéril.

\section{4 .1 Parcelas}

\subsubsection{Grade 1}

Na Grade 1, as 64 parcelas amostraram 9.543 indivíduos dos quais 107 eram árvores mortas em pé. Os demais permitiram o registro de 59 famílias botânicas e 250 espécies arbóreas. Destas, 26 foram identificadas em nível de gênero e 9 em nível de família (Tabela 1).

Dez famílias foram responsáveis pela amostragem de 65\% do total das espécies: Myrtaceae (25\%) com 62 espécies, Lauraceae (16\%) com 39 espécies, 
Rubiaceae (5\%) com 13 espécies, Melastomataceae (5\%) com 12 espécies, Fabaceae (4\%) com 10 espécies, Sapindaceae e Sapotaceae (2\%) com 6 espécies cada, Mimosaceae, Monimiaceae e Myrsinaceae (2\%) com 5 espécies cada. As 49 famílias restantes amostraram 87 espécies, ou seja, 35\% do total de espécies (Figura 15). Observa-se ainda que 27 famílias foram representadas por apenas um indivíduo cada.

\subsubsection{Grade 2}

Na Grade 2, o método de parcelas amostrou 10.124 indivíduos, sendo 109 árvores mortas em pé. Foram registradas 61 famílias botânicas e 348 espécies arbóreas. Destas 62 foram identificadas em nível de gênero, 12 em nível de famílias e 7 definidas como morfoespécies (Tabela 1).

Onze famílias foram responsáveis pela amostragem de $66 \%$ do total de espécies: Myrtaceae (26\%) com 91 espécies, Lauraceae (12\%) 43 espécies, Rubiaceae (7\%) 25 espécies, Fabaceae (4\%) 13 espécies, Sapotaceae (3\%) com 11 espécies, Sapindaceae (3\%) com 10 espécies, Melastomataceae (3\%) com 9 espécies, Myrsinaceae (2\%) com 8 espécies, Annonaceae, Mimosaceae e Monimiaceae (2\%) com 7 espécies cada. As 50 famílias restantes amostraram 117 espécies, 34\% do total (Figura 15). Observa-se também que 23 famílias foram representadas por apenas um indivíduo cada. 
Tabela 1. Relação das famílias e espécies amostradas no componente arbóreo da Floresta Ombrófila Densa, no Parque Estadual Carlos Botelho. SP. Brasil, com o emprego do método de parcelas Gr1 - Grade 1, Gr2 - Grade 2

\begin{tabular}{|c|c|c|c|c|c|}
\hline & Famílias & & Espécies & Gr 1 & Gr 2 \\
\hline 1 & Anacardiaceae & 1 & Tapirira guianensis Aubl. & $\mathrm{X}$ & $\mathrm{X}$ \\
\hline 2 & Annonaceae & 2 & Duguetia lanceolata A.St. Hil. & - & $\mathrm{X}$ \\
\hline & & 3 & Guatteria australis A. St. Hil. & $\mathrm{X}$ & $\mathrm{X}$ \\
\hline & & 4 & Guatteria nigrescens Mart. & - & $\mathrm{X}$ \\
\hline & & 5 & Rollinia parviflora A. St. Hil. & $\mathrm{X}$ & - \\
\hline & & 6 & Rollinia sericea (R. E. Fries) R. E. Fries & $\mathrm{X}$ & $\mathrm{X}$ \\
\hline & & 7 & Rollinia sp. & - & $\mathrm{X}$ \\
\hline & & 8 & Rollinia sylvatica (A. St. Hil.) Mart. & - & $\mathrm{X}$ \\
\hline & & 9 & Xylopia langsdorfiana St. Hil. \& Tul. & $\mathrm{X}$ & $\mathrm{X}$ \\
\hline \multirow[t]{2}{*}{3} & Apocynaceae & 10 & Aspidosperma olivaceum Müll. Arg. & $\mathrm{X}$ & - \\
\hline & & 11 & Malouetia arborea (Vell.) Miers & - & $\mathrm{X}$ \\
\hline 4 & Aquifoliaceae & 12 & IIex taubertiana Loes. & $\mathrm{X}$ & $\mathrm{X}$ \\
\hline & & 13 & Ilex amara (Vell.) Loes. & $\mathrm{X}$ & $\mathrm{X}$ \\
\hline & & 14 & Ilex paraguariensis A. St. Hil. & $\mathrm{X}$ & $\mathrm{X}$ \\
\hline & & 15 & Ilex theazans Mart. & $\mathrm{X}$ & $\mathrm{X}$ \\
\hline \multirow[t]{4}{*}{5} & Araliaceae & 16 & Didymopamax calvus (Cham.) Decne. \& Planch. & - & $\mathrm{X}$ \\
\hline & & 17 & Didymopanax angustissimus March. & $\mathrm{X}$ & $\mathrm{X}$ \\
\hline & & 18 & Didymopanax navarroi A Samp. & $\mathrm{X}$ & $\mathrm{X}$ \\
\hline & & 19 & Didymopanax sp. & - & $\mathrm{X}$ \\
\hline \multirow[t]{3}{*}{6} & Arecaceae & 20 & Attalea dubia (Mart.) Burret & $\mathrm{X}$ & - \\
\hline & & & Euterpe edulis Mart. & $\mathrm{X}$ & $\mathrm{X}$ \\
\hline & & 22 & Geonoma schottiana Mart. & - & $\mathrm{X}$ \\
\hline
\end{tabular}


Tabela 1. Relação das famílias e espécies amostradas no componente arbóreo da Floresta Ombrófila Densa, no Parque Estadual Carlos Botelho. SP. Brasil, com o emprego do método de parcelas Gr1 - Grade 1, Gr2 - Grade 2

\begin{tabular}{|c|c|c|c|c|c|}
\hline & Famílias & & Espécies & Gr 1 & Gr 2 \\
\hline & & 23 & Geonoma sp. & - & $\mathrm{X}$ \\
\hline \multirow[t]{9}{*}{7} & Asteraceae & 24 & Piptocarpha axillaris (Less.) Baker & - & $\mathrm{X}$ \\
\hline & & 25 & Piptocarpha macropoda (DC.) Baker & $\mathrm{X}$ & - \\
\hline & & 26 & Piptocarpha organensis Cabrera & - & $\mathrm{X}$ \\
\hline & & 27 & Piptocarpha sp.1 & $\mathrm{X}$ & - \\
\hline & & 28 & Vanillosmopsis erythropappa (DC.) Sch. Bip. & - & $\mathrm{X}$ \\
\hline & & 29 & Vernonia cf. grandifolia DC. & - & $\mathrm{X}$ \\
\hline & & 30 & Vernonia diffusa Less. & $\mathrm{X}$ & - \\
\hline & & 31 & Vernonia puberula Less. & - & $\mathrm{X}$ \\
\hline & & 32 & Vernonia quinqueflora Less. & - & $\mathrm{X}$ \\
\hline \multirow[t]{4}{*}{8} & Bignoniaceae & 33 & Jacaranda micrantha Cham. & - & $\mathrm{X}$ \\
\hline & & 34 & Jacaranda puberula Cham. & $\mathrm{X}$ & $\mathrm{X}$ \\
\hline & & 35 & Tabebuia heptaphylla (Vell.) Toledo & $\mathrm{X}$ & $\mathrm{X}$ \\
\hline & & 36 & Tabebuia sp. & - & $\mathrm{X}$ \\
\hline 9 & Bombacaceae & 37 & Quararibea turbinata (Sw.) Poir. & - & $\mathrm{X}$ \\
\hline \multirow[t]{4}{*}{10} & Boraginaceae & 38 & Cordia ecalyculata Vell. & - & $\mathrm{X}$ \\
\hline & & 39 & Cordia sellowiana Cham. & $\mathrm{X}$ & $\mathrm{X}$ \\
\hline & & 40 & Cordia sp. 1 & $\mathrm{X}$ & $\mathrm{X}$ \\
\hline & & 41 & Cordia trichotoma (Vell.) Arrab. ex Steud. & - & $\mathrm{X}$ \\
\hline 11 & Burseraceae & 42 & Protium hepatphyllum (Aubl.) March. & $\mathrm{X}$ & $\mathrm{X}$ \\
\hline 12 & Caesalpiniaceae & 43 & Copaifera langsdorffii Desf. & $\mathrm{X}$ & $\mathrm{X}$ \\
\hline
\end{tabular}


Tabela 1. Relação das famílias e espécies amostradas no componente arbóreo da Floresta Ombrófila Densa, no Parque Estadual Carlos Botelho. SP. Brasil, com o emprego do método de parcelas Gr1 - Grade 1, Gr2 - Grade 2

\begin{tabular}{|c|c|c|c|c|c|}
\hline & Famílias & & Espécies & Gr 1 & Gr 2 \\
\hline & & 44 & Copaifera trapezifolia Hayne & $\mathrm{X}$ & - \\
\hline & & 45 & Sclerolobium denudatum Vog. & $\mathrm{X}$ & $\mathrm{X}$ \\
\hline & & 46 & Senna macranthera (DC. ex Coll.) Irwin \& Barneby & - & $\mathrm{X}$ \\
\hline & & 47 & Senna multijuja (Rich.) Irwin \& Barneby & - & $\mathrm{X}$ \\
\hline & & 48 & Swartzia acutifolia Vog. & - & $\mathrm{X}$ \\
\hline 13 & Canellaceae & 49 & Capsicodendron dinisii (Schw.) Occh. & $\mathrm{X}$ & $\mathrm{X}$ \\
\hline \multirow[t]{3}{*}{14} & Cecropiaceae & 50 & Cecropia glaziovi Sneth. & $\mathrm{X}$ & - \\
\hline & & 51 & Cecropia sp. & - & $\mathrm{X}$ \\
\hline & & 52 & Coussapoa microcarpa (Schott) Rizzini & $\mathrm{X}$ & $\mathrm{X}$ \\
\hline \multirow[t]{3}{*}{15} & Celastraceae & 53 & Maytenus alaternoides Reiss. & - & $\mathrm{X}$ \\
\hline & & 54 & Maytenus ilicifolia Mart. ex Reiss. & - & $\mathrm{X}$ \\
\hline & & 55 & Maytenus robusta Reiss. & $\mathrm{X}$ & $\mathrm{X}$ \\
\hline \multirow[t]{2}{*}{16} & Chrysobalanaceae & 56 & Hirtella hebeclada Moric. ex DC. & $\mathrm{X}$ & $\mathrm{X}$ \\
\hline & & 57 & Parinari excelsa Sabine & - & $\mathrm{X}$ \\
\hline 17 & Clethraceae & 58 & Clethra scabra Pers. & $X$ & $\mathrm{X}$ \\
\hline \multirow[t]{2}{*}{18} & Clusiaceae & 59 & Clusia criuva Cambess. & $\mathrm{X}$ & $\mathrm{X}$ \\
\hline & & 60 & Garcinia gadneriana (Planch. \& Triana) Zappi & $\mathrm{X}$ & $\mathrm{X}$ \\
\hline 19 & Combretaceae & 61 & Buchenavia kleinii Excell & $\mathrm{X}$ & $\mathrm{X}$ \\
\hline 20 & Cunoniaceae & 62 & Lamanonia ternata Vell. & $\mathrm{X}$ & $\mathrm{X}$ \\
\hline
\end{tabular}


Tabela 1. Relação das famílias e espécies amostradas no componente arbóreo da Floresta Ombrófila Densa, no Parque Estadual Carlos Botelho. SP. Brasil, com o emprego do método de parcelas Gr1 - Grade 1, Gr2 - Grade 2

\begin{tabular}{|c|c|c|c|}
\hline Famílias & Espécies & Gr 1 & Gr 2 \\
\hline & 63 Weinmannia discolor Gardner & $\mathrm{X}$ & $\mathrm{X}$ \\
\hline & 64 Weinmannia paulliniifolia Pohl & $\mathrm{X}$ & $\mathrm{X}$ \\
\hline 21 Elaeocarpaceae & 65 Sloanea monosperma Vell. & $\mathrm{X}$ & $\mathrm{X}$ \\
\hline 22 Erythroxylaceae & 66 Erythroxylum cf. argentinum Schulz. & - & $\mathrm{X}$ \\
\hline & 67 Erythroxylum sp. & $\mathrm{X}$ & - \\
\hline \multirow[t]{5}{*}{23 Euphorbiaceae } & 68 Alchornea triplinervia (Spreng.) Müll. Arg. & $\mathrm{X}$ & $\mathrm{X}$ \\
\hline & 69 Hyeronima alchorneoides Allem. & $\mathrm{X}$ & $\mathrm{X}$ \\
\hline & 70 Pera glabrata (Scott) Poep. Ex Baill. & $\mathrm{X}$ & - \\
\hline & 71 Pera obovata (Klotzsch) Baill. & - & $\mathrm{X}$ \\
\hline & 72 Sapium glandulatum (Vell.) Pax & $\mathrm{X}$ & $\mathrm{X}$ \\
\hline \multirow[t]{13}{*}{24 Fabaceae } & 73 Andira anthelmia (Vell.) Macbr. & $\mathrm{X}$ & $\mathrm{X}$ \\
\hline & 74 Andira sp. & - & $\mathrm{X}$ \\
\hline & 75 Dahlstedtia pentaphylla (Taub.) Burkart & - & $\mathrm{X}$ \\
\hline & 76 Dahlstedtia pinnata (Benth.) Malme & - & $\mathrm{X}$ \\
\hline & 77 Dalbergia brasiliensis Vog. & $\mathrm{X}$ & $\mathrm{X}$ \\
\hline & 78 Dalbergia frutescens (Vell.) Britton & $\mathrm{X}$ & $\mathrm{X}$ \\
\hline & 79 Fabaceae 1 & $\mathrm{X}$ & - \\
\hline & 80 Machaerium nictitans (Vell.) Benth. & $\mathrm{X}$ & $\mathrm{X}$ \\
\hline & 81 Machaerium sp. & $\mathrm{X}$ & - \\
\hline & 82 Myrocarpus frondosus Allem. & $\mathrm{X}$ & $\mathrm{X}$ \\
\hline & 83 Ormosia arborea (Vell.) Harms & - & $\mathrm{X}$ \\
\hline & 84 Ormosia dasycarpa Jacks. & $\mathrm{X}$ & $\mathrm{X}$ \\
\hline & 85 Platymiscium floribundum Vog. & - & $\mathrm{X}$ \\
\hline
\end{tabular}


Tabela 1. Relação das famílias e espécies amostradas no componente arbóreo da Floresta Ombrófila Densa, no Parque Estadual Carlos Botelho. SP. Brasil, com o emprego do método de parcelas Gr1 - Grade 1, Gr2 - Grade 2

\begin{tabular}{|c|c|c|c|c|}
\hline & Famílias & Espécies & Gr 1 & Gr 2 \\
\hline & & 86 Pterocarpus rohrii Vahl. & $\mathrm{X}$ & $\mathrm{X}$ \\
\hline & & 87 Zollernia illicifolia (Bron.) Vog. & $\mathrm{X}$ & $\mathrm{X}$ \\
\hline \multirow[t]{5}{*}{25} & Flacourteaceae & 88 Xylosma glaberrima Sleumer & $\mathrm{X}$ & - \\
\hline & & 89 Casearia decandra Jacq. & $\mathrm{X}$ & $\mathrm{X}$ \\
\hline & & 90 Casearia obliqua Spreng. & $\mathrm{X}$ & $\mathrm{X}$ \\
\hline & & 91 Casearia sp. & - & $\mathrm{X}$ \\
\hline & & 92 Casearia sylvestris Sw. & $\mathrm{X}$ & $\mathrm{X}$ \\
\hline \multirow[t]{2}{*}{26} & Hippocrateaceae & 93 Cheiloclinium cognatum (Miers) A.C. Sm. & $\mathrm{X}$ & - \\
\hline & & 94 Salacia elliptica (Mart. Ex Schult.) G. Don. & $\mathrm{X}$ & $\mathrm{X}$ \\
\hline \multirow[t]{2}{*}{27} & Humiriaceae & 95 Humiriastrum dentatum (Casar.) Cuatrec. & - & $\mathrm{X}$ \\
\hline & & 96 Vantanea compacta (Schnzl.) Cuatr. & $\mathrm{X}$ & $\mathrm{X}$ \\
\hline & Icacinaceae & 97 Citronella paniculata (Mart.) Howard & $\mathrm{X}$ & $X$ \\
\hline \multirow[t]{7}{*}{29} & Morfoespécie & 98 Morfoespécie 1 & - & $\mathrm{X}$ \\
\hline & & 99 Morfoespécie 2 & - & $\mathrm{X}$ \\
\hline & & 100 Morfoespécie 3 & - & $\mathrm{X}$ \\
\hline & & 101 Morfoespécie 4 & - & $\mathrm{X}$ \\
\hline & & 102 Morfoespécie 5 & - & $\mathrm{X}$ \\
\hline & & 103 Morfoespécie 6 & - & $\mathrm{X}$ \\
\hline & & 104 Morfoespécie 7 & - & $\mathrm{X}$ \\
\hline 30 & Lacistemataceae & 105 Lacistema hasslerianum Chodat. & - & $\mathrm{X}$ \\
\hline
\end{tabular}


Tabela 1. Relação das famílias e espécies amostradas no componente arbóreo da Floresta Ombrófila Densa, no Parque Estadual Carlos Botelho. SP. Brasil, com o emprego do método de parcelas Gr1 - Grade 1, Gr2 - Grade 2

\begin{tabular}{|c|c|c|c|}
\hline Famílias & Espécies & Gr 1 & Gr 2 \\
\hline \multirow[t]{27}{*}{31 Lauraceae } & 106 Aiouea acaradomatifera Koest. & $\mathrm{X}$ & $\mathrm{X}$ \\
\hline & 107 Aiouea saligna Meisn. & $\mathrm{X}$ & - \\
\hline & 108 Aiоuеa sp. & - & $\mathrm{X}$ \\
\hline & 109 Aniba firmula (Nees \& Mart.) Mez & $\mathrm{X}$ & $\mathrm{X}$ \\
\hline & 110 Aniba viridis $\mathrm{Mez}$ & $\mathrm{X}$ & $\mathrm{X}$ \\
\hline & 111 Beilschmiedia emarginata (Meisn.) Kosterm. & $\mathrm{X}$ & $\mathrm{X}$ \\
\hline & 112 Cinnamomum hirsutum Lorea-Hern. & $\mathrm{X}$ & - \\
\hline & 113 Cinnamomum sp. & - & $\mathrm{X}$ \\
\hline & 114 Cinnamomum sp.1 & - & $\mathrm{X}$ \\
\hline & 115 Cinnamomum triplinerve (Ruiz. \& Pav.) Kosterm. & - & $\mathrm{X}$ \\
\hline & 116 Cryptocarya moschata Nees \& Mart. & $\mathrm{X}$ & $\mathrm{X}$ \\
\hline & 117 Cryptocarya sp. & - & $\mathrm{X}$ \\
\hline & 118 Cryptocarya sp. 1 & $\mathrm{X}$ & - \\
\hline & 119 Endlicheria paniculata (Spreng.) Macbr. & $\mathrm{X}$ & $\mathrm{X}$ \\
\hline & 120 Lauraceae sp.1 & $\mathrm{X}$ & $\mathrm{X}$ \\
\hline & 121 Lauraceae sp.2 & $\mathrm{X}$ & $\mathrm{X}$ \\
\hline & 122 Lauraceae sp.3 & $\mathrm{X}$ & $\mathrm{X}$ \\
\hline & 123 Lauraceae sp.4 & - & $\mathrm{X}$ \\
\hline & 124 Licaria armeniaca (Nees) Kostern & - & $\mathrm{X}$ \\
\hline & 125 Nectandra aff. barbellata Coe-Teix. & - & $\mathrm{X}$ \\
\hline & 126 Nectandra debilis Mez & $\mathrm{X}$ & - \\
\hline & 127 Nectandra leucantha Nees \& Mart. & - & $\mathrm{X}$ \\
\hline & 128 Nectandra membranacea (SW.) Griseb. & $\mathrm{X}$ & $\mathrm{X}$ \\
\hline & 129 Nectandra oppositfolia Nees \& Mart. & $\mathrm{X}$ & $\mathrm{X}$ \\
\hline & 130 Ocotea aciphylla (Nees) Mez & $\mathrm{X}$ & $\mathrm{X}$ \\
\hline & 131 Ocotea aff. bragai Coe-Teix. & - & $\mathrm{X}$ \\
\hline & 132 Ocotea aff. lancifolia (Schott) Mez & $\mathrm{X}$ & - \\
\hline
\end{tabular}


Tabela 1. Relação das famílias e espécies amostradas no componente arbóreo da Floresta Ombrófila Densa, no Parque Estadual Carlos Botelho. SP. Brasil, com o emprego do método de parcelas Gr1 - Grade 1, Gr2 - Grade 2

\begin{tabular}{|c|c|c|c|}
\hline Famílias & Espécies & Gr 1 & Gr 2 \\
\hline & 133 Ocotea bicolor Vattimo & $\mathrm{X}$ & $\mathrm{X}$ \\
\hline & 134 Ocotea brachybotrya (Meisn.) Mez & $\mathrm{X}$ & $\mathrm{X}$ \\
\hline & 135 Ocotea catharinensis Mez & $\mathrm{X}$ & $\mathrm{X}$ \\
\hline & 136 Ocotea daphinifolia (Meisn.) Mez & $\mathrm{X}$ & $\mathrm{X}$ \\
\hline & 137 Ocotea dispersa (Nees) Mez & $\mathrm{X}$ & $\mathrm{X}$ \\
\hline & 138 Ocotea divaricata (Nees) Mez & - & $\mathrm{X}$ \\
\hline & 139 Ocotea elegans Mez & $\mathrm{X}$ & $\mathrm{X}$ \\
\hline & 140 Ocotea glaziovii Mez & $\mathrm{X}$ & $\mathrm{X}$ \\
\hline & 141 Ocotea mosenii Mez & - & $\mathrm{X}$ \\
\hline & 142 Ocotea nectandrifolia Mez & $\mathrm{X}$ & - \\
\hline & 143 Ocotea odorifera (Vell.) Rohwer & $\mathrm{X}$ & $\mathrm{X}$ \\
\hline & 144 Ocotea porosa (Nees \& Mart.) Barroso & - & $\mathrm{X}$ \\
\hline & 145 Ocotea pulchella Mart. & $\mathrm{X}$ & $\mathrm{X}$ \\
\hline & 146 Ocotea pulchra Vatt. & $\mathrm{X}$ & $\mathrm{X}$ \\
\hline & 147 Ocotea silvestris Vatt. & $\mathrm{X}$ & $\mathrm{X}$ \\
\hline & 148 Ocotea sp.1 & $\mathrm{X}$ & $\mathrm{X}$ \\
\hline & 149 Ocotea sp.2 & $\mathrm{X}$ & $\mathrm{X}$ \\
\hline & 150 Ocotea sp.3 & - & $\mathrm{X}$ \\
\hline & 151 Ocotea tabacifolia (Meisn.) Rohwer. & $\mathrm{X}$ & $\mathrm{X}$ \\
\hline & 152 Ocotea teleiandra (Meisn.) Mez & $\mathrm{X}$ & $\mathrm{X}$ \\
\hline & 153 Ocotea vaccinioides (Meisn.) Mez & $\mathrm{X}$ & - \\
\hline & 154 Ocotea velloziana (Meisn.) Mez & $\mathrm{X}$ & - \\
\hline & 155 Ocotea venulosa Benth. \& Hook. & $\mathrm{X}$ & - \\
\hline & 156 Persea pyrifolia (D. Don.) Spreng. & $\mathrm{X}$ & $\mathrm{X}$ \\
\hline & 157 Persea sp.1 & $\mathrm{X}$ & - \\
\hline & 158 Rhodostemenodaphne macrocalyx (Meissn.) Madr. & $\mathrm{X}$ & $\mathrm{X}$ \\
\hline
\end{tabular}


Tabela 1. Relação das famílias e espécies amostradas no componente arbóreo da Floresta Ombrófila Densa, no Parque Estadual Carlos Botelho. SP. Brasil, com o emprego do método de parcelas Gr1 - Grade 1, Gr2 - Grade 2

\begin{tabular}{|c|c|c|c|c|}
\hline & Famílias & Espécies & Gr 1 & Gr 2 \\
\hline 32 & Lecythidaceae & 159 Cariniana estrellensis (Raddi) Kuntze & $\mathrm{X}$ & - \\
\hline 33 & Magnoliaceae & 160 Talauma ovata A. St. Hil. & $\mathrm{X}$ & $\mathrm{X}$ \\
\hline \multirow[t]{2}{*}{34} & Malphigiaceae & 161 Byrsonima ligustrifolia St. Hil. & $\mathrm{X}$ & $\mathrm{X}$ \\
\hline & & 162 Byrsonima myricifolia Griseb. & $\mathrm{X}$ & $\mathrm{X}$ \\
\hline \multirow[t]{15}{*}{35} & Melastomataceae & 163 Leandra dasytricha Cogn. & $\mathrm{X}$ & - \\
\hline & & 164 Leandra sp. & $\mathrm{X}$ & - \\
\hline & & 165 Meriania claussenii Triana & $\mathrm{X}$ & - \\
\hline & & 166 Miconia cabucu Hoenhe & $\mathrm{X}$ & $\mathrm{X}$ \\
\hline & & 167 Miconia cubatanensis Hoenhe & $\mathrm{X}$ & $\mathrm{X}$ \\
\hline & & 168 Miconia petropolitana Cogn. & $\mathrm{X}$ & $\mathrm{X}$ \\
\hline & & 169 Miconia pusilliflora (DC.) Naudin & $\mathrm{X}$ & $\mathrm{X}$ \\
\hline & & 170 Miconia sellowiana Naudin & $\mathrm{X}$ & - \\
\hline & & 171 Miconia sp. & - & $\mathrm{X}$ \\
\hline & & 172 Miconia sp.1 & $\mathrm{X}$ & - \\
\hline & & 173 Miconia theaezans (Bonpl.) Cogn. & - & $\mathrm{X}$ \\
\hline & & 174 Miconia valtherii Nadin & $\mathrm{X}$ & - \\
\hline & & 175 Mouriri chamissoana Cogn. & - & $\mathrm{X}$ \\
\hline & & 176 Tibouchina pulchra (Cham.) Cogn. & $\mathrm{X}$ & $\mathrm{X}$ \\
\hline & & 177 Tibouchina sellowiana Cogn. & $\mathrm{X}$ & $\mathrm{X}$ \\
\hline \multirow[t]{4}{*}{36} & Meliaceae & 178 Cabralea canjerana (Vell.) Mart. & $\mathrm{X}$ & $\mathrm{X}$ \\
\hline & & 179 Cedrella fissilis Vell. & $\mathrm{X}$ & $\mathrm{X}$ \\
\hline & & 180 Cedrella odorata L. & - & $\mathrm{X}$ \\
\hline & & 181 Guarea macrophylla Vahl & $\mathrm{X}$ & $\mathrm{X}$ \\
\hline
\end{tabular}


Tabela 1. Relação das famílias e espécies amostradas no componente arbóreo da Floresta Ombrófila Densa, no Parque Estadual Carlos Botelho. SP. Brasil, com o emprego do método de parcelas Gr1 - Grade 1, Gr2 - Grade 2

\begin{tabular}{|c|c|c|c|c|}
\hline & Famílias & Espécies & Gr 1 & Gr 2 \\
\hline & & 182 Trichilia hirta L. & - & $\mathrm{X}$ \\
\hline & & 183 Trichilia pallida SW. & - & $\mathrm{X}$ \\
\hline \multirow[t]{7}{*}{37} & Mimosaceae & 184 Inga cylindrica (Vell.) Mart. & - & $\mathrm{X}$ \\
\hline & & 185 Inga edulis Mart. & - & $\mathrm{X}$ \\
\hline & & 186 Inga laurina (SW.) Willd. & $\mathrm{X}$ & $\mathrm{X}$ \\
\hline & & 187 Inga marginata Willd. & $\mathrm{X}$ & $\mathrm{X}$ \\
\hline & & 188 Inga sellowiana Benth. & $\mathrm{X}$ & $\mathrm{X}$ \\
\hline & & 189 Inga sessilis (Vell.) Mart. & $\mathrm{X}$ & $\mathrm{X}$ \\
\hline & & 190 Pithecellobium langsdorffi Benth. & $\mathrm{X}$ & $\mathrm{X}$ \\
\hline \multirow[t]{7}{*}{38} & Monimiaceae & 191 Mollinedia elegans Tul. & $\mathrm{X}$ & $\mathrm{X}$ \\
\hline & & 192 Mollinedia floribunda Tul. & - & $\mathrm{X}$ \\
\hline & & 193 Mollinedia oligantha Perk. & $\mathrm{X}$ & $\mathrm{X}$ \\
\hline & & 194 Mollinedia oligotricha Perk. & $\mathrm{X}$ & $\mathrm{X}$ \\
\hline & & 195 Mollinedia schottiana (Spreng.) Perk. & $\mathrm{X}$ & $\mathrm{X}$ \\
\hline & & 196 Mollinedia sp. & - & $\mathrm{X}$ \\
\hline & & 197 Mollinedia sp.1 & $\mathrm{X}$ & $\mathrm{X}$ \\
\hline 39 & Moraceae & 198 Sorocea bonplandii (Baill.) Burger Lanj. \&. Boer & $\mathrm{X}$ & $\mathrm{X}$ \\
\hline \multirow[t]{6}{*}{40} & Myrsinaceae & 199 Ardisia guianensis (Aubl.) Mez & - & $\mathrm{X}$ \\
\hline & & 200 Cybianthus brasiliensis (Mez) G. Agos. & - & $\mathrm{X}$ \\
\hline & & 201 Cybianthus peruvianus (A. DC.) Miq. & - & $\mathrm{X}$ \\
\hline & & 202 Rapanea ferruginea (Ruiz \& Pav.) Mez & $\mathrm{X}$ & $\mathrm{X}$ \\
\hline & & 203 Rapanea gardneriana (A. DC.) Mez & $\mathrm{X}$ & $\mathrm{X}$ \\
\hline & & 204 Rapanea hermogenesii Jung-Mend. \& Bernacci & $\mathrm{X}$ & $\mathrm{X}$ \\
\hline
\end{tabular}


Tabela 1. Relação das famílias e espécies amostradas no componente arbóreo da Floresta Ombrófila Densa, no Parque Estadual Carlos Botelho. SP. Brasil, com o emprego do método de parcelas Gr1 - Grade 1, Gr2 - Grade 2

\begin{tabular}{|c|c|c|c|}
\hline Famílias & Espécies & Gr 1 & Gr 2 \\
\hline & 205 Rapanea sp. & - & $\mathrm{X}$ \\
\hline & 206 Rapanea umbellata (Mart.) Mez & $\mathrm{X}$ & $\mathrm{X}$ \\
\hline & 207 Stylogyne laevigata (Mart.) Mez & $\mathrm{X}$ & - \\
\hline \multirow[t]{23}{*}{41 Myrtaceae } & 208 Calycorectes aff. psidiiflorus (Berg) Sobral & $\mathrm{X}$ & - \\
\hline & 209 Calycorectes australis Legr. & $\mathrm{X}$ & $\mathrm{X}$ \\
\hline & 210 Calyptranthes lanceolata Berg & $\mathrm{X}$ & $\mathrm{X}$ \\
\hline & 211 Calyptranthes lucida DC. & $\mathrm{X}$ & $\mathrm{X}$ \\
\hline & 212 Calyptranthes obovata Kiaersk. & - & $\mathrm{X}$ \\
\hline & 213 Calyptranthes sp. 1 & $\mathrm{X}$ & $\mathrm{X}$ \\
\hline & 214 Calyptranthes sp. 2 & $\mathrm{X}$ & $\mathrm{X}$ \\
\hline & 215 Calyptranthes sp.3 & $\mathrm{X}$ & - \\
\hline & 216 Campomanesia guaviroba (DC.) Kiaersk. & $\mathrm{X}$ & $\mathrm{X}$ \\
\hline & 217 Campomanesia schlechtendahliana (O.Berg) Nied. & $\mathrm{X}$ & $\mathrm{X}$ \\
\hline & 218 Campomanesia sp. & - & $\mathrm{X}$ \\
\hline & 219 Eugenia beaurepairiana (Kiaersk.) Legr. & $\mathrm{X}$ & $\mathrm{X}$ \\
\hline & 220 Eugenia cambucarana Kiaersk & $\mathrm{X}$ & $\mathrm{X}$ \\
\hline & 221 Eugenia candolleana DC. & - & $\mathrm{X}$ \\
\hline & 222 Eugenia capitulifera Berg & $\mathrm{X}$ & $\mathrm{X}$ \\
\hline & 223 Eugenia cerasiflora Miq. & $\mathrm{X}$ & $\mathrm{X}$ \\
\hline & 224 Eugenia cereja Legr. & $\mathrm{X}$ & - \\
\hline & 225 Eugenia cf. fluminensis Berg & - & $\mathrm{X}$ \\
\hline & 226 Eugenia cf. schuchiana Berg & - & $\mathrm{X}$ \\
\hline & 227 Eugenia convexinervia Legr. & - & $\mathrm{X}$ \\
\hline & 228 Eugenia copacabanensis Kiaersk. & - & $\mathrm{X}$ \\
\hline & 229 Eugenia cuprea (Berg) Nied. & - & $X$ \\
\hline & 230 Eugenia florida DC. & - & $\mathrm{X}$ \\
\hline
\end{tabular}


Tabela 1. Relação das famílias e espécies amostradas no componente arbóreo da Floresta Ombrófila Densa, no Parque Estadual Carlos Botelho. SP. Brasil, com o emprego do método de parcelas Gr1 - Grade 1, Gr2 - Grade 2

\begin{tabular}{|c|c|c|c|}
\hline Famílias & Espécies & Gr 1 & Gr 2 \\
\hline & 231 Eugenia handroana Legr. & $\mathrm{X}$ & $\mathrm{X}$ \\
\hline & 232 Eugenia involucrata DC. & $\mathrm{X}$ & $\mathrm{X}$ \\
\hline & 233 Eugenia melanogina (Legr.) Sobral & $\mathrm{X}$ & $\mathrm{X}$ \\
\hline & 234 Eugenia mosenii (Kausel) Sobral & $\mathrm{X}$ & $\mathrm{X}$ \\
\hline & 235 Eugenia neoglomerata Sobral & $\mathrm{X}$ & $\mathrm{X}$ \\
\hline & 236 Eugenia neoverrucosa Sobral & - & $\mathrm{X}$ \\
\hline & 237 Eugenia prasina Berg & $\mathrm{X}$ & - \\
\hline & 238 Eugenia pruinosa Legr. & $\mathrm{X}$ & $\mathrm{X}$ \\
\hline & 239 Eugenia riedeliana Berg & $\mathrm{X}$ & $\mathrm{X}$ \\
\hline & 240 Eugenia sp.1 & $\mathrm{X}$ & $\mathrm{X}$ \\
\hline & 241 Eugenia sp.10 & - & $\mathrm{X}$ \\
\hline & 242 Eugenia sp.11 & - & $\mathrm{X}$ \\
\hline & 243 Eugenia sp.12 & - & $\mathrm{X}$ \\
\hline & 244 Eugenia sp.13 & - & $\mathrm{X}$ \\
\hline & 245 Eugenia sp.2 & $\mathrm{X}$ & $\mathrm{X}$ \\
\hline & 246 Eugenia sp.3 & $\mathrm{X}$ & $\mathrm{X}$ \\
\hline & 247 Eugenia sp.4 & $\mathrm{X}$ & $\mathrm{X}$ \\
\hline & 248 Eugenia sp.5 & $\mathrm{X}$ & $\mathrm{X}$ \\
\hline & 249 Eugenia sp.6 & - & $\mathrm{X}$ \\
\hline & 250 Eugenia sp.7 & - & $\mathrm{X}$ \\
\hline & 251 Eugenia sp.8 & - & $\mathrm{X}$ \\
\hline & 252 Eugenia sp.9 & - & $\mathrm{X}$ \\
\hline & 253 Eugenia stictosepala Kiaersk. & $\mathrm{X}$ & $\mathrm{X}$ \\
\hline & 254 Eugenia subavenia Berg & $\mathrm{X}$ & $\mathrm{X}$ \\
\hline & 255 Eugenia umbelliflora Berg & $\mathrm{X}$ & $\mathrm{X}$ \\
\hline & 256 Gomidesia anacardiaefolia (Gard.) Berg & - & $\mathrm{X}$ \\
\hline & 257 Gomidesia riedeliana Berg & - & $\mathrm{X}$ \\
\hline
\end{tabular}


Tabela 1. Relação das famílias e espécies amostradas no componente arbóreo da Floresta Ombrófila Densa, no Parque Estadual Carlos Botelho. SP. Brasil, com o emprego do método de parcelas Gr1 - Grade 1, Gr2 - Grade 2

\begin{tabular}{|c|c|c|c|}
\hline Famílias & Espécies & Gr 1 & Gr 2 \\
\hline & 258 Gomidesia schaueriana Berg & $\mathrm{X}$ & $\mathrm{X}$ \\
\hline & 259 Gomidesia sp. & - & $\mathrm{X}$ \\
\hline & 260 Gomidesia spectabilis (DC.) Berg & - & $\mathrm{X}$ \\
\hline & 261 Gomidesia tijucensis (Kiaersk.) Legr. & $\mathrm{X}$ & $\mathrm{X}$ \\
\hline & 262 Marlierea sp.1 & $\mathrm{X}$ & $\mathrm{X}$ \\
\hline & 263 Marlierea sp.2 & - & $\mathrm{X}$ \\
\hline & 264 Marlierea eugeniopsoides (Legr. \& Kausel) Legr. & $\mathrm{X}$ & $\mathrm{X}$ \\
\hline & 265 Marlierea parviflora Berg & $\mathrm{X}$ & $\mathrm{X}$ \\
\hline & 266 Marlierea racemosa (Vell.) Kiaersk. & - & $\mathrm{X}$ \\
\hline & 267 Marlierea reitzii Legr. & $\mathrm{X}$ & $\mathrm{X}$ \\
\hline & 268 Marlierea tomentosa Cambess. & $\mathrm{X}$ & $\mathrm{X}$ \\
\hline & 269 Myrceugenia aff. pilotantha (Kiaerk.) Landrum & $\mathrm{X}$ & - \\
\hline & 270 Myrceugenia campestris (DC.) Legr. \& Kausel. & $\mathrm{X}$ & $\mathrm{X}$ \\
\hline & 271 Myrceugenia glaucescens (Cambess.) Legr. \& Kausel & $\mathrm{X}$ & $\mathrm{X}$ \\
\hline & 272 Myrceugenia kleinii Legr. \& Kausel & $\mathrm{X}$ & $\mathrm{X}$ \\
\hline & 273 Myrceugenia myrcioides (Cambess.) Berg & $\mathrm{X}$ & $\mathrm{X}$ \\
\hline & 274 Myrceugenia seriatoramosa (Kiaersk.) Legr. \& Kausel. & - & $\mathrm{X}$ \\
\hline & 275 Myrceugenia sp.1 & $\mathrm{X}$ & $\mathrm{X}$ \\
\hline & 276 Myrceugenia sp.2 & - & $\mathrm{X}$ \\
\hline & 277 Myrcia aff. glabra (Berg) Legr. & $\mathrm{X}$ & - \\
\hline & 278 Myrcia aff. macrocarpa Barb. Rodr. & - & $\mathrm{X}$ \\
\hline & 279 Myrcia aff.obtecta (Berg) Kiaersk. & $\mathrm{X}$ & - \\
\hline & 280 Myrcia fallax (Rich.) DC. & $\mathrm{X}$ & $\mathrm{X}$ \\
\hline & 281 Myrcia hatschbachii Legr. & $\mathrm{X}$ & $\mathrm{X}$ \\
\hline & 282 Myrcia heringii Legr. & $\mathrm{X}$ & - \\
\hline & 283 Myrcia pubipetala Miq. & $\mathrm{X}$ & $\mathrm{X}$ \\
\hline & 284 Myrcia richardiana (Berg) Kiaersk. & $\mathrm{X}$ & - \\
\hline
\end{tabular}


Tabela 1. Relação das famílias e espécies amostradas no componente arbóreo da Floresta Ombrófila Densa, no Parque Estadual Carlos Botelho. SP. Brasil, com o emprego do método de parcelas Gr1 - Grade 1, Gr2 - Grade 2

\begin{tabular}{|c|c|c|c|}
\hline Famílias & Espécies & Gr 1 & Gr 2 \\
\hline & 285 Myrcia rostrata DC. & - & $\mathrm{X}$ \\
\hline & 286 Myrcia sp & - & $\mathrm{X}$ \\
\hline & 287 Myrcia sp.1 & $\mathrm{X}$ & $\mathrm{X}$ \\
\hline & 288 Myrcia sp.2 & $\mathrm{X}$ & $\mathrm{X}$ \\
\hline & 289 Myrcia sp.3 & - & $\mathrm{X}$ \\
\hline & 290 Myrcia sp.4 & - & $\mathrm{X}$ \\
\hline & 291 Myrcia tenuivenosa Kiaersk & $\mathrm{X}$ & $\mathrm{X}$ \\
\hline & 292 Myrciaria sp.1 & $\mathrm{X}$ & $\mathrm{X}$ \\
\hline & 293 Myrciaria sp.2 & - & $\mathrm{X}$ \\
\hline & 294 Myrciaria sp.3 & - & $\mathrm{X}$ \\
\hline & 295 Myrtaceae sp.1 & $\mathrm{X}$ & $\mathrm{X}$ \\
\hline & 296 Myrtaceae sp.2 & $\mathrm{X}$ & $\mathrm{X}$ \\
\hline & 297 Myrtaceae sp.3 & $\mathrm{X}$ & $\mathrm{X}$ \\
\hline & 298 Myrtaceae sp.4 & $\mathrm{X}$ & $\mathrm{X}$ \\
\hline & 299 Myrtaceae sp.5 & - & $\mathrm{X}$ \\
\hline & 300 Myrtaceae sp.6 & - & $\mathrm{X}$ \\
\hline & 301 Neomitranthes glomerata (Legr.) Legr. & $\mathrm{X}$ & $\mathrm{X}$ \\
\hline & 302 Pimenta pseudocaryophyllus (Gomes) Landrum & - & $\mathrm{X}$ \\
\hline & 303 Plinia complanata Kawas. \& Holst. & $\mathrm{X}$ & $\mathrm{X}$ \\
\hline & 304 Plinia pauciflora Kawas. \& Holst. & $\mathrm{X}$ & $\mathrm{X}$ \\
\hline & 305 Psidium cattleyanum Sabine & - & $\mathrm{X}$ \\
\hline & 306 Psydium cf. myrtoides Berg & - & $\mathrm{X}$ \\
\hline & 307 Siphoneugena densiflora Berg & $\mathrm{X}$ & $\mathrm{X}$ \\
\hline 42 Nyctaginaceae & 308 Guapira opposita (Vell.) Reitz & $\mathrm{X}$ & $\mathrm{X}$ \\
\hline 43 Ochnaceae & 309 Ouratea multiflora Engl. & - & $\mathrm{X}$ \\
\hline
\end{tabular}


Tabela 1. Relação das famílias e espécies amostradas no componente arbóreo da Floresta Ombrófila Densa, no Parque Estadual Carlos Botelho. SP. Brasil, com o emprego do método de parcelas Gr1 - Grade 1, Gr2 - Grade 2

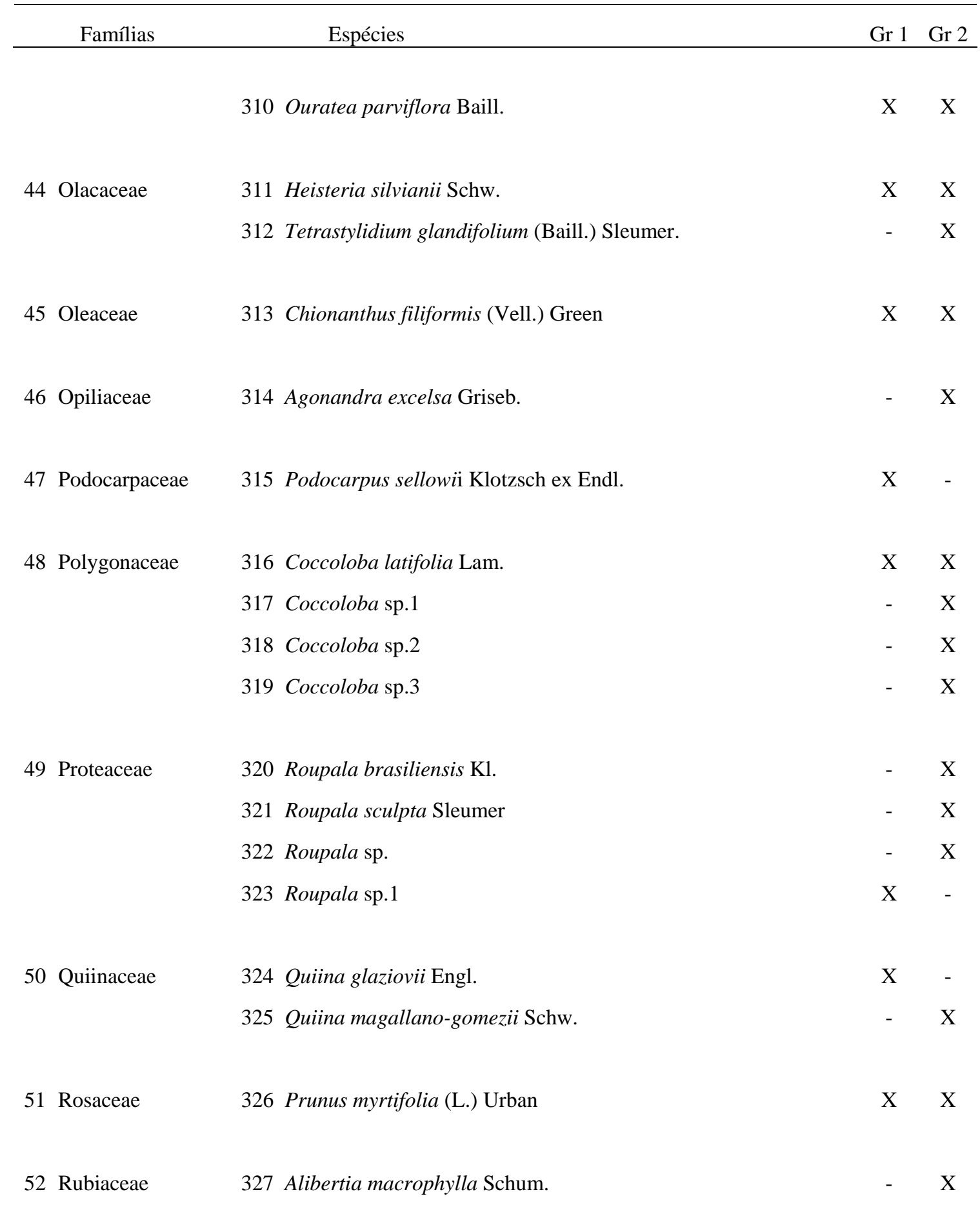


Tabela 1. Relação das famílias e espécies amostradas no componente arbóreo da Floresta Ombrófila Densa, no Parque Estadual Carlos Botelho. SP. Brasil, com o emprego do método de parcelas Gr1 - Grade 1, Gr2 - Grade 2

\begin{tabular}{|c|c|c|c|}
\hline Famílias & Espécies & Gr 1 & Gr 2 \\
\hline & 328 Alibertia myrciifolia Schum. & $\mathrm{X}$ & $\mathrm{X}$ \\
\hline & 329 Alibertia sp. & $\mathrm{X}$ & - \\
\hline & 330 Alibertia sp. 1 & - & $\mathrm{X}$ \\
\hline & 331 Alibertia sp. 2 & - & $\mathrm{X}$ \\
\hline & 332 Alseis floribunda Schott & $\mathrm{X}$ & $\mathrm{X}$ \\
\hline & 333 Amaioua guianensis Aubl. & - & $\mathrm{X}$ \\
\hline & 334 Amaioua cutifólia Mart. & $\mathrm{X}$ & $\mathrm{X}$ \\
\hline & 335 Bathysa australis (St. Hil.) Benth. \& Hook. & $\mathrm{X}$ & $\mathrm{X}$ \\
\hline & 336 Chomelia catharinae (Smith. \& Downs.) Steyerm. & - & $\mathrm{X}$ \\
\hline & 337 Chomelia sp. & $\mathrm{X}$ & - \\
\hline & 338 Coussarea contracta (Wal.) Müll. Arg. & - & $\mathrm{X}$ \\
\hline & 339 Coussarea sp. & $\mathrm{X}$ & $\mathrm{X}$ \\
\hline & 340 Faramea montevidensis (Cham.\& Schltdl.) DC. & - & $\mathrm{X}$ \\
\hline & 341 Ixora breviflora Hiem & - & $\mathrm{X}$ \\
\hline & 342 Ixora burchelliana Müll. Arg. & $\mathrm{X}$ & $\mathrm{X}$ \\
\hline & 343 Ixora heterodoxa Müll. Arg. & - & $\mathrm{X}$ \\
\hline & 344 Ixora sp. & - & $\mathrm{X}$ \\
\hline & 345 Posoqueria cutifólia Mart. & $\mathrm{X}$ & $\mathrm{X}$ \\
\hline & 346 Psychotria suterella Müll. Arg. & $\mathrm{X}$ & $\mathrm{X}$ \\
\hline & 347 Psychotria velloziana Benth. & $\mathrm{X}$ & $\mathrm{X}$ \\
\hline & 348 Randia aff. Armata (Sw.) DC. & - & $\mathrm{X}$ \\
\hline & 349 Rubiaceae sp.1 & $\mathrm{X}$ & $\mathrm{X}$ \\
\hline & 350 Rubiaceae sp.2 & - & $\mathrm{X}$ \\
\hline & 351 Rudgea jasminoides (Cham.) Müell. Arg. & $\mathrm{X}$ & $\mathrm{X}$ \\
\hline & 352 Rudgea blanchetiana Müell. Arg. & - & $\mathrm{X}$ \\
\hline & 353 Psychotria sp. & - & $\mathrm{X}$ \\
\hline
\end{tabular}


Tabela 1. Relação das famílias e espécies amostradas no componente arbóreo da Floresta Ombrófila Densa, no Parque Estadual Carlos Botelho. SP. Brasil, com o emprego do método de parcelas Gr1 - Grade 1, Gr2 - Grade 2

\begin{tabular}{|c|c|c|c|c|}
\hline & Famílias & Espécies & Gr 1 & Gr 2 \\
\hline \multirow[t]{4}{*}{53} & Rutaceae & 354 Esenbeckia grandiflora Mart. & $\mathrm{X}$ & $\mathrm{X}$ \\
\hline & & 355 Esenbeckia sp. & - & $\mathrm{X}$ \\
\hline & & 356 Zanthoxylum fagara (L.) Sarg. & - & $\mathrm{X}$ \\
\hline & & 357 Zanthoxylum rhoifolium Lam. & $\mathrm{X}$ & $\mathrm{X}$ \\
\hline \multirow[t]{2}{*}{54} & Sabiaceae & 358 Meliosma selowii Urb. & $\mathrm{X}$ & $\mathrm{X}$ \\
\hline & & 359 Meliosma sinuata Urban. & $\mathrm{X}$ & $\mathrm{X}$ \\
\hline \multirow[t]{10}{*}{55} & Sapindaceae & 360 Allophylus edulis (A. St.Hil., Camb. \& A. Juss.) Radlk.) Radlk. & $\mathrm{X}$ & $\mathrm{X}$ \\
\hline & & 361 Allophylus petiolulatus Radlk & $\mathrm{X}$ & $\mathrm{X}$ \\
\hline & & 362 Cupania oblongifolia Mart.. & $\mathrm{X}$ & $\mathrm{X}$ \\
\hline & & 363 Cupania sp. & - & $\mathrm{X}$ \\
\hline & & 364 Cupania vernalis Cambess. & $\mathrm{X}$ & $\mathrm{X}$ \\
\hline & & 365 Dodonaea viscosa Jacq. & - & $\mathrm{X}$ \\
\hline & & 366 Matayba elaeagnoides Radlk. & - & $\mathrm{X}$ \\
\hline & & 367 Matayba guianensis Aubl. & $\mathrm{X}$ & $\mathrm{X}$ \\
\hline & & 368 Matayba juglandifolia Radlk. & $\mathrm{X}$ & $\mathrm{X}$ \\
\hline & & 369 Matayba sp. & - & $\mathrm{X}$ \\
\hline \multirow[t]{8}{*}{56} & Sapotaceae & 370 Chrysophyllum flexuosum Mart. & - & $\mathrm{X}$ \\
\hline & & 371 Chrysophyllum inornatum Mart. & - & $\mathrm{X}$ \\
\hline & & 372 Chrysophyllum viride Mart. \& Eichl. & $X$ & $\mathrm{X}$ \\
\hline & & 373 Diploon cuspidatum (Hoehne) Cronquist & $\mathrm{X}$ & $\mathrm{X}$ \\
\hline & & 374 Ecclinusa ramiflora Mart. & $\mathrm{X}$ & $\mathrm{X}$ \\
\hline & & 375 Micropholis crassipedicellata (Mart. \& Eichler ex Miq.) Pierre & $\mathrm{X}$ & $\mathrm{X}$ \\
\hline & & 376 Pouteria bullata (Moore) Baehni & $\mathrm{X}$ & $\mathrm{X}$ \\
\hline & & 377 Pouteria caimito (Ruiz \& Pav.) Radlk. & $\mathrm{X}$ & $\mathrm{X}$ \\
\hline
\end{tabular}


Tabela 1. Relação das famílias e espécies amostradas no componente arbóreo da Floresta Ombrófila Densa, no Parque Estadual Carlos Botelho. SP. Brasil, com o emprego do método de parcelas Gr1 - Grade 1, Gr2 - Grade 2

\begin{tabular}{|c|c|c|c|c|}
\hline & Famílias & Espécies & Gr 1 & Gr 2 \\
\hline & & 378 Pouteria macrophylla (Lam.) Eyma & - & $\mathrm{X}$ \\
\hline & & 379 Pouteria psammophila (Mart.) Radlk. & - & $\mathrm{X}$ \\
\hline & & 380 Pouteria sp & - & $\mathrm{X}$ \\
\hline 57 & Simaroubaceae & 381 Picramnia sp. & - & $\mathrm{X}$ \\
\hline \multirow[t]{7}{*}{58} & Solanaceae & 382 Brunfelsia pauciflora (Cham. \& Schldl.) Benth. & - & $\mathrm{X}$ \\
\hline & & 383 Cyphomandra sp. & - & $\mathrm{X}$ \\
\hline & & 384 Solanum argenteum Dunal & - & $\mathrm{X}$ \\
\hline & & 385 Solanum bullatum Vell. & $\mathrm{X}$ & - \\
\hline & & 386 Solanum cf. rufescens Sendttn. & - & $\mathrm{X}$ \\
\hline & & 387 Solanum excelsum Salisb. & $\mathrm{X}$ & $\mathrm{X}$ \\
\hline & & 388 Solanum pseudoquina A. St. Hil. & $X$ & $\mathrm{X}$ \\
\hline 59 & Styracaceae & 389 Styrax acuminatus Pohl & $X$ & - \\
\hline \multirow[t]{3}{*}{60} & Symplocaceae & 390 Symplocos celastrinea Mart. ex Miq. & $\mathrm{X}$ & - \\
\hline & & 391 Symplocos falcata Brand & $\mathrm{X}$ & $\mathrm{X}$ \\
\hline & & 392 Symplocos variabilis Mat & $\mathrm{X}$ & $\mathrm{X}$ \\
\hline 61 & Theaceae & 393 Gordonia fruticosa (Schrad) Keing. & - & $\mathrm{X}$ \\
\hline 62 & Thymelaeaceae & 394 Daphnopsis gemmiflora (Miers.) Domke. & $\mathrm{X}$ & $\mathrm{X}$ \\
\hline \multirow[t]{3}{*}{63} & Verbenaceae & 395 Aegiphila brachiata Vell. & - & $\mathrm{X}$ \\
\hline & & 396 Aegiphila sellowiana Cham. & $\mathrm{X}$ & $\mathrm{X}$ \\
\hline & & 397 Aegiphila sp. & $\mathrm{X}$ & - \\
\hline
\end{tabular}


Tabela 1. Relação das famílias e espécies amostradas no componente arbóreo da Floresta Ombrófila Densa, no Parque Estadual Carlos Botelho. SP. Brasil, com o emprego do método de parcelas Gr1 - Grade 1, Gr2 - Grade 2

\begin{tabular}{|c|c|c|c|c|}
\hline & Famílias & Espécies & Gr 1 & Gr 2 \\
\hline & & 398 Verbenaceae 1 & $X$ & - \\
\hline & & 399 Vitex aff. polygama Cham. & $\mathrm{X}$ & - \\
\hline & Vochysiaceae & 400 Vochysia selloi Warm. & $\mathrm{X}$ & - \\
\hline & & 401 Vochysia sp. 1 & $\mathrm{X}$ & - \\
\hline & Winteraceae & 402 Drimys winteri Forst. \& Forst. & $\mathrm{X}$ & $\mathrm{X}$ \\
\hline 65 & & 402 & 250 & 348 \\
\hline
\end{tabular}

As famílias que apresentaram a maior riqueza de espécies foram: Myrtaceae (25\%) com 100 espécies, Lauraceae (13\%) com 53 espécies, Rubiaceae (7\%) com 27 espécies, Fabaceae e Melastomataceae (4\%) com 15 espécies cada, Sapotaceae (3\%), com 11 espécies, Sapindaceae (3\%) com 10 espécies, Myrsinaceae e Asteraceae (2\%) com 9 espécies cada e Annonaceae (2\%) com 8 espécies. Nestas 10 famílias estão representadas 257 espécies ou, 64,0\% de todas as espécies amostradas. As 55 famílias restantes amostraram 144 espécies, ou seja, 36,0\% das espécies (Figura 10). Observa-se ainda que 26 famílias foram representadas por apenas uma espécie cada. 


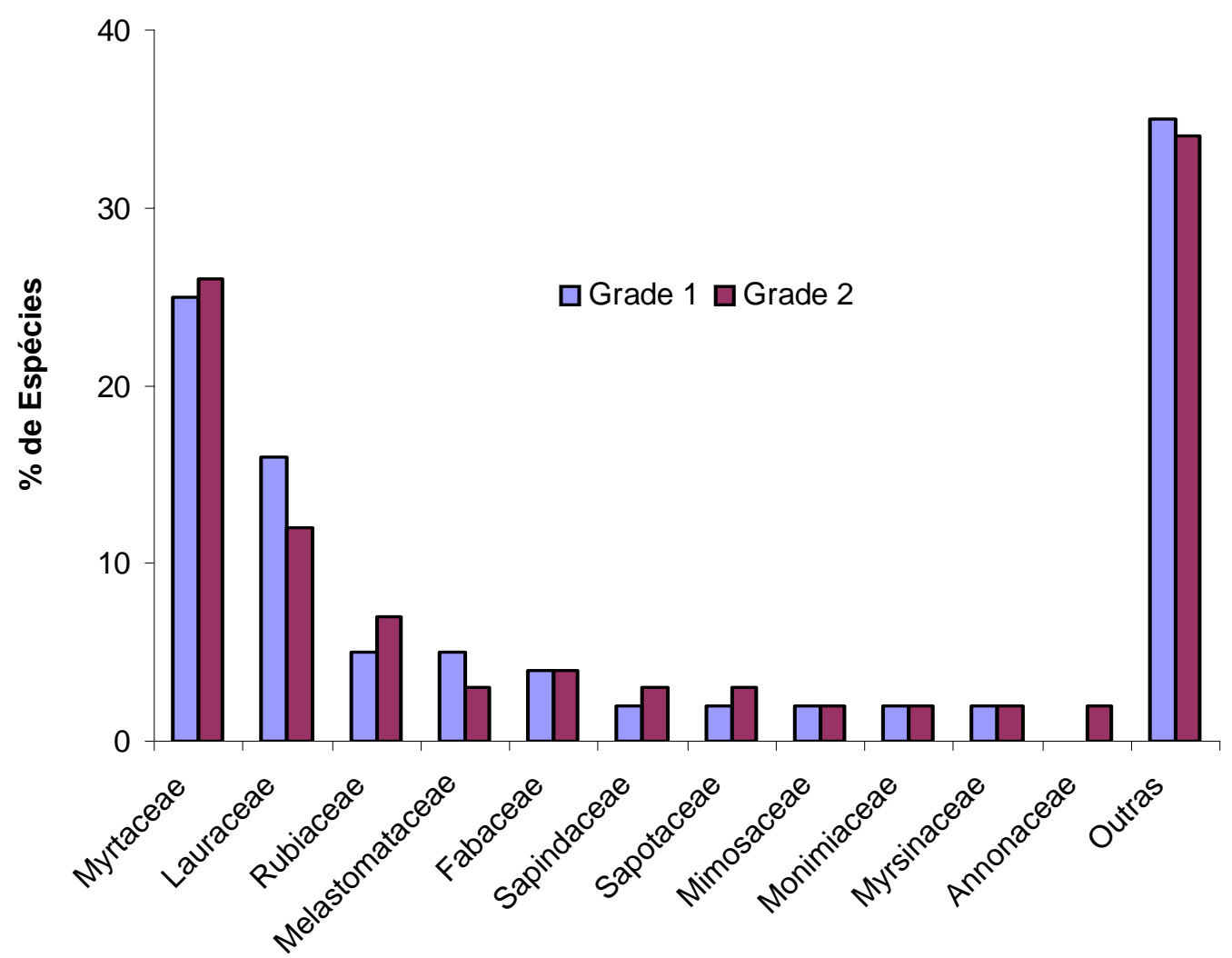

Figura 10 - Distribuição, em porcentagem das espécies por família, amostrada através do emprego de parcelas no levantamento do componente arbóreo na Floresta Ombrófila Densa (Grade 1 e Grade 2) no Parque Estadual Carlos Botelho. SP. Brasil

\subsection{Quadrantes:}

\subsubsection{Grade 1}

Na grade 1, o método de quadrantes amostrou 1.276 indivíduos, dos quais 10 eram representados por árvores mortas em pé. Foram registradas 50 famílias botânicas e 175 espécies arbóreas. Destas, 15 foram identificadas em nível de gênero, 5 foram identificadas em nível de família e 1 foi determinada como morfoespécie (Tabela 2). 
Das 50 famílias identificadas, 10 foram responsáveis pela amostragem de 63\% do total das espécies. Estas famílias, que apresentaram a maior riqueza de espécies, foram: Myrtaceae (25\%) com 44 espécies, Lauraceae (11\%) com 20 espécies, Rubiaceae (6\%) com 11 espécies, Melastomataceae (4\%) com 7 espécies, Fabaceae e Sapotaceae (3\%) com 6 espécies cada, Sapindaceae (3\%) com 5 espécies, Annonaceae, Mimosaceae e Myrsinaceae (2\%) com 4 espécies cada. As 40 Famílias restantes amostraram apenas $37 \%$ do total das espécies. Observa-se ainda que 26 famílias foram representadas por apenas 1 espécie cada (Figura 11).

\subsubsection{Grade 2}

Na Grade 2, o método de quadrantes amostrou 1.270 indivíduos, dos quais 4 são árvores mortas em pé.

Foram registradas 50 famílias e 207 espécies arbóreas, sendo que 24 espécies foram identificadas apenas em nível de gênero, 4 foram identificadas em nível de família e 1 foi determinada como morfoespécie.

As famílias com maior riqueza de espécies foram: Myrtaceae (30\%) com 62 espécies, Lauraceae (10\%) com 20 espécies, Rubiaceae (7\%) com 14 espécies, Sapotaceae e Fabaceae (4\%) com 8 espécies cada, Melastomataceae, Sapindaceae e Mimosaceae (2\%) com 5 espécies cada, Annonaceae, Boraginaceae e Monimiaceae (2\%) com 4 espécies cada. Estas famílias amostraram $67 \%$ do total das espécies, sendo o restante , 33\% do total das espécies amostradas por 39 famílias (Figura 11). Observa-se ainda que 18 famílias foram representadas por apenas 1 espécie cada. 
Tabela 2. Relação das famílias e espécies amostradas no componente arbóreo da Floresta Ombrófila Densa, no Parque Estadual Carlos Botelho.SP.Brasil, com o emprego do método de quadrantes. Gr1 - Grade 1 e Gr2 - Grade 2

Familias

1 Anacardiaceae

2 Annonaceae

3 Apocynaceae

4 Aquifoliaceae

5 Araliaceae

6 Arecaceae

7 Asteraceae

8 Bignoniaceae
1 Tapirira guianensis Aubl.

2 Duguetia lanceolata A.St. Hil.

3 Guatteria australis A. St. Hil.

4 Rollinia parviflora A. St. Hil.

5 Rollinia sericea (R. E. Fries) R. E. Fries

6 Xylopia langsdorfiana St. Hil. \& Tul.

7 Aspidosperma olivaceum Müll. Arg.

8 Ilex amara (Vell.) Loes.

9 Ilex paraguariensis A. St. Hil.

10 IIex taubertiana Loes.

11 Ilex theazans Mat.

12 Didymopanax angustissimus March.

13 Didymopanax navarroi A Samp.

14 Euterpe edulis Mart.

15 Piptocarpha macropoda (DC.) Baker

16 Piptocarpha sp.

17 Vernonia diffusa Less.

18 Vernonia puberula Less.

19 Vernonia quinqueflora Less.

20 Jacaranda micrantha Cham.
X $\quad \mathrm{X}$

Gr 1 Gr 2

$\mathrm{X}$

$\begin{array}{cc}- & \text { X } \\ \text { X } & \text { X } \\ \text { X } & - \\ \text { X } & \text { X } \\ \text { X } & \text { X }\end{array}$

$\mathrm{X}$

X $\quad \mathrm{X}$

X $\quad \mathrm{X}$

X -

- $\quad X$

X -

X $\quad X$

X -

X -

X -

$-\quad X$

$-\quad X$

- X 
Tabela 2. Relação das famílias e espécies amostradas no componente arbóreo da Floresta Ombrófila Densa, no Parque Estadual Carlos Botelho.SP.Brasil, com o emprego do método de quadrantes. Gr1 - Grade 1 e Gr2 - Grade 2

\begin{tabular}{|c|c|c|c|}
\hline Familias & Especies & Gr 1 & Gr 2 \\
\hline & 21 Jacaranda puberula Cham. & $\mathrm{x}$ & $\mathrm{X}$ \\
\hline & 22 Tabebuia heptaphylla (Vell.) Toledo & - & $\mathrm{X}$ \\
\hline \multirow[t]{4}{*}{9 Boraginaceae } & 23 Cordia ecalyculata Vell. & - & $\mathrm{X}$ \\
\hline & 24 Cordia sellowiana Cham. & $\mathrm{X}$ & $\mathrm{X}$ \\
\hline & 25 Cordia sp. 1 & $\mathrm{X}$ & $\mathrm{X}$ \\
\hline & 26 Cordia trichotoma (Vell.) Arrab. Ex Steud. & - & $\mathrm{X}$ \\
\hline 10 Burseraceae & 27 Protium hepatphyllum (Aubl.) March. & $\mathrm{x}$ & $\mathrm{X}$ \\
\hline \multirow[t]{4}{*}{11 Caesalpiniaceae } & 28 Copaifera langsdorffii Desf. & $\mathrm{x}$ & $\mathrm{X}$ \\
\hline & 29 Copaifera trapezifolia Hayne & $\mathrm{x}$ & - \\
\hline & 30 Sclerolobium denudatum Vog. & $\mathrm{X}$ & $\mathrm{X}$ \\
\hline & 31 Senna multijuja (Rich.) h.s. Irwin \& Barneby & - & $\mathrm{X}$ \\
\hline 12 Canellaceae & 32 Capsicodendron dinisii (Schw.) Occh. & $\mathrm{x}$ & $\mathrm{X}$ \\
\hline \multirow[t]{3}{*}{13 Cecropiaceae } & 33 Cedrella fissilis Vell. & $\mathrm{x}$ & - \\
\hline & 34 Cecropia glaziovi Sneth. & $\mathrm{X}$ & - \\
\hline & 35 Coussapoa microcarpa (Schott) Rizzini & $\mathrm{X}$ & $\mathrm{X}$ \\
\hline \multirow[t]{2}{*}{14 Celastraceae } & 36 Maytenus ilicifolia Mart.ex. Reiss. & - & $\mathrm{X}$ \\
\hline & 37 Maytenus robusta Reiss. & $\mathrm{x}$ & $\mathrm{X}$ \\
\hline \multirow[t]{2}{*}{15 Chrysobalanaceae } & 38 Hirtella hebeclada Moric. Ex DC. & $\mathrm{x}$ & $\mathrm{X}$ \\
\hline & 39 Parinari excelsa Sabine & $\mathrm{x}$ & $\mathrm{X}$ \\
\hline
\end{tabular}


Tabela 2. Relação das famílias e espécies amostradas no componente arbóreo da Floresta Ombrófila Densa, no Parque Estadual Carlos Botelho.SP.Brasil, com o emprego do método de quadrantes. Gr1 - Grade 1 e Gr2 - Grade 2

\begin{tabular}{|c|c|c|c|}
\hline Familias & Especies & Gr 1 & Gr 2 \\
\hline 16 Clethraceae & 40 Clethra scabra Pers. & $\mathrm{X}$ & - \\
\hline 17 Clusiaceae & 41 Garcinia gadneriana (Planch.\& Triana) Zappi & $\mathrm{X}$ & $\mathrm{X}$ \\
\hline 18 Combretaceae & 42 Buchenavia kleinii Excell & $\mathrm{X}$ & - \\
\hline \multirow[t]{3}{*}{19 Cunoniaceae } & 43 Lamanonia ternata Vell. & $\mathrm{X}$ & $\mathrm{X}$ \\
\hline & 44 Weinmannia discolor Gardner & $\mathrm{X}$ & $\mathrm{X}$ \\
\hline & 45 Weinmannia paulliniifolia Pohl & $\mathrm{X}$ & $\mathrm{X}$ \\
\hline 20 Elaeocarpaceae & 46 Sloanea monosperma Vell. & $\mathrm{X}$ & $\mathrm{X}$ \\
\hline \multirow[t]{3}{*}{21 Euphorbiaceae } & 47 Alchornea triplinervia (Spreng.) Müll. Arg. & $\mathrm{X}$ & $\mathrm{X}$ \\
\hline & 48 Hyeronima alchorneoides Allem. & $\mathrm{X}$ & $\mathrm{X}$ \\
\hline & 49 Sapium glandulatum (Vell.) Pax & $\mathrm{X}$ & $\mathrm{X}$ \\
\hline \multirow[t]{10}{*}{22 Fabaceae } & 50 Andira anthelmia (Vell.) Macbr. & $\mathrm{X}$ & $\mathrm{X}$ \\
\hline & 51 Dahlstedtia pentaphylla ( Taub.) Burkart & - & $\mathrm{X}$ \\
\hline & 52 Dahlstedtia pinnata (Benth.) Malme & - & $\mathrm{X}$ \\
\hline & 53 Dalbergia brasiliensis Vog. & - & $\mathrm{X}$ \\
\hline & 54 Fabaceae 1 & $\mathrm{X}$ & - \\
\hline & 55 Myrocarpus frondosus Allem. & $\mathrm{X}$ & $\mathrm{X}$ \\
\hline & 56 Ormosia dasycarpa Jacks. & $\mathrm{X}$ & $\mathrm{X}$ \\
\hline & 57 Platymiscium floribundum Vogel & - & $\mathrm{X}$ \\
\hline & 58 Pterocarpus rohrii Vahl. & $\mathrm{X}$ & $\mathrm{X}$ \\
\hline & 59 Zollernia illicifolia (Bron.) Vog. & $\mathrm{X}$ & - \\
\hline \multirow[t]{3}{*}{23 Flacourtiaceae } & 60 Casearia decandra Jacq. & $\mathrm{X}$ & $\mathrm{X}$ \\
\hline & 61 Casearia obliqua Spreng. & $\mathrm{X}$ & $\mathrm{X}$ \\
\hline & 62 Casearia sylvestris Sw. & - & $\mathrm{X}$ \\
\hline
\end{tabular}


Tabela 2. Relação das famílias e espécies amostradas no componente arbóreo da Floresta Ombrófila Densa, no Parque Estadual Carlos Botelho.SP.Brasil, com o emprego do método de quadrantes. Gr1 - Grade 1 e Gr2 - Grade 2

\begin{tabular}{|c|c|c|c|}
\hline Familias & Especies & Gr 1 & Gr 2 \\
\hline 24 Hippocrateaceae & 63 Salacia elliptica (Mart. ex Schult.) G. Don. & - & $\mathrm{X}$ \\
\hline 25 Humiriaceae & 64 Vantanea compacta (Schnzl.) Cuatr. & $\mathrm{X}$ & $\mathrm{X}$ \\
\hline 26 Icacinaceae & 65 Citronella paniculata (Mart.) Howard & $\mathrm{X}$ & $\mathrm{X}$ \\
\hline 27 Morfoespécie & 66 Morfoespécie 3 & - & $\mathrm{X}$ \\
\hline \multirow[t]{20}{*}{28 Lauraceae } & 67 Aiouea acaradomatifera Koest. & $\mathrm{X}$ & $\mathrm{X}$ \\
\hline & 68 Aniba viridis $\mathrm{Mez}$ & $\mathrm{X}$ & $\mathrm{X}$ \\
\hline & 69 Beilschmiedia emarginata (Meisn.) Kosterm. & $\mathrm{X}$ & - \\
\hline & 70 Cinnamomum sp. & - & $\mathrm{X}$ \\
\hline & 71 Cryptocarya moschata Nees \& Mart. & $\mathrm{X}$ & $\mathrm{X}$ \\
\hline & 72 Cryptocarya sp. & - & $\mathrm{X}$ \\
\hline & 73 Cryptocarya sp. 1 & $\mathrm{X}$ & - \\
\hline & 74 Endlicheria paniculata (Spreng.) Macbr. & $\mathrm{X}$ & $\mathrm{X}$ \\
\hline & 75 Lauraceae sp.3 & - & $\mathrm{X}$ \\
\hline & 76 Nectandra aff. membranacea (SW.) Griseb. & - & $\mathrm{X}$ \\
\hline & 77 Ocotea aciphylla (Nees) Mez & $\mathrm{X}$ & $\mathrm{X}$ \\
\hline & 78 Ocotea bicolor Vattimo & $\mathrm{X}$ & $\mathrm{X}$ \\
\hline & 79 Ocotea brachybotrya (Meisn.) Mez & $\mathrm{X}$ & - \\
\hline & 80 Ocotea catharinensis Mez & $\mathrm{X}$ & $\mathrm{X}$ \\
\hline & 81 Ocotea dispersa (Nees) Mez & $\mathrm{X}$ & $\mathrm{X}$ \\
\hline & 82 Ocotea elegans Mez & $\mathrm{X}$ & $\mathrm{X}$ \\
\hline & 83 Ocotea glaziovii Mez & $\mathrm{X}$ & $\mathrm{X}$ \\
\hline & 84 Ocotea odorifera (Vell.) Rohwer & $\mathrm{X}$ & $\mathrm{X}$ \\
\hline & 85 Ocotea pulchra Vatt. & & $\mathrm{X}$ \\
\hline & 86 Ocotea silvestris Vatt. & & $\mathrm{X}$ \\
\hline
\end{tabular}


Tabela 2. Relação das famílias e espécies amostradas no componente arbóreo da Floresta Ombrófila Densa, no Parque Estadual Carlos Botelho.SP.Brasil, com o emprego do método de quadrantes. Gr1 - Grade 1 e Gr2 - Grade 2

\begin{tabular}{|c|c|c|c|}
\hline Familias & Especies & Gr 1 & Gr 2 \\
\hline & 87 Ocotea teleiandra (Meisn.) Mez & $\mathrm{X}$ & $\mathrm{X}$ \\
\hline & 88 Ocotea vaccinioides (Meisn.) Mez & $\mathrm{X}$ & - \\
\hline & 89 Ocotea velloziana (Meisn.) Mez & $\mathrm{X}$ & - \\
\hline & 90 Persea pyrifolia (D. Don.) Spreng. & - & $\mathrm{X}$ \\
\hline & 91 Rhodostemenodaphne macrocalyx (Meissn.) Madr. & $\mathrm{X}$ & $\mathrm{X}$ \\
\hline 29 Magnoliaceae & 92 Talauma ovata A. St. Hil. & $\mathrm{X}$ & $\mathrm{X}$ \\
\hline \multirow[t]{2}{*}{30 Malphigiaceae } & 93 Byrsonima ligustrifolia A. St. Hil. & $\mathrm{X}$ & $\mathrm{X}$ \\
\hline & 94 Byrsonima myricifolia Griseb. & - & $\mathrm{X}$ \\
\hline \multirow[t]{8}{*}{31 Melastomataceae } & 95 Miconia cabucu Hoenhe & $\mathrm{X}$ & $\mathrm{X}$ \\
\hline & 96 Miconia cubatanensis Hoenhe & $\mathrm{X}$ & $\mathrm{X}$ \\
\hline & 97 Miconia petropolitana Cogn. & $\mathrm{X}$ & $\mathrm{X}$ \\
\hline & 98 Miconia pusilliflora (DC.) Naudin & $\mathrm{X}$ & - \\
\hline & 99 Miconia sellowiana Naudin & $\mathrm{X}$ & - \\
\hline & 100 Mouriri chamissoana Cogn. & - & $\mathrm{X}$ \\
\hline & 101 Tibouchina pulchra (Cham.)Cogn. & $\mathrm{X}$ & $\mathrm{X}$ \\
\hline & 102 Tibouchina sellowiana Cogn. & $\mathrm{X}$ & - \\
\hline \multirow[t]{2}{*}{32 Meliaceae } & 103 Cabralea canjerana (Vell.) Mart. & $\mathrm{X}$ & $\mathrm{X}$ \\
\hline & 104 Guarea macrophylla Vahl & $\mathrm{X}$ & $\mathrm{X}$ \\
\hline \multirow[t]{4}{*}{33 Mimosaceae } & 105 Inga edulis Mart. & - & $\mathrm{X}$ \\
\hline & 106 Inga laurina (SW.) Willd. & & $\mathrm{X}$ \\
\hline & 107 Inga marginata Willd. & & $\mathrm{X}$ \\
\hline & 108 Inga sellowiana Benth. & & $\mathrm{X}$ \\
\hline
\end{tabular}


Tabela 2. Relação das famílias e espécies amostradas no componente arbóreo da Floresta Ombrófila Densa, no Parque Estadual Carlos Botelho.SP.Brasil, com o emprego do método de quadrantes. Gr1 - Grade 1 e Gr2 - Grade 2

\begin{tabular}{|c|c|c|c|}
\hline Familias & Especies & Gr 1 & Gr 2 \\
\hline & 109 Inga sessilis (Vell.) Mart. & $\mathrm{X}$ & - \\
\hline & 110 Pithecellobium langsdorffi Benth. & $\mathrm{X}$ & $\mathrm{X}$ \\
\hline \multirow[t]{4}{*}{34 Monimiaceae } & 111 Mollinedia elegans Tul. & - & $\mathrm{X}$ \\
\hline & 112 Mollinedia oligantha Perk. & $\mathrm{X}$ & $\mathrm{X}$ \\
\hline & 113 Mollinedia oligotricha Perk. & $\mathrm{X}$ & $\mathrm{X}$ \\
\hline & 114 Mollinedia schottiana (Spreng.) Perk. & $\mathrm{X}$ & $\mathrm{X}$ \\
\hline 35 Moraceae & 115 Sorocea bonplandii (Baill.) Burger Lanj.\&. Boer & $\mathrm{X}$ & $\mathrm{X}$ \\
\hline \multirow[t]{4}{*}{36 Myrsinaceae } & 116 Rapanea ferruginea (Ruiz \& Pav.) Mez & $\mathrm{X}$ & - \\
\hline & 117 Rapanea gardneriana (A. DC.) Mez & $\mathrm{X}$ & $\mathrm{X}$ \\
\hline & 118 Rapanea hermogenesii Jung-Mend. \& Bernacci & $\mathrm{X}$ & $\mathrm{X}$ \\
\hline & 119 Rapanea umbellata (Mart.) Mez & $\mathrm{X}$ & $\mathrm{X}$ \\
\hline \multirow[t]{13}{*}{37 Myrtaceae } & 120 Calycorectes australis Legr. & $\mathrm{X}$ & $\mathrm{X}$ \\
\hline & 121 Calyptranthes lanceolata Berg & - & $\mathrm{X}$ \\
\hline & 122 Calyptranthes lucida DC. & $\mathrm{X}$ & $\mathrm{X}$ \\
\hline & 123 Calyptranthes sp. 1 & - & $\mathrm{X}$ \\
\hline & 124 Calyptranthes sp.2 & $\mathrm{X}$ & $\mathrm{X}$ \\
\hline & 125 Calyptranthes sp.3 & $\mathrm{X}$ & - \\
\hline & 126 Campomanesia guaviroba (DC.) Kiaersk. & $\mathrm{X}$ & $\mathrm{X}$ \\
\hline & 127 Campomanesia sp. & - & $\mathrm{X}$ \\
\hline & 128 Eugenia beaurepairiana (Kiaersk.) Legr. & $\mathrm{X}$ & $\mathrm{X}$ \\
\hline & 129 Eugenia cambucarana Kiaersk & & $\mathrm{X}$ \\
\hline & 130 Eugenia capitulifera Berg & & - \\
\hline & 131 Eugenia cerasiflora Miq. & & $\mathrm{X}$ \\
\hline & 132 Eugenia cereja Legr. & & $\mathrm{X}$ \\
\hline
\end{tabular}


Tabela 2. Relação das famílias e espécies amostradas no componente arbóreo da Floresta Ombrófila Densa, no Parque Estadual Carlos Botelho.SP.Brasil, com o emprego do método de quadrantes. Gr1 - Grade 1 e Gr2 - Grade 2

\begin{tabular}{|c|c|c|c|}
\hline Familias & Especies & Gr 1 & Gr 2 \\
\hline & 133 Eugenia convexinervia Legr. & - & $\mathrm{X}$ \\
\hline & 134 Eugenia copacabanensis Kiaersk. & - & $\mathrm{X}$ \\
\hline & 135 Eugenia cuprea (Berg) Nied. & - & $\mathrm{X}$ \\
\hline & 136 Eugenia florida DC. & - & $\mathrm{X}$ \\
\hline & 137 Eugenia handroana Legr. & $\mathrm{X}$ & $\mathrm{X}$ \\
\hline & 138 Eugenia involucrata DC. & $\mathrm{X}$ & - \\
\hline & 139 Eugenia melanogina ( Legr. ) Sobral & $\mathrm{x}$ & $\mathrm{X}$ \\
\hline & 140 Eugenia mosenii (Kausel) Sobral & $\mathrm{X}$ & $\mathrm{X}$ \\
\hline & 141 Eugenia neoglomerata Sobral & - & $\mathrm{X}$ \\
\hline & 142 Eugenia pruinosa Legr. & - & $\mathrm{X}$ \\
\hline & 143 Eugenia riedeliana Berg & $\mathrm{x}$ & $\mathrm{X}$ \\
\hline & 144 Eugenia sp.1 & $\mathrm{x}$ & $\mathrm{X}$ \\
\hline & 145 Eugenia sp.2 & $\mathrm{X}$ & $\mathrm{X}$ \\
\hline & 146 Eugenia sp.3 & $\mathrm{X}$ & $\mathrm{X}$ \\
\hline & 147 Eugenia sp.4 & $\mathrm{x}$ & - \\
\hline & 148 Eugenia sp.5 & $\mathrm{X}$ & $\mathrm{X}$ \\
\hline & 149 Eugenia sp.6 & - & $\mathrm{X}$ \\
\hline & 150 Eugenia sp.9 & - & $\mathrm{X}$ \\
\hline & 151 Eugenia stictosepala Kiaersk. & $\mathrm{x}$ & $\mathrm{X}$ \\
\hline & 152 Eugenia subavenia Berg & $\mathrm{X}$ & $\mathrm{X}$ \\
\hline & 153 Eugenia umbelliflora Berg & - & $\mathrm{X}$ \\
\hline & 154 Gomidesia anacardiaefolia (Gard.) Berg & - & $\mathrm{X}$ \\
\hline & 155 Gomidesia riedeliana Berg & - & $\mathrm{X}$ \\
\hline & 156 Gomidesia schaueriana Berg & & - \\
\hline & 157 Gomidesia sp. & & - \\
\hline & 158 Gomidesia spectabilis (DC.) Berg & & - \\
\hline & 159 Gomidesia tijucensis ( Kiaersk.) Legr.. & & $\mathrm{X}$ \\
\hline & 160 Marlierea sp.1 & & $\mathrm{x}$ \\
\hline
\end{tabular}


Tabela 2. Relação das famílias e espécies amostradas no componente arbóreo da Floresta Ombrófila Densa, no Parque Estadual Carlos Botelho.SP.Brasil, com o emprego do método de quadrantes. Gr1 - Grade 1 e Gr2 - Grade 2

\begin{tabular}{|c|c|c|c|}
\hline Familias & Especies & Gr 1 & Gr 2 \\
\hline & 161 Marlierea sp.2 & - & $\mathrm{X}$ \\
\hline & 162 Marlierea eugeniopsoides (Legr. \& Kausel) Legr.. & - & $\mathrm{X}$ \\
\hline & 163 Marlierea parviflora Berg & $\mathrm{X}$ & $\mathrm{X}$ \\
\hline & 164 Marlierea reitzii Legr.. & $\mathrm{X}$ & $\mathrm{X}$ \\
\hline & 165 Marlierea tomentosa Cambess. & $\mathrm{X}$ & $\mathrm{X}$ \\
\hline & 166 Myrceugenia campestris ( DC.) Legr. \& Kausel. & - & $\mathrm{X}$ \\
\hline & 167 Myrceugenia glaucescens (Cambess.) Legr. \& Kausel & $\mathrm{X}$ & $\mathrm{X}$ \\
\hline & 168 Myrceugenia kleinii Legr. \& Kausel & $\mathrm{X}$ & $\mathrm{X}$ \\
\hline & 169 Myrceugenia myrcioides (Cambess.) Berg & $\mathrm{X}$ & $\mathrm{X}$ \\
\hline & 170 Myrceugenia sp.1 & $\mathrm{X}$ & - \\
\hline & 171 Myrcia aff. glabra (Berg) Legr. & $\mathrm{X}$ & - \\
\hline & 172 Myrcia aff. macrocarpa Barb. Rodr. & - & $\mathrm{X}$ \\
\hline & 173 Myrcia aff.obtecta (Berg) Kiaersk. & $\mathrm{X}$ & - \\
\hline & 174 Myrcia fallax (Rich.) DC. & $\mathrm{X}$ & $\mathrm{X}$ \\
\hline & 175 Myrcia hatschbachii Legr. & - & $\mathrm{X}$ \\
\hline & 176 Myrcia heringii Legr. & $\mathrm{x}$ & - \\
\hline & 177 Myrcia pubipetala Miq. & $\mathrm{X}$ & $\mathrm{X}$ \\
\hline & 178 Myrcia rostrata DC. & - & $\mathrm{X}$ \\
\hline & 179 Myrcia sp.1 & $\mathrm{X}$ & - \\
\hline & 180 Myrcia sp.2 & - & $\mathrm{X}$ \\
\hline & 181 Myrcia tenuivenosa Kiaersk & - & $\mathrm{X}$ \\
\hline & 182 Myrciaria sp. & - & $\mathrm{X}$ \\
\hline & 183 Myrciaria sp.1 & & $\mathrm{X}$ \\
\hline & 184 Myrciaria sp.2 & & - \\
\hline & 185 Myrciaria sp.3 & & $\mathrm{X}$ \\
\hline & 186 Myrtaceae sp.1 & & $\mathrm{X}$ \\
\hline & 187 Myrtaceae sp.2 & & $\mathrm{X}$ \\
\hline & 188 Myrtaceae sp.3 & & $\mathrm{X}$ \\
\hline
\end{tabular}


Tabela 2. Relação das famílias e espécies amostradas no componente arbóreo da Floresta Ombrófila Densa, no Parque Estadual Carlos Botelho.SP.Brasil, com o emprego do método de quadrantes. Gr1 - Grade 1 e Gr2 - Grade 2

\begin{tabular}{|c|c|c|c|}
\hline Familias & Especies & Gr 1 & Gr 2 \\
\hline & 189 Myrtaceae sp.4 & $\mathrm{X}$ & $\mathrm{X}$ \\
\hline & 190 Neomitranthes glomerata (Legr.) Legr. & $\mathrm{X}$ & $\mathrm{X}$ \\
\hline & 191 Plinia complanata Kawas. \& Holst. & $\mathrm{X}$ & - \\
\hline & 192 Plinia pauciflora Kawas. \& Holst & - & $\mathrm{X}$ \\
\hline & 193 Psydium cf. myrtoides Berg & - & $\mathrm{X}$ \\
\hline & 194 Siphoneugena densiflora Berg & $\mathrm{X}$ & $\mathrm{X}$ \\
\hline 38 Nyctaginaceae & 195 Guapira opposita (Vell.) Reitz & $\mathrm{x}$ & $\mathrm{X}$ \\
\hline \multirow[t]{2}{*}{39 Ochnaceae } & 196 Ouratea multiflora Engl. & - & $\mathrm{X}$ \\
\hline & 197 Ouratea parviflora Baill. & $\mathrm{X}$ & $\mathrm{X}$ \\
\hline 40 Olacaceae & 198 Heisteria silvianii Schw. & $\mathrm{X}$ & $\mathrm{X}$ \\
\hline 41 Oleaceae & 199 Chionanthus filiformis (Vell.) Green & $\mathrm{X}$ & $\mathrm{X}$ \\
\hline \multirow[t]{2}{*}{42 Polygonaceae } & 200 Coccoloba latifolia Lam. & $\mathrm{X}$ & $\mathrm{X}$ \\
\hline & 201 Coccoloba sp.1 & - & $\mathrm{X}$ \\
\hline \multirow[t]{3}{*}{43 Proteaceae } & 202 Roupala brasiliensis $\mathrm{Kl}$. & - & $\mathrm{X}$ \\
\hline & 203 Roupala sculpta Sleumer & - & $\mathrm{X}$ \\
\hline & 204 Roupala sp. & - & $\mathrm{X}$ \\
\hline 44 Quiinaceae & 205 Quiina magallano-gomezii Schw. & $\mathrm{x}$ & $\mathrm{X}$ \\
\hline 45 Rosaceae & 206 Prunus myrtifolia ( L.) Urban & $\mathrm{X}$ & $\mathrm{X}$ \\
\hline 46 Rubiaceae & 207 Alibertia myrciifolia Schum. & $\mathrm{X}$ & $\mathrm{X}$ \\
\hline
\end{tabular}


Tabela 2. Relação das famílias e espécies amostradas no componente arbóreo da Floresta Ombrófila Densa, no Parque Estadual Carlos Botelho.SP.Brasil, com o emprego do método de quadrantes. Gr1 - Grade 1 e Gr2 - Grade 2

\begin{tabular}{|c|c|c|c|}
\hline Familias & Especies & Gr 1 & Gr 2 \\
\hline & 208 Alibertia sp. & $\mathrm{x}$ & $\mathrm{X}$ \\
\hline & 209 Alseis floribunda Schott & $\mathrm{x}$ & $\mathrm{X}$ \\
\hline & 210 Amaioua $\quad$ ntermédia Mart. & $\mathrm{x}$ & $\mathrm{X}$ \\
\hline & 211 Bathysa australis (St. Hil.) Benth. \& Hook. & $\mathrm{X}$ & $\mathrm{X}$ \\
\hline & 212 Chomelia catharinae (Smith. \& Downs.) Steyerm. & - & $\mathrm{X}$ \\
\hline & 213 Coussarea sp. & $\mathrm{X}$ & $\mathrm{X}$ \\
\hline & 214 Faramea montevidensis (Cham.\& Schltdl.) DC. & - & $\mathrm{X}$ \\
\hline & 215 Ixora burchelliana Müll. Arg. & $\mathrm{x}$ & $\mathrm{X}$ \\
\hline & 216 Posoqueria acutifolia Mart. & $\mathrm{X}$ & $\mathrm{X}$ \\
\hline & 217 Psychotria suterella Müll. Arg. & $\mathrm{x}$ & $\mathrm{X}$ \\
\hline & 218 Psychotria velloziana Benth. & $\mathrm{X}$ & $\mathrm{X}$ \\
\hline & 219 Rubiaceae sp.1 & - & $\mathrm{X}$ \\
\hline & 220 Rudgea jasminoides (Cham.) Müell. Arg. & $\mathrm{X}$ & $\mathrm{X}$ \\
\hline \multirow[t]{3}{*}{47 Rutaceae } & 221 Esenbeckia grandiflora Mart. & $\mathrm{x}$ & $\mathrm{X}$ \\
\hline & 222 Zanthoxylum fagara (L.) Sarg. & - & $\mathrm{X}$ \\
\hline & 223 Zanthoxylum rhoifolium Lam. & $\mathrm{X}$ & - \\
\hline \multirow[t]{2}{*}{48 Sabiaceae } & 224 Meliosma selowii Urban. & $\mathrm{x}$ & $\mathrm{X}$ \\
\hline & 225 Meliosma sinuata Urban. & $\mathrm{X}$ & $\mathrm{X}$ \\
\hline \multirow[t]{6}{*}{49 Sapindaceae } & 226 Allophylus edulis (A. St.Hil., Camb. \& A. Juss.) Radlk. & $\mathrm{x}$ & - \\
\hline & 227 Allophylus petiolulatus Radlk & - & $\mathrm{X}$ \\
\hline & 228 Cupania oblongifolia Mart. & $\mathrm{x}$ & $\mathrm{X}$ \\
\hline & 229 Cupania vernalis Cambess. & $\mathrm{X}$ & $\mathrm{X}$ \\
\hline & 230 Matayba guianensis Aubl. & $\mathrm{x}$ & $\mathrm{X}$ \\
\hline & 231 Matayba juglandifolia Radlk. & $\mathrm{x}$ & $\mathrm{X}$ \\
\hline
\end{tabular}


Tabela 2. Relação das famílias e espécies amostradas no componente arbóreo da Floresta Ombrófila Densa, no Parque Estadual Carlos Botelho.SP.Brasil, com o emprego do método de quadrantes. Gr1 - Grade 1 e Gr2 - Grade 2

\begin{tabular}{|c|c|c|c|}
\hline Familias & Especies & Gr 1 & Gr 2 \\
\hline \multirow[t]{9}{*}{50 Sapotaceae } & 232 Chrysophyllum flexuosum Mart. & - & $\mathrm{X}$ \\
\hline & 233 Chrysophyllum inornatum Mart. & - & $\mathrm{X}$ \\
\hline & 234 Chrysophyllum viride Mart. \& Eichl. & $\mathrm{x}$ & $\mathrm{X}$ \\
\hline & 235 Diploon cuspidatum (Hoehne) Cronquist & $\mathrm{X}$ & $\mathrm{X}$ \\
\hline & $\begin{array}{l}236 \text { Ecclinusa ramiflora Mart. } \\
\text { Micropholis crassipedicellata (Mart. \& Eichler ex Miq.) }\end{array}$ & $\mathrm{x}$ & $\mathrm{X}$ \\
\hline & 237 Pierre & $\mathrm{x}$ & - \\
\hline & 238 Pouteria bullata (Moore) Baehni & $\mathrm{x}$ & $\mathrm{X}$ \\
\hline & 239 Pouteria caimito (Ruiz \& Pav.) Radlk. & $\mathrm{x}$ & $\mathrm{X}$ \\
\hline & 240 Pouteria macrophylla (Lam.) Eyma & - & $\mathrm{X}$ \\
\hline \multirow[t]{3}{*}{51 Solanaceae } & 241 Solanum argenteum Dunal & - & $\mathrm{X}$ \\
\hline & 242 Solanum cf. rufescens Sendttn. & - & $\mathrm{X}$ \\
\hline & 243 Solanum pseudoquina ${ }^{\text {a }}$ St. Hil. & $\mathrm{x}$ & - \\
\hline \multirow[t]{2}{*}{52 Symplocaceae } & 244 Symplocos falcata Brand & $\mathrm{x}$ & - \\
\hline & 245 Symplocos variabilis Mat & $\mathrm{x}$ & $\mathrm{X}$ \\
\hline 53 Theaceae & 246 Gordonia fruticosa (Schrad) Keing. & - & $\mathrm{X}$ \\
\hline \multirow[t]{2}{*}{54 Verbenaceae } & 247 Aegiphila brachiata Vell. & - & $\mathrm{X}$ \\
\hline & 248 Aegiphila sellowiana Cham. & $\mathrm{x}$ & $\mathrm{X}$ \\
\hline 55 Vochysiaceae & 249 Vochysia sp. 1 & $\mathrm{x}$ & - \\
\hline 56 Winteraceae & 250 Drimys winteri Forst. \& Forst. & $\mathrm{X}$ & $\mathrm{X}$ \\
\hline
\end{tabular}




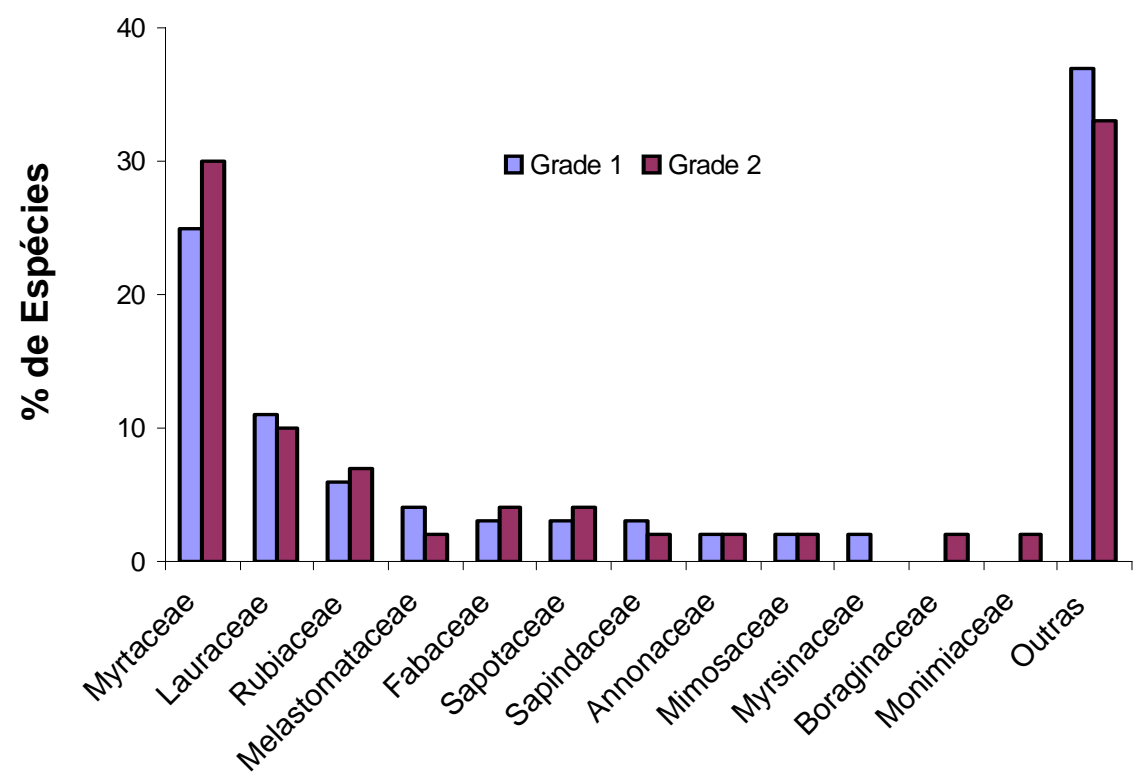

Figura 11 - Distribuição, em porcentagem das espécies por família, amostrada através do emprego do método de quadrantes no levantamento do componente arbóreo na Floresta Ombrófila Densa (Grade 1 e Grade 2) no Parque Estadual Carlos Botelho. SP. Brasil.

\subsection{Relascopia}

\subsubsection{Grade 1}

Na Grade 1, o método de relascopia amostrou 638 indivíduos, registrando 41 famílias e 155 espécies arbóreas. Destas, 35 foram identificadas apenas em nível de gênero e 3 foram identificadas em nível de família (Tabela 3).

Dez famílias foram responsáveis pela amostragem de 68\% do total das espécies: Myrtaceae (24\%) com 37 espécies, Lauraceae (12\%) com 19 espécies, Fabaceae (6\%) com 10 espécies, Rubiaceae e Sapotaceae (5\%) com 8 espécies cada, Melastomataceae (4\%) com 6 espécies, Annonaceae, Aquifoliaceae, Caesalpinaceae e Euphorbiaceae (3\%) com 4 espécies cada. As 31 famílias restantes amostraram 32\% do 
total das espécies, sendo que 16 famílias foram representadas por apenas 1 indivíduo cada (Figura 12)

\subsubsection{Grade 2}

Na Grade 2, o método de relascopia amostrou 578 indivíduos, sendo 2 representados por árvores mortas em pé.

Foram registradas 47 famílias e 157 espécies arbóreas , sendo 18 espécies identificadas em nível de gênero, 5 espécies em nível de família e 1 determinada como morfoespécie (Tabela 3).

As famílias com maior riqueza de espécies são: Myrtaceae (25\%) com 40 espécies, Lauraceae (12\%) com 19 espécies, Rubiaceae (8\%) com 12 espécies, Sapotaceae (6\%) com 9 espécies, Fabaceae (5\%) com 8 espécies. Estas 5 famílias foram responsáveis pela amostragem de 56\% do total de espécies. Ficando as 42 famílias restantes com 44\% (Figura 12). 
Tabela 3. Relação das famílias e espécies amostradas no componente arbóreo na Floresta Ombrófila Densa no Parque Estadual Carlos Botelho. SP. Brasil, com o emprego do método de relascopia. Gr1 - Grade 1 e Gr2 - Grade 2

\begin{tabular}{|c|c|c|c|c|c|}
\hline & Famílias & & Espécies & Gr 1 & Gr 2 \\
\hline 1 & Anacardiaceae & 1 & Tapirira guianensis Aubl. & $x$ & - \\
\hline \multirow[t]{3}{*}{2} & Annonaceae & 2 & Duguetia lanceolata A.St. Hil. & - & $x$ \\
\hline & & 3 & Guatteria australis A. St. Hil. & $x$ & - \\
\hline & & 4 & Rollinia parviflora A. St. Hil. & $x$ & - \\
\hline & & 5 & Rollinia sericea (R. E. Fries) R. E. Fries & - & $x$ \\
\hline & & 6 & Xylopia langsdorfiana St. Hil. \& Tul. & $x$ & $x$ \\
\hline & & 7 & Xylopia sp. & $x$ & - \\
\hline \multirow[t]{2}{*}{3} & Apocynaceae & 8 & Aspidosperma olivaceum Müll. Arg. & $x$ & - \\
\hline & & 9 & Aspidosperma sp & $x$ & - \\
\hline \multirow[t]{4}{*}{4} & Aquifoliaceae & 10 & Ilex taubertiana Loes. & $x$ & $x$ \\
\hline & & 11 & Ilex amara (Vell.) Loes. & $x$ & $x$ \\
\hline & & 12 & Ilex paraguariensis A. St. Hil. & $x$ & $x$ \\
\hline & & 13 & Ilex theazans Mat. & $x$ & - \\
\hline \multirow[t]{2}{*}{5} & Araliaceae & 14 & Didymopanax navarroi A Samp. & $x$ & $x$ \\
\hline & & 15 & Didymopanax sp. & $x$ & - \\
\hline \multirow[t]{2}{*}{6} & Arecaceae & 16 & Attalea dubia (Mart.) Burret & $x$ & - \\
\hline & & 17 & Euterpe edulis Mart. & $x$ & $x$ \\
\hline \multirow[t]{3}{*}{7} & Asteraceae & 18 & Piptocarpha axillaris (Less.) Baker & - & $x$ \\
\hline & & 19 & Vernonia puberula Less. & - & $x$ \\
\hline & & 20 & Vernonia quinqueflora Less. & - & $x$ \\
\hline
\end{tabular}


Tabela 3. Relação das famílias e espécies amostradas no componente arbóreo na Floresta Ombrófila Densa no Parque Estadual Carlos Botelho. SP. Brasil, com o emprego do método de relascopia. Gr1 - Grade 1 e Gr2 - Grade 2

\section{Famílias}

Espécies

Gr 1 Gr 2

8 Bignoniaceae

21 Jacaranda puberula Cham.

$x$

9 Boraginaceae

22 Cordia sellowiana Cham.

$x \quad x$

23 Cordia sp.

X -

24 Cordia sp. 1

- $\quad x$

25 Cordia trichotoma (Vell.) Arrab. Ex Steud.

10 Burseraceae

26 Protium hepatphyllum (Aubl.) March.

$x \quad x$

27 Protium sp.

11 Caesalpiniaceae

28 Copaifera langsdorffii Desf.

X $\quad x$

29 Copaifera trapezifolia Hayne

$\mathrm{X} \quad-$

30 Sclerolobium denudatum Vog.

X $\quad x$

31 Sclerolobium sp.

12 Canellaceae

32 Capsicodendron dinisii (Schw.) Occh.

X $\quad X$

13 Cecropiaceae

33 Coussapoa microcarpa (Schott) Rizzini

$-\quad x$

14 Celastraceae

34 Maytenus robusta Reiss.

15 Chrysobalanaceae

35 Hirtella hebeclada Moric. Ex DC.

36 Parinari excelsa Sabine

$x \quad x$

$x \quad x$

16 Clethraceae

37 Clethra scabra Pers.

$-\quad x$

17 Clusiaceae

38 Clusia criuva Cambess.

- $\quad$ X 
Tabela 3. Relação das famílias e espécies amostradas no componente arbóreo na Floresta Ombrófila Densa no Parque Estadual Carlos Botelho. SP. Brasil, com o emprego do método de relascopia. Gr1 - Grade 1 e Gr2 - Grade 2

42 Weinmannia discolor Gardner

43 Weinmannia paulliniifolia Pohl

44 Weinmannia sp.

47 Hyeronima alchorneoides Allem.

48 Hyeronima sp.

49 Pera glabrata (Scott) Poep. Ex Baill.

50 Sapium glandulatum (Vell.) Pax

52 Dahlstedtia pinnata (Benth.) Malme

53 Dalbergia brasiliensis Vog.

54 Dalbergia frutescens (Vell.) Britton

55 Fabaceae 1

$\begin{array}{ll}x & x \\ x & x \\ x & x \\ x & x \\ x & - \\ x & x \\ x & - \\ x & x \\ - & x \\ x & x\end{array}$

56 Myrocarpus frondosus Allem.

57 Myrocarpus sp.

58 Ormosia dasycarpa Jacks.

59 Platymiscium floribundum Vogel

X $\quad X$ 
Tabela 3. Relação das famílias e espécies amostradas no componente arbóreo na Floresta Ombrófila Densa no Parque Estadual Carlos Botelho. SP. Brasil, com o emprego do método de relascopia. Gr1 - Grade 1 e Gr2 - Grade 2

$X$

23 Flacourtiaceae

62 Casearia decandra Jacq.

63 Casearia obliqua Spreng.

64 Casearia sylvestris Sw.

65 Vantanea campacta (Schnzl.) Cuatr.

66 Citronella paniculata (Mart.) Howard

26 Morfoespécie

67 Morfoespécie 3

68 Aiouea acaradomatifera Koest.

69 Aniba viridis Mez

70 Cinnamomum sp.

71 Cinnamomum sp.1

72 Cryptocarya moschata Nees \& Mart.

73 Cryptocarya sp.

74 Cryptocarya sp. 1

75 Endlicheria paniculata (Spreng.) Macbr.

76 Lauraceae sp.3

77 Nectandra aff. membranacea (SW.) Griseb.

78 Nectandra oppositfolia Nees \& Mart.

79 Ocotea aciphylla (Nees) Mez

80 Ocotea bicolor Vattimo

81 Ocotea bragai Coe-Teix.

82 Ocotea catharinensis Mez
$\mathrm{X} \quad \mathrm{X}$

X X

- $\quad X$

X $\quad-$

X $\quad X$

X

X $\quad X$

X $\quad X$

X X

- X

X X

X $\quad X$

X -

- X

- X

- X

X -

X X

X X

- X

X X 
Tabela 3. Relação das famílias e espécies amostradas no componente arbóreo na Floresta Ombrófila Densa no Parque Estadual Carlos Botelho. SP. Brasil, com o emprego do método de relascopia. Gr1 - Grade 1 e Gr2 - Grade 2

83 Ocotea dispersa (Nees) Mez

84 Ocotea elegans Mez

85 Ocotea mosenii Mez

86 Ocotea dorífera (Vell.) Rohwer

87 Ocotea porosa (Nees \& Mart.) Barroso

88 Ocotea pulchra Vatt.

89 Ocotea silvestris Vatt.

90 Ocotea sp.

91 Ocotea sp.1

92 Persea pyrifolia (D. Don.) Spreng.

93 Persea sp.1

94 Rhodostemenodaphne macrocalyx (Meissn.) Madr.

95 Talauma ovata A. St. Hil.

29 Malphigiaceae

96 Byrsonima ligustrifolia St. Hil.

97 Byrsonima myricifolia Griseb.

98 Byrsonima sp.

30 Melastomataceae

99 Miconia cabucu Hoenhe

100 Miconia petropolitana Cogn.

101 Miconia sp.

102 Miconia sp.1

103 Mouriri chamissoana Cogn.

104 Tibouchina pulchra (Cham.) Cogn.

105 Tibouchina sellowiana Cogn.

106 Tibouchina sp.
X $\quad X$

$\begin{array}{cc}x & - \\ x & x \\ x & x \\ x & - \\ - & x \\ x & - \\ x & x \\ x & - \\ - & x \\ x & - \\ x & - \\ - & x\end{array}$

X $\quad X$

$\mathrm{X}$

$x$

$X$

$-\quad x$

X -

X -

$-\quad x$

$x \quad x$

$x-$

X - 
Tabela 3. Relação das famílias e espécies amostradas no componente arbóreo na Floresta Ombrófila Densa no Parque Estadual Carlos Botelho. SP. Brasil, com o emprego do método de relascopia. Gr1 - Grade 1 e Gr2 - Grade 2

\begin{tabular}{|c|c|c|c|}
\hline Famílias & Espécies & Gr 1 & Gr 2 \\
\hline \multirow[t]{3}{*}{31 Meliaceae } & 107 Cabralea canjerana (Vell.) Mart. & $x$ & $x$ \\
\hline & 108 Cedrella fissilis Vell. & - & $x$ \\
\hline & 109 Trichilia hirta L. & - & $x$ \\
\hline \multirow[t]{5}{*}{32 Mimosaceae } & 110 Inga marginata Willd. & - & $x$ \\
\hline & 111 Inga sellowiana Benth. & $x$ & $x$ \\
\hline & 112 Inga sessilis (Vell.) Mart. & $x$ & - \\
\hline & 113 Pithecellobium langsdorffi Benth. & - & $\mathrm{x}$ \\
\hline & 114 Pithecellobium sp. & $\mathrm{x}$ & - \\
\hline \multirow[t]{2}{*}{33 Monimiaceae } & 115 Mollinedia oligantha Perk. & $x$ & $x$ \\
\hline & 116 Mollinedia schottiana (Spreng.) Perk. & $\mathrm{x}$ & $\mathrm{x}$ \\
\hline \multirow[t]{2}{*}{34 Moraceae } & 117 Ficus sp. & - & $x$ \\
\hline & 118 Sorocea bonplandii (Baill.) Burger Lanj. \&. Boer & - & $\mathrm{x}$ \\
\hline 35 Myrsinaceae & 119 Rapanea umbellata (Mart.) Mez & $\mathrm{x}$ & $x$ \\
\hline \multirow[t]{9}{*}{36 Myrtaceae } & 120 Calycorectes australis Legr. & $\mathrm{x}$ & $x$ \\
\hline & 121 Calyptranthes sp.2 & $x$ & $x$ \\
\hline & 122 Campomanesia guaviroba (DC.) Kiaersk. & - & $x$ \\
\hline & 123 Campomanesia sp. & $x$ & - \\
\hline & 124 Eugenia beaurepairiana (Kiaersk.) Legr. & $\mathrm{x}$ & - \\
\hline & 125 Eugenia cambucarana Kiaersk & $\mathrm{x}$ & $x$ \\
\hline & 126 Eugenia capitulifera Berg & $x$ & $x$ \\
\hline & 127 Eugenia cerasiflora Miq. & $\mathrm{x}$ & $x$ \\
\hline & 128 Eugenia copacabanensis Kiaersk. & - & $\mathrm{x}$ \\
\hline
\end{tabular}


Tabela 3. Relação das famílias e espécies amostradas no componente arbóreo na Floresta Ombrófila Densa no Parque Estadual Carlos Botelho. SP. Brasil, com o emprego do método de relascopia. Gr1 - Grade 1 e Gr2 - Grade 2

129 Eugenia cuprea (Berg) Nied.

130 Eugenia florida DC.

131 Eugenia melanogina ( Legr. ) Sobral

132 Eugenia mosenii (Kausel) Sobral

133 Eugenia neoglomerata Sobral

134 Eugenia pruinosa Legr.

135 Eugenia riedeliana Berg

136 Eugenia sp.

137 Eugenia sp.1

138 Eugenia sp.2

139 Eugenia sp.3

140 Eugenia sp.4

141 Eugenia sp.6

142 Eugenia stictosepala Kiaersk.

143 Eugenia subavenia Berg

144 Gomidesia anacardiaefolia (Gard.) Berg

145 Gomidesia riedeliana Berg

146 Gomidesia schaueriana Berg

147 Gomidesia spectabilis (DC.) Berg

148 Gomidesia tijucensis ( Kiaersk.) Legr..

149 Marlierea sp.1

150 Marlierea parviflora Berg

151 Marlierea reitzii Legr..

152 Marlierea tomentosa Cambess.

153 Myrceugenia glaucescens (Cambess.) Legr. \& Kausel 
Tabela 3. Relação das famílias e espécies amostradas no componente arbóreo na Floresta Ombrófila Densa no Parque Estadual Carlos Botelho. SP. Brasil, com o emprego do método de relascopia. Gr1 - Grade 1 e Gr2 - Grade 2

\begin{tabular}{|c|c|c|c|}
\hline Famílias & Espécies & Gr 1 & Gr 2 \\
\hline & 156 Myrceugenia sp.1 & $x$ & - \\
\hline & 157 Myrcia aff. Glabra (Berg) Legr. & $x$ & - \\
\hline & 158 Myrcia aff. Macrocarpa Barb. Rodr. & - & $x$ \\
\hline & 159 Myrcia aff.obtecta (Berg) Kiaersk. & $x$ & - \\
\hline & 160 Myrcia fallax (Rich.) DC. & $x$ & - \\
\hline & 161 Myrcia hatschbachii Legr. & $x$ & $x$ \\
\hline & 162 Myrcia pubipetala Miq. & $x$ & - \\
\hline & 163 Myrcia sp.1 & $x$ & - \\
\hline & 164 Myrcia sp.2 & - & $x$ \\
\hline & 165 Myrcia sp.6 & $x$ & - \\
\hline & 166 Myrcia tenuivenosa Kiaersk & - & $x$ \\
\hline & 167 Myrciaria sp.2 & - & $x$ \\
\hline & 168 Myrciaria sp.3 & - & $x$ \\
\hline & 169 Myrtaceae sp.1 & $x$ & $x$ \\
\hline & 170 Myrtaceae sp.2 & - & $x$ \\
\hline & 171 Myrtaceae sp.3 & $x$ & - \\
\hline & 172 Myrtaceae sp.4 & - & $\mathrm{x}$ \\
\hline & 173 Neomitranthes glomerata (Legr.) Legr. & - & $x$ \\
\hline & 174 Pimenta pseudocaryophyllus (Gomes) Landrum & - & $x$ \\
\hline & 175 Plinia pauciflora Kawas. \& Holst & $x$ & $x$ \\
\hline & 176 Psydium cf. myrtoides Berg & $x$ & - \\
\hline & 177 Siphoneugena densiflora Berg & $x$ & $x$ \\
\hline & 178 Siphoneugena sp. & $x$ & - \\
\hline 37 Nyctaginaceae & 179 Guapira opposita (Vell.) Reitz & $x$ & $x$ \\
\hline 38 Ochnaceae & 180 Ouratea parviflora Baill. & - & $x$ \\
\hline
\end{tabular}


Tabela 3. Relação das famílias e espécies amostradas no componente arbóreo na Floresta Ombrófila Densa no Parque Estadual Carlos Botelho. SP. Brasil, com o emprego do método de relascopia. Gr1 - Grade 1 e Gr2 - Grade 2

39 Olacaceae

40 Oleaceae

41 Opiliaceae

42 Polygonaceae

43 Proteaceae

44 Rosaceae

45 Rubiaceae
181 Heisteria silvianii Schw.

182 Chionanthus filiformis (Vell.) Green

183 Chionanthus sp.

184 Agonandra excelsa Griseb.

185 Coccoloba sp.1

186 Roupala brasiliensis KI.

187 Prunus myrtifolia (L.) Urban

188 Alibertia myrciifolia Schum.

189 Alibertia sp.

190 Alseis floribunda Schott

191 Amaioua guianensis Aubl.

192 Amaioua ntermédia Mart.

193 Bathysa australis (St. Hil.) Benth. \& Hook.

194 Coussarea sp.

195 Faramea montevidensis (Cham.\& Schltdl.) DC.

196 Ixora burchelliana Müll. Arg.

197 Posoqueria acutifolia Mart.

198 Psychotria velloziana Benth.

199 Rubiaceae sp.1

200 Rudgea jasminoides (Cham.) Müell. Arg.

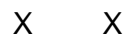

$\mathrm{X} \quad \mathrm{x}$

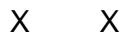

X -

x

$-\quad x$

$-\quad x$

$x \quad x$

X $\quad X$

X $\quad x$

$-\quad x$

$-\quad x$

$x \quad x$

X $\quad x$

$x \quad x$

$-\quad x$

X -

X $\quad X$

$x \quad x$

$-\quad X$

$-\quad x$ 
Tabela 3. Relação das famílias e espécies amostradas no componente arbóreo na Floresta Ombrófila Densa no Parque Estadual Carlos Botelho. SP. Brasil, com o emprego do método de relascopia. Gr1 - Grade 1 e Gr2 - Grade 2

46 Rutaceae

47 Sabiaceae

48 Sapindaceae

49 Sapotaceae

50 Solanaceae
201 Esenbeckia grandiflora Mart.

202 Esenbeckia sp.

203 Meliosma selowii Urban.

204 Meliosma sinuata Urban.

205 Cupania oblongifolia Mart.

206 Cupania vernalis Cambess.

207 Matayba guianensis Aubl.

208 Matayba juglandifolia Radlk.

209 Chrysophyllum flexuosum Mart.

210 Chrysophyllum inornatum Mart.

211 Chrysophyllum sp.

212 Chrysophyllum viride Mart. \& Eichl.

213 Diploon cuspidatum (Hoehne) Cronquist

214 Ecclinusa ramiflora Mart.

215 Micropholis crassipedicellata (Mart. \& Eichler ex Miq.) Pierre

216 Micropholis sp.

217 Pouteria bullata (Moore) Baehni

218 Pouteria caimito (Ruiz \& Pav.) Radlk.

219 Pouteria psammophila (Mart.) Radlk.

220 Pouteria sp

221 Solanum excelsum Salisb.
X

$x$

$\begin{array}{ll}- & X \\ x & -\end{array}$

- $\quad X$

X

X $\mathrm{X}$

X $\mathrm{X}$

$\begin{array}{ll}- & x \\ - & x \\ x & - \\ x & x \\ x & x \\ x & x \\ x & - \\ x & - \\ x & x \\ x & x \\ - & x \\ - & x\end{array}$

x 
Tabela 3. Relação das famílias e espécies amostradas no componente arbóreo na Floresta Ombrófila Densa no Parque Estadual Carlos Botelho. SP. Brasil, com o emprego do método de relascopia. Gr1 - Grade 1 e Gr2 - Grade 2

51 Symplocaceae 222 Symplocos celastrinea Mart. ex Miq.

223 Symplocos falcata Brand

X -

224 Symplocos variabilis Mat

$\mathrm{X} \quad \mathrm{X}$

$x \quad x$

52 Verbenaceae

225 Aegiphila sellowiana Cham.

- $\quad X$

53 Vochysiaceae

226 Vochysia sp. 1

$x$ 


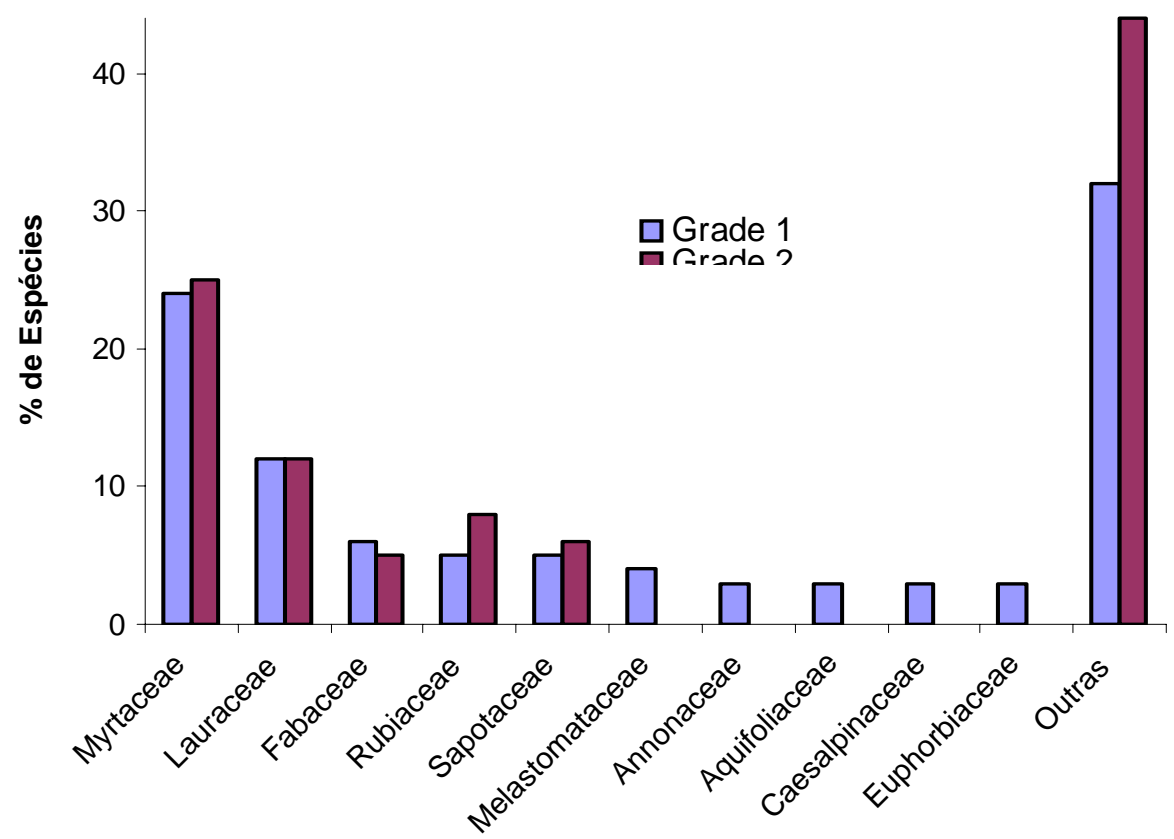

Figura 12 - Distribuição, em porcentagem das espécies por família, amostrada através do emprego do método de relascopia no levantamento do componente arbóreo na Floresta Ombrófila Densa (Grade 1 e Grade 2) no Parque Estadual Carlos Botelho.SP.Brasil

Os dados apresentados na Tabela 1 mostram que no método de parcelas, algumas famílias foram amostradas apenas na Grade 1 e outras na Grade 2. Assim as famílias Bombacaceae, Lacistemataceae, Opiliaceae, Simaroubaceae, Theaceae, mais o grupo de morfoespécies, ocorrem apenas na Grade 2, enquanto que as famílias Lecytidaceae, Podocarpaceae, Styracaceae e Vochysiaceae só ocorrem na Grade 1.

Das famílias amostradas pelo método de quadrantes, Anacardiaceae, Apocynaceae e Vochysiaceae estavam presentes apenas na Grade 1, enquanto que Hipocrateaceae e a Morfoespécie 3, ocorreram apenas na Grade 2 (Tabelas 2).

Dentre os três métodos empregados, o método de relascopia foi o que apresentou a maior heterogeneidade na amostragem em nível de família entre as duas 
áreas estudadas. Na Tabela 3, observamos que as famílias Anacardiaceae, Apocynaceae,. Elaeocarpaceae, Rutaceae, Solanaceae, Vochysiaceae e Wintteraceae foram amostradas apenas na Grade 1, e as famílias Asteraceae, Bignoniaceae, Cecropiaceae, Clethraceae, Clusiaceae, Combretaceae, Moraceae, Ochinaceae, Opiliaceae, Polygonaceae, Proteaceae e a Morfoespécie 3, presentes na Grade 2.

Considerando os três métodos de amostragem (parcelas, quadrantes e relascopia), observamos que das 65 famílias amostradas (Anexo B), 5 famílias não tiveram ocorrência comum nas duas grades de amostragem. Estas famílias foram representadas na amostragem por apenas uma espécie cada.

Ocorreram apenas na Grade 1 as famílias Lecytidaceae (Cariniana estrellensis) , Podocarpaceae (Podocarpus sellowii) e Styracaceae (Styrax acuminatus), e na Grade 2 as famílias Bombacaceae (Quararibea turbinata) e Simaroubaceae (Picramnia sp.). Com exceção de Lecytidaceae representado por Cariniana estrellensis, as quatro famílias restantes não foram amostradas, até o presente, nos trabalhos desenvolvidos na área por Custodio Filho et al. (1992), Dias (1993), Negreiros et al. (1995), Dias et al. (1995) e Custodio Filho (2002).

A espécie Quararibea turbinata, representante da família Bombacaceae, foi denominada por Mantovani (1993) como exclusiva da Floresta Ombrófila Densa, sendo espécie típica de sub-bosque.

Nas duas áreas de amostragem, 15 famílias se destacaram por estarem sempre entre aquelas com o maior número de espécies, independente do método de amostragem empregado (Tabela 4). As famílias Myrtaceae, Lauraceae, Fabaceae e Sapotaceae estavam presentes entre as dez famílias com maior riqueza de espécies, para os três métodos de amostragem empregados (parcelas, quadrantes e relascopia). Estas famílias estão entre as que apresentam maior riqueza de espécie, na maioria dos trabalhos realizados na Encosta Atlântica, como registrado em (Mantovani, 1993, Dias et al 1995, Ivanauska 2000, Custodio Filho 2002 e Aguiar 2004). 
Nestas famílias, com exceção de Fabaceae, houve a dominância de um ou mais gêneros com relação ao número de espécies amostradas. Na família Myrtaceae, os gêneros mais expressivos foram Eugenia e Myrcia; em Lauraceae houve maior expressividade do gênero Ocotea e em Sapotaceae os gêneros com maior número de espécies foram Pouteria e Chrysophillum. Estes resultados são similares aos encontrados por Guedes-Bruni (1988), em levantamento da vegetação efetuado em 6 áreas distribuídas ao longo de um gradiente altitudinal da Encosta Atlântica no Estado do Rio de Janeiro.

Tabela 4. Relação das famílias com maior riqueza de espécies amostrada por três métodos de amostragem (parcelas, quadrantes e relascopia) na Floresta Ombrófila Densa (Grade 1 e Grade 2) - Parque Estadual Carlos Botelho.SP.Brasil.

\begin{tabular}{lcccccc}
\hline Famílias & \multicolumn{7}{c}{ Par-G1 } & Qua-G1 Rel-G1 & Par-G2 & Qua-G2 & Rel-G2 \\
\hline Myrtaceae & 62 & 44 & 37 & 91 & 62 & 40 \\
Lauraceae & 39 & 20 & 19 & 43 & 20 & 19 \\
Rubiaceae & 13 & 11 & & 25 & 14 & 12 \\
Fabaceae & 10 & 6 & 10 & 13 & 8 & 8 \\
Sapotaceae & 6 & 6 & 8 & 11 & 8 & 9 \\
Sapindaceae & 6 & 5 & 8 & 10 & - & - \\
Melastomataceae & 12 & 7 & 6 & 9 & 5 & - \\
Myrsinaceae & 5 & 4 & - & 8 & - & - \\
Mimosaceae & 5 & 4 & - & 7 & 5 & - \\
Annonaceae & - & 4 & 4 & 7 & 4 & - \\
Aquifoliaceae & - & - & 4 & -- & - & - \\
Caesalpinaceae & - & - & 4 & - & - & - \\
Euphorbiaceae & - & - & 4 & - & - & - \\
Monimiaceae & 5 & - & - & 7 & 4 & - \\
Boraginaceae & - & - & - & - & 4 & - \\
\hline
\end{tabular}




\subsection{Fitossociologia}

Os resultados obtidos pelo emprego dos métodos de parcelas, quadrantes e relascopia, na amostragem do componente arbóreo da vegetação na Grade 1 e Grade 2, permitiram a determinação dos parâmetros fitossociológicos importantes para a análise desta vegetação.

Em cada área de amostragem determinou-se a Freqüência Relativa, Dominância Relativa, Densidade Relativa e Índice de Valor de Importância para cada espécie amostrada pelos métodos empregados.

Nas Tabelas 5, 6 e 7, estão relacionadas respectivamente, em ordem decrescente de IVI, as espécies amostradas pelos métodos de parcelas, quadrantes e relascopia empregados na amostragem da Grade-1.

No método de parcelas, as 10 espécies com maior valor de IVI são: Micropholis crassipedicellata (16,94), Euterpe edulis (14,61), Ocotea catharinensis $(10,34)$, Pouteria bullata (7,23), Alchornea triplinervia $(6,78)$, Mollinedia oligantha (6,14), Alibertia sp. (5,63), Vantanea compacta $(5,45)$, Bathysa australis $(5,25)$ e Cabralea canjerana $(5,1)$ (Tabela 5). Estas espécies respondem por 30\% do total de indivíduos amostrados pelo método de parcelas na Grade 1.

Alguns parâmetros foram determinantes para a definição da posição de cada espécie na comunidade estudada. Assim, a primeira posição ocupada por Micropholis crassipedicellata foi determinada pelo alto valor de Dominância Relativa $(13,05)$ alcançada por esta espécie. A segunda posição ocupada por Euterpe edulis teve como parâmetro decisivo a Densidade Relativa $(10,44)$ determinada para esta espécie na amostragem.

As espécies Ocotea catharinensis, Pouteria bullata, Alchornea triplinervia, Vantanea compacta e Cabralea cajerana, tiveram a Dominância Relativa como o parâmetro mais determinante para o seu posicionamento. Para Mollinedia oligantha e 
Alibertia sp., o parâmetro determinante foi a Densidade Relativa. É importante salientar ainda que Alibertia sp., mesmo apresentando Dominância Relativa com valor inferior a um, manteve-se entre as dez espécies com maior valor de IVI.

Para os métodos de quadrantes e relascopia (Tabelas 6 e 7), observa-se que Euterpe edulis passou a ocupar a primeira posição em relação aos valores de IVI, em função de apresentar os maiores valores de Densidade Relativa. 
Tabela 5. Relação de espécies em ordem decrescente de IVI, amostradas pelo método de parcela, na Grade-1, instalada na Floresta Ombrófila Densa, no Parque Estadual Carlos Botelho.SP.Brasil. Ni - Número de Indivíduos; FR Freqüência Relativa; DR - Densidade Relativa; DOR - Dominância Relativa e IVI - Índice de Valor de Importância

\begin{tabular}{|c|c|c|c|c|c|}
\hline ESPÉCIES & $\mathrm{Ni}$ & DR & DOR & FR & IVI \\
\hline Micropholis crassipedicellata & 258 & 2,5611 & 13,0509 & 1,3285 & 16,9405 \\
\hline Euterpe edulis & 1084 & 10,4468 & 2,6199 & 1,5459 & 14,6126 \\
\hline Ocotea catharinensis & 227 & 2,4841 & 6,5131 & 1,3527 & 10,3499 \\
\hline Pouteria bullata & 167 & 1,6657 & 4,1657 & 1,4010 & 7,2324 \\
\hline Alchornea triplinervia & 114 & 1,4057 & 4,2709 & 1,1111 & 6,7878 \\
\hline Mollinedia oligantha & 290 & 3,4855 & 1,2540 & 1,4010 & 6,1404 \\
\hline Alibertia sp. & 310 & 3,3218 & 0,9096 & 1,4010 & 5,6324 \\
\hline Vantanea compacta & 128 & 1,2517 & 3,0176 & 1,1836 & 5,4529 \\
\hline Bathysa australis & 234 & 2,3589 & 1,8328 & 1,0628 & 5,2545 \\
\hline Cabralea canjerana & 104 & 1,2132 & 2,6858 & 1,2077 & 5,1067 \\
\hline Ocotea bicolor & 140 & 1,6272 & 2,1083 & 1,0145 & 4,7499 \\
\hline Ocotea elegans & 111 & 1,8005 & 1,6530 & 1,1594 & 4,6129 \\
\hline Guapira opposita & 146 & 1,6368 & 1,4791 & 1,2077 & 4,3237 \\
\hline Coussarea sp. & 203 & 2,1279 & 0,7059 & 1,2802 & 4,1139 \\
\hline Ormosia dasycarpa & 142 & 1,4250 & 1,3817 & 0,8696 & 3,6763 \\
\hline Morta & 107 & 1,1073 & 1,3989 & 1,1594 & 3,6656 \\
\hline Chionanthus filiformis & 134 & 1,3191 & 0,9547 & 1,0628 & 3,3366 \\
\hline Matayba juglandifolia & 107 & 1,1361 & 1,0629 & 1,1353 & 3,3343 \\
\hline Eugenia stictosepala & 160 & 1,5983 & 0,3681 & 1,2802 & 3,2466 \\
\hline Ocotea odorifera & 87 & 1,0784 & 1,1051 & 0,8696 & 3,0531 \\
\hline Amaioua intermedia & 128 & 1,3191 & 0,6430 & 1,0870 & 3,0491 \\
\hline Mollinedia schottiana & 118 & 1,3191 & 0,3355 & 1,3768 & 3,0314 \\
\hline Ocotea aciphylla & 74 & 1,0206 & 1,2410 & 0,7246 & 2,9862 \\
\hline Cryptocarya sp. 1 & 64 & 0,6162 & 1,4524 & 0,8213 & 2,8899 \\
\hline Byrsonima ligustrifolia & 120 & 1,1939 & 0,7339 & 0,9179 & 2,8457 \\
\hline Ocotea pulchra & 105 & 1,0302 & 0,7879 & 1,0145 & 2,8326 \\
\hline Rudgea jasminoides & 128 & 1,3287 & 0,3076 & 1,1111 & 2,7474 \\
\hline Myrcia pubipetala & 83 & 0,7992 & 0,7835 & 1,1353 & 2,7180 \\
\hline Tapirira guianensis & 67 & 0,6547 & 1,1677 & 0,8937 & 2,7162 \\
\hline Xylopia langsdorfiana & 98 & 1,1361 & 0,5205 & 0,8696 & 2,5262 \\
\hline Esenbeckia grandiflora & 104 & 1,0880 & 0,3833 & 1,0145 & 2,4857 \\
\hline Myrocarpus frondosus & 79 & 0,7992 & 0,7507 & 0,9179 & 2,4678 \\
\hline Pouteria caimito & 50 & 0,5007 & 1,1500 & 0,7729 & 2,4236 \\
\hline Tibouchina pulchra & 77 & 0,7799 & 0,9515 & 0,6763 & 2,4077 \\
\hline Parinari excelsa & 62 & 0,6162 & 0,9647 & 0,7488 & 2,3297 \\
\hline
\end{tabular}


Tabela 5. Relação de espécies em ordem decrescente de IVI, amostradas pelo método de parcela, na Grade-1, instalada na Floresta Ombrófila Densa, no Parque Estadual Carlos Botelho.SP.Brasil. Ni - Número de Indivíduos; FR Freqüência Relativa; DR - Densidade Relativa; DOR - Dominância Relativa e IVI - Índice de Valor de Importância

\begin{tabular}{llrrrr}
\hline ESPÉCIES & $\mathrm{Ni}$ & $\mathrm{DR}$ & DOR & FR & IVI \\
\hline Guatteria australis & 65 & 0,8088 & 0,5625 & 0,9420 & 2,3133 \\
Matayba guianensis & 57 & 0,5777 & 0,9367 & 0,7729 & 2,2874 \\
Rapanea umbellata & 75 & 0,7606 & 0,4530 & 1,0386 & 2,2523 \\
Copaifera trapezifolia & 50 & 0,4814 & 0,9928 & 0,7488 & 2,2230 \\
Byrsonima myricifolia & 79 & 0,7799 & 0,5151 & 0,8696 & 2,1646 \\
Cryptocarya moschata & 40 & 0,3851 & 1,1764 & 0,5797 & 2,1413 \\
Aniba viridis & 64 & 0,6932 & 0,4803 & 0,8937 & 2,0673 \\
Posoqueria acutifolia & 70 & 0,6932 & 0,3609 & 0,8696 & 1,9237 \\
Didymopanax navarroi & 30 & 0,2889 & 1,0464 & 0,5556 & 1,8908 \\
Cordia sellowiana & 62 & 0,6162 & 0,4521 & 0,8213 & 1,8895 \\
Myrcia fallax & 83 & 0,8088 & 0,3454 & 0,7246 & 1,8788 \\
Pterocarpus rohrii & 50 & 0,4814 & 0,7341 & 0,6522 & 1,8677 \\
Maytenus robusta & 43 & 0,5584 & 0,5892 & 0,7005 & 1,8482 \\
Symplocos falcata & 36 & 0,3466 & 0,7881 & 0,6522 & 1,7869 \\
Siphoneugena densiflora & 56 & 0,5584 & 0,3798 & 0,8213 & 1,7595 \\
Hirtella hebeclada & 48 & 0,4814 & 0,5018 & 0,7488 & 1,7320 \\
Copaifera langsdorffii & 54 & 0,5199 & 0,3921 & 0,7971 & 1,7091 \\
Miconia cabucu Hoenhe & 58 & 0,5584 & 0,3844 & 0,7488 & 1,6916 \\
Aspidosperma olivaceum & 45 & 0,4429 & 0,5777 & 0,6522 & 1,6728 \\
Meliosma sinuata & 44 & 0,5777 & 0,5708 & 0,5072 & 1,6557 \\
Sorocea bonplandii & 61 & 0,5970 & 0,1789 & 0,8454 & 1,6213 \\
Buchenavia kleinii & 11 & 0,1059 & 1,2140 & 0,2657 & 1,5856 \\
Sclerolobium denudatum & 44 & 0,4429 & 0,5804 & 0,5556 & 1,5789 \\
Andira anthelmia & 47 & 0,4622 & 0,3003 & 0,7971 & 1,5595 \\
Eugenia subavenia & 69 & 0,6740 & 0,0966 & 0,7729 & 1,5435 \\
Miconia pusilliflora & 61 & 0,5873 & 0,1495 & 0,7729 & 1,5098 \\
Cupania oblongifolia & 40 & 0,4910 & 0,3986 & 0,6039 & 1,4935 \\
Miconia petropolitana & 57 & 0,5777 & 0,1566 & 0,7488 & 1,4831 \\
Eugenia sp.1 & 42 & 0,4429 & 0,2411 & 0,7971 & 1,4811 \\
Myrceugenia sp.1 & 46 & 0,4429 & 0,2156 & 0,8213 & 1,4797 \\
Protium hepatphyllum & 41 & 0,4718 & 0,4591 & 0,5314 & 1,4623 \\
Alibertia myrciifolia & 61 & 0,6162 & 0,2038 & 0,6280 & 1,4480 \\
Lamanonia ternata & 29 & 0,3081 & 0,7034 & 0,4348 & 1,4463 \\
Eugenia handroana & 49 & 0,4718 & 0,1728 & 0,7971 & 1,4417 \\
Pithecellobium langsdorffi & 53 & 0,5392 & 0,2667 & 0,6039 & 1,4097 \\
& & & & & \\
& & & &
\end{tabular}


Tabela 5. Relação de espécies em ordem decrescente de IVI, amostradas pelo método de parcela, na Grade-1, instalada na Floresta Ombrófila Densa, no Parque Estadual Carlos Botelho.SP.Brasil. Ni - Número de Indivíduos; FR Freqüência Relativa; DR - Densidade Relativa; DOR - Dominância Relativa e IVI - Índice de Valor de Importância

\begin{tabular}{lrrrrr}
\hline ESPÉCIES & $\mathrm{Ni}$ & $\mathrm{DR}$ & DOR & FR & IVI \\
\hline Prunus myrtifolia & 35 & 0,3466 & 0,4866 & 0,5556 & 1,3887 \\
Marlierea parviflora & 50 & 0,4814 & 0,2023 & 0,6763 & 1,3601 \\
Eugenia sp.5 & 34 & 0,3274 & 0,4384 & 0,5556 & 1,3213 \\
Inga sellowiana & 46 & 0,4429 & 0,1524 & 0,7005 & 1,2958 \\
Ocotea dispersa & 40 & 0,4140 & 0,2356 & 0,6280 & 1,2776 \\
Plinia pauciflora & 35 & 0,3370 & 0,2571 & 0,6763 & 1,2704 \\
Eugenia involucrata & 41 & 0,4814 & 0,1368 & 0,6522 & 1,2704 \\
Myrtaceae sp.3 & 24 & 0,2407 & 0,5055 & 0,4831 & 1,2293 \\
Hyeronima alchorneoides & 40 & 0,4910 & 0,3783 & 0,3382 & 1,2075 \\
Weinmannia paulliniifolia & 27 & 0,2600 & 0,4356 & 0,5072 & 1,2028 \\
Gomidesia tijucensis & 39 & 0,3755 & 0,1700 & 0,6280 & 1,1735 \\
Myrceugenia myrcioides & 40 & 0,4525 & 0,0850 & 0,6280 & 1,1655 \\
Ouratea parviflora & 43 & 0,4140 & 0,2184 & 0,5314 & 1,1639 \\
Aiouea acaradomatifera & 26 & 0,3274 & 0,4097 & 0,3623 & 1,0994 \\
Sloanea monosperma & 25 & 0,2792 & 0,3279 & 0,4831 & 1,0903 \\
Myrcia sp.1 & 31 & 0,3081 & 0,2037 & 0,5556 & 1,0674 \\
Ixora burchelliana & 35 & 0,3659 & 0,1895 & 0,4589 & 1,0144 \\
Tibouchina sellowiana & 32 & 0,3177 & 0,3552 & 0,3140 & 0,9869 \\
Myrceugenia glaucescens & 34 & 0,3466 & 0,1768 & 0,4589 & 0,9823 \\
Drimys winteri & 35 & 0,3466 & 0,1182 & 0,5072 & 0,9721 \\
Eugenia mosenii & 35 & 0,3755 & 0,1606 & 0,4106 & 0,9467 \\
Ocotea pulchella & 20 & 0,2022 & 0,3646 & 0,3623 & 0,9291 \\
Cupania vernalis & 24 & 0,2407 & 0,2528 & 0,4348 & 0,9283 \\
Capsicodendron dinisii & 22 & 0,2118 & 0,3176 & 0,3865 & 0,9159 \\
Eugenia beaurepairiana & 23 & 0,2215 & 0,2093 & 0,4831 & 0,9139 \\
Eugenia capitulifera & 33 & 0,3177 & 0,1056 & 0,4831 & 0,9065 \\
Ocotea teleiandra & 25 & 0,3851 & 0,1097 & 0,4106 & 0,9054 \\
Ilex amara & 30 & 0,2985 & 0,1501 & 0,4348 & 0,8833 \\
Jacaranda puberula & 25 & 0,2600 & 0,2594 & 0,3623 & 0,8817 \\
Campomanesia guaviroba & 17 & 0,1733 & 0,3460 & 0,3382 & 0,8575 \\
Eugenia sp.2 & 24 & 0,2311 & 0,1040 & 0,4589 & 0,7940 \\
Calyptranthes lucida & 26 & 0,2600 & 0,0960 & 0,4348 & 0,7908 \\
Psychotria velloziana & 17 & 0,1637 & 0,3081 & 0,3140 & 0,7858 \\
Eugenia cerasiflora & 21 & 0,2503 & 0,1070 & 0,4106 & 0,7680 \\
Coccoloba latifolia & 16 & 0,2118 & 0,2431 & 0,2899 & 0,7448 \\
& & & & & \\
& & & &
\end{tabular}


Tabela 5. Relação de espécies em ordem decrescente de IVI, amostradas pelo método de parcela, na Grade-1, instalada na Floresta Ombrófila Densa, no Parque Estadual Carlos Botelho.SP.Brasil. Ni - Número de Indivíduos; FR Freqüência Relativa; DR - Densidade Relativa; DOR - Dominância Relativa e IVI - Índice de Valor de Importância

\begin{tabular}{|c|c|c|c|c|c|}
\hline ESPÉCIES & $\mathrm{Ni}$ & $\mathrm{DR}$ & DOR & FR & IVI \\
\hline Diploon cuspidatum & 18 & 0,2022 & 0,2525 & 0,2899 & 0,7445 \\
\hline Symplocos variabilis & 20 & 0,1926 & 0,2227 & 0,3140 & 0,7293 \\
\hline Marlierea tomentosa & 19 & 0,2022 & 0,1770 & 0,3382 & 0,7174 \\
\hline Casearia decandra & 21 & 0,2022 & 0,1488 & 0,3623 & 0,7134 \\
\hline Eugenia riedeliana & 20 & 0,1926 & 0,0697 & 0,4106 & 0,6729 \\
\hline Ilex paraguariensis & 19 & 0,1829 & 0,1701 & 0,3140 & 0,6671 \\
\hline Heisteria silvianii & 19 & 0,1829 & 0,0944 & 0,3865 & 0,6638 \\
\hline Rollinia sericea & 19 & 0,1829 & 0,1156 & 0,3623 & 0,6609 \\
\hline Endlicheria paniculata & 21 & 0,2311 & 0,1151 & 0,3140 & 0,6602 \\
\hline Myrtaceae sp.2 & 20 & 0,2503 & 0,0368 & 0,3382 & 0,6253 \\
\hline Ocotea silvestris & 18 & 0,1829 & 0,0903 & 0,3382 & 0,6114 \\
\hline Ocotea glaziovii & 16 & 0,1829 & 0,1376 & 0,2899 & 0,6104 \\
\hline Ilex theazans & 18 & 0,1733 & 0,1190 & 0,3140 & 0,6063 \\
\hline Didymopanax angustissimus & 14 & 0,1348 & 0,1728 & 0,2899 & 0,5975 \\
\hline Eugenia melanogina & 17 & 0,1637 & 0,1076 & 0,3140 & 0,5853 \\
\hline Quiina glaziovii & 18 & 0,1733 & 0,1035 & 0,2899 & 0,5667 \\
\hline Clethra scabra & 10 & 0,1059 & 0,2304 & 0,2174 & 0,5537 \\
\hline Coussapoa microcarpa & 13 & 0,1348 & 0,1504 & 0,2657 & 0,5509 \\
\hline Casearia obliqua & 23 & 0,2407 & 0,0684 & 0,2415 & 0,5507 \\
\hline Pera glabrata & 11 & 0,1059 & 0,2021 & 0,2415 & 0,5496 \\
\hline Persea pyrifolia & 12 & 0,1252 & 0,1510 & 0,2657 & 0,5419 \\
\hline Citronella paniculata & 13 & 0,1348 & 0,1809 & 0,2174 & 0,5331 \\
\hline Myrcia aff. Glabra & 11 & 0,1059 & 0,1839 & 0,2415 & 0,5313 \\
\hline Eugenia sp.3 & 14 & 0,1348 & 0,1269 & 0,2657 & 0,5274 \\
\hline Iiex taubertiana & 12 & 0,1155 & 0,1384 & 0,2657 & 0,5197 \\
\hline Eugenia cambucarana & 14 & 0,1444 & 0,1331 & 0,2415 & 0,5191 \\
\hline Clusia criuva & 6 & 0,0578 & 0,2986 & 0,1449 & 0,5013 \\
\hline Garcinia gadneriana & 13 & 0,1541 & 0,0205 & 0,3140 & 0,4886 \\
\hline Rapanea hermogenesii & 14 & 0,1637 & 0,0261 & 0,2899 & 0,4796 \\
\hline Ocotea brachybotrya & 13 & 0,1733 & 0,0352 & 0,2657 & 0,4742 \\
\hline Casearia sylvestris & 14 & 0,1444 & 0,0545 & 0,2657 & 0,4646 \\
\hline Inga sessilis & 14 & 0,1348 & 0,0371 & 0,2899 & 0,4617 \\
\hline Podocarpus sellowii & 9 & 0,0867 & 0,1974 & 0,1691 & 0,4531 \\
\hline Eugenia pruinosa & 8 & 0,0867 & 0,1943 & 0,1691 & 0,4500 \\
\hline
\end{tabular}


Tabela 5. Relação de espécies em ordem decrescente de IVI, amostradas pelo método de parcela, na Grade-1, instalada na Floresta Ombrófila Densa, no Parque Estadual Carlos Botelho.SP.Brasil. Ni - Número de Indivíduos; FR Freqüência Relativa; DR - Densidade Relativa; DOR - Dominância Relativa e IVI - Índice de Valor de Importância

\begin{tabular}{lcrrrr}
\hline ESPÉCIES & $\mathrm{Ni}$ & $\mathrm{DR}$ & $\mathrm{DOR}$ & FR & IVI \\
\hline Calycorectes australis & 11 & 0,1155 & 0,1139 & 0,2174 & 0,4468 \\
Eugenia sp.4 & 12 & 0,1348 & 0,0439 & 0,2657 & 0,4444 \\
Myrtaceae sp.4 & 12 & 0,1155 & 0,0872 & 0,2415 & 0,4442 \\
Eugenia neoglomerata & 13 & 0,1252 & 0,0265 & 0,2899 & 0,4415 \\
Calyptranthes sp.2 & 12 & 0,1252 & 0,0844 & 0,2174 & 0,4270 \\
Weinmannia discolor & 10 & 0,1059 & 0,1397 & 0,1691 & 0,4147 \\
Ecclinusa ramiflora & 7 & 0,0867 & 0,1650 & 0,1449 & 0,3966 \\
Rapanea ferruginea & 12 & 0,1155 & 0,0869 & 0,1932 & 0,3957 \\
Miconia valtherii & 11 & 0,1155 & 0,0260 & 0,2415 & 0,3830 \\
Marlierea reitzii & 10 & 0,0963 & 0,0686 & 0,2174 & 0,3822 \\
Zollernia illicifolia & 11 & 0,1059 & 0,0566 & 0,2174 & 0,3799 \\
Chrysophyllum viride & 8 & 0,0770 & 0,1090 & 0,1932 & 0,3793 \\
Cedrella fissilis & 7 & 0,0674 & 0,1602 & 0,1449 & 0,3726 \\
Neomitranthes glomerata & 13 & 0,1252 & 0,0514 & 0,1932 & 0,3698 \\
Beilschmiedia emarginata & 9 & 0,0867 & 0,1287 & 0,1449 & 0,3603 \\
Mollinedia oligotricha & 10 & 0,1059 & 0,0277 & 0,2174 & 0,3510 \\
Solanum excelsum & 9 & 0,0867 & 0,1659 & 0,0966 & 0,3491 \\
Alseis floribunda & 9 & 0,1348 & 0,0443 & 0,1691 & 0,3481 \\
Miconia cubatanensis & 9 & 0,0963 & 0,0101 & 0,2415 & 0,3479 \\
Myrtaceae sp.1 & 9 & 0,0867 & 0,0625 & 0,1932 & 0,3424 \\
Fabaceae 1 & 9 & 0,0867 & 0,0413 & 0,1932 & 0,3212 \\
Piptocarpha macropoda & 10 & 0,0963 & 0,0759 & 0,1449 & 0,3172 \\
Talauma ovata & 6 & 0,0578 & 0,1570 & 0,0966 & 0,3114 \\
Myrceugenia kleinii & 8 & 0,0770 & 0,0573 & 0,1691 & 0,3035 \\
Vochysia sp. 1 & 6 & 0,0578 & 0,1232 & 0,1208 & 0,3018 \\
Gomidesia schaueriana & 7 & 0,0674 & 0,0885 & 0,1449 & 0,3008 \\
Sapium glandulatum & 7 & 0,0674 & 0,1123 & 0,1208 & 0,3005 \\
Calyptranthes sp.1 & 7 & 0,0674 & 0,0710 & 0,1449 & 0,2833 \\
Mollinedia sp.1 & 7 & 0,1059 & 0,0275 & 0,1449 & 0,2783 \\
Eugenia umbelliflora & 4 & 0,0385 & 0,1386 & 0,0966 & 0,2737 \\
Marlierea eugeniopsoides & 6 & 0,0770 & 0,0501 & 0,1449 & 0,2721 \\
Zanthoxylum rhoifolium & 9 & 0,0963 & 0,0542 & 0,1208 & 0,2713 \\
Tabebuia heptaphylla & 6 & 0,0674 & 0,0406 & 0,1449 & 0,2529 \\
Ocotea tabacifolia & 7 & 0,0674 & 0,0155 & 0,1691 & 0,2520 \\
Ocotea daphinifolia & 7 & 0,0867 & 0,0136 & 0,1449 & 0,2451 \\
& & & & & \\
& & & &
\end{tabular}


Tabela 5. Relação de espécies em ordem decrescente de IVI, amostradas pelo método de parcela, na Grade-1, instalada na Floresta Ombrófila Densa, no Parque Estadual Carlos Botelho.SP.Brasil. Ni - Número de Indivíduos; FR Freqüência Relativa; DR - Densidade Relativa; DOR - Dominância Relativa e IVI - Índice de Valor de Importância

\begin{tabular}{lcrrrr}
\hline ESPÉCIES & $\mathrm{Ni}$ & $\mathrm{DR}$ & DOR & FR & IVI \\
\hline Guarea macrophylla & 8 & 0,0867 & 0,0363 & 0,1208 & 0,2437 \\
Meliosma selowii & 5 & 0,0963 & 0,0263 & 0,1208 & 0,2433 \\
Persea sp.1 & 5 & 0,0481 & 0,0856 & 0,0966 & 0,2303 \\
Ocotea vaccinioides & 5 & 0,0481 & 0,0502 & 0,1208 & 0,2191 \\
Nectandra oppositfolia & 4 & 0,0578 & 0,0847 & 0,0725 & 0,2150 \\
Allophylus edulis & 4 & 0,0385 & 0,0765 & 0,0966 & 0,2116 \\
Plinia complanata & 5 & 0,0963 & 0,0159 & 0,0966 & 0,2088 \\
Miconia sellowiana & 7 & 0,0674 & 0,0179 & 0,1208 & 0,2061 \\
Ocotea sp.2 & 3 & 0,0289 & 0,1185 & 0,0483 & 0,1957 \\
Roupala sp.1 & 5 & 0,0481 & 0,0150 & 0,1208 & 0,1839 \\
Myrceugenia campestris & 5 & 0,0770 & 0,0067 & 0,0966 & 0,1803 \\
Inga laurina & 4 & 0,0578 & 0,0148 & 0,0966 & 0,1691 \\
Vernonia diffusa & 3 & 0,0385 & 0,0816 & 0,0483 & 0,1684 \\
Dalbergia frutescens & 4 & 0,0481 & 0,0233 & 0,0966 & 0,1680 \\
Ocotea velloziana & 4 & 0,0385 & 0,0289 & 0,0966 & 0,1640 \\
Solanum pseudoquina & 4 & 0,0481 & 0,0168 & 0,0966 & 0,1615 \\
Solanum bullatum & 5 & 0,0481 & 0,0168 & 0,0966 & 0,1615 \\
Cariniana estrellensis & 1 & 0,0096 & 0,1214 & 0,0242 & 0,1552 \\
Eugenia cereja & 4 & 0,0385 & 0,0431 & 0,0725 & 0,1541 \\
Myrcia hatschbachii & 7 & 0,0770 & 0,0288 & 0,0483 & 0,1541 \\
Ocotea nectandrifolia & 3 & 0,0289 & 0,0522 & 0,0725 & 0,1536 \\
Inga marginata & 5 & 0,0481 & 0,0080 & 0,0966 & 0,1527 \\
Myrciaria sp.1 & 4 & 0,0385 & 0,0167 & 0,0966 & 0,1519 \\
Attalea dubia & 3 & 0,0289 & 0,0710 & 0,0483 & 0,1482 \\
Styrax acuminatus & 4 & 0,0385 & 0,0270 & 0,0725 & 0,1380 \\
Lauraceae sp.2 & 3 & 0,0289 & 0,0357 & 0,0725 & 0,1371 \\
Cordia sp. 1 & 7 & 0,0770 & 0,0111 & 0,0483 & 0,1364 \\
Chomelia sp. & 4 & 0,0578 & 0,0049 & 0,0725 & 0,1352 \\
Myrceugenia aff. Pilotantha & 4 & 0,0385 & 0,0148 & 0,0725 & 0,1258 \\
Leandra sp. & 3 & 0,0289 & 0,0239 & 0,0725 & 0,1253 \\
Piptocarpha sp.1 & 3 & 0,0289 & 0,0235 & 0,0725 & 0,1249 \\
Aniba firmula & 2 & 0,0193 & 0,0544 & 0,0483 & 0,1220 \\
Lauraceae sp.3 & 2 & 0,0193 & 0,0508 & 0,0483 & 0,1184 \\
Ocotea venulosa & 2 & 0,0578 & 0,0081 & 0,0483 & 0,1142 \\
Daphnopsis gemmiflora & 3 & 0,0289 & 0,0116 & 0,0725 & 0,1130 \\
& & & & & \\
& 5 & 5 & & &
\end{tabular}


Tabela 5. Relação de espécies em ordem decrescente de IVI, amostradas pelo método de parcela, na Grade-1, instalada na Floresta Ombrófila Densa, no Parque Estadual Carlos Botelho.SP.Brasil. Ni - Número de Indivíduos; FR Freqüência Relativa; DR - Densidade Relativa; DOR - Dominância Relativa e IVI - Índice de Valor de Importância

\begin{tabular}{lcrrrr}
\hline ESPÉCIES & $\mathrm{Ni}$ & $\mathrm{DR}$ & DOR & FR & IVI \\
\hline Marlierea sp.1 & 2 & 0,0193 & 0,0418 & 0,0483 & 0,1093 \\
Lauraceae sp.1 & 3 & 0,0289 & 0,0067 & 0,0725 & 0,1081 \\
Eugenia prasina & 3 & 0,0289 & 0,0055 & 0,0725 & 0,1068 \\
Myrcia aff.obtecta & 2 & 0,0193 & 0,0386 & 0,0483 & 0,1061 \\
Aiouea saligna & 3 & 0,0289 & 0,0041 & 0,0725 & 0,1055 \\
Myrcia sp.2 & 3 & 0,0289 & 0,0034 & 0,0725 & 0,1048 \\
Campomanesia schlechtendahliana & 2 & 0,0289 & 0,0275 & 0,0483 & 0,1047 \\
Symplocos celastrinea & 2 & 0,0193 & 0,0572 & 0,0242 & 0,1006 \\
Rhodostemenodaphne macrocalyx & 2 & 0,0193 & 0,0255 & 0,0483 & 0,0930 \\
Myrcia tenuivenosa & 3 & 0,0289 & 0,0116 & 0,0483 & 0,0888 \\
Aegiphila sellowiana & 2 & 0,0193 & 0,0200 & 0,0483 & 0,0876 \\
Dalbergia brasiliensis & 3 & 0,0289 & 0,0086 & 0,0483 & 0,0858 \\
Ocotea sp.1 & 2 & 0,0193 & 0,0146 & 0,0483 & 0,0822 \\
Rapanea gardneriana & 2 & 0,0289 & 0,0040 & 0,0483 & 0,0812 \\
Miconia sp.1 & 1 & 0,0096 & 0,0453 & 0,0242 & 0,0791 \\
Cheiloclinium cognatum & 2 & 0,0193 & 0,0075 & 0,0483 & 0,0751 \\
Myrcia richardiana & 2 & 0,0193 & 0,0062 & 0,0483 & 0,0737 \\
Psychotria suterella & 2 & 0,0193 & 0,0054 & 0,0483 & 0,0729 \\
Rollinia parviflora & 2 & 0,0193 & 0,0025 & 0,0483 & 0,0700 \\
Mollinedia elegans & 2 & 0,0193 & 0,0018 & 0,0483 & 0,0693 \\
Calyptranthes sp.3 & 2 & 0,0096 & 0,0263 & 0,0242 & 0,0600 \\
Nectandra membranacea & 1 & 0,0096 & 0,0231 & 0,0242 & 0,0569 \\
Ocotea aff. Lancifolia & 1 & 0,0096 & 0,0207 & 0,0242 & 0,0545 \\
Vochysia selloi & 1 & 0,0096 & 0,0155 & 0,0242 & 0,0493 \\
Machaerium sp. & 1 & 0,0096 & 0,0129 & 0,0242 & 0,0466 \\
Cecropia glaziovi & 1 & 0,0096 & 0,0114 & 0,0242 & 0,0452 \\
Calycorectes aff. psidiiflorus & 1 & 0,0096 & 0,0084 & 0,0242 & 0,0422 \\
Xylosma glaberrima & 1 & 0,0096 & 0,0063 & 0,0242 & 0,0400 \\
Leandra dasytricha & 1 & 0,0096 & 0,0047 & 0,0242 & 0,0385 \\
Cinnamomum hirsutum & 1 & 0,0096 & 0,0028 & 0,0242 & 0,0366 \\
Aegiphila sp. & 1 & 0,0096 & 0,0022 & 0,0242 & 0,0359 \\
Allophylus petiolatus & 1 & 0,0096 & 0,0016 & 0,0242 & 0,0354 \\
Machaerium nictitans & 1 & 0,0096 & 0,0015 & 0,0242 & 0,0353 \\
Verbenaceae 1 & 1 & 0,0096 & 0,0015 & 0,0242 & 0,0353 \\
Stylogyne laevigata & 1 & 0,0096 & 0,0012 & 0,0242 & 0,0350 \\
& & & & & \\
& 2 & & &
\end{tabular}


Tabela 5. Relação de espécies em ordem decrescente de IVI, amostradas pelo método de parcela, na Grade-1, instalada na Floresta Ombrófila Densa, no Parque Estadual Carlos Botelho.SP.Brasil. Ni - Número de Indivíduos; FR Freqüência Relativa; DR - Densidade Relativa; DOR - Dominância Relativa e IVI - Índice de Valor de Importância

\begin{tabular}{lcrrrr}
\hline ESPÉCIES & $\mathrm{Ni}$ & $\mathrm{DR}$ & $\mathrm{DOR}$ & $\mathrm{FR}$ & IVI \\
\hline Vitex aff. polygama & 1 & 0,0096 & 0,0010 & 0,0242 & 0,0348 \\
Calyptranthes lanceolata & 1 & 0,0096 & 0,0009 & 0,0242 & 0,0347 \\
Salacia elliptica & 1 & 0,0096 & 0,0009 & 0,0242 & 0,0346 \\
Myrcia heringii & 1 & 0,0096 & 0,0008 & 0,0242 & 0,0346 \\
Meriania claussenii & 1 & 0,0096 & 0,0008 & 0,0242 & 0,0346 \\
Nectandra debilis & 1 & 0,0096 & 0,0008 & 0,0242 & 0,0346 \\
Erythroxylum sp. & 1 & 0,0096 & 0,0008 & 0,0242 & 0,0345 \\
\hline
\end{tabular}

Para o método de quadrantes as espécies que apresentaram o maior valor de IVI foram: Euterpe edulis (29,55), Micropholis crassipedicellata (23,76), Bathysa australis (12,13), Guapira opposita (8,56), Mollinedia oligantha (8,37), Pouteria bullata $(8,03)$, Ocotea catharinensis $(7,74)$, Vantanea compacta $(6,20)$, Coussarea sp. $(5,74)$ e Eugenia melanogina (5,71). Estas dez espécies foram responsáveis pela amostragem de 33\% do total de indivíduos obtidos pelo método de quadrantes na Grade 1 (Tabela 6). 
Tabela 6. Relação das espécies em ordem decrescente de IVI, amostradas pelo método de quadrantes, na Grade-1, instalada na Floresta Ombrófila Densa, no Parque Estadual Carlos Botelho.SP.Brasil. Ni - Número de Indivíduos; DR Densidade Relativa; DOR - Dominância Relativa; FR - Freqüência Relativa e IVI - Índice de Valor de Importância

\begin{tabular}{|c|c|c|c|c|c|}
\hline ESPECIES & $\mathrm{Ni}$ & DR & DOR & FR & IVI \\
\hline Euterpe edulis & 162 & 12,6563 & 4,2437 & 12,6563 & 29,5562 \\
\hline Micropholis crassipedicellata & 50 & 3,9062 & 15,9548 & 3,9063 & 23,7673 \\
\hline Bathysa australis & 43 & 3,5156 & 5,1035 & 3,5156 & 12,1348 \\
\hline Guapira opposita & 19 & 1,4844 & 5,5919 & 1,4844 & 8,5606 \\
\hline Mollinedia oligantha & 44 & 3,4375 & 1,4951 & 3,4375 & 8,3701 \\
\hline Pouteria bullata & 24 & 1,8750 & 4,2868 & 1,8750 & 8,0368 \\
\hline Ocotea catharinensis & 27 & 2,1094 & 3,5215 & 2,1094 & 7,7403 \\
\hline Vantanea compacta & 19 & 1,4844 & 3,2363 & 1,4844 & 6,2050 \\
\hline Coussarea sp. & 31 & 2,4219 & 0,8963 & 2,4219 & 5,7401 \\
\hline Eugenia melanogina & 3 & 0,2344 & 5,2425 & 0,2344 & 5,7112 \\
\hline Alchornea triplinervia & 16 & 1,3281 & 2,4831 & 1,3281 & 5,1394 \\
\hline Cabralea canjerana & 19 & 1,4844 & 1,9581 & 1,4844 & 4,9268 \\
\hline Pouteria caimito & 9 & 0,7031 & 3,1205 & 0,7031 & 4,5268 \\
\hline Alibertia sp. & 25 & 1,9531 & 0,4679 & 1,9531 & 4,3742 \\
\hline Eugenia stictosepala . & 22 & 1,7188 & 0,6462 & 1,7188 & 4,0837 \\
\hline Ormosia dasycarpa & 20 & 1,5625 & 0,5458 & 1,5625 & 3,6708 \\
\hline Byrsonima ligustrifolia & 18 & 1,4063 & 0,7950 & 1,4063 & 3,6075 \\
\hline Ocotea bicolor & 15 & 1,1719 & 1,0880 & 1,1719 & 3,4318 \\
\hline Ocotea elegans & 10 & 0,7812 & 1,8537 & 0,7813 & 3,4162 \\
\hline Diploon cuspidatum & 5 & 0,3906 & 2,4301 & 0,3906 & 3,2113 \\
\hline Mollinedia schottiana & 17 & 1,3281 & 0,3032 & 1,3281 & 2,9594 \\
\hline Matayba juglandifolia & 14 & 1,0938 & 0,6548 & 1,0938 & 2,8423 \\
\hline Myrocarpus frondosus & 13 & 1,0156 & 0,7833 & 1,0156 & 2,8145 \\
\hline Cryptocarya sp. 1 & 10 & 0,7812 & 1,1467 & 0,7813 & 2,7092 \\
\hline Ocotea odorifera & 13 & 1,0156 & 0,6454 & 1,0156 & 2,6766 \\
\hline Xylopia langsdorfiana & 12 & 1,0156 & 0,5649 & 1,0156 & 2,5961 \\
\hline Ocotea aciphylla & 8 & 0,6250 & 1,2784 & 0,6250 & 2,5284 \\
\hline Rudgea jasminoides & 14 & 1,0938 & 0,1592 & 1,0938 & 2,3467 \\
\hline Ocotea pulchra & 12 & 0,9375 & 0,4389 & 0,9375 & 2,3139 \\
\hline Amaioua intermedia & 12 & 0,9375 & 0,3591 & 0,9375 & 2,2341 \\
\hline Tibouchina pulchra & 9 & 0,7031 & 0,7930 & 0,7031 & 2,1992 \\
\hline Miconia cabucu & 12 & 0,9375 & 0,3011 & 0,9375 & 2,1761 \\
\hline Copaifera trapezifolia & 9 & 0,7031 & 0,7174 & 0,7031 & 2,1236 \\
\hline Cordia sellowiana & 10 & 0,7812 & 0,5597 & 0,7813 & 2,1222 \\
\hline Alibertia myrciifolia & 12 & 0,9375 & 0,2471 & 0,9375 & 2,1221 \\
\hline
\end{tabular}


Tabela 6. Relação das espécies em ordem decrescente de IVI, amostradas pelo método de quadrantes, na Grade-1, instalada na Floresta Ombrófila Densa, no Parque Estadual Carlos Botelho.SP.Brasil. Ni - Número de Indivíduos; DR Densidade Relativa; DOR - Dominância Relativa; FR - Freqüência Relativa e IVI - Índice de Valor de Importância

\begin{tabular}{lcrrrr}
\hline ESPECIES & $\mathrm{Ni}$ & $\mathrm{DR}$ & $\mathrm{DOR}$ & $\mathrm{FR}$ & $\mathrm{IVI}$ \\
\hline Matayba guianensis & 9 & 0,7031 & 0,6369 & 0,7031 & 2,0431 \\
Didymopanax navarroi & 7 & 0,5469 & 0,9256 & 0,5469 & 2,0193 \\
Aniba viridis & 9 & 0,7031 & 0,5892 & 0,7031 & 1,9954 \\
Symplocos falcata & 7 & 0,5469 & 0,8936 & 0,5469 & 1,9874 \\
Eugenia mosenii & 9 & 0,7031 & 0,5721 & 0,7031 & 1,9783 \\
Myrtaceae sp.2 & 5 & 0,3906 & 1,0903 & 0,3906 & 1,8715 \\
Sorocea bonplandii & 10 & 0,7812 & 0,2767 & 0,7813 & 1,8392 \\
morta & 10 & 0,7812 & 0,2715 & 0,7813 & 1,8340 \\
Miconia pusilliflora & 6 & 0,8594 & 0,1146 & 0,8594 & 1,8333 \\
Cryptocarya moschata & 7 & 0,5469 & 0,7287 & 0,5469 & 1,8225 \\
Esenbeckia grandiflora & 10 & 0,7812 & 0,2486 & 0,7813 & 1,8111 \\
Parinari excelsa & 6 & 0,4687 & 0,8557 & 0,4688 & 1,7932 \\
Marlierea parviflora & 10 & 0,7812 & 0,2194 & 0,7813 & 1,7819 \\
Andira anthelmia & 10 & 0,7812 & 0,1833 & 0,7813 & 1,7458 \\
Myrcia fallax & 9 & 0,7031 & 0,2908 & 0,7031 & 1,6971 \\
Lamanonia ternata & 7 & 0,5469 & 0,5987 & 0,5469 & 1,6924 \\
Copaifera langsdorffii & 4 & 0,3125 & 1,0670 & 0,3125 & 1,6920 \\
Chionanthus filiformis & 9 & 0,7031 & 0,2319 & 0,7031 & 1,6381 \\
Eugenia sp.2 & 8 & 0,6250 & 0,3596 & 0,6250 & 1,6096 \\
Myrcia pubipetala & 8 & 0,6250 & 0,3437 & 0,6250 & 1,5937 \\
Posoqueria acutifolia & 8 & 0,6250 & 0,2830 & 0,6250 & 1,5330 \\
Aspidosperma olivaceum & 6 & 0,4687 & 0,5916 & 0,4688 & 1,5291 \\
Cupania oblongifolia & 7 & 0,5469 & 0,3481 & 0,5469 & 1,4418 \\
Guatteria australis & 8 & 0,6250 & 0,1308 & 0,6250 & 1,3808 \\
Meliosma sinuata & 5 & 0,3906 & 0,5897 & 0,3906 & 1,3709 \\
Casearia obliqua & 8 & 0,6250 & 0,0875 & 0,6250 & 1,3375 \\
Maytenus robusta & 5 & 0,3906 & 0,4809 & 0,3906 & 1,2621 \\
Ouratea parviflora & 7 & 0,5469 & 0,1663 & 0,5469 & 1,2601 \\
Hirtella hebeclada & 6 & 0,4687 & 0,2980 & 0,4688 & 1,2355 \\
Eugenia handroana & 7 & 0,5469 & 0,1356 & 0,5469 & 1,2294 \\
Inga sellowiana & 7 & 0,5469 & 0,1113 & 0,5469 & 1,2050 \\
Ocotea teleiandra & 7 & 0,5469 & 0,0824 & 0,5469 & 1,1762 \\
Eugenia subavenia & 7 & 0,5469 & 0,0638 & 0,5469 & 1,1576 \\
Eugenia beaurepairiana & 6 & 0,4687 & 0,2079 & 0,4688 & 1,1454 \\
Coccoloba latifolia & 5 & 0,3906 & 0,3582 & 0,3906 & 1,1394 \\
Myrceugenia glaucescens & 6 & 0,4687 & 0,1780 & 0,4688 & 1,1155 \\
& & & & &
\end{tabular}


Tabela 6. Relação das espécies em ordem decrescente de IVI, amostradas pelo método de quadrantes, na Grade-1, instalada na Floresta Ombrófila Densa, no Parque Estadual Carlos Botelho.SP.Brasil. Ni - Número de Indivíduos; DR Densidade Relativa; DOR - Dominância Relativa; FR - Freqüência Relativa e IVI - Índice de Valor de Importância

\begin{tabular}{lcrrrr}
\hline ESPECIES & $\mathrm{Ni}$ & $\mathrm{DR}$ & $\mathrm{DOR}$ & $\mathrm{FR}$ & $\mathrm{IVI}$ \\
\hline Casearia decandra & 6 & 0,4687 & 0,1633 & 0,4688 & 1,1008 \\
Rapanea umbellata & 6 & 0,4687 & 0,1632 & 0,4688 & 1,1007 \\
Eugenia sp.1 & 6 & 0,4687 & 0,1093 & 0,4688 & 1,0468 \\
Hyeronima alchorneoides & 5 & 0,3906 & 0,2617 & 0,3906 & 1,0430 \\
Miconia petropolitana & 11 & 0,4687 & 0,0898 & 0,4688 & 1,0273 \\
Myrceugenia myrcioides & 6 & 0,4687 & 0,0616 & 0,4688 & 0,9991 \\
Sclerolobium denudatum & 5 & 0,3906 & 0,2119 & 0,3906 & 0,9932 \\
Pithecellobium langsdorffi & 5 & 0,3906 & 0,1843 & 0,3906 & 0,9655 \\
Drimys winteri & 5 & 0,3906 & 0,1449 & 0,3906 & 0,9261 \\
Gomidesia tijucensis & 5 & 0,3906 & 0,1355 & 0,3906 & 0,9167 \\
Ocotea glaziovii & 3 & 0,2344 & 0,4249 & 0,2344 & 0,8937 \\
Eugenia sp.3 & 5 & 0,3906 & 0,1087 & 0,3906 & 0,8900 \\
Sloanea monosperma & 5 & 0,3906 & 0,1041 & 0,3906 & 0,8854 \\
Inga sessilis & 5 & 0,3906 & 0,0864 & 0,3906 & 0,8676 \\
Siphoneugena densiflora & 5 & 0,3906 & 0,0776 & 0,3906 & 0,8588 \\
Eugenia riedeliana & 5 & 0,3906 & 0,0754 & 0,3906 & 0,8567 \\
Calyptranthes lucida & 4 & 0,3125 & 0,2269 & 0,3125 & 0,8519 \\
Heisteria silvianii & 5 & 0,3906 & 0,0634 & 0,3906 & 0,8446 \\
Pterocarpus rohrii & 4 & 0,3125 & 0,2042 & 0,3125 & 0,8292 \\
Cupania vernalis & 3 & 0,2344 & 0,3578 & 0,2344 & 0,8265 \\
Ocotea dispersa & 4 & 0,3125 & 0,1985 & 0,3125 & 0,8235 \\
Eugenia involucrata & 4 & 0,3125 & 0,1944 & 0,3125 & 0,8194 \\
Garcinia gadneriana & 5 & 0,3906 & 0,0380 & 0,3906 & 0,8193 \\
Sapium glandulatum & 2 & 0,1563 & 0,4970 & 0,1563 & 0,8095 \\
Marlierea tomentosa & 3 & 0,2344 & 0,3311 & 0,2344 & 0,7999 \\
Myrcia sp.1 & 4 & 0,3125 & 0,1395 & 0,3125 & 0,7645 \\
Weinmannia paulliniifolia & 1 & 0,0781 & 0,6025 & 0,0781 & 0,7587 \\
Rapanea hermogenesii & 4 & 0,3125 & 0,0666 & 0,3125 & 0,6916 \\
Ixora burchelliana & 4 & 0,3125 & 0,0625 & 0,3125 & 0,6875 \\
Tapirira guianensis & 3 & 0,2344 & 0,1996 & 0,2344 & 0,6683 \\
Jacaranda puberula & 4 & 0,3125 & 0,0288 & 0,3125 & 0,6538 \\
Eugenia sp.5 & 3 & 0,2344 & 0,1766 & 0,2344 & 0,6454 \\
Capsicodendron dinisii & 3 & 0,2344 & 0,1643 & 0,2344 & 0,6331 \\
Calyptranthes sp.2 & 3 & 0,2344 & 0,1513 & 0,2344 & 0,6201 \\
Psychotria velloziana & 2 & 0,1563 & 0,3063 & 0,1563 & 0,6188 \\
Ocotea silvestris & 3 & 0,2344 & 0,1344 & 0,2344 & 0,6031 \\
& & & & &
\end{tabular}


Tabela 6. Relação das espécies em ordem decrescente de IVI, amostradas pelo método de quadrantes, na Grade-1, instalada na Floresta Ombrófila Densa, no Parque Estadual Carlos Botelho.SP.Brasil. Ni - Número de Indivíduos; DR Densidade Relativa; DOR - Dominância Relativa; FR - Freqüência Relativa e IVI - Índice de Valor de Importância

\begin{tabular}{lcrrrr}
\hline ESPECIES & $\mathrm{Ni}$ & DR & DOR & FR & IVI \\
\hline Myrceugenia kleinii & 3 & 0,2344 & 0,1287 & 0,2344 & 0,5974 \\
Ocotea brachybotrya & 2 & 0,1563 & 0,2810 & 0,1563 & 0,5935 \\
Protium hepatphyllum & 2 & 0,1563 & 0,2778 & 0,1563 & 0,5903 \\
Weinmannia discolor & 3 & 0,2344 & 0,0859 & 0,2344 & 0,5547 \\
Eugenia cambucarana & 3 & 0,2344 & 0,0793 & 0,2344 & 0,5480 \\
Myrcia aff.obtecta & 2 & 0,1563 & 0,2175 & 0,1563 & 0,5300 \\
Didymopanax angustissimus & 1 & 0,0781 & 0,3650 & 0,0781 & 0,5212 \\
Chrysophyllum viride & 1 & 0,0781 & 0,3462 & 0,0781 & 0,5025 \\
Vochysia sp. 1 & 1 & 0,0781 & 0,3416 & 0,0781 & 0,4978 \\
Buchenavia kleinii & 1 & 0,0781 & 0,3324 & 0,0781 & 0,4887 \\
Tibouchina sellowiana & 2 & 0,1563 & 0,1731 & 0,1563 & 0,4856 \\
Zollernia illicifolia & 2 & 0,1563 & 0,1181 & 0,1563 & 0,4306 \\
Calycorectes australis & 1 & 0,0781 & 0,2624 & 0,0781 & 0,4186 \\
Symplocos variabilis & 2 & 0,1563 & 0,0871 & 0,1563 & 0,3996 \\
Ilex paraguariensis & 2 & 0,1563 & 0,0799 & 0,1563 & 0,3924 \\
Neomitranthes glomerata & 2 & 0,1563 & 0,0756 & 0,1563 & 0,3881 \\
Marlierea sp.1 & 1 & 0,0781 & 0,2298 & 0,0781 & 0,3861 \\
Eugenia cereja & 2 & 0,1563 & 0,0680 & 0,1563 & 0,3805 \\
Myrtaceae sp.4 & 2 & 0,1563 & 0,0606 & 0,1563 & 0,3731 \\
Myrtaceae sp.1 & 2 & 0,1563 & 0,0452 & 0,1563 & 0,3577 \\
Eugenia cerasiflora & 2 & 0,1563 & 0,0406 & 0,1563 & 0,3531 \\
Miconia sellowiana & 2 & 0,1563 & 0,0392 & 0,1563 & 0,3517 \\
Ilex amara & 2 & 0,1563 & 0,0345 & 0,1563 & 0,3470 \\
Rapanea ferruginea & 2 & 0,1563 & 0,0271 & 0,1563 & 0,3396 \\
Myrceugenia sp.1 & 2 & 0,1563 & 0,0237 & 0,1563 & 0,3362 \\
Marlierea reitzii & 2 & 0,1563 & 0,0232 & 0,1563 & 0,3357 \\
Alseis floribunda & 2 & 0,1563 & 0,0229 & 0,1563 & 0,3354 \\
Iiex taubertiana & 2 & 0,1563 & 0,0168 & 0,1563 & 0,3293 \\
Rollinia sericea & 2 & 0,1563 & 0,0137 & 0,1563 & 0,3262 \\
Prunus myrtifolia & 2 & 0,1563 & 0,0136 & 0,1563 & 0,3261 \\
Meliosma selowii & 2 & 0,1563 & 0,0124 & 0,1563 & 0,3249 \\
Citronella paniculata & 1 & 0,0781 & 0,1471 & 0,0781 & 0,3033 \\
Campomanesia guaviroba & 1 & 0,0781 & 0,1257 & 0,0781 & 0,2820 \\
Cecropia glaziovi & 1 & 0,0781 & 0,0643 & 0,0781 & 0,2205 \\
Zanthoxylum rhoifolium & 1 & 0,0781 & 0,0559 & 0,0781 & 0,2121 \\
Clethra scabra & 1 & 0,0781 & 0,0540 & 0,0781 & 0,2103 \\
& & & & &
\end{tabular}


Tabela 6. Relação das espécies em ordem decrescente de IVI, amostradas pelo método de quadrantes, na Grade-1, instalada na Floresta Ombrófila Densa, no Parque Estadual Carlos Botelho.SP.Brasil. Ni - Número de Indivíduos; DR Densidade Relativa; DOR - Dominância Relativa; FR - Freqüência Relativa e IVI - Índice de Valor de Importância

\begin{tabular}{lcrrrr}
\hline ESPECIES & $\mathrm{Ni}$ & $\mathrm{DR}$ & $\mathrm{DOR}$ & $\mathrm{FR}$ & IVI \\
\hline Talauma ovata & 1 & 0,0781 & 0,0499 & 0,0781 & 0,2061 \\
Aegiphila sellowiana & 1 & 0,0781 & 0,0487 & 0,0781 & 0,2049 \\
Rhodostemenodaphne macrocalyx & 1 & 0,0781 & 0,0409 & 0,0781 & 0,1972 \\
Coussapoa microcarpa & 1 & 0,0781 & 0,0373 & 0,0781 & 0,1935 \\
Mollinedia oligotricha & 1 & 0,0781 & 0,0363 & 0,0781 & 0,1925 \\
Piptocarpha macropoda & 1 & 0,0781 & 0,0343 & 0,0781 & 0,1905 \\
Eugenia sp.4 & 1 & 0,0781 & 0,0292 & 0,0781 & 0,1854 \\
Vernonia diffusa & 1 & 0,0781 & 0,0274 & 0,0781 & 0,1836 \\
Calyptranthes sp.3 & 1 & 0,0781 & 0,0270 & 0,0781 & 0,1832 \\
Ocotea vaccinioides & 1 & 0,0781 & 0,0216 & 0,0781 & 0,1779 \\
Myrciaria sp.1 & 1 & 0,0781 & 0,0190 & 0,0781 & 0,1753 \\
Piptocarpha sp. & 1 & 0,0781 & 0,0190 & 0,0781 & 0,1753 \\
Fabaceae 1 & 1 & 0,0781 & 0,0172 & 0,0781 & 0,1735 \\
Guarea macrophylla & 1 & 0,0781 & 0,0169 & 0,0781 & 0,1732 \\
Ecclinusa ramiflora & 1 & 0,0781 & 0,0140 & 0,0781 & 0,1702 \\
Psychotria suterella & 1 & 0,0781 & 0,0131 & 0,0781 & 0,1693 \\
Miconia cubatanensis & 1 & 0,0781 & 0,0100 & 0,0781 & 0,1662 \\
Endlicheria paniculata & 1 & 0,0781 & 0,0092 & 0,0781 & 0,1654 \\
Aiouea acaradomatifera & 1 & 0,0781 & 0,0087 & 0,0781 & 0,1649 \\
Ocotea velloziana & 1 & 0,0781 & 0,0087 & 0,0781 & 0,1649 \\
Allophylus edulis & 1 & 0,0781 & 0,0085 & 0,0781 & 0,1647 \\
Inga marginata & 1 & 0,0781 & 0,0073 & 0,0781 & 0,1635 \\
Cordia sp. & 1 & 0,0781 & 0,0066 & 0,0781 & 0,1629 \\
Solanum pseudoquina & 1 & 0,0781 & 0,0066 & 0,0781 & 0,1629 \\
Cedrella fissilis & 1 & 0,0781 & 0,0062 & 0,0781 & 0,1625 \\
Quiina magallano-gomezii & 1 & 0,0781 & 0,0062 & 0,0781 & 0,1625 \\
Myrcia aff. glabra & 1 & 0,0781 & 0,0058 & 0,0781 & 0,1621 \\
Plinia complanata & 1 & 0,0781 & 0,0056 & 0,0781 & 0,1619 \\
Myrtaceae sp.3 & 1 & 0,0781 & 0,0052 & 0,0781 & 0,1615 \\
Myrcia heringii & 1 & 0,0781 & 0,0047 & 0,0781 & 0,1609 \\
Rollinia parviflora & 1 & 0,0781 & 0,0045 & 0,0781 & 0,1607 \\
Rapanea gardneriana & 1 & 0,0781 & 0,0043 & 0,0781 & 0,1606 \\
Beilschmiedia emarginata & 1 & 0,0781 & 0,0004 & 0,0781 & 0,1567 \\
\hline & & & & &
\end{tabular}


Na Tabela 7 observa-se que para o método de relascopia, as dez espécies com maior valor de IVI foram: Euterpe edulis $(21,13)$, Micropholis sp. $(17,05)$, Ocotea catharinensis (12,91), Micropholis crassipedicellata (11,34), Vantanea compacta $(10,19)$, Pouteria bullata $(8,40)$, Ocotea bicolor $(7,91)$, Alchornea triplinervia $(7,54)$, Myrcia pubipetala $(6,71)$, e Cabralea canjerana $(6,16)$. 
Tabela 7. Relação de espécies em ordem decrescente de IVI, amostradas pelo método de relascopia, na Grade-1, instalada na Floresta Ombrófila Densa, no Parque Estadual Carlos Botelho. SP. Brasil. Ni - Número de Indivíduos; DR Densidade Relativa; DOR - Dominância Relativa; FR - Freqüência Relativa e IVI - Índice de Valor de Importância

\begin{tabular}{|c|c|c|c|c|c|}
\hline ESPECIES & $\mathrm{Ni}$ & DR & DOR & FR & IVI \\
\hline Euterpe edulis & 20 & 14,608 & 3,195 & 3,327 & 21,130 \\
\hline Micropholis sp. & 42 & 4,984 & 6,709 & 5,360 & 17,054 \\
\hline Ocotea catharinensis & 41 & 1,187 & 6,550 & 5,176 & 12,913 \\
\hline Micropholis crassipedicellata & 36 & 0,423 & 5,751 & 5,176 & 11,349 \\
\hline Vantanea compacta & 20 & 3,301 & 3,195 & 3,697 & 10,193 \\
\hline Pouteria bullata & 19 & 2,780 & 3,035 & 2,588 & 8,403 \\
\hline Ocotea bicolor & 16 & 2,952 & 2,556 & 2,403 & 7,911 \\
\hline Alchornea triplinervia & 20 & 1,389 & 3,195 & 2,957 & 7,541 \\
\hline Myrcia pubipetala & 5 & 5,179 & 0,799 & 0,739 & 6,717 \\
\hline Cabralea canjerana & 18 & 0,676 & 2,716 & 2,773 & 6,165 \\
\hline Guapira opposita & 13 & 1,706 & 1,917 & 2,033 & 5,656 \\
\hline Ocotea sp. & 16 & 0,694 & 2,396 & 1,848 & 4,938 \\
\hline Alibertia sp. & 6 & 2,592 & 0,958 & 1,109 & 4,659 \\
\hline Bathysa australis & 9 & 1,808 & 1,438 & 1,294 & 4,540 \\
\hline Meliosma sinuata & 7 & 1,843 & 1,438 & 1,109 & 4,389 \\
\hline Mollinedia oligantha & 6 & 2,292 & 0,799 & 0,924 & 4,015 \\
\hline Ormosia dasycarpa & 8 & 1,251 & 1,278 & 1,294 & 3,823 \\
\hline Cryptocarya sp.1 & 9 & 0,574 & 1,438 & 1,479 & 3,490 \\
\hline Mollinedia schottiana & 3 & 2,412 & 0,479 & 0,555 & 3,446 \\
\hline Ocotea elegans & 9 & 0,299 & 1,438 & 1,664 & 3,400 \\
\hline Matayba juglandifolia & 7 & 1,162 & 1,118 & 1,109 & 3,389 \\
\hline Eugenia stictosepala & 1 & 2,450 & 0,319 & 0,370 & 3,140 \\
\hline Chionanthus filiformis & 3 & 1,973 & 0,479 & 0,555 & 3,007 \\
\hline Eugenia capitulifera & 1 & 1,612 & 0,639 & 0,739 & 2,991 \\
\hline Posoqueria acutifolia & 3 & 1,935 & 0,479 & 0,555 & 2,968 \\
\hline Tapirira guianensis & 8 & 0,347 & 1,278 & 1,109 & 2,734 \\
\hline Ocotea aciphylla & 8 & 0,476 & 1,278 & 0,924 & 2,678 \\
\hline Matayba guianensis & 7 & 0,247 & 1,118 & 1,294 & 2,659 \\
\hline Ilex amara & 2 & 1,892 & 0,319 & 0,370 & 2,581 \\
\hline Copaifera trapezifolia & 7 & 0,314 & 1,118 & 1,109 & 2,542 \\
\hline Myrocarpus frondosus & 6 & 0,255 & 0,958 & 1,109 & 2,323 \\
\hline Hirtella hebeclada & 5 & 0,587 & 0,799 & 0,924 & 2,310 \\
\hline Ocotea dispersa & 4 & 0,877 & 0,639 & 0,739 & 2,256 \\
\hline Esenbeckia sp. & 3 & 1,546 & 0,319 & 0,370 & 2,235 \\
\hline Pouteria caimito & 3 & 1,201 & 0,479 & 0,555 & 2,235 \\
\hline
\end{tabular}


Tabela 7. Relação de espécies em ordem decrescente de IVI, amostradas pelo método de relascopia, na Grade-1, instalada na Floresta Ombrófila Densa, no Parque Estadual Carlos Botelho. SP. Brasil. Ni - Número de Indivíduos; DR Densidade Relativa; DOR - Dominância Relativa; FR - Freqüência Relativa e IVI - Índice de Valor de Importância

\begin{tabular}{|c|c|c|c|c|c|}
\hline ESPECIES & $\mathrm{Ni}$ & $\mathrm{DR}$ & DOR & FR & IVI \\
\hline Ocotea pulchra & 5 & 0,491 & 0,799 & 0,924 & 2,214 \\
\hline Symplocos falcata & 5 & 0,484 & 0,799 & 0,924 & 2,207 \\
\hline Aspidosperma sp. & 5 & 0,455 & 0,799 & 0,924 & 2,178 \\
\hline Drimys winteri & 3 & 1,318 & 0,479 & 0,370 & 2,167 \\
\hline Tibouchina pulchra & 6 & 0,290 & 0,958 & 0,739 & 1,988 \\
\hline Pithecellobium sp. & 1 & 1,117 & 0,479 & 0,370 & 1,966 \\
\hline Prunus myrtifolia & 5 & 0,170 & 0,799 & 0,924 & 1,893 \\
\hline Cryptocarya sp. & 6 & 0,160 & 0,958 & 0,739 & 1,858 \\
\hline Inga sellowiana & 3 & 1,504 & 0,160 & 0,185 & 1,849 \\
\hline Guatteria australis & 3 & 0,942 & 0,479 & 0,370 & 1,791 \\
\hline Ocotea odorifera & 5 & 0,248 & 0,799 & 0,739 & 1,786 \\
\hline Myrceugenia sp.1 & 3 & 0,752 & 0,479 & 0,555 & 1,785 \\
\hline Myrtaceae sp.1 & 3 & 0,749 & 0,479 & 0,555 & 1,783 \\
\hline Amaioua intermedia & 3 & 0,699 & 0,479 & 0,555 & 1,733 \\
\hline Sclerolobium sp. & 5 & 0,337 & 0,799 & 0,555 & 1,690 \\
\hline Parinari excelsa & 4 & 0,272 & 0,639 & 0,739 & 1,650 \\
\hline Cryptocarya moschata & 5 & 0,085 & 0,799 & 0,739 & 1,623 \\
\hline Rapanea umbellata & 3 & 0,583 & 0,479 & 0,555 & 1,617 \\
\hline Tibouchina sp. & 3 & 0,523 & 0,479 & 0,555 & 1,556 \\
\hline Pterocarpus rohrii & 4 & 0,160 & 0,639 & 0,739 & 1,538 \\
\hline Esenbeckia grandiflora & 3 & 0,463 & 0,479 & 0,555 & 1,497 \\
\hline Chionanthus sp. & 3 & 0,461 & 0,479 & 0,555 & 1,495 \\
\hline Protium hepatphyllum & 4 & 0,112 & 0,639 & 0,739 & 1,490 \\
\hline Lamanonia ternata & 4 & 0,102 & 0,639 & 0,739 & 1,480 \\
\hline Capsicodendron dinisii & 2 & 0,778 & 0,319 & 0,370 & 1,468 \\
\hline Miconia саbиси & 2 & 0,762 & 0,319 & 0,370 & 1,452 \\
\hline Aniba viridis & 2 & 0,758 & 0,319 & 0,370 & 1,447 \\
\hline Maytenus robusta & 3 & 0,347 & 0,479 & 0,555 & 1,380 \\
\hline Miconia sp. & 1 & 1,027 & 0,160 & 0,185 & 1,371 \\
\hline Myrocarpus sp. & 3 & 0,319 & 0,479 & 0,555 & 1,352 \\
\hline Ilex theazans & 2 & 0,656 & 0,319 & 0,370 & 1,345 \\
\hline Marlierea tomentosa & 1 & 0,646 & 0,319 & 0,370 & 1,335 \\
\hline Cupania vernalis & 3 & 0,268 & 0,479 & 0,555 & 1,302 \\
\hline Rollinia parviflora & 1 & 0,893 & 0,160 & 0,185 & 1,237 \\
\hline Ilex paraguariensis & 3 & 0,193 & 0,479 & 0,555 & 1,227 \\
\hline
\end{tabular}


Tabela 7. Relação de espécies em ordem decrescente de IVI, amostradas pelo método de relascopia, na Grade-1, instalada na Floresta Ombrófila Densa, no Parque Estadual Carlos Botelho. SP. Brasil. Ni - Número de Indivíduos; DR Densidade Relativa; DOR - Dominância Relativa; FR - Freqüência Relativa e IVI - Índice de Valor de Importância

\begin{tabular}{|c|c|c|c|c|c|}
\hline ESPECIES & $\mathrm{Ni}$ & $\mathrm{DR}$ & DOR & FR & IVI \\
\hline Eugenia sp. & 2 & 0,178 & 0,479 & 0,555 & 1,212 \\
\hline Myrcia hatschbachii & 2 & 0,693 & 0,319 & 0,185 & 1,197 \\
\hline Eugenia pruinosa & 1 & 0,109 & 0,479 & 0,555 & 1,143 \\
\hline Coussarea sp. & 3 & 0,424 & 0,319 & 0,370 & 1,113 \\
\hline Pera glabrata & 2 & 0,417 & 0,319 & 0,370 & 1,106 \\
\hline Didymopanax navarroi & 3 & 0,067 & 0,479 & 0,555 & 1,101 \\
\hline Xylopia langsdorfiana & 2 & 0,407 & 0,319 & 0,370 & 1,096 \\
\hline Didymopanax sp. & 3 & 0,181 & 0,479 & 0,370 & 1,030 \\
\hline Attalea dubia & 3 & 0,146 & 0,479 & 0,370 & 0,995 \\
\hline Hyeronima sp. & 2 & 0,603 & 0,160 & 0,185 & 0,948 \\
\hline Byrsonima sp. & 2 & 0,222 & 0,319 & 0,370 & 0,911 \\
\hline Eugenia sp.1 & 1 & 0,198 & 0,319 & 0,370 & 0,887 \\
\hline Eugenia riedeliana & 3 & 0,519 & 0,160 & 0,185 & 0,864 \\
\hline Weinmannia sp. & 2 & 0,140 & 0,319 & 0,370 & 0,829 \\
\hline Cordia sellowiana & 3 & 0,124 & 0,319 & 0,370 & 0,813 \\
\hline Psydium cf. myrtoides & 2 & 0,102 & 0,319 & 0,370 & 0,791 \\
\hline Gomidesia tijucensis & 1 & 0,435 & 0,160 & 0,185 & 0,780 \\
\hline Marlierea reitzii & 1 & 0,435 & 0,160 & 0,185 & 0,780 \\
\hline Myrtaceae sp.3 & 3 & 0,088 & 0,319 & 0,370 & 0,777 \\
\hline Diploon cuspidatum & 3 & 0,087 & 0,319 & 0,370 & 0,777 \\
\hline Talauma ovata & 2 & 0,087 & 0,319 & 0,370 & 0,776 \\
\hline Vochysia sp.1 & 2 & 0,071 & 0,319 & 0,370 & 0,760 \\
\hline Nectandra oppositfolia & 2 & 0,067 & 0,319 & 0,370 & 0,756 \\
\hline Iiex taubertiana & 2 & 0,065 & 0,319 & 0,370 & 0,754 \\
\hline Alibertia myrciifolia & 2 & 0,050 & 0,319 & 0,370 & 0,739 \\
\hline Eugenia cambucarana & 4 & 0,035 & 0,319 & 0,370 & 0,725 \\
\hline Sclerolobium denudatum & 2 & 0,030 & 0,319 & 0,370 & 0,719 \\
\hline Chrysophyllum sp. & 2 & 0,024 & 0,319 & 0,370 & 0,713 \\
\hline Chrysophyllum viride & 2 & 0,023 & 0,319 & 0,370 & 0,713 \\
\hline Eugenia melanogina & 1 & 0,351 & 0,160 & 0,185 & 0,696 \\
\hline Eugenia mosenii & 3 & 0,313 & 0,160 & 0,185 & 0,657 \\
\hline Dalbergia brasiliensis & 1 & 0,289 & 0,160 & 0,185 & 0,634 \\
\hline Xylopia sp. & 1 & 0,289 & 0,160 & 0,185 & 0,634 \\
\hline Myrcia sp.1 & 1 & 0,268 & 0,160 & 0,185 & 0,613 \\
\hline Inga sessilis & 1 & 0,229 & 0,160 & 0,185 & 0,574 \\
\hline
\end{tabular}


Tabela 7. Relação de espécies em ordem decrescente de IVI, amostradas pelo método de relascopia, na Grade-1, instalada na Floresta Ombrófila Densa, no Parque Estadual Carlos Botelho. SP. Brasil. Ni - Número de Indivíduos; DR Densidade Relativa; DOR - Dominância Relativa; FR - Freqüência Relativa e IVI - Índice de Valor de Importância

\begin{tabular}{|c|c|c|c|c|c|}
\hline ESPECIES & $\mathrm{Ni}$ & DR & DOR & FR & IVI \\
\hline Fabaceae 1 & 1 & 0,217 & 0,160 & 0,185 & 0,562 \\
\hline Dalbergia frutescens & 1 & 0,214 & 0,160 & 0,185 & 0,559 \\
\hline Siphoneugena sp. & 1 & 0,206 & 0,160 & 0,185 & 0,551 \\
\hline Eugenia sp.4 & 1 & 0,203 & 0,160 & 0,185 & 0,548 \\
\hline Casearia sylvestris & 1 & 0,146 & 0,160 & 0,185 & 0,491 \\
\hline Byrsonima ligustrifolia & 1 & 0,138 & 0,160 & 0,185 & 0,483 \\
\hline Zollernia illicifolia & 1 & 0,129 & 0,160 & 0,185 & 0,473 \\
\hline Copaifera langsdorffii & 1 & 0,099 & 0,160 & 0,185 & 0,444 \\
\hline Eugenia beaurepairiana & 2 & 0,090 & 0,160 & 0,185 & 0,435 \\
\hline Myrcia fallax & 1 & 0,086 & 0,160 & 0,185 & 0,430 \\
\hline Ixora burchelliana & 1 & 0,080 & 0,160 & 0,185 & 0,425 \\
\hline Ocotea silvestris & 1 & 0,080 & 0,160 & 0,185 & 0,425 \\
\hline Gomidesia spectabilis & 1 & 0,078 & 0,160 & 0,185 & 0,423 \\
\hline Solanum excelsum & 1 & 0,077 & 0,160 & 0,185 & 0,422 \\
\hline Myrcia aff. Glabra & 1 & 0,075 & 0,160 & 0,185 & 0,420 \\
\hline Eugenia sp.3 & 1 & 0,069 & 0,160 & 0,185 & 0,413 \\
\hline Coussapoa sp. & 1 & 0,067 & 0,160 & 0,185 & 0,412 \\
\hline Eugenia sp.6 & 2 & 0,067 & 0,160 & 0,185 & 0,412 \\
\hline Calyptranthes sp.2 & 1 & 0,060 & 0,160 & 0,185 & 0,404 \\
\hline Casearia decandra & 1 & 0,059 & 0,160 & 0,185 & 0,403 \\
\hline Byrsonima myricifolia & 1 & 0,058 & 0,160 & 0,185 & 0,402 \\
\hline Citronella paniculata & 1 & 0,057 & 0,160 & 0,185 & 0,402 \\
\hline Tibouchina sellowiana & 1 & 0,057 & 0,160 & 0,185 & 0,402 \\
\hline Myrcia aff.obtecta & 1 & 0,054 & 0,160 & 0,185 & 0,399 \\
\hline Persea sp.1 & 1 & 0,051 & 0,160 & 0,185 & 0,396 \\
\hline Plinia pauciflora & 1 & 0,051 & 0,160 & 0,185 & 0,395 \\
\hline Eugenia cerasiflora & 1 & 0,048 & 0,160 & 0,185 & 0,392 \\
\hline Heisteria silvianii & 1 & 0,043 & 0,160 & 0,185 & 0,387 \\
\hline Cordia sp. & 1 & 0,040 & 0,160 & 0,185 & 0,384 \\
\hline Dahlstedtia pinnata & 1 & 0,040 & 0,160 & 0,185 & 0,384 \\
\hline Myrcia sp.6 & 1 & 0,040 & 0,160 & 0,185 & 0,384 \\
\hline Weinmannia paulliniifolia & 1 & 0,040 & 0,160 & 0,185 & 0,384 \\
\hline Psychotria velloziana. & 6 & 0,038 & 0,160 & 0,185 & 0,383 \\
\hline Myrceugenia seriatoramosa & 1 & 0,038 & 0,160 & 0,185 & 0,382 \\
\hline Protium sp. & 1 & 0,037 & 0,160 & 0,185 & 0,382 \\
\hline
\end{tabular}


Tabela 7. Relação de espécies em ordem decrescente de IVI, amostradas pelo método de relascopia, na Grade-1, instalada na Floresta Ombrófila Densa, no Parque Estadual Carlos Botelho. SP. Brasil. Ni - Número de Indivíduos; DR Densidade Relativa; DOR - Dominância Relativa; FR - Freqüência Relativa e IVI - Índice de Valor de Importância

\begin{tabular}{lcrrrr}
\hline ESPECIES & Ni & DR & DOR & FR & IVI \\
\hline Eugenia florida & 1 & 0,036 & 0,160 & 0,185 & 0,380 \\
Miconia sp.1 & 1 & 0,033 & 0,160 & 0,185 & 0,378 \\
Symplocos celastrinea & 1 & 0,032 & 0,160 & 0,185 & 0,377 \\
Aspidosperma olivaceum & 1 & 0,031 & 0,160 & 0,185 & 0,375 \\
Hyeronima alchorneoides & 1 & 0,031 & 0,160 & 0,185 & 0,375 \\
Symplocos variabilis & 1 & 0,026 & 0,160 & 0,185 & 0,371 \\
Aiouea acaradomatifera & 1 & 0,025 & 0,160 & 0,185 & 0,370 \\
Siphoneugena densiflora & 1 & 0,023 & 0,160 & 0,185 & 0,368 \\
Calycorectes sp. & 1 & 0,021 & 0,160 & 0,185 & 0,366 \\
Ocotea mosenii & 1 & 0,018 & 0,160 & 0,185 & 0,363 \\
Persea pyrifolia & 1 & 0,017 & 0,160 & 0,185 & 0,361 \\
Campomanesia sp. & 1 & 0,014 & 0,160 & 0,185 & 0,359 \\
Cinnamomum sp. & 1 & 0,012 & 0,160 & 0,185 & 0,357 \\
Andira anthelmia & 1 & 0,011 & 0,160 & 0,185 & 0,356 \\
Sloanea sp. & 1 & 0,009 & 0,160 & 0,185 & 0,354 \\
Ecclinusa ramiflora & 1 & 0,009 & 0,160 & 0,185 & 0,354 \\
\hline
\end{tabular}

Nas Tabelas 08, 09 e 10, são apresentadas as relações das espécies, em ordem decrescente de IVI, amostradas respectivamente pelo emprego dos métodos de parcelas, quadrantes e relascopia, na Grade 2 de amostragem.

Para o método de parcelas, as espécies com maior valor de IVI foram: Euterpe edulis (15,71), Alchornea triplinervia (10,52), Guapira opposita $(8,14)$, Ocotea catharinensis (8,1), Mollinedia oligantha (7,01), Bathysa australis (6,12), Cabralea canjerana (5,55), Marlierea parviflora (4,93), Coussarea sp. (4,38), Mollinedia schottiana $(4,29)$ e Eugenia stictosepala $(4,29)$. (Tabela 08).

Estas espécies foram reponsáveis pela amostragem de 33\% do total de indivíduos obtidos pelo método de parcelas na Grade 2. 
Tabela 8. Relação de espécies em ordem decrescente de IVI, amostradas pelo método de parcelas, na Grade-2, instalada na Floresta Ombrófila Densa, no Parque Estadual Carlos Botelho.SP.Brasil. Ni - Número de Indivíduos; FR Freqüência Relativa; DR - Densidade Relativa; DOR - Dominância Relativa e IVI - Índice de Valor de Importância

\begin{tabular}{|c|c|c|c|c|c|}
\hline ESPECIE & $\mathrm{Ni}$ & $\mathrm{DR}$ & DOR & FR & IVI \\
\hline Euterpe edulis & 1185 & 10,97324 & 3,22850 & 1,51086 & 15,71260 \\
\hline Alchornea triplinervia & 134 & 1,55570 & 7,74555 & 1,22757 & 10,52882 \\
\hline Guapira opposita & 244 & 2,63913 & 4,23140 & 1,27479 & 8,14532 \\
\hline Ocotea catharinensis & 203 & 2,18539 & 4,78586 & 1,13314 & 8,10439 \\
\hline Mollinedia oligantha & 324 & 3,84295 & 1,99570 & 1,18036 & 7,01901 \\
\hline Bathysa australis & 242 & 2,31503 & 2,50855 & 1,29839 & 6,12198 \\
\hline Cabralea canjerana & 75 & 0,80563 & 3,75645 & 0,99150 & 5,55358 \\
\hline Marlierea parviflora & 230 & 2,13909 & 1,45352 & 1,34561 & 4,93822 \\
\hline Coussarea sp. & 245 & 2,36133 & 0,74774 & 1,27479 & 4,38386 \\
\hline Mollinedia schottiana & 189 & 2,10205 & 0,75692 & 1,44004 & 4,29900 \\
\hline Eugenia stictosepala . & 263 & 2,44467 & 0,74142 & 1,10954 & 4,29563 \\
\hline Pterocarpus rohrii & 99 & 0,92601 & 1,74234 & 1,06232 & 3,73068 \\
\hline Posoqueria acutifolia & 153 & 1,46310 & 1,00519 & 1,13314 & 3,60143 \\
\hline Rudgea jasminoides & 192 & 1,85202 & 0,46838 & 1,22757 & 3,54797 \\
\hline Morta & 109 & 0,93527 & 1,39224 & 1,08593 & 3,41344 \\
\hline Sorocea bonplandii & 134 & 1,26864 & 0,82189 & 1,18036 & 3,27089 \\
\hline Ocotea elegans & 65 & 0,92601 & 1,50337 & 0,75543 & 3,18482 \\
\hline Pouteria bullata & 74 & 0,68525 & 1,54228 & 0,82625 & 3,05378 \\
\hline Parinari excelsa & 73 & 0,67599 & 1,62681 & 0,70822 & 3,01101 \\
\hline Eugenia subavenia & 158 & 1,48162 & 0,38818 & 1,01511 & 2,88491 \\
\hline Eugenia mosenii & 132 & 1,27790 & 0,65783 & 0,89707 & 2,83280 \\
\hline Ocotea bicolor & 67 & 0,83341 & 1,32223 & 0,66100 & 2,81664 \\
\hline Myrceugenia myrcioides & 132 & 1,32420 & 0,41873 & 1,03872 & 2,78165 \\
\hline Matayba juglandifolia & 98 & 1,01861 & 0,61298 & 1,13314 & 2,76473 \\
\hline Vantanea compacta & 45 & 0,45375 & 1,61748 & 0,56657 & 2,63780 \\
\hline Myrciaria sp.2 & 92 & 0,98157 & 0,84944 & 0,75543 & 2,58644 \\
\hline Chrysophyllum viride & 39 & 0,41671 & 1,63150 & 0,51936 & 2,56757 \\
\hline Myrocarpus frondosus & 79 & 0,73155 & 0,87131 & 0,87347 & 2,47633 \\
\hline Eugenia cuprea & 120 & 1,33346 & 0,30161 & 0,82625 & 2,46132 \\
\hline Matayba guianensis & 54 & 0,50931 & 1,21994 & 0,70822 & 2,43746 \\
\hline Hyeronima alchorneoides & 45 & 0,41671 & 1,33797 & 0,66100 & 2,41567 \\
\hline Cryptocarya moschata & 39 & 0,36114 & 1,37182 & 0,61379 & 2,34675 \\
\hline Maytenus robusta & 70 & 0,92601 & 0,71873 & 0,68461 & 2,32935 \\
\hline Eugenia neoglomerata & 104 & 0,99083 & 0,37011 & 0,94429 & 2,30523 \\
\hline Alibertia sp. 1 & 111 & 1,12973 & 0,27129 & 0,82625 & 2,22727 \\
\hline
\end{tabular}


Tabela 8. Relação de espécies em ordem decrescente de IVI, amostradas pelo método de parcelas, na Grade-2, instalada na Floresta Ombrófila Densa, no Parque Estadual Carlos Botelho.SP.Brasil. Ni - Número de Indivíduos; FR Freqüência Relativa; DR - Densidade Relativa; DOR - Dominância Relativa e IVI - Índice de Valor de Importância

\begin{tabular}{|c|c|c|c|c|c|}
\hline ESPECIE & $\mathrm{Ni}$ & $\mathrm{DR}$ & DOR & FR & IVI \\
\hline Didymopanax navarroi & 36 & 0,34262 & 1,21206 & 0,66100 & 2,21569 \\
\hline Heisteria silvianii & 50 & 0,47227 & 1,06818 & 0,66100 & 2,20144 \\
\hline Myrtaceae sp.2 & 80 & 0,75007 & 0,47299 & 0,87347 & 2,09653 \\
\hline Calycorectes australis & 59 & 0,54635 & 0,68590 & 0,82625 & 2,05850 \\
\hline Chionanthus filiformis & 83 & 0,78711 & 0,44202 & 0,77904 & 2,00817 \\
\hline Eugenia melanogina & 77 & 0,76859 & 0,53910 & 0,66100 & 1,96869 \\
\hline Copaifera langsdorffii. & 51 & 0,47227 & 0,81028 & 0,66100 & 1,94355 \\
\hline Amaioua intermedia & 67 & 0,62969 & 0,48462 & 0,77904 & 1,89334 \\
\hline Alibertia myrciifolia & 85 & 0,82415 & 0,34785 & 0,70822 & 1,88022 \\
\hline Rapanea umbellata & 62 & 0,60191 & 0,47607 & 0,77904 & 1,85701 \\
\hline Eugenia riedeliana & 69 & 0,65747 & 0,32409 & 0,84986 & 1,83141 \\
\hline Cordia trichotoma & 53 & 0,49079 & 0,69659 & 0,61379 & 1,80117 \\
\hline Sclerolobium denudatum & 23 & 0,21298 & 1,11642 & 0,42493 & 1,75433 \\
\hline Eugenia capitulifera & 67 & 0,62043 & 0,30072 & 0,82625 & 1,74740 \\
\hline Eugenia sp.6 & 62 & 0,57413 & 0,39633 & 0,75543 & 1,72588 \\
\hline Ocotea teleiandra & 57 & 0,63895 & 0,25300 & 0,80264 & 1,69459 \\
\hline Hirtella hebeclada & 60 & 0,55561 & 0,46735 & 0,66100 & 1,68396 \\
\hline Siphoneugena densiflora & 53 & 0,49079 & 0,37066 & 0,77904 & 1,64048 \\
\hline Ouratea parviflora & 86 & 0,83341 & 0,27244 & 0,51936 & 1,62521 \\
\hline Marlierea tomentosa & 64 & 0,64821 & 0,33768 & 0,63739 & 1,62328 \\
\hline Mollinedia oligotricha & 61 & 0,75007 & 0,10550 & 0,73182 & 1,58739 \\
\hline Pithecellobium langsdorffi & 60 & 0,55561 & 0,62421 & 0,37771 & 1,55753 \\
\hline Gomidesia anacardiaefolia & 64 & 0,61117 & 0,11465 & 0,82625 & 1,55207 \\
\hline Myrceugenia glaucescens & 47 & 0,43523 & 0,39576 & 0,70822 & 1,53920 \\
\hline Citronella paniculata & 41 & 0,41671 & 0,42740 & 0,68461 & 1,52871 \\
\hline Gomidesia riedeliana & 37 & 0,37040 & 0,50311 & 0,61379 & 1,48730 \\
\hline Marlierea reitzii & 29 & 0,26854 & 0,71011 & 0,47214 & 1,45080 \\
\hline Cupania vernalis & 45 & 0,42597 & 0,28292 & 0,70822 & 1,41710 \\
\hline Duguetia lanceolata & 55 & 0,54635 & 0,48695 & 0,37771 & 1,41101 \\
\hline Ocotea aciphylla & 33 & 0,44449 & 0,59604 & 0,35411 & 1,39463 \\
\hline Capsicodendron dinisii & 30 & 0,28706 & 0,60447 & 0,49575 & 1,38728 \\
\hline Casearia decandra & 40 & 0,37966 & 0,28222 & 0,63739 & 1,29927 \\
\hline Rollinia sericea & 34 & 0,32410 & 0,41565 & 0,54297 & 1,28272 \\
\hline Eugenia cerasiflora & 40 & 0,37966 & 0,24011 & 0,63739 & 1,25717 \\
\hline Garcinia gadneriana & 45 & 0,43523 & 0,09633 & 0,66100 & 1,19256 \\
\hline
\end{tabular}


Tabela 8. Relação de espécies em ordem decrescente de IVI, amostradas pelo método de parcelas, na Grade-2, instalada na Floresta Ombrófila Densa, no Parque Estadual Carlos Botelho.SP.Brasil. Ni - Número de Indivíduos; FR Freqüência Relativa; DR - Densidade Relativa; DOR - Dominância Relativa e IVI - Índice de Valor de Importância

\begin{tabular}{|c|c|c|c|c|c|}
\hline ESPECIE & $\mathrm{Ni}$ & DR & DOR & FR & IVI \\
\hline Andira anthelmia & 32 & 0,30558 & 0,36068 & 0,51936 & 1,18562 \\
\hline Marlierea sp.1 & 33 & 0,31484 & 0,49497 & 0,35411 & 1,16392 \\
\hline Eugenia sp.3 & 32 & 0,30558 & 0,26004 & 0,59018 & 1,15580 \\
\hline Eugenia sp.1 & 43 & 0,39819 & 0,13925 & 0,61379 & 1,15122 \\
\hline Casearia sylvestris & 36 & 0,33336 & 0,16028 & 0,63739 & 1,13104 \\
\hline Chomelia catharinae & 41 & 0,45375 & 0,12742 & 0,54297 & 1,12413 \\
\hline Aniba viridis & 27 & 0,32410 & 0,27414 & 0,51936 & 1,11760 \\
\hline Mollinedia elegans & 48 & 0,50931 & 0,06454 & 0,54297 & 1,11681 \\
\hline Eugenia sp.2 & 24 & 0,22224 & 0,48660 & 0,40132 & 1,11016 \\
\hline Jacaranda puberula & 17 & 0,15742 & 0,61096 & 0,33050 & 1,09888 \\
\hline Protium hepatphyllum & 27 & 0,25002 & 0,50361 & 0,33050 & 1,08413 \\
\hline Alseis floribunda & 29 & 0,27780 & 0,34631 & 0,44854 & 1,07265 \\
\hline Eugenia pruinosa & 28 & 0,26854 & 0,32120 & 0,47214 & 1,06189 \\
\hline Myrcia aff. Macrocarpa & 33 & 0,31484 & 0,26858 & 0,47214 & 1,05557 \\
\hline Byrsonima ligustrifolia & 34 & 0,31484 & 0,31182 & 0,42493 & 1,05159 \\
\hline Coccoloba sp.1 & 34 & 0,33336 & 0,26259 & 0,44854 & 1,04449 \\
\hline Gomidesia schaueriana & 23 & 0,21298 & 0,44961 & 0,37771 & 1,04031 \\
\hline Cupania oblongifolia & 28 & 0,26854 & 0,31146 & 0,44854 & 1,02854 \\
\hline Myrcia tenuivenosa & 20 & 0,18520 & 0,50873 & 0,33050 & 1,02443 \\
\hline Myrcia fallax & 32 & 0,29632 & 0,14869 & 0,56657 & 1,01159 \\
\hline Campomanesia guaviroba & 13 & 0,12038 & 0,64934 & 0,21246 & 0,98218 \\
\hline Gomidesia spectabilis & 35 & 0,32410 & 0,05545 & 0,56657 & 0,94612 \\
\hline Casearia obliqua & 27 & 0,25928 & 0,22969 & 0,44854 & 0,93751 \\
\hline Neomitranthes glomerata & 36 & 0,38892 & 0,15807 & 0,37771 & 0,92471 \\
\hline Guatteria australis & 30 & 0,37040 & 0,12699 & 0,42493 & 0,92233 \\
\hline Meliosma sinuata & 24 & 0,23150 & 0,28265 & 0,40132 & 0,91548 \\
\hline Coussapoa microcarpa & 6 & 0,05556 & 0,73569 & 0,11804 & 0,90928 \\
\hline Platymiscium floribundum & 27 & 0,25002 & 0,25686 & 0,40132 & 0,90820 \\
\hline Roupala brasiliensis & 23 & 0,23150 & 0,24852 & 0,42493 & 0,90496 \\
\hline Myrcia hatschbachii & 18 & 0,37040 & 0,29582 & 0,23607 & 0,90229 \\
\hline Ocotea mosenii & 8 & 0,08334 & 0,64738 & 0,16525 & 0,89597 \\
\hline Ocotea dispersa & 25 & 0,25002 & 0,17075 & 0,47214 & 0,89292 \\
\hline Psychotria suterella & 31 & 0,32410 & 0,12643 & 0,42493 & 0,87546 \\
\hline Cordia sp. 1 & 30 & 0,27780 & 0,21569 & 0,37771 & 0,87120 \\
\hline Tibouchina pulchra & 23 & 0,21298 & 0,36512 & 0,28329 & 0,86138 \\
\hline
\end{tabular}


Tabela 8. Relação de espécies em ordem decrescente de IVI, amostradas pelo método de parcelas, na Grade-2, instalada na Floresta Ombrófila Densa, no Parque Estadual Carlos Botelho.SP.Brasil. Ni - Número de Indivíduos; FR Freqüência Relativa; DR - Densidade Relativa; DOR - Dominância Relativa e IVI - Índice de Valor de Importância

\begin{tabular}{|c|c|c|c|c|c|}
\hline ESPECIE & $\mathrm{Ni}$ & $\mathrm{DR}$ & DOR & FR & IVI \\
\hline Psychotria velloziana & 20 & 0,19446 & 0,30669 & 0,35411 & 0,85526 \\
\hline Xylopia langsdorfiana & 27 & 0,25928 & 0,12226 & 0,47214 & 0,85369 \\
\hline Eugenia handroana & 26 & 0,24076 & 0,07846 & 0,51936 & 0,83858 \\
\hline Guarea macrophylla & 26 & 0,25002 & 0,11617 & 0,47214 & 0,83834 \\
\hline Myrceugenia campestris & 27 & 0,29632 & 0,05354 & 0,47214 & 0,82200 \\
\hline Diploon cuspidatum & 26 & 0,25002 & 0,21228 & 0,35411 & 0,81641 \\
\hline Myrtaceae sp.3 & 23 & 0,23150 & 0,20623 & 0,35411 & 0,79184 \\
\hline Weinmannia paulliniifolia & 18 & 0,16668 & 0,31782 & 0,30689 & 0,79140 \\
\hline Ixora burchelliana & 26 & 0,25002 & 0,28126 & 0,25968 & 0,79096 \\
\hline Esenbeckia grandiflora & 30 & 0,28706 & 0,17251 & 0,28329 & 0,74286 \\
\hline Myrciaria sp.1 & 29 & 0,26854 & 0,11265 & 0,35411 & 0,73530 \\
\hline Prunus myrtifolia & 26 & 0,24076 & 0,12943 & 0,35411 & 0,72430 \\
\hline Dahlstedtia pinnata & 26 & 0,28706 & 0,06356 & 0,35411 & 0,70473 \\
\hline Endlicheria paniculata & 20 & 0,21298 & 0,07830 & 0,40132 & 0,69260 \\
\hline Sloanea monosperma & 70 & 0,21298 & 0,12303 & 0,35411 & 0,69012 \\
\hline Marlierea eugeniopsoides & 27 & 0,30558 & 0,03468 & 0,33050 & 0,67077 \\
\hline Lamanonia ternata & 13 & 0,12038 & 0,28570 & 0,25968 & 0,66576 \\
\hline Myrceugenia kleinii & 21 & 0,19446 & 0,10901 & 0,35411 & 0,65758 \\
\hline Eugenia cambucarana & 11 & 0,11112 & 0,34440 & 0,18886 & 0,64438 \\
\hline Byrsonima myricifolia & 15 & 0,13890 & 0,22202 & 0,28329 & 0,64421 \\
\hline Calyptranthes sp.2 & 12 & 0,11112 & 0,33901 & 0,18886 & 0,63899 \\
\hline Quiina magallano-gomezii & 21 & 0,19446 & 0,07876 & 0,35411 & 0,62733 \\
\hline Clethra scabra & 14 & 0,12964 & 0,16641 & 0,33050 & 0,62655 \\
\hline Inga edulis & 16 & 0,14816 & 0,13685 & 0,33050 & 0,61551 \\
\hline Eugenia umbelliflora & 12 & 0,11112 & 0,33089 & 0,16525 & 0,60726 \\
\hline Ormosia dasycarpa & 21 & 0,19446 & 0,17141 & 0,23607 & 0,60194 \\
\hline Miconia cabucu & 20 & 0,18520 & 0,08614 & 0,33050 & 0,60184 \\
\hline Inga marginata & 17 & 0,17594 & 0,13807 & 0,28329 & 0,59729 \\
\hline Gomidesia sp. & 22 & 0,20372 & 0,07420 & 0,30689 & 0,58482 \\
\hline Calyptranthes lanceolata & 19 & 0,18520 & 0,02185 & 0,37771 & 0,58477 \\
\hline Symplocos variabilis & 16 & 0,15742 & 0,09020 & 0,33050 & 0,57812 \\
\hline Myrcia sp.2 & 10 & 0,09260 & 0,26871 & 0,21246 & 0,57378 \\
\hline Myrciaria sp.3 & 15 & 0,13890 & 0,14170 & 0,28329 & 0,56389 \\
\hline Ocotea silvestris & 13 & 0,12038 & 0,15945 & 0,28329 & 0,56312 \\
\hline Eugenia copacabanensis & 6 & 0,05556 & 0,36240 & 0,14164 & 0,55960 \\
\hline
\end{tabular}


Tabela 8. Relação de espécies em ordem decrescente de IVI, amostradas pelo método de parcelas, na Grade-2, instalada na Floresta Ombrófila Densa, no Parque Estadual Carlos Botelho.SP.Brasil. Ni - Número de Indivíduos; FR Freqüência Relativa; DR - Densidade Relativa; DOR - Dominância Relativa e IVI - Índice de Valor de Importância

\begin{tabular}{|c|c|c|c|c|c|}
\hline ESPECIE & $\mathrm{Ni}$ & $\mathrm{DR}$ & DOR & FR & IVI \\
\hline Tabebuia heptaphylla & 22 & 0,21298 & 0,10020 & 0,23607 & 0,54926 \\
\hline Ocotea pulchra & 22 & 0,20372 & 0,08409 & 0,23607 & 0,52389 \\
\hline Rapanea gardneriana & 17 & 0,15742 & 0,10324 & 0,25968 & 0,52034 \\
\hline Coussarea contracta & 17 & 0,15742 & 0,05474 & 0,30689 & 0,51905 \\
\hline Ocotea glaziovii & 2 & 0,10186 & 0,14911 & 0,25968 & 0,51065 \\
\hline Myrcia pubipetala & 18 & 0,16668 & 0,05765 & 0,28329 & 0,50762 \\
\hline Ilex paraguariensis & 16 & 0,14816 & 0,16904 & 0,18886 & 0,50606 \\
\hline Myrtaceae sp.4 & 15 & 0,13890 & 0,08353 & 0,28329 & 0,50572 \\
\hline Vernonia puberula & 9 & 0,08334 & 0,20799 & 0,21246 & 0,50380 \\
\hline Swartzia acutifolia & 8 & 0,07408 & 0,30894 & 0,11804 & 0,50106 \\
\hline Miconia petropolitana & 20 & 0,19446 & 0,04660 & 0,25968 & 0,50074 \\
\hline Buchenavia kleinii & 5 & 0,04630 & 0,32892 & 0,11804 & 0,49325 \\
\hline Symplocos falcata & 11 & 0,12038 & 0,15981 & 0,21246 & 0,49265 \\
\hline Aiouea acaradomatifera & 12 & 0,12964 & 0,18323 & 0,16525 & 0,47812 \\
\hline Rhodostemenodaphne macrocalyx & 13 & 0,12038 & 0,11052 & 0,23607 & 0,46697 \\
\hline Faramea montevidensis & 16 & 0,14816 & 0,05375 & 0,25968 & 0,46159 \\
\hline Plinia pauciflora & 13 & 0,12038 & 0,10487 & 0,23607 & 0,46132 \\
\hline Inga sellowiana & 13 & 0,12038 & 0,06176 & 0,25968 & 0,44182 \\
\hline Iiex taubertiana & 11 & 0,10186 & 0,17431 & 0,16525 & 0,44142 \\
\hline Chrysophyllum inornatum & 4 & 0,03704 & 0,30987 & 0,09443 & 0,44134 \\
\hline Ecclinusa ramiflora & 13 & 0,12038 & 0,10500 & 0,21246 & 0,43785 \\
\hline Myrceugenia seriatoramosa & 10 & 0,09260 & 0,15342 & 0,18886 & 0,43488 \\
\hline Calyptranthes sp.1 & 14 & 0,12964 & 0,06564 & 0,23607 & 0,43136 \\
\hline Eugenia beaurepairiana & 12 & 0,12038 & 0,05104 & 0,25968 & 0,43110 \\
\hline Cordia sellowiana & 7 & 0,07408 & 0,21248 & 0,14164 & 0,42820 \\
\hline Sapium glandulatum & 7 & 0,06482 & 0,19706 & 0,16525 & 0,42713 \\
\hline Rapanea hermogenesii & 15 & 0,14816 & 0,04664 & 0,21246 & 0,40727 \\
\hline Ilex theazans & 12 & 0,11112 & 0,10405 & 0,18886 & 0,40403 \\
\hline Mouriri chamissoana & 8 & 0,07408 & 0,13562 & 0,18886 & 0,39856 \\
\hline Piptocarpha axillaris & 8 & 0,07408 & 0,12294 & 0,18886 & 0,38588 \\
\hline Coccoloba sp.2 & 8 & 0,12038 & 0,07473 & 0,18886 & 0,38397 \\
\hline Ocotea odorifera & 3 & 0,02778 & 0,27951 & 0,07082 & 0,37811 \\
\hline Ilex amara & 10 & 0,09260 & 0,04529 & 0,23607 & 0,37396 \\
\hline Aegiphila sellowiana & 9 & 0,08334 & 0,10489 & 0,16525 & 0,35348 \\
\hline Pouteria macrophylla & 9 & 0,09260 & 0,08923 & 0,16525 & 0,34708 \\
\hline
\end{tabular}


Tabela 8. Relação de espécies em ordem decrescente de IVI, amostradas pelo método de parcelas, na Grade-2, instalada na Floresta Ombrófila Densa, no Parque Estadual Carlos Botelho.SP.Brasil. Ni - Número de Indivíduos; FR Freqüência Relativa; DR - Densidade Relativa; DOR - Dominância Relativa e IVI - Índice de Valor de Importância

\begin{tabular}{|c|c|c|c|c|c|}
\hline ESPECIE & $\mathrm{Ni}$ & $\mathrm{DR}$ & DOR & FR & IVI \\
\hline Pouteria psammophila & 8 & 0,07408 & 0,07625 & 0,18886 & 0,33919 \\
\hline Maytenus ilicifolia & 9 & 0,08334 & 0,06051 & 0,18886 & 0,33271 \\
\hline Plinia complanata & 10 & 0,09260 & 0,01743 & 0,21246 & 0,32250 \\
\hline Dalbergia brasiliensis & 9 & 0,08334 & 0,09383 & 0,14164 & 0,31882 \\
\hline Ocotea aff. Bragai & 6 & 0,06482 & 0,10411 & 0,14164 & 0,31057 \\
\hline Pouteria sp. & 4 & 0,04630 & 0,16960 & 0,09443 & 0,31033 \\
\hline Pouteria caimito & 18 & 0,16668 & 0,11445 & 0,02361 & 0,30474 \\
\hline Inga laurina & 10 & 0,09260 & 0,01641 & 0,18886 & 0,29787 \\
\hline Ocotea tabacifolia & 9 & 0,08334 & 0,04094 & 0,16525 & 0,28953 \\
\hline Vernonia quinqueflora & 4 & 0,03704 & 0,15556 & 0,09443 & 0,28703 \\
\hline Daphnopsis gemmiflora & 7 & 0,06482 & 0,05075 & 0,16525 & 0,28082 \\
\hline Ormosia arborea & 7 & 0,06482 & 0,09529 & 0,11804 & 0,27815 \\
\hline Inga sessilis & 6 & 0,05556 & 0,10118 & 0,11804 & 0,27478 \\
\hline Miconia cubatanensis & 10 & 0,09260 & 0,01372 & 0,16525 & 0,27157 \\
\hline Dahlstedtia pentaphylla & 9 & 0,11112 & 0,01580 & 0,14164 & 0,26857 \\
\hline Cinnamomum sp.1 & 3 & 0,05556 & 0,15171 & 0,04721 & 0,25448 \\
\hline Cryptocarya sp. & 6 & 0,04630 & 0,08851 & 0,11804 & 0,25285 \\
\hline Ocotea sp.1 & 1 & 0,00926 & 0,21918 & 0,02361 & 0,25204 \\
\hline Clusia criuva & 6 & 0,05556 & 0,07407 & 0,11804 & 0,24767 \\
\hline Roupala sculpta & 11 & 0,10186 & 0,02652 & 0,11804 & 0,24642 \\
\hline Drimys winteri & 7 & 0,06482 & 0,03732 & 0,14164 & 0,24378 \\
\hline Aniba firmula & 6 & 0,05556 & 0,04270 & 0,14164 & 0,23991 \\
\hline Cordia ecalyculata & 6 & 0,06482 & 0,03197 & 0,14164 & 0,23843 \\
\hline Didymopanax sp. & 3 & 0,02778 & 0,16188 & 0,04721 & 0,23688 \\
\hline Nectandra membranacea & 8 & 0,07408 & 0,06748 & 0,09443 & 0,23599 \\
\hline Zollernia illicifolia & 3 & 0,03704 & 0,12671 & 0,07082 & 0,23457 \\
\hline Agonandra excelsa & 6 & 0,05556 & 0,10551 & 0,07082 & 0,23189 \\
\hline Aegiphila brachiata & 6 & 0,06482 & 0,02251 & 0,14164 & 0,22898 \\
\hline Rubiaceae sp.1 & 6 & 0,05556 & 0,04568 & 0,11804 & 0,21928 \\
\hline Cedrella fissilis & 1 & 0,00926 & 0,18493 & 0,02361 & 0,21780 \\
\hline Eugenia sp.5 & 4 & 0,03704 & 0,08470 & 0,09443 & 0,21617 \\
\hline Alibertia macrophylla & 6 & 0,05556 & 0,01723 & 0,14164 & 0,21444 \\
\hline Eugenia sp.4 & 7 & 0,06482 & 0,03108 & 0,11804 & 0,21394 \\
\hline Pera obovata & 3 & 0,02778 & 0,12681 & 0,04721 & 0,20180 \\
\hline Rapanea sp. & 6 & 0,05556 & 0,02533 & 0,11804 & 0,19892 \\
\hline
\end{tabular}


Tabela 8. Relação de espécies em ordem decrescente de IVI, amostradas pelo método de parcelas, na Grade-2, instalada na Floresta Ombrófila Densa, no Parque Estadual Carlos Botelho.SP.Brasil. Ni - Número de Indivíduos; FR Freqüência Relativa; DR - Densidade Relativa; DOR - Dominância Relativa e IVI - Índice de Valor de Importância

\begin{tabular}{|c|c|c|c|c|c|}
\hline ESPECIE & $\mathrm{Ni}$ & $\mathrm{DR}$ & DOR & FR & IVI \\
\hline Campomanesia sp. & 2 & 0,01852 & 0,13234 & 0,04721 & 0,19808 \\
\hline Campomanesia schlechtendahliana & 2 & 0,01852 & 0,13159 & 0,04721 & 0,19732 \\
\hline Jacaranda micrantha & 5 & 0,04630 & 0,03074 & 0,11804 & 0,19507 \\
\hline Rollinia sylvatica & 6 & 0,05556 & 0,01741 & 0,11804 & 0,19101 \\
\hline Solanum cf. rufescens & 5 & 0,04630 & 0,01540 & 0,11804 & 0,17973 \\
\hline Pimenta pseudocaryophyllus & 3 & 0,02778 & 0,08102 & 0,07082 & 0,17962 \\
\hline Ocotea porosa & 3 & 0,02778 & 0,08017 & 0,07082 & 0,17878 \\
\hline Cinnamomum sp. & 3 & 0,02778 & 0,07721 & 0,07082 & 0,17582 \\
\hline Senna multijuja & 2 & 0,02778 & 0,07657 & 0,07082 & 0,17517 \\
\hline Calyptranthes lucida & 6 & 0,05556 & 0,01223 & 0,09443 & 0,16222 \\
\hline Gordonia fruticosa & 3 & 0,02778 & 0,10797 & 0,02361 & 0,15936 \\
\hline Chrysophyllum flexuosum & 1 & 0,00926 & 0,12596 & 0,02361 & 0,15883 \\
\hline Salacia elliptica & 7 & 0,05556 & 0,02903 & 0,07082 & 0,15542 \\
\hline Persea pyrifolia & 3 & 0,02778 & 0,05549 & 0,07082 & 0,15409 \\
\hline Matayba elaeagnoides & 3 & 0,02778 & 0,05345 & 0,07082 & 0,15205 \\
\hline Eugenia florida & 4 & 0,03704 & 0,03769 & 0,07082 & 0,14555 \\
\hline Lauraceae sp.4 & 1 & 0,03704 & 0,08088 & 0,02361 & 0,14153 \\
\hline Ouratea multiflora & 7 & 0,09260 & 0,00987 & 0,02361 & 0,12608 \\
\hline Malouetia arborea & 1 & 0,00926 & 0,09099 & 0,02361 & 0,12386 \\
\hline Weinmannia discolor & 3 & 0,02778 & 0,02158 & 0,07082 & 0,12018 \\
\hline Allophylus petiolatus & 3 & 0,02778 & 0,02036 & 0,07082 & 0,11896 \\
\hline Tapirira guianensis & 3 & 0,02778 & 0,01715 & 0,07082 & 0,11575 \\
\hline Trichilia hirta & 1 & 0,00926 & 0,08208 & 0,02361 & 0,11495 \\
\hline Piptocarpha organensis & 2 & 0,01852 & 0,04920 & 0,04721 & 0,11493 \\
\hline Brunfelsia pauciflora & 2 & 0,01852 & 0,04891 & 0,04721 & 0,11464 \\
\hline Solanum pseudoquina & 3 & 0,02778 & 0,01347 & 0,07082 & 0,11207 \\
\hline Mollinedia floribunda & 3 & 0,02778 & 0,01302 & 0,07082 & 0,11162 \\
\hline Coccoloba latifolia & 3 & 0,02778 & 0,01104 & 0,07082 & 0,10965 \\
\hline Meliosma selowii & 2 & 0,02778 & 0,03382 & 0,04721 & 0,10881 \\
\hline Myrtaceae sp.5 & 3 & 0,02778 & 0,01010 & 0,07082 & 0,10871 \\
\hline Myrcia rostrata & 3 & 0,02778 & 0,00801 & 0,07082 & 0,10661 \\
\hline Eugenia neoverrucosa & 3 & 0,02778 & 0,02781 & 0,04721 & 0,10281 \\
\hline Casearia sp. & 3 & 0,02778 & 0,00369 & 0,07082 & 0,10230 \\
\hline Picramnia sp. & 3 & 0,02778 & 0,00366 & 0,07082 & 0,10227 \\
\hline Eugenia sp.11 & 1 & 0,00926 & 0,06885 & 0,02361 & 0,10172 \\
\hline
\end{tabular}


Tabela 8. Relação de espécies em ordem decrescente de IVI, amostradas pelo método de parcelas, na Grade-2, instalada na Floresta Ombrófila Densa, no Parque Estadual Carlos Botelho.SP.Brasil. Ni - Número de Indivíduos; FR Freqüência Relativa; DR - Densidade Relativa; DOR - Dominância Relativa e IVI - Índice de Valor de Importância

\begin{tabular}{|c|c|c|c|c|c|}
\hline ESPECIE & $\mathrm{Ni}$ & $\mathrm{DR}$ & DOR & FR & IVI \\
\hline Psidium cattleyanum & 1 & 0,00926 & 0,06797 & 0,02361 & 0,10084 \\
\hline Calyptranthes obovata & 2 & 0,01852 & 0,03464 & 0,04721 & 0,10038 \\
\hline Ocotea daphinifolia & 2 & 0,01852 & 0,05491 & 0,02361 & 0,09703 \\
\hline Amaioua guianensis & 2 & 0,02778 & 0,01781 & 0,04721 & 0,09280 \\
\hline Cupania sp. & 2 & 0,01852 & 0,02508 & 0,04721 & 0,09081 \\
\hline Cybianthus brasiliensis & 6 & 0,05556 & 0,00850 & 0,02361 & 0,08767 \\
\hline Mollinedia sp. & 1 & 0,02778 & 0,01049 & 0,04721 & 0,08549 \\
\hline Lauraceae sp.3 & 2 & 0,03704 & 0,02249 & 0,02361 & 0,08314 \\
\hline Eugenia sp.12 & 2 & 0,01852 & 0,01715 & 0,04721 & 0,08289 \\
\hline Solanum excelsum & 1 & 0,00926 & 0,04905 & 0,02361 & 0,08191 \\
\hline Eugenia sp.13 & 1 & 0,00926 & 0,04830 & 0,02361 & 0,08117 \\
\hline Ixora heterodoxa & 2 & 0,01852 & 0,01403 & 0,04721 & 0,07977 \\
\hline Solanum argenteum & 2 & 0,01852 & 0,01325 & 0,04721 & 0,07898 \\
\hline Tibouchina sellowiana & 2 & 0,01852 & 0,01144 & 0,04721 & 0,07718 \\
\hline Zanthoxylum rhoifolium & 2 & 0,01852 & 0,01063 & 0,04721 & 0,07637 \\
\hline Myrtaceae sp.1 & 2 & 0,01852 & 0,01028 & 0,04721 & 0,07602 \\
\hline Dalbergia frutescens & 1 & 0,00926 & 0,04234 & 0,02361 & 0,07521 \\
\hline Morfoespécie.3 & 1 & 0,00926 & 0,04211 & 0,02361 & 0,07498 \\
\hline Eugenia candolleana & 2 & 0,01852 & 0,00910 & 0,04721 & 0,07483 \\
\hline Marlierea racemosa & 1 & 0,00926 & 0,04142 & 0,02361 & 0,07429 \\
\hline Ocotea divaricata & 2 & 0,01852 & 0,00840 & 0,04721 & 0,07413 \\
\hline Myrtaceae sp.6 & 2 & 0,01852 & 0,00699 & 0,04721 & 0,07272 \\
\hline Didymopanax angustissimus & 2 & 0,01852 & 0,00649 & 0,04721 & 0,07222 \\
\hline Cinnamomum triplinerve & 1 & 0,00926 & 0,03895 & 0,02361 & 0,07182 \\
\hline Eugenia involucrata & 2 & 0,01852 & 0,00559 & 0,04721 & 0,07133 \\
\hline Psychotria sp. & 2 & 0,01852 & 0,00469 & 0,04721 & 0,07042 \\
\hline Eugenia cf. fluminensis & 2 & 0,01852 & 0,00465 & 0,04721 & 0,07039 \\
\hline Marlierea sp.2 & 1 & 0,01852 & 0,00370 & 0,04721 & 0,06944 \\
\hline Quararibea turbinata & 2 & 0,01852 & 0,00369 & 0,04721 & 0,06942 \\
\hline Aiouea sp. & 2 & 0,01852 & 0,00319 & 0,04721 & 0,06892 \\
\hline Erythroxylum cf.argentinum & 2 & 0,01852 & 0,00246 & 0,04721 & 0,06819 \\
\hline Gomidesia tijucensis & 2 & 0,01852 & 0,00234 & 0,04721 & 0,06807 \\
\hline Trichilia pallida & 2 & 0,01852 & 0,00233 & 0,04721 & 0,06806 \\
\hline Cybianthus peruvianus & 2 & 0,01852 & 0,00192 & 0,04721 & 0,06765 \\
\hline Morfoespécie.5 & 1 & 0,01852 & 0,02311 & 0,02361 & 0,06524 \\
\hline
\end{tabular}


Tabela 8. Relação de espécies em ordem decrescente de IVI, amostradas pelo método de parcelas, na Grade-2, instalada na Floresta Ombrófila Densa, no Parque Estadual Carlos Botelho.SP.Brasil. Ni - Número de Indivíduos; FR Freqüência Relativa; DR - Densidade Relativa; DOR - Dominância Relativa e IVI - Índice de Valor de Importância

\begin{tabular}{|c|c|c|c|c|c|}
\hline ESPECIE & $\mathrm{Ni}$ & $\mathrm{DR}$ & DOR & FR & IVI \\
\hline Rapanea ferruginea & 2 & 0,01852 & 0,01225 & 0,02361 & 0,05437 \\
\hline Coccoloba sp.3 & 1 & 0,00926 & 0,01996 & 0,02361 & 0,05283 \\
\hline Vanillosmopsis erythropappa & 1 & 0,00926 & 0,01736 & 0,02361 & 0,05023 \\
\hline Senna macranthera & 1 & 0,00926 & 0,01577 & 0,02361 & 0,04864 \\
\hline Rubiaceae sp.2 & 2 & 0,01852 & 0,00570 & 0,02361 & 0,04783 \\
\hline Eugenia sp.9 & 1 & 0,01852 & 0,00550 & 0,02361 & 0,04763 \\
\hline Andira sp. & 1 & 0,00926 & 0,01334 & 0,02361 & 0,04621 \\
\hline Cecropia sp. & 1 & 0,00926 & 0,01308 & 0,02361 & 0,04595 \\
\hline Maytenus alaternoides & 1 & 0,01852 & 0,00317 & 0,02361 & 0,04530 \\
\hline Morfoespécie.4 & 1 & 0,00926 & 0,01220 & 0,02361 & 0,04507 \\
\hline Licaria armeniaca & 1 & 0,01852 & 0,00289 & 0,02361 & 0,04502 \\
\hline Morfoespécie.1 & 1 & 0,00926 & 0,01135 & 0,02361 & 0,04422 \\
\hline Ixora sp. & 1 & 0,00926 & 0,01076 & 0,02361 & 0,04363 \\
\hline Humiriastrum dentatum & 1 & 0,00926 & 0,00919 & 0,02361 & 0,04206 \\
\hline Myrcia sp. & 1 & 0,00926 & 0,00887 & 0,02361 & 0,04174 \\
\hline Talauma ovata & 1 & 0,00926 & 0,00877 & 0,02361 & 0,04163 \\
\hline Ardisia guianensis & 1 & 0,00926 & 0,00825 & 0,02361 & 0,04112 \\
\hline Tetrastylidium glandifolium & 1 & 0,00926 & 0,00815 & 0,02361 & 0,04102 \\
\hline Vernonia cf. grandifolia & 1 & 0,00926 & 0,00805 & 0,02361 & 0,04091 \\
\hline Eugenia convexinervia & 1 & 0,00926 & 0,00755 & 0,02361 & 0,04042 \\
\hline Zanthoxylum fagara & 1 & 0,00926 & 0,00616 & 0,02361 & 0,03903 \\
\hline Myrcia sp.4 & 1 & 0,00926 & 0,00581 & 0,02361 & 0,03868 \\
\hline Ocotea sp.3 & 1 & 0,00926 & 0,00548 & 0,02361 & 0,03834 \\
\hline Morfoespécie.6 & 1 & 0,00926 & 0,00515 & 0,02361 & 0,03802 \\
\hline Myrcia sp.1 & 1 & 0,00926 & 0,00491 & 0,02361 & 0,03778 \\
\hline Morfoespécie.7 & 1 & 0,00926 & 0,00468 & 0,02361 & 0,03755 \\
\hline Beilschmiedia emarginata & 1 & 0,00926 & 0,00453 & 0,02361 & 0,03739 \\
\hline Nectandra aff. Barbellata & 1 & 0,00926 & 0,00423 & 0,02361 & 0,03710 \\
\hline Lauraceae sp.2 & 1 & 0,00926 & 0,00409 & 0,02361 & 0,03695 \\
\hline Morfoespécie.2 & 1 & 0,00926 & 0,00401 & 0,02361 & 0,03688 \\
\hline Lauraceae sp.1 & 1 & 0,00926 & 0,00387 & 0,02361 & 0,03674 \\
\hline Dodonaea viscosa . & 1 & 0,00926 & 0,00380 & 0,02361 & 0,03667 \\
\hline Micropholis crassipedicellata & 1 & 0,00926 & 0,00380 & 0,02361 & 0,03667 \\
\hline Nectandra oppositfolia & 1 & 0,00926 & 0,00347 & 0,02361 & 0,03633 \\
\hline Miconia pusilliflora & 1 & 0,00926 & 0,00333 & 0,02361 & 0,03620 \\
\hline
\end{tabular}


Tabela 8. Relação de espécies em ordem decrescente de IVI, amostradas pelo método de parcelas, na Grade-2, instalada na Floresta Ombrófila Densa, no Parque Estadual Carlos Botelho.SP.Brasil. Ni - Número de Indivíduos; FR Freqüência Relativa; DR - Densidade Relativa; DOR - Dominância Relativa e IVI - Índice de Valor de Importância

\begin{tabular}{|c|c|c|c|c|c|}
\hline ESPECIE & $\mathrm{Ni}$ & DR & DOR & FR & IVI \\
\hline Inga cylindrica & 1 & 0,00926 & 0,00327 & 0,02361 & 0,03614 \\
\hline Alibertia sp. 2 & 1 & 0,00926 & 0,00314 & 0,02361 & 0,03601 \\
\hline Cedrella odorata & 1 & 0,00926 & 0,00308 & 0,02361 & 0,03595 \\
\hline Randia aff. Armata & 1 & 0,00926 & 0,00266 & 0,02361 & 0,03553 \\
\hline Machaerium nictitans & 1 & 0,00926 & 0,00249 & 0,02361 & 0,03536 \\
\hline Miconia sp. & 1 & 0,00926 & 0,00249 & 0,02361 & 0,03536 \\
\hline Mollinedia sp.1 & 1 & 0,00926 & 0,00249 & 0,02361 & 0,03536 \\
\hline Myrcia sp.3 & 1 & 0,00926 & 0,00249 & 0,02361 & 0,03536 \\
\hline Rollinia sp. & 1 & 0,00926 & 0,00249 & 0,02361 & 0,03536 \\
\hline Guatteria nigrescens & 1 & 0,00926 & 0,00222 & 0,02361 & 0,03509 \\
\hline Miconia theaezans & 1 & 0,00926 & 0,00217 & 0,02361 & 0,03503 \\
\hline Ocotea sp.2 & 1 & 0,00926 & 0,00217 & 0,02361 & 0,03503 \\
\hline Tabebuia sp. & 1 & 0,00926 & 0,00211 & 0,02361 & 0,03498 \\
\hline Lacistema hasslerianum & 1 & 0,00926 & 0,00186 & 0,02361 & 0,03473 \\
\hline Didymopamax calvus & 1 & 0,00926 & 0,00158 & 0,02361 & 0,03445 \\
\hline Myrceugenia sp.2 & 1 & 0,00926 & 0,00145 & 0,02361 & 0,03432 \\
\hline Allophylus edulis & 1 & 0,00926 & 0,00141 & 0,02361 & 0,03428 \\
\hline Eugenia sp.10 & 1 & 0,00926 & 0,00141 & 0,02361 & 0,03428 \\
\hline Eugenia sp.8 & 1 & 0,00926 & 0,00141 & 0,02361 & 0,03428 \\
\hline Eugenia cf. schuchiana & 1 & 0,00926 & 0,00137 & 0,02361 & 0,03424 \\
\hline Matayba sp. & 1 & 0,00926 & 0,00129 & 0,02361 & 0,03415 \\
\hline Ocotea brachybotrya & 1 & 0,00926 & 0,00129 & 0,02361 & 0,03415 \\
\hline Eugenia sp.7 & 1 & 0,00926 & 0,00125 & 0,02361 & 0,03411 \\
\hline Ocotea pulchella & 1 & 0,00926 & 0,00125 & 0,02361 & 0,03411 \\
\hline Roupala sp. & 1 & 0,00926 & 0,00106 & 0,02361 & 0,03392 \\
\hline Myrceugenia sp.1 & 1 & 0,00926 & 0,00099 & 0,02361 & 0,03385 \\
\hline Psydium cf. myrtoides & 1 & 0,00926 & 0,00099 & 0,02361 & 0,03385 \\
\hline Ixora breviflora & 1 & 0,00926 & 0,00095 & 0,02361 & 0,03382 \\
\hline Rudgea blanchetiana & 1 & 0,00926 & 0,00095 & 0,02361 & 0,03382 \\
\hline Esenbeckia sp. & 1 & 0,00926 & 0,00088 & 0,02361 & 0,03375 \\
\hline Cyphomandra sp. & 1 & 0,00926 & 0,00082 & 0,02361 & 0,03368 \\
\hline Geonoma schottiana & 1 & 0,00926 & 0,00079 & 0,02361 & 0,03365 \\
\hline Geonoma sp. & 1 & 0,00926 & 0,00079 & 0,02361 & 0,03365 \\
\hline Nectandra leucantha & 1 & 0,00926 & 0,00079 & 0,02361 & 0,03365 \\
\hline
\end{tabular}


No método de quadrantes as espécies com maior valor de IVI são: Euterpe edulis (33,35), Alchornea triplinervia $(14,65)$, Cabralea canjerana $(13,79)$, Bathysa australis (9,27), Mollinedia oligantha (8,04), Guapira opposita (7,93), Ocotea catharinensis (7,54), Marlierea parviflora (7,03), Eugenia mosenii $(5,51)$ e Sorocea bomplandii $(5,10)$. (Tabela 9).

Estas espécies amostraram 34 \% do total de indivíduos obtidos pelo método de quadrantes na Grade 2. 
Tabela 9. Relação de espécies em ordem decrescente de IVI, amostradas pelo método de quadrantes, na Grade-2, instalada na Floresta Ombrófila Densa, no Parque Estadual Carlos Botelho.SP.Brasil. Ni - Número de Indivíduos; FR Freqüência Relativa; DR - Densidade Relativa; DOR - Dominância Relativa e IVI - Índice de Valor de Importância

\begin{tabular}{|c|c|c|c|c|c|}
\hline ESPÉCIES & $\mathrm{Ni}$ & DR & DOR & FR & IVI \\
\hline Euterpe edulis & 190 & 14,8322 & 3,6946 & 14,8322 & 33,3589 \\
\hline Alchornea triplinervia & 22 & 1,7955 & 11,0672 & 1,7955 & 14,6582 \\
\hline Cabralea canjerana & 14 & 1,2490 & 11,2946 & 1,2490 & 13,7926 \\
\hline Bathysa australis & 36 & 2,8103 & 3,6567 & 2,8103 & 9,2773 \\
\hline Mollinedia oligantha & 44 & 3,4348 & 1,1742 & 3,4348 & 8,0438 \\
\hline Guapira opposita & 25 & 1,9516 & 4,0308 & 1,9516 & 7,9340 \\
\hline Ocotea catharinensis & 20 & 1,5613 & 4,4227 & 1,5613 & 7,5453 \\
\hline Marlierea parviflora & 34 & 2,6542 & 1,7241 & 2,6542 & 7,0324 \\
\hline Eugenia mosenii & 29 & 2,2639 & 0,9922 & 2,2639 & 5,5199 \\
\hline Sorocea bonplandii & 24 & 1,9516 & 1,1999 & 1,9516 & 5,1031 \\
\hline Rudgea jasminoides & 26 & 2,1077 & 0,4175 & 2,1077 & 4,6330 \\
\hline Eugenia stictosepala & 25 & 1,9516 & 0,3151 & 1,9516 & 4,2183 \\
\hline Myrciaria sp.2 & 12 & 0,9368 & 2,1102 & 0,9368 & 3,9837 \\
\hline Coussarea sp. & 23 & 1,7955 & 0,3909 & 1,7955 & 3,9818 \\
\hline Hyeronima alchorneoides & 8 & 0,6245 & 2,6889 & 0,6245 & 3,9379 \\
\hline Pterocarpus rohrii. & 13 & 1,0929 & 1,6506 & 1,0929 & 3,8364 \\
\hline Myrceugenia myrcioides & 22 & 1,7174 & 0,3205 & 1,7174 & 3,7553 \\
\hline Mollinedia schottiana & 21 & 1,6393 & 0,3697 & 1,6393 & 3,6484 \\
\hline Matayba guianensis & 9 & 0,7026 & 2,2128 & 0,7026 & 3,6180 \\
\hline Posoqueria acutifolia & 18 & 1,4052 & 0,7920 & 1,4052 & 3,6023 \\
\hline Myrocarpus frondosus & 13 & 1,0148 & 1,5425 & 1,0148 & 3,5722 \\
\hline Didymopanax navarroi & 5 & 0,4684 & 2,0747 & 0,4684 & 3,0115 \\
\hline Citronella paniculata & 13 & 1,0148 & 0,8675 & 1,0148 & 2,8971 \\
\hline Chrysophyllum inornatum & 3 & 0,2342 & 2,4256 & 0,2342 & 2,8939 \\
\hline Eugenia melanogina & 15 & 1,1710 & 0,3861 & 1,1710 & 2,7281 \\
\hline Heisteria silvianii & 8 & 0,6245 & 1,2775 & 0,6245 & 2,5265 \\
\hline Vantanea compacta & 7 & 0,5464 & 1,3634 & 0,5464 & 2,4562 \\
\hline Matayba juglandifolia & 12 & 0,9368 & 0,5042 & 0,9368 & 2,3778 \\
\hline Gomidesia anacardiaefolia & 14 & 1,0929 & 0,1620 & 1,0929 & 2,3478 \\
\hline Parinari excelsa & 7 & 0,5464 & 1,1280 & 0,5464 & 2,2209 \\
\hline Maytenus robusta & 12 & 0,9368 & 0,3186 & 0,9368 & 2,1921 \\
\hline Myrtaceae sp.2 & 11 & 0,8587 & 0,4605 & 0,8587 & 2,1779 \\
\hline Chrysophyllum viride & 4 & 0,3123 & 1,5069 & 0,3123 & 2,1314 \\
\hline Eugenia neoglomerata & 12 & 0,9368 & 0,2121 & 0,9368 & 2,0857 \\
\hline Calycorectes australis & 11 & 0,8587 & 0,3180 & 0,8587 & 2,0354 \\
\hline Eugenia subavenia & 12 & 0,9368 & 0,1210 & 0,9368 & 1,9945 \\
\hline
\end{tabular}


Tabela 9. Relação de espécies em ordem decrescente de IVI, amostradas pelo método de quadrantes, na Grade-2, instalada na Floresta Ombrófila Densa, no Parque Estadual Carlos Botelho.SP.Brasil. Ni - Número de Indivíduos; FR Freqüência Relativa; DR - Densidade Relativa; DOR - Dominância Relativa e IVI - Índice de Valor de Importância

\begin{tabular}{lccrrr}
\hline ESPÉCIES & $\mathrm{Ni}$ & DR & DOR & FR & IVI \\
\hline Ouratea parviflora & 11 & 0,8587 & 0,2734 & 0,8587 & 1,9908 \\
Ocotea teleiandra & 12 & 0,9368 & 0,1124 & 0,9368 & 1,9859 \\
Platymiscium floribundum & 8 & 0,6245 & 0,7257 & 0,6245 & 1,9747 \\
Cryptocarya moschata & 5 & 0,3903 & 1,1900 & 0,3903 & 1,9707 \\
Capsicodendron dinisii & 8 & 0,6245 & 0,7054 & 0,6245 & 1,9544 \\
Eugenia cuprea & 11 & 0,8587 & 0,2105 & 0,8587 & 1,9279 \\
Coccoloba sp.1 & 2 & 0,1561 & 1,5826 & 0,1561 & 1,8948 \\
Amaioua intermedia & 10 & 0,7806 & 0,3115 & 0,7806 & 1,8728 \\
Eugenia sp.6 & 10 & 0,7806 & 0,2953 & 0,7806 & 1,8566 \\
Eugenia capitulifera & 10 & 0,7806 & 0,2245 & 0,7806 & 1,7858 \\
Gomidesia riedeliana & 6 & 0,4684 & 0,8341 & 0,4684 & 1,7709 \\
Ocotea odorifera & 1 & 0,0781 & 1,5166 & 0,0781 & 1,6727 \\
Alibertia myrciifolia & 9 & 0,7026 & 0,1539 & 0,7026 & 1,5591 \\
Chomelia catharinae & 8 & 0,7026 & 0,1274 & 0,7026 & 1,5326 \\
Myrceugenia glaucescens & 8 & 0,6245 & 0,2591 & 0,6245 & 1,5081 \\
Pouteria bullata & 6 & 0,4684 & 0,5601 & 0,4684 & 1,4969 \\
Rollinia sericea & 4 & 0,3123 & 0,8198 & 0,3123 & 1,4443 \\
Campomanesia guaviroba & 5 & 0,3903 & 0,6049 & 0,3903 & 1,3855 \\
Garcinia gadneriana & 8 & 0,6245 & 0,1154 & 0,6245 & 1,3644 \\
Allophylus petiolulatus & 1 & 0,0781 & 1,2016 & 0,0781 & 1,3577 \\
Eugenia riedeliana & 7 & 0,5464 & 0,2447 & 0,5464 & 1,3376 \\
Alibertia sp. & 8 & 0,6245 & 0,0855 & 0,6245 & 1,3345 \\
Ocotea bicolor & 6 & 0,4684 & 0,3877 & 0,4684 & 1,3245 \\
Jacaranda puberula & 3 & 0,2342 & 0,8519 & 0,2342 & 1,3203 \\
Psychotria suterella & 7 & 0,5464 & 0,2022 & 0,5465 & 1,2951 \\
Chionanthus filiformis & 7 & 0,5464 & 0,1699 & 0,5464 & 1,2628 \\
Rapanea umbellata & 5 & 0,3903 & 0,4229 & 0,3903 & 1,2036 \\
Eugenia sp.1 & 7 & 0,5464 & 0,1042 & 0,5464 & 1,1971 \\
Marlierea reitzii & 4 & 0,3123 & 0,5489 & 0,3123 & 1,1734 \\
Myrcia tenuivenosa & 3 & 0,2342 & 0,6903 & 0,2342 & 1,1587 \\
Vernonia puberula & 3 & 0,2342 & 0,6318 & 0,2342 & 1,1002 \\
Coussapoa microcarpa & 2 & 0,1561 & 0,7764 & 0,1561 & 1,0887 \\
Hirtella hebeclada Moric & 5 & 0,4684 & 0,1487 & 0,4684 & 1,0855 \\
Cupania vernalis & 6 & 0,4684 & 0,1367 & 0,4684 & 1,0735 \\
morta & 4 & 0,3123 & 0,4156 & 0,3123 & 1,0401 \\
Guatteria australis & 6 & 0,4684 & 0,1027 & 0,4684 & 1,0394 \\
& & & & & \\
& 5 & & &
\end{tabular}


Tabela 9. Relação de espécies em ordem decrescente de IVI, amostradas pelo método de quadrantes, na Grade-2, instalada na Floresta Ombrófila Densa, no Parque Estadual Carlos Botelho.SP.Brasil. Ni - Número de Indivíduos; FR Freqüência Relativa; DR - Densidade Relativa; DOR - Dominância Relativa e IVI - Índice de Valor de Importância

\begin{tabular}{lcrrrr}
\hline ESPÉCIES & $\mathrm{Ni}$ & DR & DOR & FR & IVI \\
\hline Protium hepatphyllum & 4 & 0,3123 & 0,4109 & 0,3123 & 1,0354 \\
Cordia trichotoma & 5 & 0,3903 & 0,2395 & 0,3903 & 1,0202 \\
Gomidesia spectabilis & 6 & 0,4684 & 0,0631 & 0,4684 & 0,9999 \\
Guarea macrophylla & 5 & 0,3903 & 0,1953 & 0,3903 & 0,9759 \\
Pithecellobium langsdorffi & 5 & 0,3903 & 0,1909 & 0,3903 & 0,9716 \\
Eugenia sp.2 & 2 & 0,2342 & 0,4973 & 0,2342 & 0,9657 \\
Casearia decandra & 4 & 0,3123 & 0,3227 & 0,3123 & 0,9473 \\
Ocotea aciphylla & 4 & 0,3123 & 0,2805 & 0,3123 & 0,9050 \\
Chrysophyllum flexuosum & 1 & 0,0781 & 0,7338 & 0,0781 & 0,8900 \\
Cordia sp. 1 & 5 & 0,3903 & 0,1000 & 0,3903 & 0,8807 \\
Myrciaria sp.3 & 4 & 0,3123 & 0,2391 & 0,3123 & 0,8636 \\
Eugenia cerasiflora & 5 & 0,3903 & 0,0800 & 0,3903 & 0,8606 \\
Dahlstedtia pinnata & 5 & 0,3903 & 0,0375 & 0,3903 & 0,8181 \\
Mollinedia elegans & 5 & 0,3903 & 0,0367 & 0,3903 & 0,8173 \\
Duguetia lanceolata & 4 & 0,3123 & 0,1405 & 0,3123 & 0,7650 \\
Eugenia copacabanensis & 1 & 0,0781 & 0,6055 & 0,0781 & 0,7617 \\
Pouteria caimito & 3 & 0,2342 & 0,2932 & 0,2342 & 0,7616 \\
Ocotea dispersa & 4 & 0,3123 & 0,1303 & 0,3123 & 0,7548 \\
Eugenia cambucarana & 3 & 0,2342 & 0,2462 & 0,2342 & 0,7145 \\
Neomitranthes glomerata & 4 & 0,3123 & 0,0892 & 0,3123 & 0,7137 \\
Symplocos variabilis & 2 & 0,1561 & 0,3950 & 0,1561 & 0,7073 \\
Inga edulis & 3 & 0,2342 & 0,2253 & 0,2342 & 0,6937 \\
Aniba viridis & 3 & 0,2342 & 0,2119 & 0,2342 & 0,6803 \\
Casearia sylvestris & 4 & 0,3123 & 0,0498 & 0,3123 & 0,6744 \\
Miconia cabucu & 4 & 0,3123 & 0,0496 & 0,3123 & 0,6742 \\
Casearia obliqua & 3 & 0,2342 & 0,2048 & 0,2342 & 0,6732 \\
Siphoneugena densiflora & 4 & 0,3123 & 0,0395 & 0,3123 & 0,6640 \\
Marlierea tomentosa & 3 & 0,3123 & 0,0348 & 0,3123 & 0,6593 \\
Ormosia dasycarpa & 3 & 0,2342 & 0,1725 & 0,2342 & 0,6409 \\
Myrcia fallax & 0,2342 & 0,1353 & 0,2342 & 0,6037 \\
Dalbergia brasiliensis & 3 & 0,2342 & 0,1313 & 0,2342 & 0,5997 \\
Eugenia beaurepairiana & 0,2342 & 0,1168 & 0,2342 & 0,5852 \\
Faramea montevidensis & 3 & 0,2342 & 0,1055 & 0,2342 & 0,5739 \\
Cinnamomum sp. & 0,2342 & 0,4167 & 0,0781 & 0,5728 \\
Weinmannia paulliniifolia & 0,2342 & 0,0845 & 0,2342 & 0,5529 \\
Aegiphila brachiata & 3 & & & &
\end{tabular}


Tabela 9. Relação de espécies em ordem decrescente de IVI, amostradas pelo método de quadrantes, na Grade-2, instalada na Floresta Ombrófila Densa, no Parque Estadual Carlos Botelho.SP.Brasil. Ni - Número de Indivíduos; FR Freqüência Relativa; DR - Densidade Relativa; DOR - Dominância Relativa e IVI - Índice de Valor de Importância

\begin{tabular}{lcrrrr}
\hline ESPÉCIES & Ni & DR & DOR & FR & IVI \\
\hline Prunus myrtifolia & 3 & 0,2342 & 0,0815 & 0,2342 & 0,5499 \\
Eugenia sp.3 & 3 & 0,2342 & 0,0760 & 0,2342 & 0,5444 \\
Eugenia handroana & 3 & 0,2342 & 0,0672 & 0,2342 & 0,5356 \\
Tibouchina pulchra & 2 & 0,1561 & 0,2204 & 0,1561 & 0,5327 \\
Sloanea monosperma & 3 & 0,2342 & 0,0608 & 0,2342 & 0,5292 \\
Esenbeckia grandiflora & 3 & 0,2342 & 0,0562 & 0,2342 & 0,5246 \\
Vernonia quinqueflora & 1 & 0,0781 & 0,3643 & 0,0781 & 0,5204 \\
Cupania oblongifolia & 2 & 0,1561 & 0,1989 & 0,1561 & 0,5111 \\
Inga marginata & 3 & 0,2342 & 0,0304 & 0,2342 & 0,4988 \\
Myrceugenia campestris & 3 & 0,2342 & 0,0297 & 0,2342 & 0,4980 \\
Byrsonima myricifolia & 1 & 0,0781 & 0,3386 & 0,0781 & 0,4948 \\
Inga laurina & 3 & 0,2342 & 0,0252 & 0,2342 & 0,4936 \\
Dahlstedtia pentaphylla & 3 & 0,2342 & 0,0227 & 0,2342 & 0,4910 \\
Roupala brasiliensis & 2 & 0,1561 & 0,1642 & 0,1561 & 0,4765 \\
Myrceugenia kleinii & 2 & 0,1561 & 0,1477 & 0,1561 & 0,4600 \\
Gordonia fruticosa & 1 & 0,0781 & 0,2786 & 0,0781 & 0,4347 \\
Byrsonima ligustrifolia & 1 & 0,0781 & 0,2617 & 0,0781 & 0,4178 \\
Copaifera langsdorffii & 2 & 0,1561 & 0,1041 & 0,1561 & 0,4164 \\
Mouriri chamissoana & 1 & 0,0781 & 0,2507 & 0,0781 & 0,4069 \\
Morfoespécie 3 & 1 & 0,0781 & 0,2453 & 0,0781 & 0,4015 \\
Plinia pauciflora & 2 & 0,1561 & 0,0875 & 0,1561 & 0,3998 \\
Cryptocarya sp. & 2 & 0,1561 & 0,0823 & 0,1561 & 0,3945 \\
Eugenia sp.5 & 2 & 0,1561 & 0,0753 & 0,1561 & 0,3875 \\
Gomidesia sp. & 2 & 0,1561 & 0,0624 & 0,1561 & 0,3747 \\
Alseis floribunda & 2 & 0,1561 & 0,0588 & 0,1561 & 0,3710 \\
Myrcia aff. Macrocarpa & 2 & 0,1561 & 0,0543 & 0,1561 & 0,3666 \\
Diploon cuspidatum & 2 & 0,1561 & 0,0530 & 0,1561 & 0,3653 \\
Andira anthelmia & 2 & 0,1561 & 0,0372 & 0,1561 & 0,3495 \\
Gomidesia schaueriana & 2 & 0,1561 & 0,0367 & 0,1561 & 0,3489 \\
Eugenia umbelliflora & 2 & 0,1561 & 0,0352 & 0,1561 & 0,3475 \\
Persea pyrifolia & 2 & 0,0781 & 0,1875 & 0,0781 & 0,3437 \\
Psychotria velloziana & 2 & 0,1561 & 0,0304 & 0,1561 & 0,3426 \\
Myrtaceae sp.4 & 2 & 0,1561 & 0,0302 & 0,1561 & 0,3425 \\
Maytenus ilicifolia & 2 & 0,1561 & 0,0249 & 0,1561 & 0,3371 \\
Quiina magallano-gomezii & 2 & 0,1561 & 0,0236 & 0,1561 & 0,3358 \\
Myrtaceae sp.3 & 0,1561 & 0,0229 & 0,1561 & 0,3351 \\
& & & & & \\
& 2 & & &
\end{tabular}


Tabela 9. Relação de espécies em ordem decrescente de IVI, amostradas pelo método de quadrantes, na Grade-2, instalada na Floresta Ombrófila Densa, no Parque Estadual Carlos Botelho.SP.Brasil. Ni - Número de Indivíduos; FR Freqüência Relativa; DR - Densidade Relativa; DOR - Dominância Relativa e IVI - Índice de Valor de Importância

\begin{tabular}{lcrrrr}
\hline ESPÉCIES & $\mathrm{Ni}$ & DR & DOR & FR & IVI \\
\hline Sapium glandulatum & 2 & 0,1561 & 0,0202 & 0,1561 & 0,3325 \\
Pouteria macrophylla & 2 & 0,1561 & 0,0175 & 0,1561 & 0,3297 \\
Calyptranthes lanceolata & 2 & 0,1561 & 0,0162 & 0,1561 & 0,3285 \\
Ilex amara & 2 & 0,1561 & 0,0130 & 0,1561 & 0,3252 \\
Marlierea eugeniopsoides & 2 & 0,1561 & 0,0118 & 0,1561 & 0,3240 \\
Nectandra aff. membranacea & 1 & 0,0781 & 0,1456 & 0,0781 & 0,3018 \\
Aegiphila sellowiana & 1 & 0,0781 & 0,1335 & 0,0781 & 0,2896 \\
Myrcia sp.2 & 1 & 0,0781 & 0,1099 & 0,0781 & 0,2661 \\
Myrcia pubipetala & 1 & 0,0781 & 0,0952 & 0,0781 & 0,2513 \\
Ocotea elegans & 1 & 0,0781 & 0,0944 & 0,0781 & 0,2505 \\
Meliosma selowii & 1 & 0,0781 & 0,0894 & 0,0781 & 0,2456 \\
Calyptranthes sp.2 & 1 & 0,0781 & 0,0675 & 0,0781 & 0,2236 \\
Lamanonia ternata & 1 & 0,0781 & 0,0574 & 0,0781 & 0,2135 \\
Ocotea silvestris & 1 & 0,0781 & 0,0511 & 0,0781 & 0,2072 \\
Eugenia convexinervia & 1 & 0,0781 & 0,0440 & 0,0781 & 0,2001 \\
Tabebuia heptaphylla & 1 & 0,0781 & 0,0423 & 0,0781 & 0,1984 \\
Zanthoxylum fagara & 1 & 0,0781 & 0,0359 & 0,0781 & 0,1920 \\
Ecclinusa ramiflora & 1 & 0,0781 & 0,0349 & 0,0781 & 0,1910 \\
Jacaranda micrantha & 1 & 0,0781 & 0,0349 & 0,0781 & 0,1910 \\
Solanum cf. rufescens & 1 & 0,0781 & 0,0329 & 0,0781 & 0,1890 \\
Sclerolobium denudatum & 1 & 0,0781 & 0,0314 & 0,0781 & 0,1876 \\
Salacia elliptica & 1 & 0,0781 & 0,0310 & 0,0781 & 0,1871 \\
Rapanea gardneriana & 1 & 0,0781 & 0,0291 & 0,0781 & 0,1852 \\
Ilex paraguariensis & 1 & 0,0781 & 0,0255 & 0,0781 & 0,1816 \\
Ixora burchelliana & 1 & 0,0781 & 0,0255 & 0,0781 & 0,1816 \\
Drimys winteri & 1 & 0,0781 & 0,0251 & 0,0781 & 0,1812 \\
Eugenia sp.9 & 1 & 0,0781 & 0,0226 & 0,0781 & 0,1787 \\
Calyptranthes lucida & 1 & 0,0781 & 0,0218 & 0,0781 & 0,1779 \\
Rhodostemenodaphne macrocalyx & 1 & 0,0781 & 0,0210 & 0,0781 & 0,1771 \\
Cecropia sp. & 1 & 0,0781 & 0,0209 & 0,0781 & 0,1771 \\
Myrciaria sp. & 1 & 0,0781 & 0,0202 & 0,0781 & 0,1763 \\
Inga sellowiana & 1 & 0,0781 & 0,0198 & 0,0781 & 0,1759 \\
Ilex theazans & 1 & 0,0781 & 0,0183 & 0,0781 & 0,1744 \\
Ocotea glaziovii & & 0,0781 & 0,0172 & 0,0781 & 0,1734 \\
Aiouea acaradomatifera & 0,0781 & 0,0158 & 0,0781 & 0,1720 \\
Marlierea sp.2 & & & & & \\
& 1 & & & &
\end{tabular}


Tabela 9. Relação de espécies em ordem decrescente de IVI, amostradas pelo método de quadrantes, na Grade-2, instalada na Floresta Ombrófila Densa, no Parque Estadual Carlos Botelho.SP.Brasil. Ni - Número de Indivíduos; FR Freqüência Relativa; DR - Densidade Relativa; DOR - Dominância Relativa e IVI - Índice de Valor de Importância

\begin{tabular}{|c|c|c|c|c|c|}
\hline ESPÉCIES & $\mathrm{Ni}$ & DR & DOR & FR & IVI \\
\hline Myrcia hatschbachii & 1 & 0,0781 & 0,0155 & 0,0781 & 0,1716 \\
\hline Senna multijuja & 1 & 0,0781 & 0,0145 & 0,0781 & 0,1707 \\
\hline Miconia petropolitana & 1 & 0,0781 & 0,0142 & 0,0781 & 0,1703 \\
\hline Ouratea multiflora & 1 & 0,0781 & 0,0123 & 0,0781 & 0,1684 \\
\hline Campomanesia sp. & 1 & 0,0781 & 0,0109 & 0,0781 & 0,1670 \\
\hline Endlicheria paniculata & 1 & 0,0781 & 0,0109 & 0,0781 & 0,1670 \\
\hline Calyptranthes sp.1 & 1 & 0,0781 & 0,0090 & 0,0781 & 0,1651 \\
\hline Solanum argenteum & 1 & 0,0781 & 0,0090 & 0,0781 & 0,1651 \\
\hline Ocotea pulchra & 1 & 0,0781 & 0,0082 & 0,0781 & 0,1643 \\
\hline Lauraceae sp.3 & 1 & 0,0781 & 0,0082 & 0,0781 & 0,1643 \\
\hline Rapanea hermogenesii & 1 & 0,0781 & 0,0080 & 0,0781 & 0,1641 \\
\hline Coccoloba latifolia & 1 & 0,0781 & 0,0077 & 0,0781 & 0,1639 \\
\hline Myrciaria sp.1 & 1 & 0,0781 & 0,0077 & 0,0781 & 0,1639 \\
\hline Xylopia langsdorfiana & 1 & 0,0781 & 0,0075 & 0,0781 & 0,1636 \\
\hline Myrcia rostrata & 1 & 0,0781 & 0,0073 & 0,0781 & 0,1634 \\
\hline Meliosma sinuata & 1 & 0,0781 & 0,0070 & 0,0781 & 0,1632 \\
\hline Weinmannia discolor & 1 & 0,0781 & 0,0066 & 0,0781 & 0,1627 \\
\hline Roupala sp. & 1 & 0,0781 & 0,0062 & 0,0781 & 0,1623 \\
\hline Rubiaceae sp.1 & 1 & 0,0781 & 0,0062 & 0,0781 & 0,1623 \\
\hline Psydium cf. myrtoides & 1 & 0,0781 & 0,0057 & 0,0781 & 0,1619 \\
\hline Talauma ovata & 1 & 0,0781 & 0,0054 & 0,0781 & 0,1615 \\
\hline Cordia ecalyculata & 1 & 0,0781 & 0,0051 & 0,0781 & 0,1613 \\
\hline Eugenia pruinosa & 1 & 0,0781 & 0,0051 & 0,0781 & 0,1613 \\
\hline Roupala sculpita & 1 & 0,0781 & 0,0051 & 0,0781 & 0,1613 \\
\hline Cordia sellowiana & 1 & 0,0781 & 0,0048 & 0,0781 & 0,1609 \\
\hline Mollinedia oligotricha & 1 & 0,0781 & 0,0048 & 0,0781 & 0,1609 \\
\hline Eugenia florida & 1 & 0,0781 & 0,0046 & 0,0781 & 0,1607 \\
\hline Miconia cubatanensis & 1 & 0,0781 & 0,0046 & 0,0781 & 0,1607 \\
\hline
\end{tabular}

Para o método de relascopia as dez espécies com maior valor de IVI, foram: Euterpe edulis $(18,90)$, Ocotea catharinensis $(17,81)$, Alchornea triplinervia $(13,06)$, Guapira opposita (11,55), Bathysa australis (9,79), Cabralea canjerana $(8,80)$, Coussarea sp. (8,19), Mollinedia oligantha (7,98), Marlierea parviflora $(5,61)$ e Pouteria bullata $(5,19)$. (Tabela 10). 
Tabela 10. Relação de espécies em ordem decrescente de IVI, amostradas pelo método de relascopia, na Grade-2, instalada na Floresta Ombrófila Densa, no Parque Estadual Carlos Botelho.SP.Brasil. Ni - Número de Indivíduos; FR Freqüência Relativa; DR - Densidade Relativa; DOR - Dominância Relativa e IVI - Índice de Valor de Importância

\begin{tabular}{lcrrrr}
\hline ESPECIES & Ni & DR & DOR & FR & IVI \\
\hline Euterpe edulis & 17 & 13,353 & 2,972 & 2,579 & 18,904 \\
Ocotea catharinensis & 45 & 4,762 & 7,692 & 5,357 & 17,812 \\
Alchornea triplinervia & 37 & 2,006 & 6,294 & 4,762 & 13,062 \\
Guapira opposita & 23 & 3,566 & 4,021 & 3,968 & 11,555 \\
Bathysa australis & 18 & 4,438 & 2,972 & 2,381 & 9,791 \\
Cabralea canjerana & 16 & 3,426 & 2,797 & 2,579 & 8,803 \\
Coussarea sp. & 6 & 5,954 & 1,049 & 1,190 & 8,193 \\
Mollinedia oligantha & 9 & 4,827 & 1,573 & 1,587 & 7,988 \\
Marlierea parviflora & 11 & 1,710 & 1,923 & 1,984 & 5,617 \\
Pouteria bullata & 11 & 1,282 & 1,923 & 1,984 & 5,190 \\
Pterocarpus rohrii & 13 & 0,427 & 2,273 & 2,381 & 5,080 \\
Rollinia sericea & 6 & 2,956 & 1,049 & 0,992 & 4,997 \\
Eugenia mosenii & 7 & 1,614 & 1,224 & 1,190 & 4,029 \\
Sorocea bonplandii & 8 & 1,202 & 1,399 & 1,389 & 3,990 \\
Chrysophyllum viride & 10 & 0,807 & 1,748 & 1,389 & 3,944 \\
Vantanea compacta & 9 & 0,544 & 1,573 & 1,786 & 3,904 \\
Parinari excelsa & 9 & 0,484 & 1,573 & 1,786 & 3,843 \\
Myrocarpus frondosus & 8 & 0,819 & 1,399 & 1,587 & 3,805 \\
-Matayba guianensis & 9 & 0,578 & 1,573 & 1,587 & 3,739 \\
Andira anthelmia & 6 & 1,241 & 1,049 & 0,992 & 3,282 \\
Cordia trichotoma & 7 & 0,592 & 1,224 & 1,389 & 3,204 \\
Inga marginata & 3 & 2,057 & 0,524 & 0,595 & 3,177 \\
Maytenus robusta & 4 & 1,649 & 0,699 & 0,794 & 3,142 \\
Posoqueria acutifolia & 6 & 0,842 & 1,049 & 1,190 & 3,082 \\
Heisteria silvianii & 7 & 0,307 & 1,224 & 1,389 & 2,920 \\
Copaifera langsdorffii & 6 & 0,666 & 1,049 & 1,190 & 2,906 \\
Eugenia stictosepala & 5 & 1,222 & 0,874 & 0,794 & 2,889 \\
Tibouchina pulchra & 7 & 0,456 & 1,224 & 1,190 & 2,871 \\
Eugenia neoglomerata & 3 & 1,833 & 0,524 & 0,397 & 2,754 \\
Ocotea elegans & 7 & 0,437 & 1,049 & 1,190 & 2,676 \\
Calycorectes australis & 5 & 0,708 & 0,874 & 0,992 & 2,574 \\
Didymopanax navarroi & 6 & 0,324 & 1,049 & 1,190 & 2,563 \\
Capsicodendron dinisii & 6 & 0,512 & 1,049 & 0,992 & 2,554 \\
Hyeronima alchorneoides & 5 & 0,602 & 0,874 & 0,992 & 2,469 \\
Rapanea umbellata & 5 & 0,546 & 0,874 & 0,992 & 2,412 \\
Neomitranthes glomerata & 2 & 1,524 & 0,350 & 0,397 & 2,271 \\
& & & & & \\
& & & & & \\
& & & & &
\end{tabular}


Tabela 10. Relação de espécies em ordem decrescente de IVI, amostradas pelo método de relascopia, na Grade-2, instalada na Floresta Ombrófila Densa, no Parque Estadual Carlos Botelho.SP.Brasil. Ni - Número de Indivíduos; FR Freqüência Relativa; DR - Densidade Relativa; DOR - Dominância Relativa e IVI - Índice de Valor de Importância

\begin{tabular}{|c|c|c|c|c|c|}
\hline ESPECIES & $\mathrm{Ni}$ & DR & DOR & FR & IVI \\
\hline Myrcia hatschbachii & 3 & 1,118 & 0,524 & 0,595 & 2,237 \\
\hline Duguetia lanceolata & 3 & 1,305 & 0,524 & 0,397 & 2,226 \\
\hline Rudgea jasminoides & 3 & 1,043 & 0,524 & 0,595 & 2,162 \\
\hline Marlierea reitzii & 5 & 0,264 & 0,874 & 0,992 & 2,130 \\
\hline Alibertia sp. & 3 & 0,955 & 0,524 & 0,595 & 2,075 \\
\hline Chionanthus filiformis & 2 & 1,316 & 0,350 & 0,397 & 2,062 \\
\hline Alibertia myrciifolia & 2 & 1,472 & 0,350 & 0,198 & 2,020 \\
\hline Ocotea mosenii Mez & 5 & 0,133 & 0,874 & 0,992 & 2,000 \\
\hline Endlicheria paniculata & 2 & 1,239 & 0,350 & 0,397 & 1,986 \\
\hline Amaioua intermedia & 4 & 0,642 & 0,699 & 0,595 & 1,937 \\
\hline Byrsonima ligustrifolia & 4 & 0,397 & 0,699 & 0,794 & 1,890 \\
\hline Ocotea bicolor & 1 & 1,497 & 0,175 & 0,198 & 1,871 \\
\hline Citronella paniculata & 4 & 0,374 & 0,699 & 0,794 & 1,867 \\
\hline Clethra scabra & 2 & 1,095 & 0,350 & 0,397 & 1,842 \\
\hline Gomidesia schaueriana & 4 & 0,339 & 0,699 & 0,794 & 1,832 \\
\hline Lamanonia ternata & 4 & 0,178 & 0,699 & 0,794 & 1,671 \\
\hline Coussapoa microcarpa & 4 & 0,166 & 0,699 & 0,794 & 1,659 \\
\hline Myrcia tenuivenosa & 3 & 0,524 & 0,524 & 0,595 & 1,644 \\
\hline Sclerolobium denudatum & 4 & 0,114 & 0,699 & 0,794 & 1,607 \\
\hline Myrtaceae sp.2 & 3 & 0,484 & 0,524 & 0,595 & 1,604 \\
\hline Cryptocarya moschata & 4 & 0,105 & 0,699 & 0,794 & 1,598 \\
\hline Campomanesia guaviroba & 4 & 0,060 & 0,699 & 0,794 & 1,553 \\
\hline Siphoneugena densiflora & 3 & 0,383 & 0,524 & 0,595 & 1,502 \\
\hline Myrciaria sp.2 & 3 & 0,370 & 0,524 & 0,595 & 1,490 \\
\hline Eugenia sp.6 & 3 & 0,343 & 0,524 & 0,595 & 1,463 \\
\hline Buchenavia kleinii & 4 & 0,163 & 0,699 & 0,595 & 1,457 \\
\hline Myrciaria sp.3 & 2 & 0,679 & 0,350 & 0,397 & 1,425 \\
\hline Ormosia dasycarpa & 3 & 0,269 & 0,524 & 0,595 & 1,388 \\
\hline Ocotea aciphylla & 2 & 0,619 & 0,350 & 0,397 & 1,365 \\
\hline Eugenia copacabanensis & 4 & 0,043 & 0,699 & 0,595 & 1,338 \\
\hline Myrceugenia glaucescens & 2 & 0,584 & 0,350 & 0,397 & 1,331 \\
\hline Faramea montevidensis & 1 & 0,935 & 0,175 & 0,198 & 1,308 \\
\hline Eugenia capitulifera & 2 & 0,538 & 0,350 & 0,397 & 1,285 \\
\hline Piptocarpha axillaris & 2 & 0,402 & 0,350 & 0,397 & 1,149 \\
\hline Myrtaceae sp.1 & 2 & 0,362 & 0,350 & 0,397 & 1,108 \\
\hline Weinmannia paulliniifolia & 2 & 0,269 & 0,350 & 0,397 & 1,015 \\
\hline
\end{tabular}


Tabela 10. Relação de espécies em ordem decrescente de IVI, amostradas pelo método de relascopia, na Grade-2, instalada na Floresta Ombrófila Densa, no Parque Estadual Carlos Botelho.SP.Brasil. Ni - Número de Indivíduos; FR Freqüência Relativa; DR - Densidade Relativa; DOR - Dominância Relativa e IVI - Índice de Valor de Importância

\begin{tabular}{|c|c|c|c|c|c|}
\hline ESPECIES & $\mathrm{Ni}$ & DR & DOR & FR & IVI \\
\hline Morta & 2 & 0,225 & 0,350 & 0,397 & 0,972 \\
\hline Roupala brasiliensis & 2 & 0,221 & 0,350 & 0,397 & 0,968 \\
\hline Casearia obliqua & 2 & 0,221 & 0,350 & 0,397 & 0,967 \\
\hline Coccoloba sp.1 & 1 & 0,578 & 0,175 & 0,198 & 0,951 \\
\hline Pithecellobium langsdorffi & 2 & 0,166 & 0,350 & 0,397 & 0,913 \\
\hline Diploon cuspidatum & 2 & 0,164 & 0,350 & 0,397 & 0,910 \\
\hline Matayba juglandifolia & 2 & 0,159 & 0,350 & 0,397 & 0,906 \\
\hline Marlierea tomentosa & 2 & 0,146 & 0,350 & 0,397 & 0,893 \\
\hline Alseis floribunda & 2 & 0,128 & 0,350 & 0,397 & 0,874 \\
\hline Chrysophyllum inornatum & 2 & 0,126 & 0,350 & 0,397 & 0,872 \\
\hline Pouteria caimito & 3 & 0,142 & 0,524 & 0,198 & 0,865 \\
\hline Clusia criuva & 2 & 0,110 & 0,350 & 0,397 & 0,857 \\
\hline Eugenia melanogina & 2 & 0,103 & 0,350 & 0,397 & 0,850 \\
\hline Cupania oblongifolia & 2 & 0,100 & 0,350 & 0,397 & 0,846 \\
\hline Jacaranda puberula & 2 & 0,097 & 0,350 & 0,397 & 0,844 \\
\hline Gomidesia riedeliana & 2 & 0,081 & 0,350 & 0,397 & 0,828 \\
\hline Eugenia cambucarana & 2 & 0,077 & 0,350 & 0,397 & 0,823 \\
\hline Vernonia puberula & 2 & 0,057 & 0,350 & 0,397 & 0,803 \\
\hline Mouriri chamissoana & 2 & 0,057 & 0,350 & 0,397 & 0,803 \\
\hline Mollinedia schottiana & 1 & 0,369 & 0,175 & 0,198 & 0,742 \\
\hline Eugenia cuprea & 3 & 0,337 & 0,175 & 0,198 & 0,710 \\
\hline Myrtaceae sp.4 & 1 & 0,317 & 0,175 & 0,198 & 0,691 \\
\hline Miconia petropolitana & 1 & 0,296 & 0,175 & 0,198 & 0,669 \\
\hline Eugenia riedeliana & 1 & 0,288 & 0,175 & 0,198 & 0,661 \\
\hline Cinnamomum sp. & 2 & 0,095 & 0,350 & 0,198 & 0,643 \\
\hline Eugenia subavenia & 1 & 0,252 & 0,175 & 0,198 & 0,625 \\
\hline Casearia decandra & 1 & 0,246 & 0,175 & 0,198 & 0,619 \\
\hline Aegiphila sellowiana & 1 & 0,237 & 0,175 & 0,198 & 0,610 \\
\hline Myrcia aff. Macrocarpa & 1 & 0,210 & 0,175 & 0,198 & 0,583 \\
\hline Dalbergia brasiliensis & 1 & 0,210 & 0,175 & 0,198 & 0,583 \\
\hline Inga sellowiana & 1 & 0,207 & 0,175 & 0,198 & 0,581 \\
\hline Plinia pauciflora & 1 & 0,160 & 0,175 & 0,198 & 0,533 \\
\hline Ilex paraguariensis & 1 & 0,153 & 0,175 & 0,198 & 0,527 \\
\hline Pimenta pseudocaryophyllus & 1 & 0,146 & 0,175 & 0,198 & 0,519 \\
\hline Hirtella hebeclada & 1 & 0,145 & 0,175 & 0,198 & 0,518 \\
\hline Lauraceae sp.3 & 1 & 0,139 & 0,175 & 0,198 & 0,512 \\
\hline
\end{tabular}


Tabela 10. Relação de espécies em ordem decrescente de IVI, amostradas pelo método de relascopia, na Grade-2, instalada na Floresta Ombrófila Densa, no Parque Estadual Carlos Botelho.SP.Brasil. Ni - Número de Indivíduos; FR Freqüência Relativa; DR - Densidade Relativa; DOR - Dominância Relativa e IVI - Índice de Valor de Importância

\begin{tabular}{|c|c|c|c|c|c|}
\hline ESPECIES & $\mathrm{Ni}$ & DR & DOR & FR & IVI \\
\hline Weinmannia discolor & 1 & 0,128 & 0,175 & 0,198 & 0,501 \\
\hline Ecclinusa ramiflora & 1 & 0,120 & 0,175 & 0,198 & 0,493 \\
\hline Dahlstedtia pinnata & 1 & 0,118 & 0,175 & 0,198 & 0,491 \\
\hline Amaioua guianensis & 1 & 0,106 & 0,175 & 0,198 & 0,480 \\
\hline Calyptranthes sp.2 & 1 & 0,098 & 0,175 & 0,198 & 0,471 \\
\hline Cordia sp. 1 & 1 & 0,096 & 0,175 & 0,198 & 0,469 \\
\hline Rhodostemenodaphne macrocalyx & 1 & 0,075 & 0,175 & 0,198 & 0,448 \\
\hline Psychotria velloziana & 1 & 0,070 & 0,175 & 0,198 & 0,443 \\
\hline Ocotea bragai & 1 & 0,068 & 0,175 & 0,198 & 0,441 \\
\hline Ocotea porosa & 1 & 0,066 & 0,175 & 0,198 & 0,439 \\
\hline Platymiscium floribundum & 1 & 0,064 & 0,175 & 0,198 & 0,437 \\
\hline Meliosma selowii & 1 & 0,056 & 0,175 & 0,198 & 0,430 \\
\hline Myrceugenia myrcioides & 1 & 0,053 & 0,175 & 0,198 & 0,426 \\
\hline Eugenia cerasiflora & 1 & 0,050 & 0,175 & 0,198 & 0,423 \\
\hline Marlierea sp.1 & 1 & 0,049 & 0,175 & 0,198 & 0,422 \\
\hline Eugenia sp.3 & 1 & 0,049 & 0,175 & 0,198 & 0,422 \\
\hline Agonandra excelsa & 1 & 0,049 & 0,175 & 0,198 & 0,422 \\
\hline Aiouea acaradomatifera & 1 & 0,048 & 0,175 & 0,198 & 0,421 \\
\hline Xylopia langsdorfiana & 1 & 0,047 & 0,175 & 0,198 & 0,421 \\
\hline Morfoespécie 3 & 1 & 0,046 & 0,175 & 0,198 & 0,419 \\
\hline Dalbergia frutescens & 1 & 0,046 & 0,175 & 0,198 & 0,419 \\
\hline Symplocos variabilis & 1 & 0,044 & 0,175 & 0,198 & 0,417 \\
\hline Pouteria psammophila & 1 & 0,042 & 0,175 & 0,198 & 0,416 \\
\hline Ouratea parviflora & 1 & 0,042 & 0,175 & 0,198 & 0,416 \\
\hline Pouteria sp & 1 & 0,041 & 0,175 & 0,198 & 0,414 \\
\hline Garcinia gadneriana & 1 & 0,040 & 0,175 & 0,198 & 0,414 \\
\hline Protium hepatphyllum & 1 & 0,040 & 0,175 & 0,198 & 0,413 \\
\hline Cryptocarya sp. & 1 & 0,037 & 0,175 & 0,198 & 0,410 \\
\hline Aniba viridis & 1 & 0,036 & 0,175 & 0,198 & 0,410 \\
\hline Sapium glandulatum & 1 & 0,035 & 0,175 & 0,198 & 0,408 \\
\hline Eugenia sp.2 & 1 & 0,032 & 0,175 & 0,198 & 0,406 \\
\hline Vernonia quinqueflora & 1 & 0,031 & 0,175 & 0,198 & 0,404 \\
\hline Cordia sellowiana & 1 & 0,030 & 0,175 & 0,198 & 0,404 \\
\hline Trichilia hirta & 1 & 0,023 & 0,175 & 0,198 & 0,397 \\
\hline Iiex taubertiana & 1 & 0,019 & 0,175 & 0,198 & 0,392 \\
\hline Gomidesia anacardiaefolia & 1 & 0,018 & 0,175 & 0,198 & 0,391 \\
\hline
\end{tabular}


Tabela 10. Relação de espécies em ordem decrescente de IVI, amostradas pelo método de relascopia, na Grade-2, instalada na Floresta Ombrófila Densa, no Parque Estadual Carlos Botelho.SP.Brasil. Ni - Número de Indivíduos; FR Freqüência Relativa; DR - Densidade Relativa; DOR - Dominância Relativa e IVI - Índice de Valor de Importância

\begin{tabular}{llrrrr}
\hline ESPECIES & $\mathrm{Ni}$ & $\mathrm{DR}$ & DOR & FR & IVI \\
\hline Symplocos falcata & 1 & 0,017 & 0,175 & 0,198 & 0,390 \\
Cinnamomum sp.1 & 1 & 0,017 & 0,175 & 0,198 & 0,390 \\
Nectandra aff.membranacea & 1 & 0,016 & 0,175 & 0,198 & 0,390 \\
Chrysophyllum flexuosum & 1 & 0,015 & 0,175 & 0,198 & 0,389 \\
Prunus myrtifolia & 1 & 0,015 & 0,175 & 0,198 & 0,388 \\
Myrceugenia seriatoramosa & 1 & 0,014 & 0,175 & 0,198 & 0,387 \\
Talauma ovata & 1 & 0,012 & 0,175 & 0,198 & 0,385 \\
Ficus sp. & 1 & 0,012 & 0,175 & 0,198 & 0,385 \\
Cedrella fissilis & 1 & 0,010 & 0,175 & 0,198 & 0,384 \\
Ilex amara & 1 & 0,009 & 0,175 & 0,198 & 0,382 \\
Ocotea sp.1 & 1 & 0,008 & 0,175 & 0,198 & 0,382 \\
Rubiaceae sp.1 & 1 & 0,008 & 0,175 & 0,198 & 0,382 \\
Ocotea silvestris & 1 & 0,008 & 0,175 & 0,198 & 0,382 \\
Myrcia sp.2 & 1 & 0,007 & 0,175 & 0,198 & 0,380
\end{tabular}

Na Tabela 11 são apresentadas as relações de espécies com maiores valores de IVI amostradas por cada método empregado (parcela, quadrantes e relascopia), nas duas áreas de estudo (Grade 1 e Grade 2). Observa-se que duas espécies se destacaram das demais, estando presente em todas as relações, Euterpe edulis e Ocotea catharinensis. Estas espécies foram seguidas por Alchornea triplinervia e Cabralea canjerana, que não estavam apenas entre os dez maiores valores de IVI em quadrantes na Grade 1, e Mollinedia oligantha e Bathysa australis, em relascopia Grade 1.

As espécies Eugenia mosenii e Sorocea bomplandii estavam presente apenas na relação apresentada para o método de quadrantes na Grade 2, e Micropholis sp., Ocotea bicolor e Myrcia pubipetala, constam apenas da relação apresentada pelo método de relascopia na Grade 1. 
A espécie Euterpe edulis ocupa a primeira posição em ordem decrescente de IVI, para os resultados obtidos em todos os métodos de amostragem. A única exceção foi para o método de parcelas na Grade 1, onde esta espécie ocupa a segunda posição.

O palmito Euterpe edulis pode ser considerado uma unidade taxonômica da Mata Atlântica, pois na maioria dos levantamentos efetuados, esta espécie está sempre entre as primeiras posições em valor de importância (Melo, 1993 e 2000; Mantovani, 1993; Ivanauska, 1997; Dias, 1993; Negreiros et al., 1995 ; Guedes-Bruni, 1998; Custodio Filho, 2002 e Aguiar, 2003).

Tabela 11. Relação das espécies com maior valor de IVI, amostradas pelos métodos parcelas, quadrantes e relascopia, para Grade 1 e Grade-2, instaladas na Floresta Ombrófila Densa, Parque Estadual Carlos Botelho.SP.Brasil. Par-G1 - parcela Grade 1; Par-G2 - parcela Grade 2; Qua-G1 - quadrantes Grade 1; Qua-G2 - quadrantes Grade2; Rel-G1 - relascopia Grade 1; Rel-G2 - relascopia Grade2

\section{Espécies}

\section{Euterpe edulis}

Alchornea triplinervia

Guapira opposita

Ocotea catharinensis

Mollinedia oligantha

Bathysa australis

Cabralea canjerana

Marlierea parviflora

Coussarea sp.

Mollinedia schottiana

Eugenia mosenii

Sorocea bomplandii

Poteria bullata

Micropholis crassipedicellata

Alibertia sp.

Vantanea compacta

Eugenia melanogina

Micropholis sp.

Ocotea bicolor

Myrcia pubipetala
Par-G1 Qua-G1 Rel-G1 Par-G2 Qua-G2 Rel-G2

\begin{tabular}{cccccc}
14,61 & 29,56 & 21,13 & 15,71 & 33,36 & 18,90 \\
6,68 & - & 7,54 & 10,26 & 14,66 & 13,06 \\
- & 8,56 & - & 8,15 & 7,93 & 11,56 \\
10,35 & 7,74 & 12,91 & 8,10 & 7,55 & 17,81 \\
6,14 & 8,37 & - & 7,02 & 8,04 & 7,99 \\
5,25 & 12,14 & - & 6,12 & 9,28 & 9,79 \\
5,11 & - & 6,17 & 5,55 & 13,79 & 8,80 \\
- & - & - & 4,94 & 7,03 & 5,62 \\
- & 5,74 & - & 4,38 & - & 8,19 \\
- & - & - & 4,30 & - & - \\
- & - & - & - & 5,52 & - \\
- & - & - & - & 5,10 & - \\
7,23 & 8,04 & 8,40 & - & - & 5,19 \\
16,94 & 23,77 & 11,35 & - & - & - \\
5,63 & - & - & - & - & - \\
5,45 & 6,21 & 10,19 & - & - & - \\
- & 5,71 & - & - & - & - \\
- & - & 17,05 & - & - & - \\
- & - & 7,91 & - & - & - \\
- & - & 6,72 & - & - & - \\
\hline
\end{tabular}




\subsection{Diversidade e Equabilidade}

Os valores de diversidade do componente arbóreo da Grade 1 e Grade 2, determinados com emprego do Índice de Shannon, para cada método de amostragem, são apresentados na Tabela 12.

Os maiores valores de diversidade foram apresentados para o método de parcelas, 4,591 e 4,702 para Grade 1 e Grade 2, respectivamente. Os menores valores foram registrados para o método de relascopia, 4,411 na Grade 1, e para o método de quadrantes, 4,459 na Grade 2.

Observa-se que os valores de diversidade obtidos para a Grade 2, $\mathrm{H}^{\prime}=4,702$, $\mathrm{H}^{\prime}=$ 4,459 e $\mathrm{H}^{\prime}=4,468$., para os métodos de parcelas, quadrantes e relascopia, respectivamente, são ligeiramente superiores aos obtidos para a Grade 1, ou seja, $\mathrm{H}^{\prime}=4,591, \mathrm{H}^{\prime}=4,442$ e $\mathrm{H}^{\prime}=4,411$.

Estes resultados podem estar sinalizando uma variação da diversidade ao longo do gradiente altitudinal da área de estudo.

Guedes-Bruni (1988) encontrou resultados similares para a vegetação da Encosta Atlântica no Estado do Rio de Janeiro. Custodio Filho (2002) analisando 6 faixas localizadas em diferentes níveis altitudinais no Parque Estadual Carlos Botelho, chama a atenção para o fato da variação nos índices de diversidades encontrados podem estar relacionadas à heterogeneidade estrutural da Floresta Ombrófila Densa, em diferentes cotas altitudinais.

O método de parcelas, apesar de apresentar para a Grade 2 o maior índice de diversidade, foi o que apresentou o menor valor para o índice e equabilidade $(\mathrm{J}=0,80)$. Provavelmente o número de indivíduos amostrados por este método (10.124), deve ter influenciado no valor deste índice. Por outro lado o método de relascopia mesmo tendo amostrado o menor número de indivíduos (578) na Grade 2, apresentou o segundo maior índice de diversidade nesta área. Observa-se que o maior índice de equabilidade 
apresentado por este método ( $\mathrm{J}=0,88)$, deve ter influenciado na definição da diversidade, pois de acordo com Magurran (1988) quanto maior o valor do índice de equabilidade maior deverá ser também o valor da diversidade.

Tabela 12. Valores da diversidade $\left(\mathrm{H}^{\prime}\right)$ e equabilidade (J), riqueza de espécies e número de indivíduos, determinados para o componente arbóreo na Grade 1 e Grade 2, instaladas na Floresta Ombrófila Densa, no Parque Estadual Carlos Botelho, SP.Brasil

\begin{tabular}{|c|c|c|c|c|c|c|}
\hline \multirow[b]{2}{*}{ Parâmetros } & \multicolumn{3}{|c|}{ GRADE 1} & \multicolumn{3}{|c|}{ GRADE 2} \\
\hline & Parc. & Quadr. & Relasc. & Parc. & Quadr. & Relasc. \\
\hline Número de Espécies & 250 & 175 & 155 & 348 & 207 & 157 \\
\hline Índice de Diversidade de Shannon $\left(\mathrm{H}^{\prime}\right)$ & 4,591 & 4,442 & 4,411 & 4,702 & 4,459 & 4,468 \\
\hline Índice de Equabilidade (J) & 0,832 & 0,86 & 0,874 & 0,803 & 0,836 & 0,884 \\
\hline Espécies com apenas 1 indivíduo (\%) & 8,8 & 25,14 & 40,64 & 23,56 & 34,29 & 43,31 \\
\hline Número médio de indivíduos por espécie & 38 & 7 & 4 & 29 & 6 & 4 \\
\hline Número de indivíduos amostrados & 9.543 & 1.276 & 638 & 10.124 & 1.270 & 578 \\
\hline
\end{tabular}

Considerando todos o métodos de amostragem empregados observa-se que os valores de $\mathrm{H}^{`}$ ficaram entre 4,411 e 4,702. Estes valores estão entre os maiores determinados para as formações florestais do Parque Estadual Carlos Botelho. Até então os maiores valores foram obtidos por Dias et al. (2000) que determinaram os valores de H` entre 4,26 e 4,40 para um trecho de floresta em estádio secundário na parte norte do Parque, e por Custodio Filho (2002) em levantamento efetuado através de transectos instalados ao longo de um gradiente altitudinal, encontrando para área, valores de $\mathrm{H}^{`}$ entre 3,27 e 4,26. Em outras áreas de domínio da Floresta Ombrófila Densa, os valores de diversidade encontrados foram também inferiores aos do presente trabalho. Mantovani (1993) determinou para Estação Ecológica Jureia-Itatins $H^{\prime}=4,191$, para a vegetação da Serra do Mar na região de Salesópolis, Mantovani et al. (1990) determinaram $H^{\prime}=4,08$ e para a Floresta Atlântica da Ilha do Cardoso, Melo (2000) encontrou um valor de $\mathrm{H}^{\prime}=3,53$. 


\subsection{Comparação dos Métodos de Amostragem}

\subsubsection{Composição Florística e Riqueza de Espécies}

Os dados apresentados na Tabela 12 mostram que os métodos de parcelas, quadrantes e relascopia, registraram para a Grade 1, 250, 175 e 155 espécies, respectivamente, e para a Grade 2, 348, 207 e 157 espécies. Observa-se pela análise desses dados que o método de parcelas foi superior aos demais, independente da área de amostragem. Na Grade 1, o método de quadrantes amostrou apenas $70 \%$ do total de espécies amostradas pelo método de parcelas, enquanto que para o método de relascopia este percentual ficou em $62 \%$.

Na Grade 2, a diferença entre os métodos foi ainda mais acentuada, pois o método de quadrantes amostrou apenas 59,5\% do total de espécies amostradas pelo método de parcelas, e o método de relascopia amostrou 44,5\% deste total.

O método de parcelas foi o que amostrou a menor porcentagem de espécies representadas por apenas 1 indivíduo, tanto na Grade 1 como na Grade 2, enquanto que o método de relascopia registrou os maiores percentuais, sendo 40,64\% para a Grade 1 e 43,31\% para a Grade 2.

A diferença entre o número de espécies amostradas pelos três métodos (parcelas, quadrantes e relascopia) se deve principalmente ao número de indivíduos amostrados por cada método.

Observa-se na Tabela 12 que na Grade 1 o método de parcelas amostrou 9.543 indivíduos, enquanto o método de quadrante amostrou $1276(13,4 \%)$ e o método de relascopia 638 (7\%) indivíduos. Na Grade 2 o método de parcelas registrou 10124 indivíduos, quadrantes 1270 (12,5\%) e relascopia 578 indivíduos (6\%).

Esta diferença permite inferir sobre a necessidade de um maior número de pontos de amostragem, tanto para o método de quadrantes quanto para o método de relascopia. 
Faria et al. (2002) comparando parcelas de área fixa com o método de Bitterlich (Relascopia), no estudo de floresta inequiâneas, chamou a atenção para a necessidade de uma maior intensidade amostral para o método de relascopia, para a caracterização da composição florística da área de estudo, entretanto, o emprego de parcelas área fixa possui custo elevado e exige maior tempo de levantamento, uma vez que neste método depara-se normalmente com a marcação e mensuração de um grande número de indivíduos.

A Figura 13 e 14 mostram a relação entre o número de espécies e o acréscimo em unidades amostrais para cada método de amostragem, na Grade 1 e Grade 2, respectivamente.

Como critério para definição da unidade amostral no método de quadrantes, optou-se pelo agrupamento dos pontos. Assim, cada grupo de 5 pontos quadrantes foi considerado como uma unidade amostral. Isto porque na área de abrangência de cada parcela foram instalados 5 pontos quadrantes.

A Figura 13 mostra que as curvas apresentadas pelo método de parcelas e quadrantes são mais regulares que a curva apresentada pelo método de relascopia. Para este método a curva apresenta-se bastante inclinada, sugerindo a necessidade de maior número de unidades amostrais.

Resultado semelhante foi encontrado por Gorenstein (2002) quando da comparação dos métodos de parcelas, quadrantes e relascopia, na amostragem de uma Floresta Estacional Semidecidual no Município de Gália -SP.

Observa-se uma acentuada tendência de estabilização para as curvas apresentadas pelos métodos de parcelas e quadrantes, a partir da $25^{\mathrm{a}}$ e $30^{\mathrm{a}}$ unidade amostral, respectivamente. Esta tendência não foi observada para o método de relascopia

A provável insuficiência amostral, apresentada pelo método de relascopia, pode ter ocorrido pela distância adotada entre os centros de amostragem. 
Veiga (1976), recomenda o emprego da equação $a=48+2 \sqrt{S}$ para determinar a distância entre os centros de amostragem, quando da utilização do Fator 4, onde $a$ - é a distância entre os pontos e $S$ - a área total a ser amostrada. Para o presente trabalho a distância ideal seria de $64 \mathrm{~m}$. entre os centros de amostragem e não 100 m., como adotado, o que proporcionaria uma maior intensidade amostral.

A Figura 14 mostra que apenas a curva apresentada pelo método de parcelas, apresenta uma ligeira tendência de estabilização a partir da $25^{\mathrm{a}}$ unidade amostral, no entanto, esta estabilização é interrompida a partir da $48^{\mathrm{a}}$ unidade amostral, pela inclusão de novas espécies, o que caracteriza uma heterogeneidade da área de estudo.

A maior inclinação das curvas apresentadas pelos métodos de quadrantes e relascopia, pode estar relacionada tanto à necessidade de um maior número de unidades amostrais como à heterogeneidade da área de estudo. 


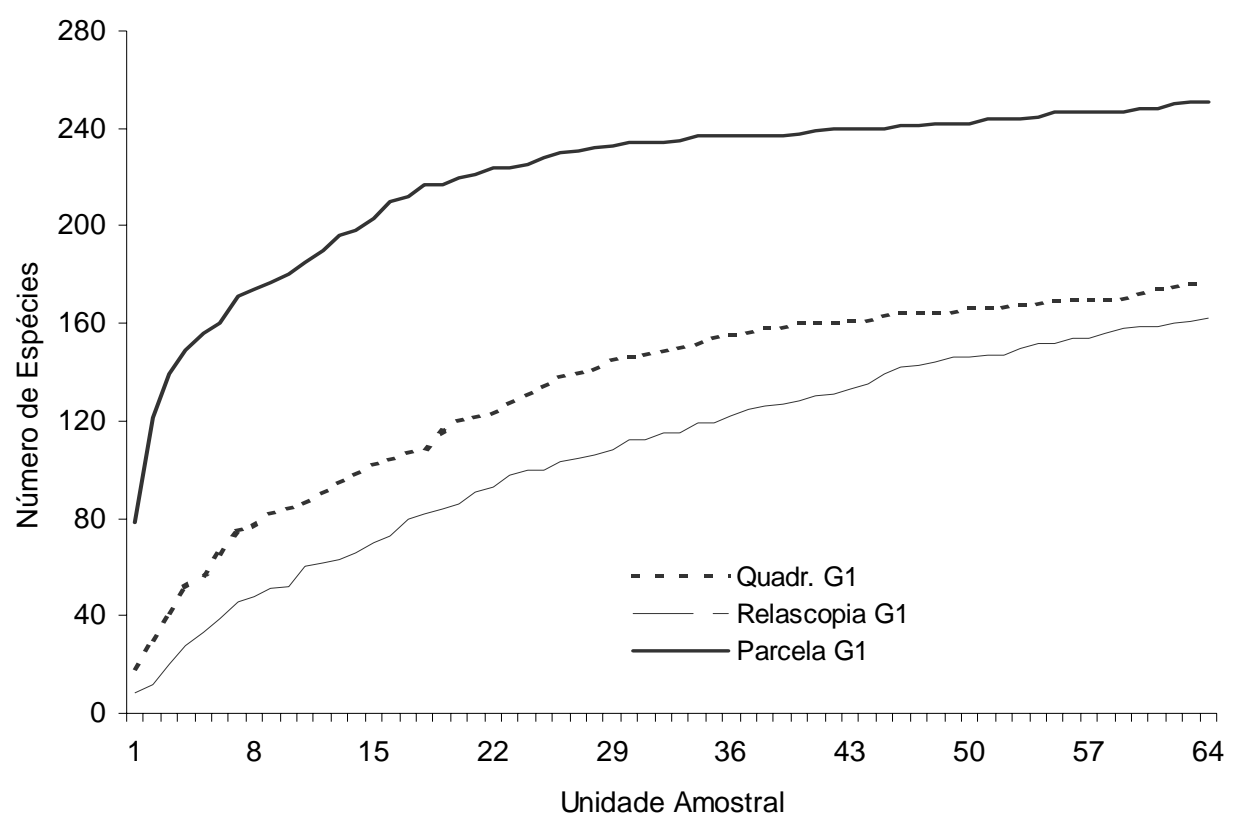

Figura 13 - Curva número de espécies por unidades amostrais, para os métodos de parcelas, quadrantes e relascopia, empregados para o estudo do componente arbóreo da Grade 1, na Floresta Ombrófila Densa, no Parque Estadual Carlos Botelho.SP.Brasil 


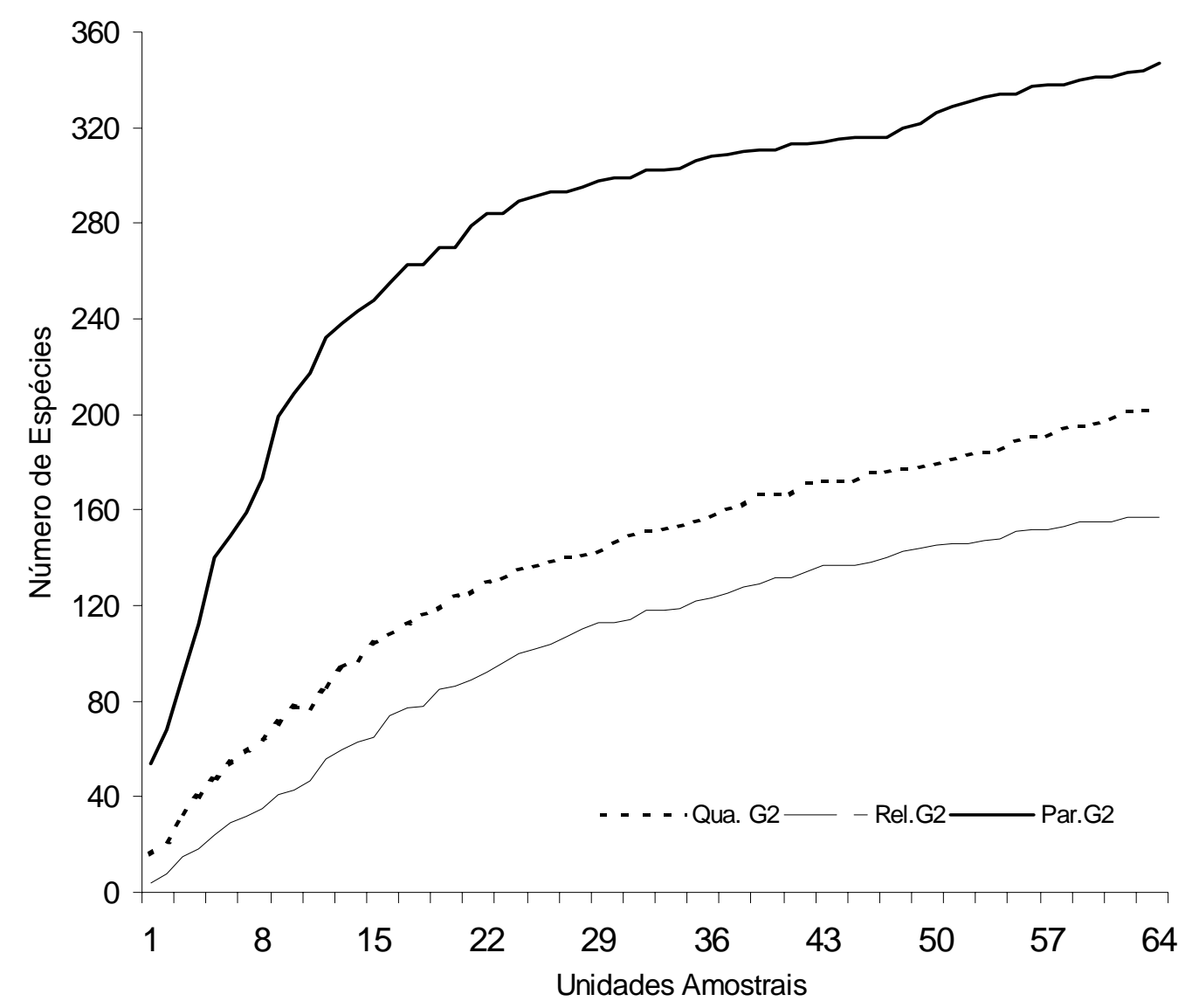

Figura 14 - Curva número de espécies por unidades amostrais, para os métodos de parcelas, quadrantes e relascopia, empregados para o estudo do componente arbóreo da Grade 2, na Floresta Ombrófila Densa, no Parque Estadual Carlos Botelho.SP.Brasil 


\subsubsection{Distância Euclidiana}

Considerando os valores dos parâmetros fitossociológicos constantes nas Tabelas 5, 6, 7, 8, 9 e 10, para os métodos de parcelas, quadrantes e relascopia, empregados no presente estudo, determinou-se a Distância Euclidiana (DE) entre eles.

Na Tabela 13 são apresentados os valores para a Distância Euclidiana entre os métodos de amostragem, em cada grade amostral, para os parâmetros fitossociológicos determinados. Observa-se que para Freqüência Relativa os menores valores foram encontrados para os métodos de parcelas e relascopia , $D E=10,24$ e $\mathrm{DE}=8,72$, para a Grade 1 e Grade 2, respectivamente. Estes métodos apresentaram também os menores valores para a Distância Euclidiana, DE=5,0 e DE=18,03, para Dominância Relativa e Índice de Valor de Importância, respectivamente para os dados amostrados na Grade 2.

Para a Grade 1, os menores valores de Distância Euclidiana , para Dominância Relativa e Índice de Valor de Importância foram determinados para os métodos de parcelas e quadrantes. Para os valores de Densidade Relativa, os métodos de parcelas e quadrantes apresentaram $\mathrm{DE}=4,56$ e $\mathrm{DE}=5,04$, para a Grade 1 e Grade 2, respectivamente, como sendo os menores valores.

Brower \& Zar citado por Mello et al. (1996) salientam que quanto menor a Distância Euclidiana entre duas comunidades, mais próximas estão estas comunidades entre si, em termos de parâmetros quantitativos.

Assim, para o componente arbóreo da Grade 1, os métodos de parcela e relascopia foram os que mais se aproximaram na determinação da Freqüência Relativa. Os métodos de parcelas e quadrantes apresentaram resultados mais próximos para Densidade Relativa, Dominância Relativa e Índice de Valor de Importância.

Na Grade 2, os melhores resultados para Freqüência Relativa, Dominância Relativa e Índice de Valor de Importância, foram apresentados pelos métodos de 
parcelas e relascopia. A Densidade Relativa foi melhor avaliada pelos métodos de parcelas e quadrantes.

Estes resultados mostram um comportamento diferente dos métodos de amostragem na determinação dos parâmetros fitossociológicos, nas duas áreas de amostragem.

Na Grade 1 e Grade 2, o menor valor da distância Euclidiana encontrada na comparação da Freqüência Relativa, mostrou que os métodos de parcelas e relascopia apresentam maior afinidade na determinação deste parâmetro. Para Densidade Relativa o valor da Distância Euclidiana mostra maior afinidade para os métodos de parcela e quadrantes.

Para Dominância Relativa e Índice de Valor de Importância, a Distância Euclidiana, mostra que na Grade1 os métodos de parcelas de quadrantes foram os que mais se aproximaram na determinação deste parâmetro, enquanto que na Grade 2, foram os métodos de parcela e relascopia 
Tabela 13. Distância Euclidiana calculada entre os valores dos parâmetros fitossociológicos das espécies amostradas pelos métodos de parcela, quadrantes e relascopia nas duas áreas de amostragem (Grade-1 e Grade2), instaladas na Floresta Ombrófila Densa, no Parque Estadual Carlos Botelho. SP. Brasil. DE/FR - distância euclidiana para freqüência relativa; DE/DR - distância euclidiana para densidade relativa; DE/DOR - distância euclidiana para dominância relativa; DE/IVI - distância euclidiana para índice de valor de importância

\begin{tabular}{llrrrr}
\hline LOCAL & MÉTODOS & DE/FR & DE/DR & DE/DOR & DE/IVI \\
& PARCELAS x RELASCOPIA & 10,64 & 11,61 & 11,17 & 25,98 \\
GRADE 1 & PARCELAS x QUADRANTES & 12,44 & 4,56 & 10,17 & 21,87 \\
& QUADRANTES x RELASCOPIA & 13,64 & 11,04 & 15,92 & 30,93 \\
& PARCELAS x RELASCOPIA & 8,72 & 8,86 & 5,00 & 18,03 \\
GRADE 2 & PARCELAS x QUADRANTES & 14,17 & 5,04 & 9,96 & 22,42 \\
& QUADRANTES x RELASCOPIA & 15,39 & 9,77 & 12,21 & 25,89 \\
\hline
\end{tabular}




\section{CONCLUSÕES}

- O número de 427 espécies e 65 famílias determinadas para a área de estudo, podem estar sendo subestimado, uma vez que muitos indivíduos foram identificados apenas em nível de gênero, família ou foram agrupados como morfoespécies. O grande número de indivíduos amostrados e ausência de material botânico fértil, contribuiram sobremaneira para esta situação. Isto mostra a necessidade de continuidade das observações de campo e coleta de material botânico fértil;

- O método de relascopia foi o que apresentou maior heterogeneidade em nível de família, amostrando um maior número de famílias diferentes nas duas grades de amostragem;

- Das 65 famílias amostradas, apenas 5 não tiveram ocorrência comum nas duas grades de amostragem. As famílias Lecytidaceae, Podocarpaceae e Styracaceae estavam presentes apenas na Grade 1 e as famílias Bombacaceae e Simaroubaceae só foram registradas na Grade 2, mostrando alta similaridade das duas áreas em nível de família;

- As famílias Myrtaceae, Lauraceae, Fabaceae e Sapotaceae apresentaram a maior riqueza de espécies, independente do método de amostragem empregado;

- Euterpe edulis e Ocotea catharinensis estão presentes entre as espécies com maior valor de IVI, amostradas pelos três métodos de amostragem empregados (parcelas, quadrantes e relascopia). Com exceção do método de parcelas na Grade 1, onde a espécie Micropholis crassipedicellata foi favorecida pelo alto valor de Dominância, Eutepe edulis ocupou sempre a primeira posição em relação aos valores do IVI; 
- Os valores de diversidade, determinados pelo Índice de Shannon para os três métodos de amostragem (parcelas, quadrantes e relascopia), estavam muito próximos entre si, não caracterizando diferenças entre estes métodos para a sua determinação;

- A área de amostragem situada em região de maior altitude (Grade 1), apresentou menor riqueza e diversidade de espécies que a área situada em menor altitude (Grade 2)., sinalizando uma variação da diversidade ao longo do gradiente altitudinal da área de estudo;

- Os métodos de amostragem empregados (parcelas, quadrantes e relascopia) permitiram a caracterização da vegetação do componente arbóreo da Floresta Ombrófila Densa no Parque Estadual Carlos Botelho, em dois níveis altitudinais. No entanto, os dados analisados apontam para a necessidade de maior intensidade amostral para os métodos de quadrantes e relascopia. 
A N E X O S 
Anexo A - Equações empregadas nas analises fitossociológicas para os métodos de parcelas, quadrantes e relascopia.

\section{Método de Parcelas}

Densidade Absoluta da Espécie $\left(\mathrm{DA}_{\mathrm{i}}\right)$

$\mathrm{DA}_{\mathrm{i}}=\mathrm{n}_{\mathrm{i}} / \mathrm{A}$

Densidade Relativa da Espécie $\left(\mathrm{DR}_{\mathrm{i}}\right)$

$\mathrm{DR}_{\mathrm{i}}=100\left(\mathrm{n}_{\mathrm{i}} / \mathrm{N}\right)$

Dominância Absoluta da Espécie $\left(\mathrm{DoA}_{\mathrm{i}}\right)$

$\mathrm{DoA}_{\mathrm{i}}=\mathrm{AB}_{\mathrm{i}} / \mathrm{A}$

Dominância Relativa da Espécie $\left(\mathrm{DoR}_{\mathrm{i}}\right)$

$\operatorname{DoR}_{\mathrm{i}}=100\left(\mathrm{AB}_{\mathrm{i}} / \mathrm{ABT}\right)$

Freqüência Absoluta da Espécie $\left(\mathrm{FA}_{\mathrm{i}}\right)$

$\mathrm{FA}_{\mathrm{i}}=100\left(\mathrm{U}_{\mathrm{i}} / \mathrm{UT}\right)$

Freqüência Relativa da Espécie $\left(\mathrm{FR}_{\mathrm{i}}\right)$

$\mathrm{FR}_{\mathrm{i}}=100\left(\mathrm{FA}_{\mathrm{i}} / \sum_{\mathrm{j}=1}^{\mathrm{i}} \mathrm{FA}_{\mathrm{j}}\right)$

Índice de Valor de Importância da Espécie ( $\left.\mathrm{IVI}_{\mathrm{i}}\right)$

$\mathrm{IVI}_{\mathrm{i}}=\mathrm{DR}_{\mathrm{i}}+\mathrm{FR}_{\mathrm{i}}+\mathrm{DoR}_{\mathrm{i}}$

Onde:

$\mathrm{N}$ - número total de indivíduos amostrados;

A - área amostrada (ha);

$\mathrm{n}_{\mathrm{i}}-$ número de indivíduos da espécie $\mathbf{i}$;

$\mathrm{AB}_{\mathrm{i}}$ - área basal da espécie $\mathbf{i}$;

$\mathrm{U}_{\mathrm{i}}$ - número total de parcelas com a ocorrência da espécie i;

UT - número total de parcelas na amostra. 


\section{Método de Quadrantes}

Densidade Total por Área (DTA)

$\mathrm{DTA}=\mathrm{U} / \mathrm{AM}$

$\mathrm{AM}=\left(\sum \mathrm{d} / \mathrm{N}\right)^{2}$

Densidade Absoluta da Espécie $\left(\mathrm{DA}_{\mathrm{i}}\right)$

$\mathrm{DA}_{\mathrm{i}}=\operatorname{DTA}\left(\mathrm{n}_{\mathrm{i}} / \mathrm{N}\right)$

Densidade Relativa da Espécie $\left(\mathrm{DR}_{\mathrm{i}}\right)$

$\mathrm{DR}_{\mathrm{i}}=100\left(\mathrm{DA}_{\mathrm{i}} / \sum \mathrm{DA}\right)$

Dominância Absoluta da Espécie (DoA $\left.\mathrm{A}_{\mathrm{i}}\right)$

$\mathrm{DoA}_{\mathrm{i}}=\mathrm{DA}_{\mathrm{i}} / \mathrm{Abm}_{\mathrm{i}}$

$\mathrm{Abm}_{\mathrm{i}}=\mathrm{AB}_{\mathrm{i}} / \mathrm{n}_{\mathrm{i}}$

Dominância relativa da Espécie $\left(\mathrm{DoR}_{\mathrm{i}}\right)$

$\mathrm{DoR}_{\mathrm{i}}=100\left(\mathrm{AB}_{\mathrm{i}} / \mathrm{ABT}\right)$

$\mathrm{FA}_{\mathrm{i}}=100\left(\mathrm{P}_{\mathrm{i}} / \mathrm{P}\right)$

$\mathrm{FR}_{\mathrm{i}}=100\left(\mathrm{FA}_{\mathrm{i}} / \sum \mathrm{FA}\right)$

Índice de Valor de Importância da Espécie $\left(\mathrm{IVI}_{\mathrm{i}}\right)$

$\mathrm{IVI}_{\mathrm{i}}=\mathrm{DR}_{\mathrm{i}}+\mathrm{DoR}_{\mathrm{i}}+\mathrm{FR}_{\mathrm{i}}$

Onde:

U - Unidade de Amostragem (ha);

AM - área média;

d - distância da árvore ao ponto de amostragem;

$\mathrm{N}$ - número total de indivíduos amostrados; 
$\mathrm{n}_{\mathrm{i}}$ - número de indivíduos da espécie $\mathbf{i}$;

$\mathrm{Abm}_{\mathrm{i}}=$ área basal média da espécie $\mathbf{i}$;

ABT - área basal total;

$\mathrm{P}$ - número total de pontos de amostragem;

$\mathrm{P}_{\mathrm{i}}$ - número de pontos onde ocorre a espécie $\boldsymbol{i}$.

\section{Método de Relascopia - (Parcelas Circulares de Raios Variáveis)}

Densidade Absoluta da Espécie $\left(\mathrm{DA}_{\mathrm{i}}\right)$

$\mathrm{DA}_{\mathrm{i}}=\sum \mathrm{fe}_{\mathrm{i}}$

$\mathrm{Fe}_{\mathrm{i}}=\mathrm{F} / \mathrm{AB}_{\mathrm{i}}$

Densidade relativa da Espécie $\left(\mathrm{DR}_{\mathrm{i}}\right)$

$\mathrm{DR}_{\mathrm{i}}=100\left(\mathrm{DAi} / \sum \mathrm{DA}\right)$

Dominância Absoluta da Espécie (DoA $\left.A_{i}\right)$

$\mathrm{DoA}_{\mathrm{i}}=\mathrm{n}_{\mathrm{i}} \mathrm{F} / \mathrm{m}$

Dominância relativa da espécie $\left(\mathrm{DoR}_{\mathrm{i}}\right)$

$\operatorname{DoR}_{\mathrm{i}}=100\left(\mathrm{DoA}_{\mathrm{i}} / \sum \mathrm{DoA}\right)$

Freqüência Absoluta da Espécie $\left(\mathrm{FA}_{\mathrm{i}}\right)$

$\mathrm{FA}_{\mathrm{i}}=100\left(\mathrm{P}_{\mathrm{i}} / \mathrm{m}\right)$

Freqüência relativa da espécie $\left(\mathrm{FR}_{\mathrm{i}}\right)$

$\mathrm{FR}_{\mathrm{i}}=100\left(\mathrm{FA}_{\mathrm{i}} / \sum \mathrm{FA}\right)$

Índice de Valor de Importância da Espécie ( $\left.\mathrm{IVI}_{\mathrm{i}}\right)$

$\mathrm{IVI}_{\mathrm{i}}=\mathrm{DR}_{\mathrm{i}}+\mathrm{DoR}_{\mathrm{i}}+\mathrm{FR}_{\mathrm{i}}$

Onde:

$\mathrm{fe}_{\mathrm{i}}$ - fator de expansão da espécie i ( $\mathrm{n}^{0}$ de indivíduos por ha);

$\mathrm{AB}_{\mathrm{i}}$ - área basal da espécie $\mathbf{i}$

$\mathrm{m}$ - número total de parcelas de raio variável;

$\mathrm{P}_{\mathrm{i}}$ - número de parcelas de raio variável onde ocorreu a espécie $\mathbf{i}$. 
Anexo B. Relação das famílias e das espécies, em ordem alfabética, amostradas pelos métodos (parcelas, quadrantes e relascopia), na Floresta Ombrófila Densa, Parque Estadual Carlos Botelho. SP. Brasil. par g 1- Parcela Grade 1; par g2- Parcela grade 2; qua g1 - Quadrante Grade 1; qua g2 Quadrante grade 2; rel g1 - Relascopia grade 1 e rel g2 - Relascopia grade 2

\begin{tabular}{|c|c|c|c|c|c|c|c|c|c|}
\hline & Familias & & Espécies & par g1 & par g2 & qua g1 & qua g2 & rel g1 & rel g2 \\
\hline 1 & Anacardiaceae & 1 & Tapirira guianensis Aubl. & $x$ & $x$ & $x$ & - & $x$ & - \\
\hline \multirow[t]{9}{*}{2} & Annonaceae & 2 & Duguetia lanceolata A.St. Hil. & - & $x$ & - & $x$ & - & $x$ \\
\hline & & 3 & Guatteria australis A. St. Hil. & $x$ & $x$ & $x$ & $x$ & $x$ & - \\
\hline & & 4 & Guatteria nigrescens Mart. & - & $\mathrm{X}$ & - & - & - & - \\
\hline & & 5 & Rollinia parviflora A. St. Hil. & $x$ & - & $x$ & - & $x$ & - \\
\hline & & 6 & Rollinia sericea (R. E. Fries) R. E. Fries & $x$ & $x$ & $x$ & $x$ & - & $x$ \\
\hline & & 7 & Rollinia sp. & - & $x$ & - & - & - & - \\
\hline & & 8 & Rollinia sylvatica (A. St. Hil.) Mart. & - & $x$ & - & - & - & - \\
\hline & & 9 & Xylopia langsdorfiana St. Hil. \& Tul. & $x$ & $x$ & $x$ & $x$ & $x$ & $x$ \\
\hline & & 10 & Xylopia sp. & - & - & - & - & $x$ & - \\
\hline \multirow[t]{3}{*}{3} & Apocynaceae & 11 & Aspidosperma olivaceum Müll. Arg. & $x$ & - & $x$ & - & $x$ & - \\
\hline & & 12 & Aspidosperma sp & - & - & - & - & $x$ & - \\
\hline & & 13 & Malouetia arborea (Vell.) Miers & - & $x$ & - & - & - & - \\
\hline \multirow[t]{2}{*}{4} & Aquifoliaceae & 14 & Ilex taubertiana Loes. & $x$ & $x$ & $x$ & - & $x$ & $x$ \\
\hline & & 15 & Ilex amara (Vell.) Loes. & $x$ & $x$ & $x$ & $x$ & $x$ & $x$ \\
\hline
\end{tabular}


Anexo B. Relação das famílias e das espécies, em ordem alfabética, amostradas pelos métodos (parcelas, quadrantes e relascopia), na Floresta Ombrófila Densa, Parque Estadual Carlos Botelho. SP. Brasil. par g 1- Parcela Grade 1; par g2- Parcela grade 2; qua g1 - Quadrante Grade 1; qua g2 Quadrante grade 2; rel g1 - Relascopia grade 1 e rel g2 - Relascopia grade 2

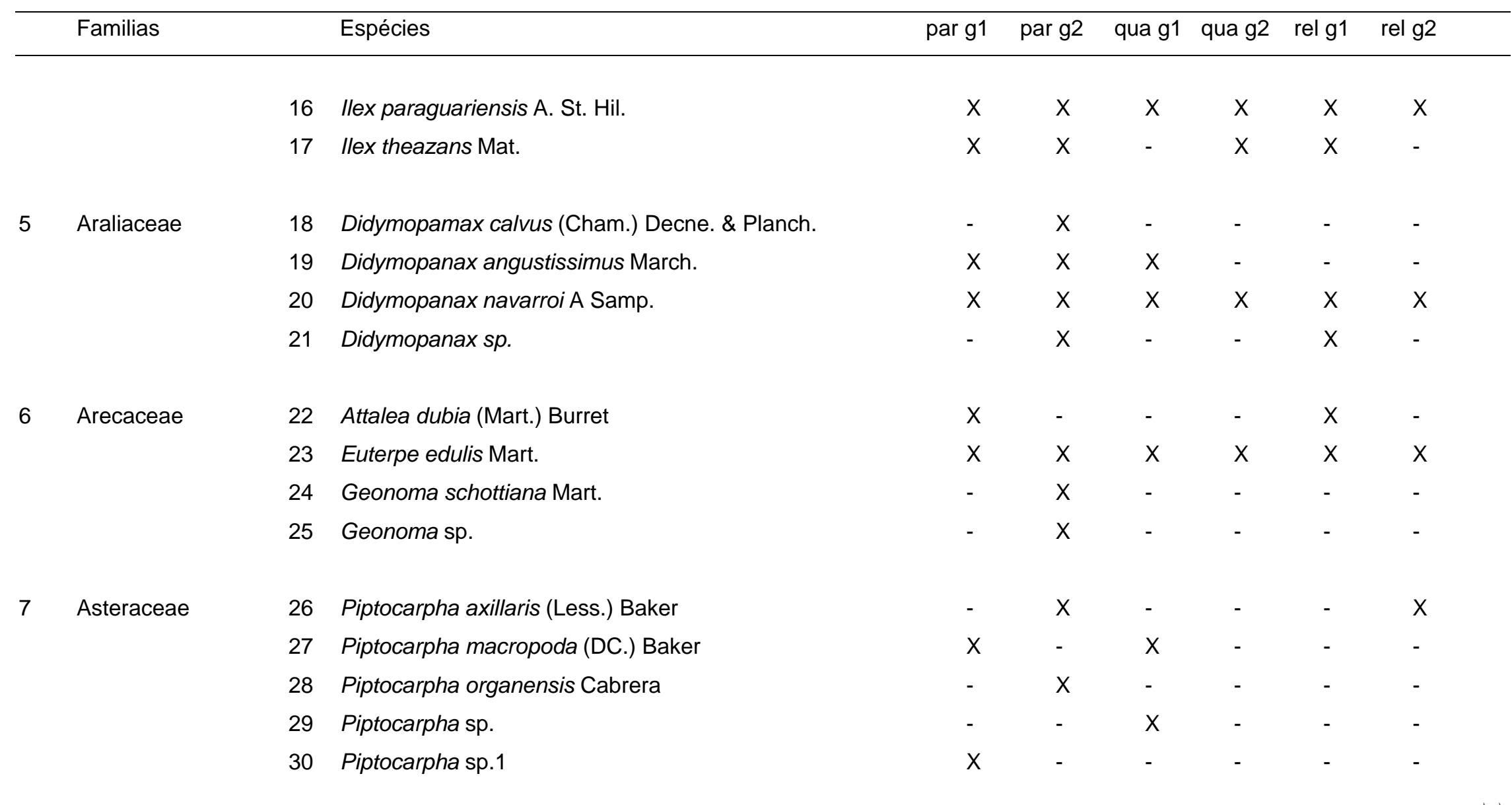


Anexo B. Relação das famílias e das espécies, em ordem alfabética, amostradas pelos métodos (parcelas, quadrantes e relascopia), na Floresta Ombrófila Densa, Parque Estadual Carlos Botelho. SP. Brasil. par g 1- Parcela Grade 1; par g2- Parcela grade 2; qua g1 - Quadrante Grade 1; qua g2 Quadrante grade 2; rel g1 - Relascopia grade 1 e rel g2 - Relascopia grade 2

\begin{tabular}{|c|c|c|c|c|c|c|c|c|c|}
\hline & Familias & & Espécies & parg1 & parg2 & qua g1 & qua g2 & rel g1 & rel g2 \\
\hline & & 31 & Vanillosmopsis erythropappa (DC.)Sch. Bip. & - & $x$ & - & - & - & - \\
\hline & & 32 & Vernonia cf. grandifolia DC. & - & $\mathrm{x}$ & - & - & - & - \\
\hline & & 33 & Vernonia diffusa Less. & $x$ & - & $x$ & - & - & - \\
\hline & & 34 & Vernonia puberula Less. & - & $x$ & - & $x$ & - & $x$ \\
\hline \multirow[t]{4}{*}{8} & Bignoniaceae & 36 & Jacaranda micrantha Cham. & - & $x$ & - & $x$ & - & - \\
\hline & & 37 & Jacaranda puberula Cham. & $x$ & $x$ & $x$ & $x$ & - & $x$ \\
\hline & & 38 & Tabebuia heptaphylla (Vell.) Toledo & $x$ & $x$ & - & $x$ & - & - \\
\hline & & 39 & Tabebuia sp. & - & $x$ & - & - & - & - \\
\hline \multirow[t]{5}{*}{10} & Boraginaceae & 41 & Cordia ecalyculata Vell. & - & $x$ & - & $x$ & - & - \\
\hline & & 42 & Cordia sellowiana Cham. & $x$ & $x$ & $x$ & $x$ & $x$ & $x$ \\
\hline & & 43 & Cordia sp. & - & - & $x$ & - & $x$ & - \\
\hline & & 44 & Cordia sp. 1 & $x$ & $x$ & - & $x$ & - & $x$ \\
\hline & & 45 & Cordia trichotoma (Vell.) Arrab. ex Steud. & - & $x$ & - & $x$ & - & $x$ \\
\hline
\end{tabular}


Anexo B. Relação das famílias e das espécies, em ordem alfabética, amostradas pelos métodos (parcelas, quadrantes e relascopia), na Floresta Ombrófila Densa, Parque Estadual Carlos Botelho. SP. Brasil. par g 1- Parcela Grade 1; par g2- Parcela grade 2; qua g1 - Quadrante Grade 1; qua g2 Quadrante grade 2; rel g1 - Relascopia grade 1 e rel g2 - Relascopia grade 2

\begin{tabular}{|c|c|c|c|c|c|c|c|c|c|}
\hline & Familias & & Espécies & par g1 & par g2 & qua g1 & qua g2 & rel g1 & rel g2 \\
\hline \multirow[t]{2}{*}{11} & Burseraceae & 46 & Protium hepatphyllum (Aubl.) March. & $x$ & $x$ & $x$ & $x$ & $x$ & $x$ \\
\hline & & 47 & Protium sp. & - & - & - & - & $\mathrm{X}$ & - \\
\hline \multirow[t]{7}{*}{12} & Caesalpiniaceae & 48 & Copaifera langsdorffii Desf. & $x$ & $x$ & $x$ & $x$ & $x$ & $x$ \\
\hline & & 49 & Copaifera trapezifolia Hayne & $\mathrm{X}$ & - & $\mathrm{X}$ & - & $\mathrm{X}$ & - \\
\hline & & 50 & Sclerolobium denudatum Vog. & $x$ & $x$ & $x$ & $\mathrm{X}$ & $\mathrm{X}$ & $\mathrm{X}$ \\
\hline & & 51 & Sclerolobium sp. & - & - & - & - & $x$ & - \\
\hline & & 52 & Senna macranthera (DC. ex Coll.) Irwin \& Barneby & - & $x$ & - & - & - & - \\
\hline & & 53 & Senna multijuja (Rich.) h.s. Irwin \& Barneby & - & $x$ & - & $\mathrm{x}$ & - & - \\
\hline & & 54 & Swartzia acutifolia Vog. & - & $x$ & - & - & - & - \\
\hline 13 & Canellaceae & 55 & Capsicodendron dinisii (Schw.) Occh. & $x$ & $x$ & $x$ & $x$ & $x$ & $x$ \\
\hline \multirow[t]{4}{*}{14} & Cecropiaceae & 56 & Cecropia glaziovi Sneth. & $x$ & - & $x$ & - & - & - \\
\hline & & 57 & Cecropia sp. & - & $x$ & - & $x$ & - & - \\
\hline & & 58 & Coussapoa microcarpa (Schott) Rizzini & $\mathrm{X}$ & $x$ & $x$ & $x$ & - & $x$ \\
\hline & & 59 & Coussapoa sp. & - & - & - & - & $x$ & - \\
\hline
\end{tabular}


Anexo B. Relação das famílias e das espécies, em ordem alfabética, amostradas pelos métodos (parcelas, quadrantes e relascopia), na Floresta Ombrófila Densa, Parque Estadual Carlos Botelho. SP. Brasil. par g 1- Parcela Grade 1; par g2- Parcela grade 2; qua g1 - Quadrante Grade 1; qua g2 Quadrante grade 2; rel g1 - Relascopia grade 1 e rel g2 - Relascopia grade 2

\begin{tabular}{|c|c|c|c|c|c|c|c|c|c|}
\hline & Familias & & Espécies & par g1 & par g2 & qua g1 & qua g2 & rel g1 & rel g2 \\
\hline \multirow[t]{3}{*}{15} & Celastraceae & 60 & Maytenus alaternoides Reiss. & - & $x$ & - & - & - & - \\
\hline & & 61 & Maytenus ilicifolia Mart.ex.Reiss. & - & $x$ & - & $x$ & - & - \\
\hline & & 62 & Maytenus robusta Reiss. & $\mathrm{X}$ & $x$ & $x$ & $x$ & $x$ & $x$ \\
\hline \multirow[t]{2}{*}{16} & Chrysobalanaceae & 63 & Hirtella hebeclada Moric. ex DC. & $x$ & $x$ & $x$ & $x$ & $x$ & $x$ \\
\hline & & 64 & Parinari excelsa Sabine & - & $x$ & $x$ & $x$ & $x$ & $x$ \\
\hline 17 & Clethraceae & 65 & Clethra scabra Pers. & $x$ & $x$ & $x$ & - & - & $x$ \\
\hline \multirow[t]{2}{*}{18} & Clusiaceae & 66 & Clusia criuva Cambess. & $\mathrm{x}$ & $x$ & - & - & - & $x$ \\
\hline & & 67 & Garcinia gadneriana (Planch.\& Triana) Zappi & $\mathrm{X}$ & $x$ & $x$ & $x$ & - & $x$ \\
\hline 19 & Combretaceae & 68 & Buchenavia kleinii Excell & $x$ & $x$ & $x$ & - & - & $x$ \\
\hline \multirow[t]{4}{*}{20} & Cunoniaceae & 69 & Lamanonia ternata Vell. & $x$ & $x$ & $x$ & $x$ & $x$ & $x$ \\
\hline & & 70 & Weinmannia discolor Gardner & $\mathrm{X}$ & $x$ & $x$ & $x$ & - & $x$ \\
\hline & & 71 & Weinmannia paulliniifolia Pohl & $x$ & $x$ & $x$ & $x$ & $x$ & $x$ \\
\hline & & 72 & Weinmannia sp. & - & - & - & - & $x$ & - \\
\hline
\end{tabular}


Anexo B. Relação das famílias e das espécies, em ordem alfabética, amostradas pelos métodos (parcelas, quadrantes e relascopia), na Floresta Ombrófila Densa, Parque Estadual Carlos Botelho. SP. Brasil. par g 1- Parcela Grade 1; par g2- Parcela grade 2; qua g1 - Quadrante Grade 1; qua g2 Quadrante grade 2; rel g1 - Relascopia grade 1 e rel g2 - Relascopia grade 2

\begin{tabular}{|c|c|c|c|c|c|c|c|c|c|}
\hline & Familias & & Espécies & par g1 & par g2 & qua g1 & qua g2 & rel g1 & rel g2 \\
\hline \multirow[t]{2}{*}{21} & Elaeocarpaceae & 73 & Sloanea monosperma Vell. & $x$ & $x$ & $x$ & $x$ & - & - \\
\hline & & 74 & Sloanea sp. & - & - & - & - & $\mathrm{X}$ & - \\
\hline \multirow[t]{2}{*}{22} & Erythroxylaceae & 75 & Erythroxylum cf.argentinum Schulz. & - & $x$ & - & - & - & - \\
\hline & & 76 & Erythroxylum sp. & $x$ & - & - & - & - & - \\
\hline \multirow[t]{6}{*}{23} & Euphorbiaceae & 77 & Alchornea triplinervia (Spreng.) Müll. Arg. & $x$ & $x$ & $x$ & $x$ & $x$ & $x$ \\
\hline & & 78 & Hyeronima alchorneoides Allem. & $x$ & $\mathrm{X}$ & $x$ & $\mathrm{X}$ & $x$ & $x$ \\
\hline & & 79 & Hyeronima sp. & - & - & - & - & $x$ & - \\
\hline & & 80 & Pera glabrata (Scott) Poep. ex Baill. & $x$ & - & - & - & $x$ & - \\
\hline & & 81 & Pera obovata (Klotzsch) Baill. & - & $x$ & - & - & - & - \\
\hline & & 82 & Sapium glandulatum (Vell.) Pax & $x$ & $x$ & $x$ & $x$ & - & $x$ \\
\hline \multirow[t]{5}{*}{24} & Fabaceae & 83 & Andira anthelmia (Vell.) Macbr. & $x$ & $x$ & $x$ & $x$ & $x$ & $x$ \\
\hline & & 84 & Andira sp. & - & $x$ & - & - & - & - \\
\hline & & 85 & Dahlstedtia pentaphylla ( Taub.) Burkart & - & $x$ & - & $x$ & - & - \\
\hline & & 86 & Dahlstedtia pinnata (Benth.) Malme & - & $x$ & - & $x$ & $x$ & $x$ \\
\hline & & 87 & Dalbergia brasiliensis Vog. & $x$ & $x$ & - & $x$ & $x$ & $x$ \\
\hline
\end{tabular}


Anexo B. Relação das famílias e das espécies, em ordem alfabética, amostradas pelos métodos (parcelas, quadrantes e relascopia), na Floresta Ombrófila Densa, Parque Estadual Carlos Botelho. SP. Brasil. par g 1- Parcela Grade 1; par g2- Parcela grade 2; qua g1 - Quadrante Grade 1; qua g2 Quadrante grade 2; rel g1 - Relascopia grade 1 e rel g2 - Relascopia grade 2

\begin{tabular}{|c|c|c|c|c|c|c|c|c|c|}
\hline & Familias & & Espécies & par g1 & par g2 & qua g1 & qua g2 & rel g1 & rel g2 \\
\hline & & 88 & Dalbergia frutescens (Vell.) Britton & $x$ & $x$ & - & - & $x$ & $x$ \\
\hline & & 89 & Fabaceae 1 & $x$ & - & $x$ & - & $x$ & - \\
\hline & & 90 & Machaerium nictitans (Vell.) Benth. & $x$ & $x$ & - & - & - & - \\
\hline & & 91 & Machaerium sp. & $x$ & - & - & - & - & - \\
\hline & & 92 & Myrocarpus frondosus Allem. & $x$ & $x$ & $x$ & $x$ & $x$ & $x$ \\
\hline & & 93 & Myrocarpus sp. & - & - & - & - & $x$ & - \\
\hline & & 94 & Ormosia arborea (Vell.) Harms & - & $x$ & - & - & - & - \\
\hline & & 95 & Ormosia dasycarpa Jacks. & $x$ & $x$ & $x$ & $x$ & $x$ & $x$ \\
\hline & & 96 & Platymiscium floribundum Vogel & - & $x$ & - & $x$ & - & $x$ \\
\hline & & 97 & Pterocarpus rohrii Vahl. & $x$ & $x$ & $x$ & $x$ & $x$ & $x$ \\
\hline & & 98 & Zollernia illicifolia (Bron.) Vog. & $x$ & $x$ & $x$ & - & $x$ & - \\
\hline \multirow[t]{5}{*}{25} & Flacourtiaceae & 99 & Casearia decandra Jacq. & $x$ & $x$ & $x$ & $x$ & $x$ & $x$ \\
\hline & & 100 & Casearia obliqua Spreng. & $x$ & $x$ & $x$ & $x$ & - & $x$ \\
\hline & & 101 & Casearia sp. & - & $x$ & - & - & - & - \\
\hline & & 102 & Casearia sylvestris Sw. & $x$ & $x$ & - & $x$ & $x$ & - \\
\hline & & 103 & Xylosma glaberrima Sleumer & $x$ & - & - & - & - & - \\
\hline
\end{tabular}


Anexo B. Relação das famílias e das espécies, em ordem alfabética, amostradas pelos métodos (parcelas, quadrantes e relascopia), na Floresta Ombrófila Densa, Parque Estadual Carlos Botelho. SP. Brasil. par g 1- Parcela Grade 1; par g2- Parcela grade 2; qua g1 - Quadrante Grade 1; qua g2 Quadrante grade 2; rel g1 - Relascopia grade 1 e rel g2 - Relascopia grade 2

\begin{tabular}{|c|c|c|c|c|c|c|c|c|c|}
\hline & Familias & & Espécies & par g1 & par g2 & qua g1 & qua g2 & rel g1 & rel g2 \\
\hline \multirow[t]{2}{*}{26} & Hippocrateaceae & 104 & Cheiloclinium cognatum (Miers) A.C. Sm. & $x$ & - & - & - & - & - \\
\hline & & 105 & Salacia elliptica (Mart. ex Schult.) G. Don. & $\mathrm{X}$ & $\mathrm{X}$ & - & $x$ & - & - \\
\hline \multirow[t]{2}{*}{27} & Humiriaceae & 106 & Humiriastrum dentatum (Casar.) Cuatrec. & - & $x$ & - & - & - & - \\
\hline & & 107 & Vantanea compacta (Schnzl.) Cuatr. & $\mathrm{x}$ & $x$ & $x$ & $x$ & $\mathrm{X}$ & $x$ \\
\hline 28 & Icacinaceae & 108 & Citronella paniculata (Mart.) Howard & $x$ & $x$ & $x$ & $x$ & $x$ & $x$ \\
\hline \multirow[t]{7}{*}{29} & Morfoespécies & 109 & Morfoespécie 1 & - & $x$ & - & - & - & - \\
\hline & & 110 & Morfoespécie 2 & - & $x$ & - & - & - & - \\
\hline & & 111 & Morfoespécie 3 & - & $x$ & - & $x$ & - & $x$ \\
\hline & & 112 & Morfoespécie 4 & - & $x$ & - & - & - & - \\
\hline & & 113 & Morfoespécie 5 & - & $x$ & - & - & - & - \\
\hline & & 114 & Morfoespécie 6 & - & $x$ & - & - & - & - \\
\hline & & 115 & Morfoespécie 7 & - & $x$ & - & - & - & - \\
\hline 30 & Lacistemataceae & 116 & Lacistema hasslerianum Chodat. & - & $x$ & - & - & - & - \\
\hline
\end{tabular}


Anexo B. Relação das famílias e das espécies, em ordem alfabética, amostradas pelos métodos (parcelas, quadrantes e relascopia), na Floresta Ombrófila Densa, Parque Estadual Carlos Botelho. SP. Brasil. par g 1- Parcela Grade 1; par g2- Parcela grade 2; qua g1 - Quadrante Grade 1; qua g2 Quadrante grade 2; rel g1 - Relascopia grade 1 e rel g2 - Relascopia grade 2

\begin{tabular}{|c|c|c|c|c|c|c|c|c|}
\hline & Familias & Espécies & par g1 & par g2 & qua g1 & qua g2 & rel g1 & rel g2 \\
\hline \multirow[t]{18}{*}{31} & Lauraceae & 117 Aiouea acaradomatifera Koest. & $x$ & $x$ & $x$ & $x$ & $x$ & $x$ \\
\hline & & 118 Aiouea saligna Meisn. & $x$ & - & - & - & - & - \\
\hline & & 119 Aiouea sp. & - & $x$ & - & - & - & - \\
\hline & & 120 Aniba firmula (Nees \& Mart.) Mez. & $x$ & $x$ & - & - & - & - \\
\hline & & 121 Aniba viridis Mez. & $x$ & $x$ & $x$ & $x$ & $x$ & $x$ \\
\hline & & 122 Beilschmiedia emarginata (Meisn.) Kosterm. & $x$ & $\mathrm{X}$ & $x$ & - & - & - \\
\hline & & 123 Cinnamomum hirsutum Lorea-Hern. & $x$ & - & - & - & - & - \\
\hline & & 124 Cinnamomum sp. & - & $x$ & - & $x$ & $x$ & $\mathrm{x}$ \\
\hline & & 125 Cinnamomum sp.1 & - & $x$ & - & - & - & $x$ \\
\hline & & 126 Cinnamomum triplinerve (Ruiz. \& Pav.) Kosterm. & - & $x$ & - & - & - & - \\
\hline & & 127 Cryptocarya moschata Nees \& Mart. & $x$ & $x$ & $x$ & $x$ & $x$ & $x$ \\
\hline & & 128 Cryptocarya sp. & - & $X$ & - & $x$ & $X$ & $X$ \\
\hline & & 129 Cryptocarya sp. 1 & $x$ & - & $x$ & - & $x$ & - \\
\hline & & 130 Endlicheria paniculata (Spreng.) Macbr. & $x$ & $x$ & $x$ & $x$ & - & $\mathrm{x}$ \\
\hline & & 131 Lauraceae sp.1 & $x$ & $x$ & - & - & - & - \\
\hline & & 132 Lauraceae sp.2 & $x$ & $x$ & - & - & - & - \\
\hline & & 133 Lauraceae sp.3 & $x$ & $x$ & - & $x$ & - & $x$ \\
\hline & & 134 Lauraceae sp.4 & - & $\mathrm{x}$ & - & - & - & - \\
\hline
\end{tabular}


Anexo B. Relação das famílias e das espécies, em ordem alfabética, amostradas pelos métodos (parcelas, quadrantes e relascopia), na Floresta Ombrófila Densa, Parque Estadual Carlos Botelho. SP. Brasil. par g 1- Parcela Grade 1; par g2- Parcela grade 2; qua g1 - Quadrante Grade 1; qua g2 Quadrante grade 2; rel g1 - Relascopia grade 1 e rel g2 - Relascopia grade 2

\begin{tabular}{|c|c|c|c|c|c|c|c|c|}
\hline Familias & & Espécies & par g1 & par g2 & qua g1 & qua g2 & rel g1 & rel g2 \\
\hline & 135 & Licaria armeniaca (Nees) Kostern & - & $x$ & - & - & - & - \\
\hline & 136 & Nectandra aff. barbellata Coe-Teix. & - & $\mathrm{x}$ & - & - & - & - \\
\hline & 137 & Nectandra aff. membranacea (SW.) Griseb. & - & - & - & $x$ & - & $x$ \\
\hline & 138 & Nectandra debilis Mez & $x$ & - & - & - & - & - \\
\hline & 139 & Nectandra leucantha Nees \& Mart. & - & $x$ & - & - & - & - \\
\hline & 140 & Nectandra membranacea (SW.) Griseb. & $x$ & $x$ & - & - & - & - \\
\hline & 141 & Nectandra oppositfolia Nees \& Mart. & $x$ & $x$ & - & - & $x$ & - \\
\hline & 142 & Ocotea aciphylla (Nees) Mez. & $x$ & $x$ & $x$ & $x$ & $x$ & $x$ \\
\hline & 143 & Ocotea aff. bragai Coe-Teix. & - & $x$ & - & - & - & $x$ \\
\hline & 144 & Ocotea aff. lancifolia (Schott) Mez & $x$ & - & - & - & - & - \\
\hline & 145 & Ocotea bicolor Vattimo & $x$ & $x$ & $x$ & $x$ & $x$ & $x$ \\
\hline & 146 & Ocotea brachybotrya (Meisn.) Mez & $x$ & $x$ & $x$ & - & - & - \\
\hline & 147 & Ocotea catharinensis Mez & $x$ & $x$ & $x$ & $x$ & $x$ & $x$ \\
\hline & 148 & Ocotea daphinifolia (Meisn.) Mez & $x$ & $x$ & - & - & - & - \\
\hline & 149 & Ocotea dispersa (Nees) Mez & $x$ & $x$ & $x$ & $x$ & $x$ & - \\
\hline & 150 & Ocotea divaricata (Nees) Mez. & - & $x$ & - & - & - & - \\
\hline & 151 & Ocotea elegans Mez & $x$ & $x$ & $x$ & $x$ & $x$ & $x$ \\
\hline & 152 & Ocotea glaziovii Mez & $x$ & $x$ & $x$ & $x$ & - & - \\
\hline
\end{tabular}


Anexo B. Relação das famílias e das espécies, em ordem alfabética, amostradas pelos métodos (parcelas, quadrantes e relascopia), na Floresta Ombrófila Densa, Parque Estadual Carlos Botelho. SP. Brasil. par g 1- Parcela Grade 1; par g2- Parcela grade 2; qua g1 - Quadrante Grade 1; qua g2 Quadrante grade 2; rel g1 - Relascopia grade 1 e rel g2 - Relascopia grade 2

\begin{tabular}{|c|c|c|c|c|c|c|c|c|}
\hline Familias & & Espécies & parg1 & parg2 & qua g1 & qua g2 & rel g1 & rel g2 \\
\hline & 153 & Ocotea mosenii Mez & - & $x$ & - & - & $x$ & $x$ \\
\hline & 154 & Ocotea nectandrifolia Mez & $x$ & - & - & - & - & - \\
\hline & 155 & Ocotea odorifera (Vell.) Rohwer & $x$ & $x$ & $x$ & $x$ & $x$ & - \\
\hline & 156 & Ocotea porosa (Nees \& Mart.) Barroso & - & $x$ & - & - & - & $x$ \\
\hline & 157 & Ocotea pulchella Mart. & $\mathrm{x}$ & $x$ & - & - & - & - \\
\hline & 158 & Ocotea pulchra Vatt. & $x$ & $x$ & $x$ & $x$ & $x$ & - \\
\hline & 159 & Ocotea silvestris Vatt. & $x$ & $x$ & $x$ & $x$ & $x$ & $x$ \\
\hline & 160 & Ocotea sp. & - & - & - & - & $x$ & - \\
\hline & 161 & Ocotea sp.1 & $x$ & $x$ & - & - & - & $x$ \\
\hline & 162 & Ocotea sp.2 & $\mathrm{x}$ & $x$ & - & - & - & - \\
\hline & 163 & Ocotea sp.3 & - & $x$ & - & - & - & - \\
\hline & 164 & Ocotea tabacifolia (Meisn.) Rohwer. & $x$ & $x$ & - & - & - & - \\
\hline & 165 & Ocotea teleiandra (Meisn.) Mez & $x$ & $x$ & $x$ & $x$ & - & - \\
\hline & 166 & Ocotea vaccinioides (Meisn.) Mez & $x$ & - & $x$ & - & - & - \\
\hline & 167 & Ocotea velloziana (Meisn.) Mez & $x$ & - & $x$ & - & - & - \\
\hline & 168 & Ocotea venulosa Benth. \& Hook. & $x$ & - & - & - & - & - \\
\hline & 169 & Ocoteabragai Coe-Teix. & - & - & - & - & - & $x$ \\
\hline & 170 & Persea pyrifolia (D. Don.) Spreng. & $x$ & $x$ & - & $x$ & $x$ & - \\
\hline
\end{tabular}


Anexo B. Relação das famílias e das espécies, em ordem alfabética, amostradas pelos métodos (parcelas, quadrantes e relascopia), na Floresta Ombrófila Densa, Parque Estadual Carlos Botelho. SP. Brasil. par g 1- Parcela Grade 1; par g2- Parcela grade 2; qua g1 - Quadrante Grade 1; qua g2 Quadrante grade 2; rel g1 - Relascopia grade 1 e rel g2 - Relascopia grade 2

\begin{tabular}{|c|c|c|c|c|c|c|c|c|}
\hline & Familias & Espécies & par g1 & par g2 & qua g1 & qua g2 & rel g1 & rel g2 \\
\hline & & 171 Persea sp.1 & $x$ & - & - & - & $x$ & - \\
\hline & & 172 Rhodostemenodaphne macrocalyx (Meissn.) Madr. & $x$ & $x$ & $x$ & $x$ & - & $\mathrm{x}$ \\
\hline 32 & Lecythidaceae & 173 Cariniana estrellensis (Raddi) Kuntze & $x$ & - & - & - & - & - \\
\hline 33 & Magnoliaceae & 174 Talauma ovata A. St. Hil. & $x$ & $x$ & $x$ & $x$ & $x$ & $x$ \\
\hline \multirow[t]{3}{*}{34} & Malphigiaceae & 175 Byrsonima ligustrifolia St. Hil. & $x$ & $x$ & $x$ & $x$ & $x$ & $x$ \\
\hline & & 176 Byrsonima myricifolia Griseb. & $x$ & $x$ & - & $x$ & $x$ & - \\
\hline & & 177 Byrsonima sp. & - & - & - & - & $x$ & - \\
\hline \multirow[t]{7}{*}{35} & Melastomataceae & 178 Leandra dasytricha Cogn. & $x$ & - & - & - & - & - \\
\hline & & 179 Leandra sp. & $x$ & - & - & - & - & - \\
\hline & & 180 Meriania claussenii Triana & $x$ & - & - & - & - & - \\
\hline & & 181 Miconia cabucu Hoenhe & $x$ & $x$ & $x$ & $x$ & $x$ & - \\
\hline & & 182 Miconia cubatanensis Hoenhe & $x$ & $x$ & $x$ & $x$ & - & - \\
\hline & & 183 Miconia petropolitana Cogn. & $x$ & $x$ & $x$ & $x$ & - & $x$ \\
\hline & & 184 Miconia pusilliflora (DC.) Naudin & $x$ & $x$ & $x$ & - & - & - \\
\hline
\end{tabular}


Anexo B. Relação das famílias e das espécies, em ordem alfabética, amostradas pelos métodos (parcelas, quadrantes e relascopia), na Floresta Ombrófila Densa, Parque Estadual Carlos Botelho. SP. Brasil. par g 1- Parcela Grade 1; par g2- Parcela grade 2; qua g1 - Quadrante Grade 1; qua g2 Quadrante grade 2; rel g1 - Relascopia grade 1 e rel g2 - Relascopia grade 2

\begin{tabular}{|c|c|c|c|c|c|c|c|c|c|}
\hline & Familias & & Espécies & par g1 & par g2 & qua g1 & qua g2 & rel g1 & rel g2 \\
\hline & & 185 & Miconia sellowiana Naudin & $\mathrm{x}$ & - & $x$ & - & - & - \\
\hline & & 186 & Miconia sp. & - & $x$ & - & - & $x$ & - \\
\hline & & 187 & Miconia sp.1 & $x$ & - & - & - & $x$ & - \\
\hline & & 188 & Miconia theaezans (Bonpl.) Cogn. & - & $x$ & - & - & - & - \\
\hline & & 189 & Miconia valtherii Nadin & $\mathrm{x}$ & - & - & - & - & - \\
\hline & & 190 & Mouriri chamissoana Cogn. & - & $x$ & - & $x$ & - & $x$ \\
\hline & & 191 & Tibouchina pulchra (Cham.)Cogn. & $x$ & $x$ & $x$ & $x$ & $x$ & $x$ \\
\hline & & 192 & Tibouchina sellowiana Cogn. & $x$ & $x$ & $x$ & - & $x$ & - \\
\hline & & 193 & Tibouchina sp. & - & - & - & - & $x$ & - \\
\hline \multirow[t]{6}{*}{36} & Meliaceae & 194 & Cabralea canjerana (Vell.) Mart. & $x$ & $x$ & $x$ & $x$ & $x$ & $x$ \\
\hline & & 195 & Cedrella fissilis Vell. & $x$ & $x$ & $x$ & - & - & $x$ \\
\hline & & 196 & Cedrella odorata L. & - & $x$ & - & - & - & - \\
\hline & & 197 & Guarea macrophylla Vahl & $x$ & $x$ & $x$ & $x$ & - & - \\
\hline & & 198 & Trichilia hirta L. & - & $x$ & - & - & - & $x$ \\
\hline & & 199 & Trichilia pallida SW. & - & $x$ & - & - & - & - \\
\hline 37 & Mimosaceae & 200 & Inga cylindrica (Vell.) Mart. & - & $x$ & - & - & - & - \\
\hline
\end{tabular}


Anexo B. Relação das famílias e das espécies, em ordem alfabética, amostradas pelos métodos (parcelas, quadrantes e relascopia), na Floresta Ombrófila Densa, Parque Estadual Carlos Botelho. SP. Brasil. par g 1- Parcela Grade 1; par g2- Parcela grade 2; qua g1 - Quadrante Grade 1; qua g2 Quadrante grade 2; rel g1 - Relascopia grade 1 e rel g2 - Relascopia grade 2

\begin{tabular}{|c|c|c|c|c|c|c|c|c|c|}
\hline & Familias & & Espécies & parg1 & par g2 & qua g1 & qua g2 & rel g1 & rel g2 \\
\hline & & 201 & Inga edulis Mart. & - & $x$ & - & $x$ & - & - \\
\hline & & 202 & Inga laurina (SW.) Willd. & $x$ & $x$ & - & $x$ & - & - \\
\hline & & 203 & Inga marginata Willd. & $x$ & $x$ & $x$ & $x$ & - & $x$ \\
\hline & & 204 & Inga sellowiana Benth. & $x$ & $x$ & $x$ & $x$ & $x$ & $x$ \\
\hline & & 205 & Inga sessilis (Vell.) Mart. & $x$ & $x$ & $x$ & - & $x$ & - \\
\hline & & 206 & Pithecellobium langsdorffi Benth. & $x$ & $x$ & $x$ & $x$ & - & $x$ \\
\hline & & 207 & Pithecellobium sp. & - & - & - & - & $x$ & - \\
\hline \multirow[t]{7}{*}{38} & Monimiaceae & 208 & Mollinedia elegans Tul. & $x$ & $x$ & - & $x$ & - & - \\
\hline & & 209 & Mollinedia floribunda Tul. & - & $x$ & - & - & - & - \\
\hline & & 210 & Mollinedia oligantha Perk.. & $x$ & $x$ & $x$ & $x$ & $x$ & $x$ \\
\hline & & 211 & Mollinedia oligotricha Perk. & $x$ & $x$ & $x$ & $x$ & - & - \\
\hline & & 212 & Mollinedia schottiana (Spreng.) Perk. & $x$ & $x$ & $x$ & $x$ & $x$ & $x$ \\
\hline & & 213 & Mollinedia sp. & - & $x$ & - & - & - & - \\
\hline & & 214 & Mollinedia sp.1 & $x$ & $x$ & - & - & - & - \\
\hline \multirow[t]{2}{*}{39} & Moraceae & 215 & Ficus sp. & - & - & - & - & - & $x$ \\
\hline & & 216 & Sorocea bonplandii (Baill.) Burger Lanj.\&. Boer & $\mathrm{x}$ & $x$ & $x$ & $x$ & - & $x$ \\
\hline
\end{tabular}


Anexo B. Relação das famílias e das espécies, em ordem alfabética, amostradas pelos métodos (parcelas, quadrantes e relascopia), na Floresta Ombrófila Densa, Parque Estadual Carlos Botelho. SP. Brasil. par g 1- Parcela Grade 1; par g2- Parcela grade 2; qua g1 - Quadrante Grade 1; qua g2 Quadrante grade 2; rel g1 - Relascopia grade 1 e rel g2 - Relascopia grade 2

\begin{tabular}{|c|c|c|c|c|c|c|c|c|c|}
\hline & Familias & & Espécies & par g1 & par g2 & qua g1 & qua g2 & rel g1 & rel g2 \\
\hline \multirow[t]{9}{*}{40} & Myrsinaceae & 217 & Ardisia guianensis (Aubl.) Mez. & - & $x$ & - & - & - & - \\
\hline & & 218 & Cybianthus brasiliensis (Mez.) G. Agos. & - & $x$ & - & - & - & - \\
\hline & & 219 & Cybianthus peruvianus (A. DC.) Miq. & - & $x$ & - & - & - & - \\
\hline & & 220 & Rapanea ferruginea (Ruiz \& Pav.) Mez & $x$ & $x$ & $x$ & - & - & - \\
\hline & & 221 & Rapanea gardneriana (A. DC.) Mez. & $x$ & $x$ & $x$ & $x$ & - & - \\
\hline & & 222 & Rapanea hermogenesii Jung-Mend. \& Bernacci & $x$ & $x$ & $x$ & $x$ & - & - \\
\hline & & 223 & Rapanea sp. & - & $x$ & - & - & - & - \\
\hline & & 224 & Rapanea umbellata (Mart.) Mez & $x$ & $x$ & $x$ & $x$ & $x$ & $x$ \\
\hline & & 225 & Stylogyne laevigata (Mart.) Mez & $x$ & - & - & - & - & - \\
\hline \multirow[t]{8}{*}{41} & Myrtaceae & 226 & Calycorectes aff. psidiiflorus (Berg.) Sobral & $x$ & - & - & - & - & - \\
\hline & & 227 & Calycorectes australis Legr. & $x$ & $x$ & $x$ & $x$ & - & $x$ \\
\hline & & 228 & Calycorectes sp. & - & - & - & - & $x$ & - \\
\hline & & 229 & Calyptranthes lanceolata Berg. & $x$ & $x$ & - & $x$ & - & - \\
\hline & & 230 & Calyptranthes lucida DC. & $x$ & $x$ & $x$ & $x$ & - & - \\
\hline & & 231 & Calyptranthes obovata Kiaersk. & - & $x$ & - & - & - & - \\
\hline & & 232 & Calyptranthes sp.1 & $x$ & $x$ & - & $x$ & - & - \\
\hline & & 233 & Calyptranthes sp.2 & $x$ & $x$ & $x$ & $x$ & $x$ & $x$ \\
\hline
\end{tabular}


Anexo B. Relação das famílias e das espécies, em ordem alfabética, amostradas pelos métodos (parcelas, quadrantes e relascopia), na Floresta Ombrófila Densa, Parque Estadual Carlos Botelho. SP. Brasil. par g 1- Parcela Grade 1; par g2- Parcela grade 2; qua g1 - Quadrante Grade 1; qua g2 Quadrante grade 2; rel g1 - Relascopia grade 1 e rel g2 - Relascopia grade 2

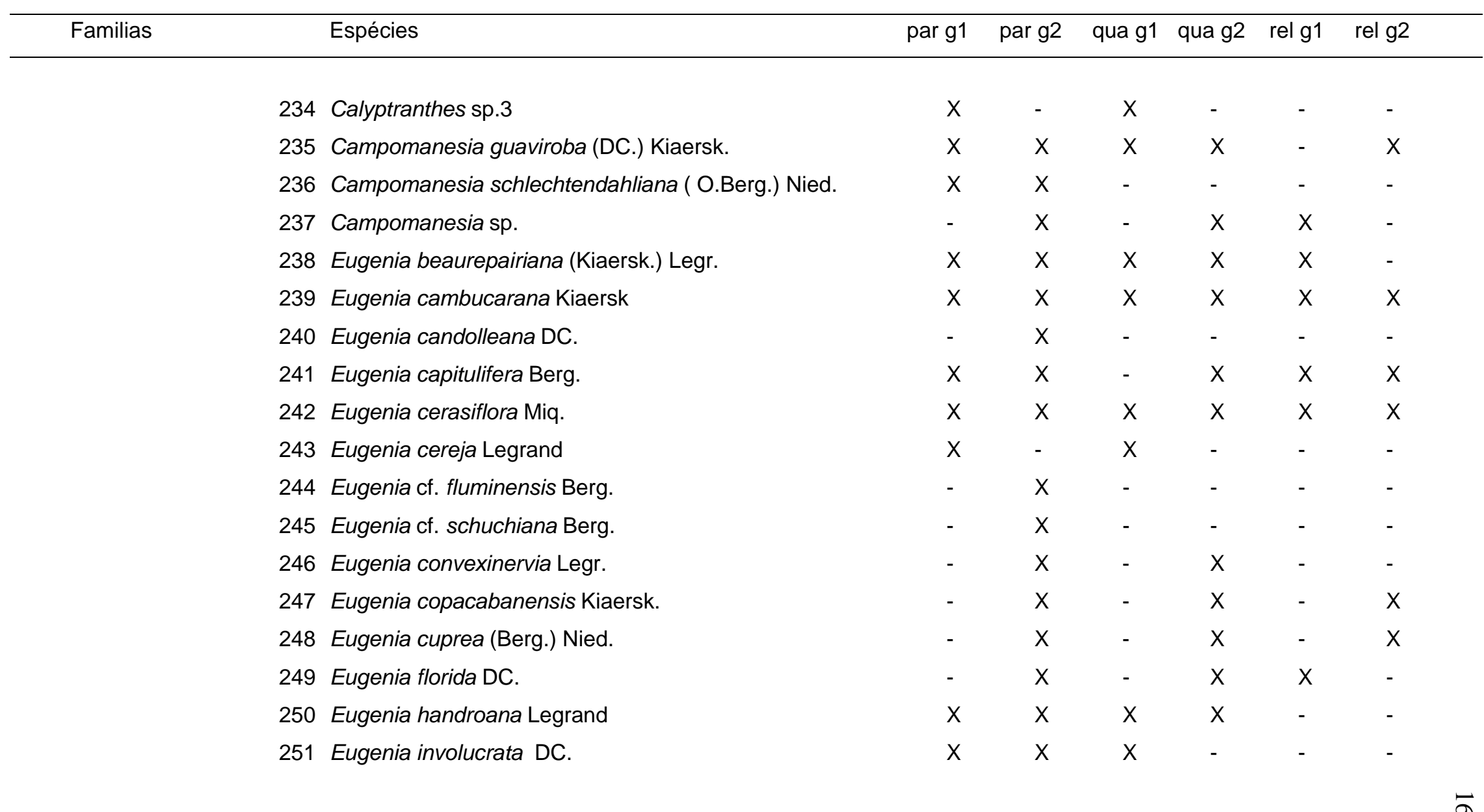


Anexo B. Relação das famílias e das espécies, em ordem alfabética, amostradas pelos métodos (parcelas, quadrantes e relascopia), na Floresta Ombrófila Densa, Parque Estadual Carlos Botelho. SP. Brasil. par g 1- Parcela Grade 1; par g2- Parcela grade 2; qua g1 - Quadrante Grade 1; qua g2 Quadrante grade 2; rel g1 - Relascopia grade 1 e rel g2 - Relascopia grade 2

\begin{tabular}{|c|c|c|c|c|c|c|c|}
\hline Familias & Espécies & par g1 & par g2 & qua g1 & qua g2 & rel g1 & rel g2 \\
\hline & 252 Eugenia melanogina ( Legrand) Sobral & $x$ & $x$ & $x$ & $x$ & $x$ & $x$ \\
\hline & 253 Eugenia mosenii (Kausel) Sobral & $x$ & $x$ & $x$ & $x$ & $x$ & $x$ \\
\hline & 254 Eugenia neoglomerata Sobral & $x$ & $x$ & - & $x$ & - & $x$ \\
\hline & 255 Eugenia neoverrucosa Sobral & - & $x$ & - & - & - & - \\
\hline & 256 Eugenia prasina Berg & $x$ & - & - & - & - & - \\
\hline & 257 Eugenia pruinosa Legrand & $x$ & $x$ & - & $x$ & $x$ & - \\
\hline & 258 Eugenia riedeliana Berg. & $x$ & $x$ & $x$ & $x$ & $x$ & $x$ \\
\hline & 259 Eugenia sp. & - & - & - & - & $x$ & - \\
\hline & 260 Eugenia sp.1 & $x$ & $x$ & $x$ & $x$ & $x$ & - \\
\hline & 261 Eugenia sp.10 & - & $x$ & - & - & - & - \\
\hline & 262 Eugenia sp.11 & - & $x$ & - & - & - & - \\
\hline & 263 Eugenia sp.12 & - & $x$ & - & - & - & - \\
\hline & 264 Eugenia sp.13 & - & $x$ & - & - & - & - \\
\hline & 265 Eugenia sp.2 & $x$ & $x$ & $x$ & $x$ & - & $x$ \\
\hline & 266 Eugenia sp.3 & $x$ & $x$ & $x$ & $x$ & $x$ & $x$ \\
\hline & 267 Eugenia sp.4 & $x$ & $x$ & $x$ & - & $x$ & - \\
\hline & 268 Eugenia sp.5 & $x$ & $x$ & $x$ & $x$ & - & - \\
\hline & 269 Eugenia sp.6 & - & $x$ & - & $x$ & $x$ & $x$ \\
\hline
\end{tabular}


Anexo B. Relação das famílias e das espécies, em ordem alfabética, amostradas pelos métodos (parcelas, quadrantes e relascopia), na Floresta Ombrófila Densa, Parque Estadual Carlos Botelho. SP. Brasil. par g 1- Parcela Grade 1; par g2- Parcela grade 2; qua g1 - Quadrante Grade 1; qua g2 Quadrante grade 2; rel g1 - Relascopia grade 1 e rel g2 - Relascopia grade 2

\begin{tabular}{|c|c|c|c|c|c|c|c|c|}
\hline Familias & & Espécies & par g1 & parg2 & qua g1 & qua g2 & rel g1 & rel g2 \\
\hline & 270 & Eugenia sp.7 & - & $x$ & - & - & - & - \\
\hline & 271 & Eugenia sp.8 & - & $x$ & - & - & - & - \\
\hline & 272 & Eugenia sp.9 & - & $x$ & - & $x$ & - & - \\
\hline & 273 & Eugenia stictosepala Kiaersk. & $x$ & $x$ & $x$ & $x$ & $x$ & $x$ \\
\hline & 274 & Eugenia subavenia Berg & $x$ & $x$ & $x$ & $x$ & - & $x$ \\
\hline & 275 & Eugenia umbelliflora Berg. & $x$ & $x$ & - & $x$ & - & - \\
\hline & 276 & Gomidesia anacardiaefolia (Gard.) Berg & - & $x$ & - & $x$ & - & $x$ \\
\hline & 277 & Gomidesia riedeliana Berg. & - & $x$ & - & $x$ & - & $x$ \\
\hline & 278 & Gomidesia schaueriana Berg & $x$ & $x$ & - & $x$ & - & $x$ \\
\hline & 279 & Gomidesia sp. & - & $x$ & - & $x$ & - & - \\
\hline & 280 & Gomidesia spectabilis (DC.) Berg & - & $x$ & - & $x$ & $x$ & - \\
\hline & 281 & Gomidesia tijucensis ( Kiaersk.) Legrand. & $x$ & $x$ & $x$ & - & $x$ & - \\
\hline & 282 & Marlierea sp.1 & $x$ & $x$ & $x$ & - & - & $x$ \\
\hline & 283 & Marlierea sp.2 & - & $x$ & - & $x$ & - & - \\
\hline & 284 & Marlierea eugeniopsoides (Legrand \& Kausel) Legrand. & $x$ & $x$ & - & $x$ & - & - \\
\hline & 285 & Marlierea parviflora Berg. & $x$ & $x$ & $x$ & $x$ & - & $x$ \\
\hline & 286 & Marlierea racemosa (Vell.) Kiaersk. & - & $x$ & - & - & - & - \\
\hline & 287 & Marlierea reitzii Legrand. & $x$ & $x$ & $x$ & $x$ & $x$ & $x$ \\
\hline
\end{tabular}


Anexo B. Relação das famílias e das espécies, em ordem alfabética, amostradas pelos métodos (parcelas, quadrantes e relascopia), na Floresta Ombrófila Densa, Parque Estadual Carlos Botelho. SP. Brasil. par g 1- Parcela Grade 1; par g2- Parcela grade 2; qua g1 - Quadrante Grade 1; qua g2 Quadrante grade 2; rel g1 - Relascopia grade 1 e rel g2 - Relascopia grade 2

\begin{tabular}{|c|c|c|c|c|c|c|c|c|}
\hline Familias & & Espécies & parg1 & parg2 & qua g1 & qua g2 & rel g1 & rel g2 \\
\hline & 288 & Marlierea tomentosa Cambess. & $\mathrm{X}$ & $\mathrm{X}$ & $\mathrm{X}$ & $\mathrm{x}$ & $x$ & $\mathrm{x}$ \\
\hline & 289 & Myrceugenia aff. pilotantha (Kiaerk.) Landrum & $x$ & - & - & - & - & - \\
\hline & 290 & Myrceugenia campestris ( DC.) Legrand \& Kausel. & $x$ & $x$ & - & $x$ & - & - \\
\hline & 291 & Myrceugenia glaucescens (Cambess.) Legrand \& Kausel & $\mathrm{X}$ & $\mathrm{X}$ & $\mathrm{X}$ & $\mathrm{X}$ & - & $x$ \\
\hline & 292 & Myrceugenia kleinii Legrand \& Kausel & $\mathrm{X}$ & $\mathrm{X}$ & $\mathrm{X}$ & $\mathrm{x}$ & - & - \\
\hline & 293 & Myrceugenia myrcioides (Cambess.) Berg & $x$ & $\mathrm{X}$ & $\mathrm{X}$ & $\mathrm{X}$ & - & $x$ \\
\hline & 294 & Myrceugenia seriatoramosa (Kiaersk.) Legrand \& Kausel. & - & $x$ & - & - & $x$ & $x$ \\
\hline & 295 & Myrceugenia sp.1 & $x$ & $x$ & $x$ & - & $x$ & - \\
\hline & 296 & Myrceugenia sp.2 & - & $x$ & - & - & - & - \\
\hline & 297 & Myrcia aff. glabra (Berg.) Legrand & $x$ & - & $x$ & - & $x$ & - \\
\hline & 298 & Myrcia aff. macrocarpa Barb. Rodr. & - & $x$ & - & $x$ & - & $x$ \\
\hline & 299 & Myrcia aff.obtecta (Berg) Kiaersk. & $x$ & - & $x$ & - & $x$ & - \\
\hline & 300 & Myrcia fallax (Rich.) DC. & $x$ & $x$ & $x$ & $x$ & $x$ & - \\
\hline & 301 & Myrcia hatschbachii Legr. & $x$ & $x$ & - & $x$ & $x$ & $x$ \\
\hline & 302 & Myrcia heringii Legrand & $x$ & - & $x$ & - & - & - \\
\hline & 303 & Myrcia pubipetala Miq. & $x$ & $x$ & $x$ & $x$ & $x$ & - \\
\hline & 304 & Myrcia richardiana (Berg.) Kiaersk. & $x$ & - & - & - & - & - \\
\hline & 305 & Myrcia rostrata DC. & - & $x$ & - & $x$ & - & - \\
\hline
\end{tabular}


Anexo B. Relação das famílias e das espécies, em ordem alfabética, amostradas pelos métodos (parcelas, quadrantes e relascopia), na Floresta Ombrófila Densa, Parque Estadual Carlos Botelho. SP. Brasil. par g 1- Parcela Grade 1; par g2- Parcela grade 2; qua g1 - Quadrante Grade 1; qua g2 Quadrante grade 2; rel g1 - Relascopia grade 1 e rel g2 - Relascopia grade 2

\begin{tabular}{|c|c|c|c|c|c|c|c|c|}
\hline Familias & & Espécies & par g1 & par g2 & qua g1 & qua g2 & rel g1 & rel g2 \\
\hline & 306 & Myrcia sp & - & $x$ & - & - & - & - \\
\hline & 307 & Myrcia sp.1 & $x$ & $x$ & $x$ & - & $x$ & - \\
\hline & 308 & Myrcia sp. 2 & $x$ & $x$ & - & $x$ & - & $x$ \\
\hline & 309 & Myrcia sp.3 & - & $x$ & - & - & - & - \\
\hline & 310 & Myrcia sp.4 & - & $x$ & - & - & - & - \\
\hline & 311 & Myrcia sp. 6 & - & - & - & - & $x$ & - \\
\hline & 312 & Myrcia tenuivenosa Kiaersk & $x$ & $x$ & - & $x$ & - & $x$ \\
\hline & 313 & Myrciaria sp. & - & - & - & $x$ & - & - \\
\hline & 314 & Myrciaria sp.1 & $x$ & $x$ & $x$ & $x$ & - & - \\
\hline & 315 & Myrciaria sp.2 & - & $x$ & - & $x$ & - & $x$ \\
\hline & 316 & Myrciaria sp.3 & - & $x$ & - & $x$ & - & $x$ \\
\hline & 317 & Myrtaceae sp.1 & $x$ & $x$ & $x$ & - & $x$ & $x$ \\
\hline & 318 & Myrtaceae sp.2 & $x$ & $x$ & $x$ & $x$ & - & $x$ \\
\hline & 319 & Myrtaceae sp.3 & $x$ & $x$ & $x$ & $x$ & $x$ & - \\
\hline & 320 & Myrtaceae sp.4 & $x$ & $x$ & $x$ & $x$ & - & $x$ \\
\hline & 321 & Myrtaceae sp.5 & - & $x$ & - & - & - & - \\
\hline & 322 & Myrtaceae sp.6 & - & $x$ & - & - & - & - \\
\hline & 323 & Neomitranthes glomerata (Legrand) Legrand & $x$ & $x$ & $\mathrm{X}$ & $x$ & - & $x$ \\
\hline
\end{tabular}


Anexo B. Relação das famílias e das espécies, em ordem alfabética, amostradas pelos métodos (parcelas, quadrantes e relascopia), na Floresta Ombrófila Densa, Parque Estadual Carlos Botelho. SP. Brasil. par g 1- Parcela Grade 1; par g2- Parcela grade 2; qua g1 - Quadrante Grade 1; qua g2 Quadrante grade 2; rel g1 - Relascopia grade 1 e rel g2 - Relascopia grade 2

\begin{tabular}{|c|c|c|c|c|c|c|c|c|c|}
\hline & Familias & & Espécies & par g1 & par g2 & qua g1 & qua g2 & rel g1 & rel g2 \\
\hline & & 324 & Pimenta pseudocaryophyllus (Gomes) Landrum & - & $x$ & - & - & - & $x$ \\
\hline & & 325 & Plinia complanata Kawas. \& Holst. & $x$ & $x$ & $x$ & - & - & - \\
\hline & & 326 & Plinia pauciflora Kawas. \& Holst & $x$ & $x$ & - & $x$ & $x$ & $x$ \\
\hline & & 327 & Psidium cattleyanum Sabine & - & $x$ & - & - & - & - \\
\hline & & 328 & Psydium cf. myrtoides Berg. & - & $x$ & - & $x$ & $x$ & - \\
\hline & & 329 & Siphoneugena densiflora Berg. & $x$ & $x$ & $x$ & $x$ & $x$ & $x$ \\
\hline & & 330 & Siphoneugena sp. & - & - & - & - & $x$ & - \\
\hline 42 & Nyctaginaceae & 331 & Guapira opposita (Vell.) Reitz & $x$ & $x$ & $x$ & $x$ & $x$ & $x$ \\
\hline \multirow[t]{2}{*}{43} & Ochnaceae & 332 & Ouratea multiflora Engl. & - & $x$ & - & $x$ & - & - \\
\hline & & 333 & Ouratea parviflora Baill. & $x$ & $x$ & $x$ & $x$ & - & $x$ \\
\hline \multirow[t]{2}{*}{44} & Olacaceae & 334 & Heisteria silvianii Schw. & $x$ & $x$ & $x$ & $x$ & $x$ & $x$ \\
\hline & & 335 & Tetrastylidium glandifolium (Baill.) Sleumer. & - & $x$ & - & - & - & - \\
\hline \multirow[t]{2}{*}{45} & Oleaceae & 336 & Chionanthus filiformis (Vell.) Green & $x$ & $x$ & $x$ & $x$ & $x$ & $x$ \\
\hline & & 337 & Chionanthus sp. & - & - & - & - & $x$ & - \\
\hline
\end{tabular}


Anexo B. Relação das famílias e das espécies, em ordem alfabética, amostradas pelos métodos (parcelas, quadrantes e relascopia), na Floresta Ombrófila Densa, Parque Estadual Carlos Botelho. SP. Brasil. par g 1- Parcela Grade 1; par g2- Parcela grade 2; qua g1 - Quadrante Grade 1; qua g2 Quadrante grade 2; rel g1 - Relascopia grade 1 e rel g2 - Relascopia grade 2

\begin{tabular}{|c|c|c|c|c|c|c|c|c|c|}
\hline & Familias & & Espécies & par g1 & par g2 & qua g1 & qua g2 & rel g1 & rel g2 \\
\hline 46 & Opiliaceae & 338 & Agonandra excelsa Griseb. & - & $x$ & - & - & - & $x$ \\
\hline 47 & Podocarpaceae & 339 & Podocarpus sellowii Klotzsch ex Endl. & $x$ & - & - & - & - & - \\
\hline \multirow[t]{4}{*}{48} & Polygonaceae & 340 & Coccoloba latifolia Lam. & $x$ & $x$ & $x$ & $x$ & - & - \\
\hline & & 341 & Coccoloba sp.1 & - & $x$ & - & $x$ & - & $x$ \\
\hline & & 342 & Coccoloba sp. 2 & - & $x$ & - & - & - & - \\
\hline & & 343 & Coccoloba sp.3 & - & $x$ & - & - & - & - \\
\hline \multirow[t]{4}{*}{49} & Proteaceae & 344 & Roupala brasiliensis KI. & - & $x$ & - & $x$ & - & $x$ \\
\hline & & 345 & Roupala sculpta Sleumer & - & $x$ & - & $x$ & - & - \\
\hline & & 346 & Roupala sp. & - & $x$ & - & $x$ & - & - \\
\hline & & 347 & Roupala sp.1 & $x$ & - & - & - & - & - \\
\hline \multirow[t]{2}{*}{50} & Quiinaceae & 348 & Quiina glaziovii Engl. & $x$ & - & - & - & - & - \\
\hline & & 349 & Quiina magallano-gomezii Schw. & - & $x$ & $x$ & $x$ & - & - \\
\hline 51 & Rosaceae & 350 & Prunus myrtifolia ( L.) Urban & $x$ & $x$ & $x$ & $x$ & $x$ & $x$ \\
\hline
\end{tabular}


Anexo B. Relação das famílias e das espécies, em ordem alfabética, amostradas pelos métodos (parcelas, quadrantes e relascopia), na Floresta Ombrófila Densa, Parque Estadual Carlos Botelho. SP. Brasil. par g 1- Parcela Grade 1; par g2- Parcela grade 2; qua g1 - Quadrante Grade 1; qua g2 Quadrante grade 2; rel g1 - Relascopia grade 1 e rel g2 - Relascopia grade 2

\begin{tabular}{|c|c|c|c|c|c|c|c|c|}
\hline & Familias & Espécies & par g1 & parg2 & qua g1 & qua g2 & rel g1 & rel g2 \\
\hline \multirow[t]{18}{*}{52} & Rubiaceae & 351 Alibertia macrophylla Schum. & - & $x$ & - & - & - & - \\
\hline & & 352 Alibertia myrciifolia Schum. & $x$ & $x$ & $x$ & $x$ & $x$ & $x$ \\
\hline & & 353 Alibertia sp. & $x$ & - & $x$ & $\mathrm{X}$ & $x$ & $x$ \\
\hline & & 354 Alibertia sp. 1 & - & $x$ & - & - & - & - \\
\hline & & 355 Alibertia sp. 2 & - & $x$ & - & - & - & - \\
\hline & & 356 Alseis floribunda Schott & $x$ & $x$ & $x$ & $x$ & - & $x$ \\
\hline & & 357 Amaioua guianensis Aubl. & - & $x$ & - & - & - & $x$ \\
\hline & & 358 Amaioua intermedia Mart. & $x$ & $x$ & $x$ & $x$ & $x$ & $x$ \\
\hline & & 359 Bathysa australis (St. Hil.) Benth. \& Hook. & $x$ & $x$ & $x$ & $x$ & $x$ & $x$ \\
\hline & & 360 Chomelia catharinae (Smith. \& Downs.) Steyerm. & - & $x$ & - & $x$ & - & - \\
\hline & & 361 Chomelia sp. & $x$ & - & - & - & - & - \\
\hline & & 362 Coussarea contracta (Wal.) Müll. Arg. & - & $x$ & - & - & - & - \\
\hline & & 363 Coussarea sp. & $x$ & $x$ & $x$ & $x$ & $x$ & $x$ \\
\hline & & 364 Faramea montevidensis (Cham.\& Schltdl.) DC. & - & $x$ & - & $x$ & - & - \\
\hline & & 365 Ixora breviflora Hiem & - & $x$ & - & - & - & - \\
\hline & & 366 Ixora burchelliana Müll. Arg. & $x$ & $x$ & $x$ & $x$ & $x$ & - \\
\hline & & 367 Ixora heterodoxa Müll. Arg. & - & $X$ & - & - & - & - \\
\hline & & 368 Ixora sp. & - & $x$ & - & - & - & - \\
\hline
\end{tabular}


Anexo B. Relação das famílias e das espécies, em ordem alfabética, amostradas pelos métodos (parcelas, quadrantes e relascopia), na Floresta Ombrófila Densa, Parque Estadual Carlos Botelho. SP. Brasil. par g 1- Parcela Grade 1; par g2- Parcela grade 2; qua g1 - Quadrante Grade 1; qua g2 Quadrante grade 2; rel g1 - Relascopia grade 1 e rel g2 - Relascopia grade 2

\begin{tabular}{|c|c|c|c|c|c|c|c|c|c|}
\hline & Familias & & Espécies & par g1 & par g2 & qua g1 & qua g2 & rel g1 & rel g2 \\
\hline & & 369 & Posoqueria acutifolia Mart. & $x$ & $x$ & $x$ & $x$ & $x$ & $x$ \\
\hline & & 370 & Psychotria sp. & - & $x$ & - & - & - & - \\
\hline & & 371 & Psychotria suterella Mull. Arg. & $x$ & $x$ & $x$ & $x$ & - & - \\
\hline & & 372 & Psychotria velloziana Benth. & $x$ & $x$ & $x$ & $x$ & $x$ & $x$ \\
\hline & & 373 & Randia aff. armata (Sw.) DC & - & $x$ & - & - & - & - \\
\hline & & 374 & Rubiaceae sp.1 & $x$ & $x$ & - & $x$ & - & $x$ \\
\hline & & 375 & Rubiaceae sp.2 & - & $x$ & - & - & - & - \\
\hline & & 376 & Rudgea jasminoides (Cham.) Müell. Arg. & $x$ & $x$ & $x$ & $x$ & - & $x$ \\
\hline & & 377 & Rudgea blanchetiana Müell. Arg. & - & $x$ & - & - & - & - \\
\hline \multirow[t]{4}{*}{53} & Rutaceae & 378 & Esenbeckia grandiflora Mart. & $x$ & $x$ & $x$ & $x$ & $x$ & - \\
\hline & & 379 & Esenbeckia sp. & - & $x$ & - & - & $x$ & - \\
\hline & & 380 & Zanthoxylum fagara (L.) Sarg. & - & $x$ & - & $x$ & - & - \\
\hline & & 381 & Zanthoxylum rhoifolium Lam. & $x$ & $x$ & $x$ & - & - & - \\
\hline \multirow[t]{2}{*}{54} & Sabiaceae & 382 & Meliosma selowii Urb. & $x$ & $x$ & $x$ & $x$ & - & $x$ \\
\hline & & 383 & Meliosma sinuata Urban. & $\mathrm{x}$ & $\mathrm{x}$ & $x$ & $x$ & $\mathrm{X}$ & - \\
\hline
\end{tabular}


Anexo B. Relação das famílias e das espécies, em ordem alfabética, amostradas pelos métodos (parcelas, quadrantes e relascopia), na Floresta Ombrófila Densa, Parque Estadual Carlos Botelho. SP. Brasil. par g 1- Parcela Grade 1; par g2- Parcela grade 2; qua g1 - Quadrante Grade 1; qua g2 Quadrante grade 2; rel g1 - Relascopia grade 1 e rel g2 - Relascopia grade 2

\begin{tabular}{|c|c|c|c|c|c|c|c|c|c|}
\hline & Familias & & Espécies & g1 & par g2 & qua g1 & qua g2 & rel g1 & rel g2 \\
\hline \multirow[t]{10}{*}{55} & Sapindaceae & 384 & Allophylus edulis (A. St.Hil., Camb. \& A. Juss.) Radlk. ) Radlk. & & $x$ & $x$ & $x$ & - & - \\
\hline & & 385 & Allophylus petiolulatus Radlk & $x$ & $x$ & - & $x$ & - & - \\
\hline & & 386 & Cupania oblongifolia Mart.. & $x$ & $x$ & $x$ & $x$ & - & $x$ \\
\hline & & 387 & Cupania sp. & - & $x$ & - & - & - & - \\
\hline & & 388 & Cupania vernalis Cambess. & $x$ & $x$ & $x$ & $x$ & $x$ & - \\
\hline & & 389 & Dodonaea viscosa Jacq. & - & $x$ & - & - & - & - \\
\hline & & 390 & Matayba elaeagnoides Radlk. & - & $x$ & - & - & - & - \\
\hline & & 391 & Matayba guianensis Aubl. & $x$ & $x$ & $x$ & $x$ & $x$ & $x$ \\
\hline & & 392 & Matayba juglandifolia Radlk. & $X$ & $x$ & $x$ & $x$ & $x$ & $x$ \\
\hline & & 393 & Matayba sp. & - & $x$ & - & - & - & - \\
\hline \multirow[t]{7}{*}{56} & Sapotaceae & 394 & Chrysophyllum flexuosum Mart. & - & $x$ & - & $x$ & - & $x$ \\
\hline & & 395 & Chrysophyllum inornatum Mart. & - & $x$ & - & $x$ & - & $x$ \\
\hline & & 396 & Chrysophyllum sp. & - & - & - & - & $x$ & - \\
\hline & & 397 & Chrysophyllum viride Mart. \& Eichl. & $X$ & $x$ & $x$ & $x$ & $x$ & $x$ \\
\hline & & 398 & Diploon cuspidatum (Hoehne) Cronquist & $X$ & $x$ & $x$ & $x$ & $x$ & $x$ \\
\hline & & 399 & Ecclinusa ramiflora Mart. & $x$ & $x$ & $x$ & $x$ & $x$ & $x$ \\
\hline & & 400 & Micropholis crassipedicellata (Mart. \& Eichler ex Miq.) Pierre & $x$ & $x$ & $x$ & - & $x$ & - \\
\hline
\end{tabular}


Anexo B. Relação das famílias e das espécies, em ordem alfabética, amostradas pelos métodos (parcelas, quadrantes e relascopia), na Floresta Ombrófila Densa, Parque Estadual Carlos Botelho. SP. Brasil. par g 1- Parcela Grade 1; par g2- Parcela grade 2; qua g1 - Quadrante Grade 1; qua g2 Quadrante grade 2; rel g1 - Relascopia grade 1 e rel g2 - Relascopia grade 2

\begin{tabular}{|c|c|c|c|c|c|c|c|c|}
\hline & Familias & Espécies & par g1 & par g2 & qua g1 & qua g2 & rel g1 & rel g2 \\
\hline & & 401 Pouteria bullata (Moore) Baehni & $x$ & $\mathrm{X}$ & $x$ & $\mathrm{X}$ & $x$ & $x$ \\
\hline & & 402 Pouteria caimito (Ruiz \& Pav.) Radlk. & $x$ & $x$ & $x$ & $x$ & $x$ & $x$ \\
\hline & & 403 Pouteria macrophylla (Lam.) Eyma & - & $x$ & - & $x$ & - & - \\
\hline & & 404 Pouteria psammophila (Mart.) Radlk. & - & $x$ & - & - & - & $x$ \\
\hline & & 405 Pouteria sp & - & $x$ & - & - & - & $x$ \\
\hline 57 & Simaroubaceae & 406 Picramnia sp. & - & $x$ & - & - & - & - \\
\hline \multirow[t]{7}{*}{58} & Solanaceae & 407 Brunfelsia pauciflora (Cham. \& Schldl.) Benth. & - & $x$ & - & - & - & - \\
\hline & & 408 Cyphomandra sp. & - & $x$ & - & - & - & - \\
\hline & & 409 Solanum argenteum Dunal & - & $x$ & - & $x$ & - & - \\
\hline & & 410 Solanum bullatum Vell. & $x$ & - & - & - & - & - \\
\hline & & 411 Solanum cf. rufescens Sendttn. & - & $x$ & - & $x$ & - & - \\
\hline & & 412 Solanum excelsum Salisb. & $x$ & $x$ & - & - & $x$ & - \\
\hline & & 413 Solanum pseudoquina A. St. Hil. & $x$ & $x$ & $x$ & - & - & - \\
\hline 59 & Styracaceae & 414 Styrax acuminatus Pohl & $x$ & - & - & - & - & - \\
\hline
\end{tabular}


Anexo B. Relação das famílias e das espécies, em ordem alfabética, amostradas pelos métodos (parcelas, quadrantes e relascopia), na Floresta Ombrófila Densa, Parque Estadual Carlos Botelho. SP. Brasil. par g 1- Parcela Grade 1; par g2- Parcela grade 2; qua g1 - Quadrante Grade 1; qua g2 Quadrante grade 2; rel g1 - Relascopia grade 1 e rel g2 - Relascopia grade 2

\begin{tabular}{|c|c|c|c|c|c|c|c|c|c|}
\hline & Familias & & Espécies & parg1 & parg2 & qua g1 & qua g2 & rel g1 & rel g2 \\
\hline \multirow[t]{3}{*}{60} & Symplocaceae & 415 & Symplocos celastrinea Mart. ex Miq. & $x$ & - & - & - & $x$ & - \\
\hline & & 416 & Symplocos falcata Brand & $x$ & $x$ & $x$ & - & $x$ & $x$ \\
\hline & & 417 & Symplocos variabilis Mat & $x$ & $x$ & $x$ & $\mathrm{X}$ & $\mathrm{X}$ & $x$ \\
\hline 61 & Theaceae & 418 & Gordonia fruticosa (Schrad) Keing. & - & $x$ & - & $x$ & - & - \\
\hline 62 & Thymelaeaceae & 419 & Daphnopsis gemmiflora (Miers.) Domke. & $x$ & $x$ & - & - & - & - \\
\hline \multirow[t]{5}{*}{63} & Verbenaceae & 420 & Aegiphila brachiata Vell. & - & $x$ & - & $x$ & - & - \\
\hline & & 421 & Aegiphila sellowiana Cham. & $x$ & $x$ & $x$ & $x$ & - & $x$ \\
\hline & & 422 & Aegiphila sp. & $x$ & - & - & - & - & - \\
\hline & & 423 & Verbenaceae 1 & $x$ & - & - & - & - & - \\
\hline & & 424 & Vitex aff. polygama Cham. & $x$ & - & - & - & - & - \\
\hline \multirow[t]{2}{*}{64} & Vochysiaceae & 425 & Vochysia selloi Warm. & $x$ & - & - & - & - & - \\
\hline & & 426 & Vochysia sp. 1 & $x$ & - & $x$ & - & $x$ & - \\
\hline 65 & Winteraceae & 427 & Drimys winteri Forst. \& Forst. & $x$ & $x$ & $x$ & $x$ & $x$ & - \\
\hline 65 & & 427 & & 250 & 348 & 175 & 207 & 155 & 157 \\
\hline
\end{tabular}




\section{REFERÊNCIAS BIBLIOFRÁFICAS}

AGUIAR, O.T. Comparação entre métodos de quadrantes e parcelas na caracterização da composição florística e fitossociológica de um trecho de Floresta Ombrófila Densa no Parque Estadual “Carlos Botelho” - São Miguel Arcanjo, SP. Piracicaba, 2003. 137p. Dissertação (Mestrado) - Escola Superior de Agricultura "Luiz de Queiroz”, Universidade de São Paulo.

ALMEIDA, F.F.M. Fundamentos geológicos do relevo paulista. IGEOG (Série Teses e Monografias), v.14, p.1 - 111, 1964.

BAITELO, J.B.; AGUIAR, O.T.; ROCHA, F.T.; PASTORE, J.A.; ESTEVES R. Estrutura fitossociológica da vegetação Arbórea da Serra da Cantareira (SP) - Núcleo Pinheirinho. Revista do Instituto Florestal, v.5, n.2, p.133 - 161, 1993.

BARROS, A.V.; BARROS, P.L.C.; SILVA, L.C.B. Estudo da diversidade de espécies de uma floresta situada em Curuá-Uma, Pará. Revista Ciência Agrária, v.33, p.49-65, 2000.

BATISTA, J.L.F. Levantamentos florestais: conceitos de amostragem aplicados ao levantamento de florestas. Piracicaba: ESALQ; Departamento de Ciências Florestais, 1998, 45p.

BRYANT, P.J. Biodiversity and conservation: a hypertext book. http://darwin.bio.uci.edu/ sustain/bio65/lec06, (1999). 
CAVASSAN, O.; CESAR, O.; MARTINS, F.R. Fitossociologia da vegetação arbórea da reserva Estadual de Bauru, Estado de São Paulo. Revista Brasileira de Botânica, v.7, n.2, p.91-100, 1984.

CUSTODIO FILHO, A .; FRANCO, C. A . D. C.; DIAS, A . C.; NEGREIROS, O . C. Composição Florística do Estrato Arbóreo do Parque Estadual de Carlos Botelho. SP. Revista do Instituto Florestal, v.4, n.1, p.184-191, 1992.

CUSTODIO FILHO, A. A Floresta Ombrófila Densa em diferentes altitudes no Parque Estadual Carlos Botelho, São Paulo, Brasil. São Paulo, 2002. 165p.Tese (Doutorado) - Instituto de Biociências, Universidade de São Paulo.

CUSTODIO FILHO, A.; NEGREIROS, O.C.; DIAS, A.C.; FRANCO, G.A.D.C. Composição florística do estrato arbóreo do Parque Estadual de Carlos Botelho.SP. Revista do Instituto Florestal, v.4, n.1, p.184 - 191, 1992.

DANSEREAU, P. Biodiversidade - Ecodiversidade e Sócio-Diversidade. Revista do Instituto Florestal, v.4, n.1, p.22 - 28, 1992.

DIAS, A.C. Estrutura e diversidade do componente arbóreo e a regeneração natural do Palmito (Euterpe edulis Mart.) em um trecho de mata secundária, no Parque Estadual de Carlos Botelho, SP. Piracicaba, 1993. 126p. Dissertação (Mestrado) Escola Superior de Agricultura “Luiz de Queiroz”, Universidade de São Paulo.

DIAS, A.C.; CUISTODIO FILHO, A.; FRANCO, G.A.D.C. Diversidade do componente arbóreo em um trecho de floresta secundária, Parque Estadual de Carlos Botelho, SP. Revista do Instituto Florestal, v.12, n.2, p.127 - 153, 2000.

DIAS, A.C.; CUSTODIO FILHO, A.; FRANCO, G.A.D.C.; COUTO, H.T.Z. Estrutura do componente arbóreo em um trecho de floresta secundária, no Parque Estadual de Carlos Botelho, SP. Revista do Instituto Florestal, v.7, n.2, p.125 - 155, 1995. 
DIAS, A.C; NEGREIROS, O.C.; VEIGA, A.A.; COUTO, H.T.Z. Comparação entre métodos empregados na amostragem de vegetação desenvolvida em comunidade de floresta pluvial tropical. Revista do Instituto Florestal, v.1, n.2, p.93 -119, 1989.

DOMINGUES, E.N.; SILVA, D.A. Geomorfologia do Parque Estadual de "Carlos Botelho” - (SP). Boletim Técnico do Instituto Florestal, v.42, p.71 - 105, 1988.

FARIAS, C.A.; SOARES, C.P.B.; SOUZA, A.L., LEITE, H.G. Comparação de métodos de amostragem para análise estrutural de florestas inequiâneas. Revista Árvore, v.26, n.5, p.541 - 548, 2002.

GORENSTEIN, M.R. Métodos de Amostragem no Levantamento da Comunidade Arbórea em Floresta Estacional Semidecidual. Piracicaba, 2002. 92p. Dissertação (Mestrado) - Escola Superior de Agricultura “Luiz de Queiroz”, Universidade de São Paulo.

GUEDES-BRUNI, R.R. Composição, estrutura e similaridade florística de dossel em seis unidades de Mata Atlântica no Rio de Janeiro. São Paulo, 1998. 231p. Tese (Doutorado) - Instituto de Biociências, Universidade de São Paulo.

HEINSDIJK, D.C.; CAMPOS, J.C.C. Programa de manejo das florestas de produção estaduais. Silvicultura em São Paulo, v.6, p.365 - 405, 1967.

HUBELL, S.P.; FOSTER R.B. Canopy gaps and the dynamics of a neotropical Forest. In: Crwley, M.J. (Ed.). Plant Ecology. Oxford: Blackwell Scientific Publications. p.77- 96, 1986.

INSERNHAGEM, I. A Fitossociologia florestal no Paraná e os programas de recuperação de áreas degradadas: uma avaliação. Curitiba, 2001. 219p. Dissertação (Mestrado) - Departamento de Botânica, Setor de Ciências Biológicas, Universidade Federal do Paraná. 
IVANAUSKAS, N. M. Caracterização florística e fisionômica da floresta atlântica sobre a formação Pariquera-Açu, na zona de morraria costeira do Estado de São Paulo. Campinas, 1997. 217p. Dissertação (Mestrado) - Instituto de Biologia, Universidade de Campinas.

KIKKWA, J.; ANDERSON, D.J. Community ecology: Oatter and process. Melbourne: Blackwell, 1986. 432p.

KRONKA, F.J.N.; MATSUKUMA, C.K.; NALON, M.A.; DEL CALI, I.H.; ROSSI, M.; MATTOS, I.F.A.; SHIN-IKE, M.S.; PONTINHA, A.A.S. Inventário Florestal do Estado de São Paulo. São Paulo: Instituto Florestal, 1993. 199p.

LEITÃO FILHO, H. Considerações sobre a floristica de florestas tropicais e subtropicais do Brasil. IPEF, v.35, p.41 - 46, 1987.

MAGURAN, A.E. Ecological diversity and its measurement. London: Croom Helm, 1988. 179p.

MANTOVANI, W. Estrutura fitossociológica, composição florística e fenologia de espécies ocorrentes em trechos da mata atlântica, da mata de planalto e de diferentes estágios serais em torno da Represa de Paraibuna, Estado de São Paulo. In: MEGURO, M. (Coord.). Estudo integrado dos ecossistemas da mata atlântica do Estado de São Paulo - Aspectos estruturais e dinâmicos. São Paulo: Compania Energética de São Paulo, 1987.

MANTOVANI, W. Estrutura e Dinâmica da Floresta Atlântica na Jureia, Iguape - SP. São Paulo, 1993. 126p. Tese (Livre Docência) - Instituto de Biociências Universidade de São Paulo. 
MANTOVANI, W.; RODRIGUES, R.R.; ROSSI, L.; ROMANIUC-NETO, S.; CATHARINO, E.L.M.; CORDEIRO, I. A vegetação na serra do Mar em Salesópolis, SP. In: SIMPOSIO DE ECOSSISTEMAS DA COSTA SUL E SUDESTE BRASILEIRA: ESTRUTURA, FUNÇÃO E MANEJO. Águas de Lindóia, 1990. Anais. São Paulo: Academia de Ciências do Estado de São Paulo, 1990. p.348 - 384 .

MARTINS, F.R. O método de quadrantes e a fitossociologia de uma floresta residual do interior do Estado de São Paulo: Parque Estadual de Vassununga. São Paulo, 1979. 239p. Tese (Doutorado) - Instituto de Biociências, Universidade de São Paulo.

MARTINS, F.R. Estrutura de uma Floresta Mesófila. Campinas: Editora da UNICAMP. 1991. 246p.

MELLO, J.M.; OLIVEIRA-FILHO, A.T.; SCOLFORO, J.R.S. Comparação entre procedimentos de amostragem para avaliação estrutural de um remanescente de Floresta Estacional Semidecidual Montana. Revista Cerne, v2, n.2, p.1 -15, . 1996.

MELO, M.M.R.F. Demografia de árvores em floresta pluvial tropical atlântica, Ilha do Cardoso, SP, Brasil. São Paulo, 2000. 155p. Tese (Doutorado) - Instituto de Biociências, Universidade de São Paulo.

MOSCOVICH, F.A.; BRENA, D.A.; LONGHI, S.J. Comparação de diferentes métodos de amostragem, de área fixa e variável, em uma floresta de Araucaria angustifolia. Ciência Florestal, v.9, n.1, p.173 - 191, 1999.

MUELLER-DOMBOIS, D.; ELLEMBERG, H. Aims and methods of vegetation ecology. New York: Johm Wiley, 1974. 547p.

NEGREIROS, O C.; DIAS, A C.; COUTO, H.T.Z. Ajuste de curvas de distribuição diamétrica em uma comunidade de floresta pluvial tropical, no Núcleo Sete Barras do Parque Estadual de Carlos Botelho/São Paulo. Revista do Instituto Florestal, v.2, n.1, p.95 - 114, 1990 . 
NEGREIROS, O.C. Características fitossociológicas de uma floresta latifoliada pluviosa tropical visando ao manejo do palmito, Euterpe edulis Mart. Piracicaba, 1983. 104p. Dissertação (Mestrado) - Escola Superior de Agricultura “Luiz de Queiroz”, Universidade de São Paulo.

NEGREIROS, O.C.; CUSTODIO FILHO, A.; DIAS, A.C.; FRANCO, G.A.D.C.; COUTO, H.T.Z; VIEIRA, M.G.L.; MOURA NETO, B.V. Análise estrutural de um trecho de floresta pluvial tropical - Parque Estadual de “Carlos Botelho”, Núcleo Sete Barras (SP. Brasil). Revista do Instituto Florestal, v.7, n.1, p.1 - 33. 1995.

NIMER, E. Climatologia do Brasil. Rio de Janeiro. IBGE: 1979. 422p.

PFEIFER, R.M.; CARVALHO, W.A.; SILVA, D.A.; ROSSI, M.; MEDICINO, L.F. Levantamento semidetalhado dos solos do Parque Estadual de Carlos Botelho (SP). Boletim Técnico do Instituto Florestal, v.40, n.1, p.75 - 109, 1986.

PIELOU, E.C Mathematical ecology. NewYork: Wiley.1977. 385p.

RICKLEFS, R.E.; MILLER G.L. Ecology. 4.Ed . New York: W.H. Freemaan, 1999. 822p.

RIZZINI, C.T. Tratado de fitogeografia do Brasil. São Paulo. HUCITEC: Ed. da Universidade de São Paulo, 1979. v.2. 374p.

SCHLUTER, D.; RICKLEFS, R.E. Species diversity: an introduction to the problem. In: RICKLEFS, R.E.; SCHLUTER, D. (Ed.). Species diversity in ecological communities: Historical and geographical perspectives. Chicago: The University of Chicago Press, 1993. p.1 - 10 .

TABARELLI, M.; VILLANI, J.P.; MANTOVANI, W. Aspectos da sucessão secundária em trecho da floresta atlântica no Parque Estadual da Serra do Mar, SP. Revista do Instituto Florestal, v.5, n.1, p.99-112, 1993. 
TABARELLI, M.; VILLANI, J.P.; MANTOVANI, W. Estudo comparativo da vegetação de dois trechos de floresta secundária no Núcleo Santa Virgínia, Parque Estadual da Serra do Mar, SP. Revista do Instituto Florestal, v.6, p.1 - 11, 1994.

VEIGA, A.A. Curso de Atualização Florestal. 3.Ed. São Paulo: Instituto Florestal, 1976. 118p. (Publicação IF, 4).

VELOSO, H.P.; GÓES FILHO, L. Fitogeografia brasileira, classificação fisionômica e ecológica da vegetação neotropical. 1982. 80p. (Projeto Radambrasil, Vegetação. Bol. Técnico, 1).

VELOSO, H.P.; RANGEL FILHO, A.L.R.; LIMA, J.C.A. Classificação da vegetação Brasileira, adaptada a um sistema universal. Rio de Janeiro: IBGE , 1991. 123p.

VICTOR, M.A . M. A devastação florestal. São Paulo: Sociedade Brasileira de Silvicultura, 1975. 49p.

WILSON, E.O. Biodiversidade. In: WILSON, E.O.; PETER, F.M. (Ed.). Rio de Janeiro: Ed. Nova Fronteira, 1997. p.3 - 24. 